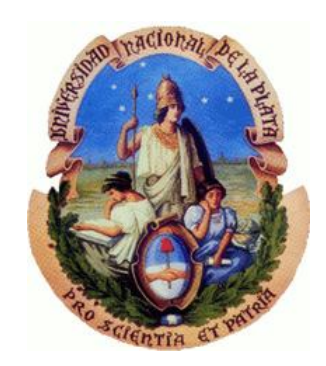

UNIVERSIDAD NACIONAL DE LA PLATA

FACULTAD DE CIENCIAS EXACTAS

DEPARTAM ENTO DE QUÍM ICA

\title{
PEROXIDACIÓN DE DIFERENTES ESPECIES LIPÍDICAS: EFECTO DE ANTIOXIDANTES
}

TRABAJO DE TESIS DOCTORAL

Boca. Natalia Soledad Fagal

DiRECTOR: Dr. Ángel CatAlÁ

2011 
El presente trabajo de Tesis para optar al título de Doctor de la Facultad de Ciencias Exactas de la Universidad Nacional de La Plata fue realizado en el Instituto de Investigaciones Fisicoquímicas Teóricas y Aplicadas (INIFTA-UNLP-CONICET) bajo la dirección del Dr. Ángel Catalá. 
A mis viejos

A mi familia y amigos

A mi "profe", el Negro Medina 
"Me lo contaron y lo olvidé;

lo vi y lo entendí;

lo hice y lo aprendí."

(Confucio. Filósofo chino. 551. - 479 a. C.) 


\section{índice}

Página

Índice 5

Reconocimientos 8

Agradecimientos 9

Abreviaturas 11

Resumen-Summary 16

Publicaciones 23

1. CAPÍTULO 1. Introducción general y objetivos.

1.1. Consideraciones generales 25

1.2. Lípidos 25

1.3. Radicales libres 28

1.4. Peroxidación lipídica 33

1.4.1. Peroxidación lipídica no enzimática 33

1.4.2. Peroxidación lipídica enzimática 37

1.5. Antioxidantes 38

1.5.1. Antioxidantes endógenos y dietarios 38

1.5.2. Modo de acción 39

1.5.2.1. Antioxidantes primarios o preventivos 39

1.5.2.2. Antioxidantes secundarios o cortadores de cadena ("chain-breaking”) 40

1.5.2.3. Antioxidantes terciarios o reparadores 41

1.5.3. Compuestos cuya actividad antioxidante se estudió en la presente tesis 41

1.5.3.1. Melatonina e indolaminas relacionadas 41

1.5.3.2. Familia de isómeros conjugados del ácido linoleico (CLAs) 50

1.6. Objetivos 54

2. CAPÍTULO 2. Efecto de melatonina e indolaminas relacionadas sobre la peroxidación lipídica de triglicéridos ricos en ácidos grasos n-3.

2.1. Introducción

2.2. Materiales y métodos 60 
2.2.2. Métodos y técnicas 60

2.2.2.1. Determinación de quimioluminiscencia 60

2.2.2.2. Determinación de sustancias reactivas al ácido tiobarbitúrico (TBARS) 61

2.2.2.3. Determinación de actividad secuestradora de radicales mediante ensayo de 1, 1, difenil-1-picrilhidracil (DPPH)

2.2.2.4. Análisis de formación de AFMK durante la peroxidación lipídica de Tg PUFAs $n$-3 en presencia de melatonina

3. CAPÍtUlo 3. Efecto de isómeros conjugados de ácido linoleico (CLAs) sobre la peroxidación lipídica de triglicéridos ricos en ácidos grasos n-3.

3.1. Introducción

3.2. Materiales y métodos

3.2.2.1. Determinación de peroxidación lipídica de ácido linoleico libre, metil linoleato, CLA c9, t11 y CLA t10, c12 por detección de quimioluminiscencia

3.2.2.2. Determinación de peroxidación lipídica de Tg PUFAs n-3por detección de quimioluminiscencia. Efecto de CLAs, LA y MLA

3.2.2.3. Determinación de actividad secuestradora de radicales de CLAs, LA y MLA por ensayo de DPPH.

4. CAPÍTULO 4. Estudio de la susceptibilidad a la peroxidación de liposomas de lípidos de retina. Efecto de sonicación, medio e iniciador de reacción. 
4.2.2.4. Determinación de tamaño de liposomas por dispersión dinámica de luz

(Dinamic Light Scattering, DLS)

4.2.2.5. Determinación espectrofotométrica de dienos y trienos conjugados

4.3. Resultados

5. CAPÍTULO 5.Efecto de melatonina e indolaminas relacionadas sobre la peroxidación iniciada por $\mathrm{Fe}^{2+}$ de liposomas sonicados de lípidos de retina

5.1. Introducción

5.2. Materiales y métodos

5.2.2. Métodos y técnicas

5.2.2.1. Obtención de homogeneizados de retina bovina

5.2.2.2. Extracción de lípidos

5.2.2.4. Determinación espectrofotométrica de dienos conjugados

5.2.2.5. Determinación de sustancias reactivas al ácido tiobarbitúrico (TBARS)

ANEXO. Técnicas y métodos

Quimioluminiscencia

Ensayo de sustancias reactivas al ácido tiobarbitúrico (TBARS) 


\section{Reconocimientos}

A la Facultad de Ciencias Exactas y a la Universidad Nacional de la Plata, por brindar formación PÚBLICA y GRATUITA de excelencia.

A INIFTA, en las personas de su ex Director Dr. Eduardo Castro y actual Director Dr. Roberto Salvarezza, por permitirme desarrollar el trabajo de tesis en esta institución.

A ANPCyT, CIC (Pcia. de Bs. As) y CONICET por financiar los proyectos de investigación y becas de estudio necesarios para el desarrollo del presente trabajo de tesis.

A la Dra. Mabel Tomás y su grupo de trabajo (CIDCA, Dpto. de Qca., Fac. de Cs. Exactas, UNLP - CONICET), por permitirme utilizar equipos e instalaciones tantas veces como fueron necesarios.

Al Dr. José Luis Alessandrini (IFLP, Dpto. Física, UNLP - CONICET) por su valiosa colaboración empleando la técnica de Dispersión de Luz Dinámica (DLS).

Al Dr. Pedro Carriquiriborde (CIMA, Dpto. Qca, Fac. de Cs. Exactas, UNLP) por permitirme utilizar equipamiento e instalaciones numerosas veces.

A la Dra. Marita Miríffico, Dra. Mónica Mele, Dr. Andrés Thomas y sus grupos de trabajo, por haber colaborado desinteresadamente en diversas ocasiones y por el préstamo de equipamiento o laboratorios. 


\section{Agradecimientos}

A Dios, por dar las oportunidades que después nosotros aprovechamos (o no).

A Ángel, mi director, por su infinita paciencia, su generosidad, sus palabras de aliento, su confianza. Por muchas veces haber sido un poco amigo y un poco padre.

Al "Negro", mi papá, por haberme enseñado que la honestidad no es sólo una palabra sino una forma de vida, por haberme dicho que yo "podía ser lo que quiera ser". Por haberme dado una vida feliz.

A Griselda, mi mamá, por ser mi fortaleza incondicional, por haberme dejado volar en libertad dándome raíces y alas, por su integridad, su valentía y su eterno amor.

A Nico, Fede y Juanma, mis hermanos (los más lindos del mundo), por el “aguante”, los chistes, las risas, las charlas... Por estar en todo momento

A mis abuelos, tíos y primos, porque son parte de mi vida y de lo que soy. Por su cariño y "aguante".

A mi abuela Pepa, por tanto amor y por las recetas de cocina... ( iTe extraño tanto!).

A “Joshela”, mi ángel de la guarda, porque siempre está, por su cariño infinito, porque ocupa un lugar muy importante en mi vida y en mi corazón... A su hermosa familia.

A los hermanos que me dio la vida, mis amigos, Barby (y su familia), Vero y Lean (mis compinches en todo momento), Marcos y Mariana (por estar en las buenas y en las malas), Vane y Guille (por hacer de cada instante junto a ellos un momento inolvidable), Darío (porque aprendí mucho de él), Pablo, Walde y Enry (mis "hermanitos" del 4to piso) y las hermosas mujeres que los acompañan, María Elisa (por ser tan genial), Martín (tan excelente persona como amigo y bailarín), Sergio y "el hermano" Massarutti (por la buena onda y predisposición), Yeimi, Jacky, Silvina, Mariela, Rita, Carlita, Laura y Tama (por la buena onda), Chufo, Tomás, Miguel, Gabriel, y Pablo (por los almuerzos desopilantes), Pame (por estar en todo momento), Rosario y familia (por el gran cariño mutuo), Seba (por ser mi profe, mi amigo y mi psicólogo más de una vez), Damián (por su ayuda incondicional), Esther (por 
escucharme y bancarme itantas veces!), a Dora Rossi (por su ayuda siempre que la necesité).

A toda la gente del 4to piso del INIFTA, por las charlas de pasillo, por los asados y todos los buenos momentos.

A Santi... porque siempre estuvo, porque está y porque deseo que siempre esté.

A Guille Varela y Santi Frías, mis hermanos del alma que ya no están y que desde alguna nube comparten mis alegrías y tristezas... como si nunca se hubieran ido.

A Vero, Ana, Carla, Flaca, Any, Marita, Mariano, Marcos V, Marcela, Diego, Milvia, Yany, Carlitos, Marcos M, Juan, y Vale, mis amigos-hermanos de la secundaria, por ser parte fundamental de lo que fui, soy y seré.

A Flore, Roly, Edgardo, Hugo, Nato y Martín, mis amigos del barrio, por la grandeza de la amistad simple y eterna.

A Nico, porque sin su "sí" generoso hoy no habría llegado hasta aquí. Por haber sido parte importante de este camino. A su familia.

A Belén, Luciana, Gaby, Negra, Tano, Sonia, Guille, Pepo, Vero, Nico W, Gaba y Maru, mis amigos de Santa Fe, por haber hecho de esos años una de las mejores etapas de mi vida y por seguir estando.

A mis compañeros de la Cátedra de Química General e Inorgánica de la Facultad de Ciencias Agrarias y Forestales, por los buenos momentos vividos.

A toda la "familia" del INIFTA por haberme hecho sentir una más desde el primer día.

A mi amada Añatuya y su gente que me da fuerzas y siempre me invita a volver al lugar de donde soy. 


\section{Abreviaturas}

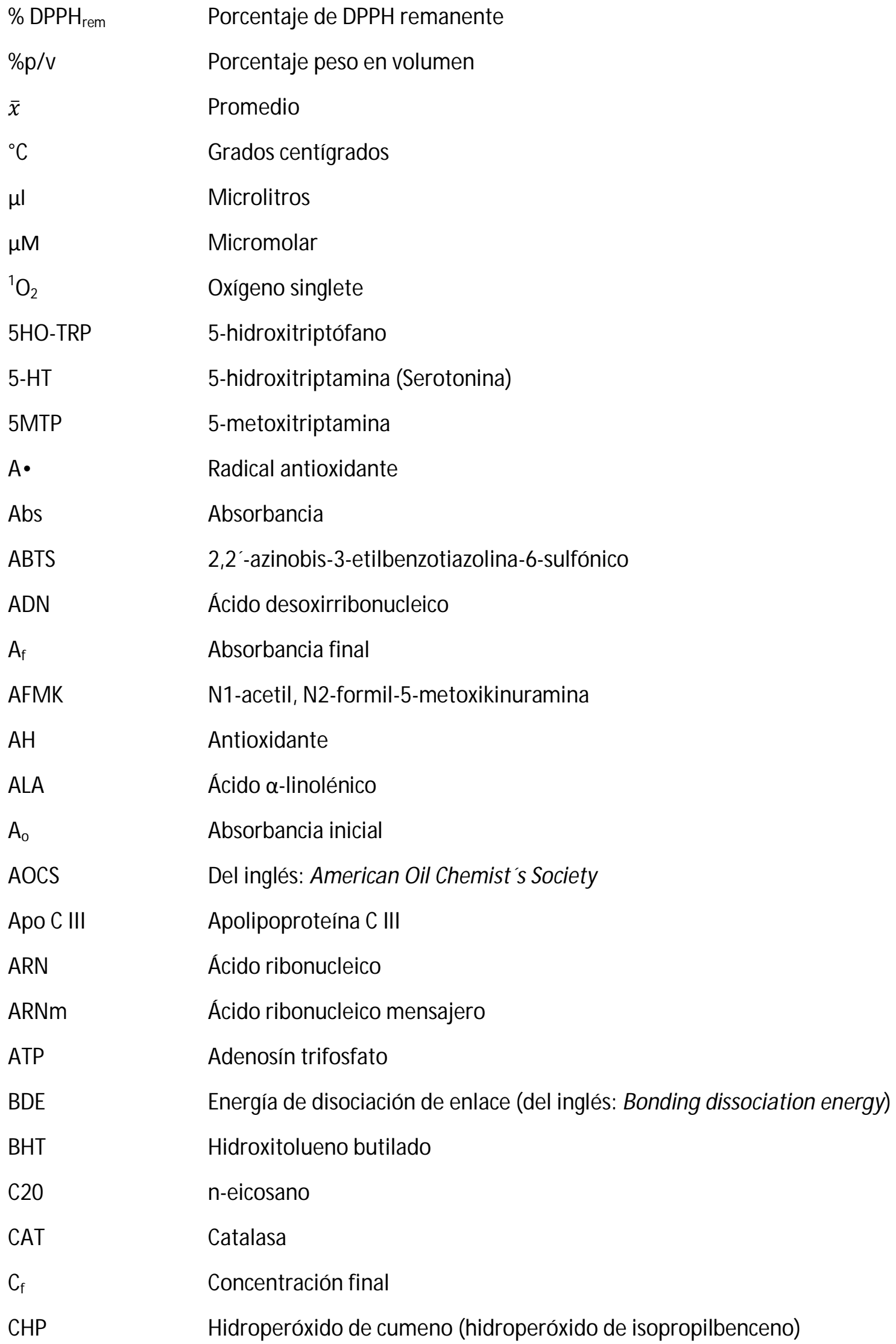


CLA

CLA c9, t11

CLA t10, c12

$\mathrm{Cm}$

$\mathrm{col}$

COX

CuZnSOD

DHA

DLS

DO

DPPH

$\mathrm{EC}_{50}$

EEUU

EPA

EPR

ESR

ETC

etc.

$\mathrm{eV}$

FOX

G6PD

GC-MS

GPx

GRd

GSH

HHE

HIOMT

HNE

$\mathrm{HO}$ •

$\mathrm{HOO} \bullet$

HPLC

$\mathrm{IC}_{50}$
Ácido linoleico conjugado (del inglés: conjugated linoleic acid)

Isómero conjugado de ácido linoleico cis 9, trans 11

Isómero conjugado de ácido linoleico trans 10 , cis 12

Centímetros

Colaboradores

Enzima ciclooxigenasa

CuZn- Superóxido dismutasa

Ácido docosahexenoico

Dispersión de luz dinámica (del inglés: dinamic light scattering)

Densidad óptica

1,1-difenil-2-picrilhidracil

Concentración efectiva 50

Estados Unidos

Ácido eicosapentenoico

Epitelio pigmentario de la retina

Resonancia de espín electrónico

Cadena de transferencia de electrones (del inglés: electron transfer chain)

Etcétera

Electronvolt

Ensayo de oxidación con $\mathrm{Fe}^{2+}$ en naranja de xilenol

Glucosa-6-fosfato deshidrogenasa

Cromatografía gaseosa acoplada a espectrometría de masas

Glutatión peroxidasa

Glutatión reductasa

Glutatión

Hidroxihexenal

Hidroxiindol-0-metiltransferasa

Hidroxinonenal

Radical hidroxilo

Radical hidroperoxilo

Cromatografía líquida de alta performance

Concentración inhibitoria 50 


\begin{tabular}{|c|c|}
\hline iso & Isómero \\
\hline $\mathrm{kHz}$ & Kilohertz \\
\hline$k_{n}$ & Constante de velocidad de la etapa " $n$ " \\
\hline$L \bullet, P U F A \bullet$ & Radical lipídico \\
\hline LA & Ácido linoleico \\
\hline LH & Lípido \\
\hline LNS & Liposomas no sonicados \\
\hline LO & Enzima lipooxigenasa \\
\hline LO* & Cetona lipídica activada \\
\hline LO•, PUFA-O• & Radical alcoxilo lipídico \\
\hline LOO•, PUFA-OO• & Radical peroxilo lipídico \\
\hline $\mathrm{LOOH}$ & Hidroperóxido lipídico \\
\hline LS & Liposomas sonicados \\
\hline M & Molaridad \\
\hline $\mathrm{m} / \mathrm{z}$ & Relación masa/carga \\
\hline$M^{+}$ & lón molecular \\
\hline MAO & M onoaminooxidasa \\
\hline máx. & Máximo \\
\hline MDA & Malondialdehído \\
\hline $\mathrm{MIH}$ & Factor inhibidor de melanocitos \\
\hline $\min$ & Minutos \\
\hline $\mathrm{ml}$ & Mililitros \\
\hline MLA & M etil linoleato \\
\hline MLT & Melatonina \\
\hline $\mathrm{mm}$ & Milímetros \\
\hline $\mathrm{mM}$ & Milimolar \\
\hline MnSOD & M n-Superóxido dismutasa \\
\hline $\mathrm{mW}$ & Miliwatts \\
\hline$n$ & Número de experimentos \\
\hline N & Normalidad \\
\hline NAS & $\mathrm{N}$-acetilserotonina \\
\hline NAT & $\mathrm{N}$-acetiltransferasa \\
\hline
\end{tabular}


ND

NIST

NO•

$\mathrm{nm}$

$\varnothing$

$\mathrm{ONOO}^{-}$

PI

PMHC

PNR

PPAR- $\alpha$

PUFA-H

PUFAs

PUFAs n-3

$\mathrm{Rh}$

RLUs

RNS

ROO•

ROS

ROSg

rpm

SD

seg

SOD

TBA

TBARS

tBHP

Tg PUFAs n-3

TLC

TRP

TVA

UV
No determinado

Del inglés: National Institute of Standards and Technology

Óxido nítrico

Nanómetros

Diámetro

lón peroxinitrito

Índice de polidispersidad

Pentametilhidroxicromano

Productos no radicales

Receptor activado por proliferadores peroxisomales.

Ácido graso poli-no-saturado (explicitando el $\mathrm{H}$ a perder)

Ácidos grasos poli-no-saturados

Ácidos grasos poli-no-saturados de la familia n-3

Radio hidrodinámico

Unidades lumínicas relativas (del inglés: relative luminic units)

Especies reactivas de nitrógeno (del inglés: reactive nitrogen species)

Radical peroxilo

Especies reactivas de oxígeno (del inglés: reactive oxygen species)

Segmentos externos de bastones (del inglés: rod outer segments)

Revoluciones por minuto

Desviación estándar

Segundos

Superóxido dismutasa

Ácido tiobarbitúrico

Sustancias reactivas al ácido tiobarbitúrico (del inglés: thiobarbituric reactive substances)

Tert butil hidroperóxido

Triglicéridos ricos en ácidos grasos poli-no-saturados de la familia n-3

Cromatografía en capa delgada (del inglés: thin layer chromatography)

Triptófano

Ácido trans-vaccénico

Ultravioleta 


$\begin{array}{ll}\text { UV-VIS } & \text { Ultravioleta-visible } \\ \text { V/v } & \text { Volumen/volumen } \\ V_{f} & \text { Volumen final } \\ \text { Vit. } & \text { Vitamina } \\ \text { VLDL } & \text { Lipoproteínas de muy baja densidad (del inglés: very low density } \\ & \text { lipoprotein) } \\ \text { w } & \text { Velocidad de reacción } \\ \text { W } & \text { Watts } \\ X \cdot & \text { Radical X } \\ X H & \text { Iniciador no radical } \\ \Delta A b s & \text { Cambio de absorbancia } \\ \Phi & \text { Eficiencia cuántica de luminiscencia }\end{array}$




\section{Resumen}

Los lípidos constituyen un grupo heterogéneo de compuestos con funciones muy importantes en el organismo tales como provisión de energía, constituyentes de membranas celulares y tejidos nerviosos, aislantes térmicos y eléctricos, función hormonal local, etc. La reacción directa entre una molécula de lípido poli-no-saturado y oxígeno molecular se conoce como Peroxidación Lipídica. Esta reacción de deterioro es catalizada por radicales libres (peroxidación no enzimática) o sistemas enzimáticos (peroxidación enzimática). Se produce por oxidación de los enlaces $\alpha$-metilénicos de los ácidos grasos no saturados que resulta en la formación de lipoperóxidos e hidroperóxidos y, finalmente, fragmentación de la molécula lipídica. Los radicales libres están implicados en el desarrollo de muchas enfermedades tales como aterosclerosis, diabetes, cáncer, enfermedades inflamatorias crónicas y enfermedades neurodegenerativas como así también en el proceso de envejecimiento. Un antioxidante es una sustancia que, presente en bajas concentraciones comparada con el sustrato peroxidable, previene o retarda la oxidación del mismo. Hay diversas sustancias a las que se les atribuye efecto antioxidante, aunque su efectividad depende de diversos factores tales como la polaridad de los mismos, el sustrato lipídico, pH, temperatura, concentración de antioxidantes y propiedades físicas del sustrato. Debido a esta variedad de factores se observó que algunos antioxidantes retardan la oxidación lipídica bajo ciertas condiciones pero la promueven en condiciones diferentes actuando como prooxidantes. En el presente trabajo de tesis realizamos estudios in vitro de peroxidación no enzimática sobre diferentes sustratos lipídicos, con mayor o menor semejanza a membranas biológicas, analizando diferentes prooxidantes y evaluando la actividad antioxidante de diversos compuestos.

En este trabajo de tesis se investigó:

\section{1) El efecto de melatonina e indolaminas relacionadas sobre la peroxidación lipídica de triglicéridos ricos en ácidos grasos n-3.}

La peroxidación de triglicéridos ricos en ácidos grasos poli-no-saturados n-3 disueltos en cloroformo fue analizada por detección de fotoemisión y ensayo de TBARS. La reacción fue iniciada por hidroperóxido de cumeno. En este sistema, hidroxitolueno butilado (BHT), 5HOtriptófano (5HO-TRP) y N-acetilserotonina (NAS) inhibieron la emisión de luz y la producción de TBARS de manera dependiente de la concentración. Sin embargo, melatonina (MLT) y 5metoxitriptamina (5MTP) aumentaron la producción de luz y TBARS de una manera dependiente de la concentración. La quimioluminiscencia fue cuantificada a través de las unidades lumínicas relativas (RLUs) totales y se determinó el parámetro IC $C_{50}$. Para 5 HO-TRP, 
NAS y BHT el valor de este último fue respectivamente 0.7, 6.2 y $9.7 \mathrm{mM}$. Para evaluar si el aumento de quimioluminiscencia producido por MLT se debe a la producción de N1-acetil, N2formil-5-metoxikinuramina (AFMK) se investigó su presencia por cromatografía en capa delgada (TLC) no encontrándose cantidades detectables del mismo. La actividad secuestradora de radicales de las indolaminas fue evaluada por la técnica de DPPH y los resultados indican que 5HO-TRP, NAS y BHT poseen actividad secuestradora de radicales dependiente de la concentración. Así, el parámetro $\mathrm{EC}_{50}$ para esta técnica obtenido fue 4.1, 4.7 y $8.4 \mu \mathrm{M}$ respectivamente, mientras que MLT y 5 MTP no presentaron actividad secuestradora a las concentraciones estudiadas.

\section{2) El efecto de isómeros conjugados de ácido linoleico (CLAs) sobre la peroxidación lipídica de triglicéridos ricos en ácidos grasos n-3.}

Diferentes concentraciones de ácido linoleico (LA), dos de sus isómeros conjugados (CLA c9, t11 y CLA t10,c12) y su metil éster (MLA) disueltos en cloroformo fueron peroxidados con tert butil hidroperóxido (tBHP) como iniciador de reacción. La reacción fue monitoreada por detección de fotoemisión. Los resultados demuestran que ambos isómeros conjugados mostraron aumento de fotoemisión significativa (a 100 y 200 mM) con respecto al control, mientras que LA y MLA no mostraron aumento de emisión de luz significativa a ninguna de las concentraciones analizadas. Estos resultados indican que en este sistema los CLAs son más susceptibles a la peroxidación que LA y M LA. También por fotoemisión se investigó el efecto de CLAs, LA y M LA sobre la peroxidación de triglicéridos ricos en ácidos grasos poli no saturados n-3 disueltos en cloroformo iniciada por tBHP. Ambos CLAs produjeron inhibición significativa de la fotoemisión siendo más efectivo el isómero t10, c12 (100 mM ) que el c9, t11 (200 mM ). LA y M LA no mostraron efecto inhibidor en este sistema. El ensayo de DPPH fue utilizado para determinar la actividad secuestradora de radicales de LA, MLA y los isómeros conjugados. CLA t10,c12 y c9,t11 reaccionaron con DPPH obteniéndose valores de $\mathrm{EC}_{50}$ de $16,4 \pm 0,8$ y 16,9 90,9 $\mathrm{mM}$, respectivamente. LA y LAME no presentaron actividad secuestradora de radical DPPH. Estos datos indican que, a diferencia de LA y MLA, los CLAs pueden proteger a los lípidos que contienen ácidos grasos poli-no-saturados de los efectos de los radicales libres. Sin embargo, se deben tener en cuenta las elevadas concentraciones necesarias para este fin.

3) La susceptibilidad a la peroxidación de liposomas de lípidos de retina y el efecto de la sonicación, el medio e iniciador de reacción sobre este sistema. 
La retina es un tejido especialmente susceptible al daño oxidativo debido a su elevado contenido en ácidos grasos poli-no-saturados (PUFAs), principalmente ácido docosahexenoico (22:6 n-3). Se sabe que el proceso de peroxidación lipídica participa de numerosos eventos fisiológicos y patológicos de la retina. Para poder comprender aspectos que no pueden ser estudiados directamente en membranas biológicas se puede recurrir al uso de membranas modelo, por ej: liposomas. Para poder evaluar sustancias antioxidantes es necesario obtener un modelo de membranas fácilmente peroxidables, para tal fin se prepararon liposomas sonicados (LS) y liposomas no sonicados (LNS) a partir de lípidos aislados de retinas bovinas. Estos liposomas fueron peroxidados con $\mathrm{Fe}^{2+} 0 \mathrm{Fe}^{3+}$ (como iniciadores de reacción) en agua, solución fisiológica o buffer Tris- $\mathrm{HCl}$ pH 7,4. El seguimiento de la reacción se realizó por espectrofotometría UV (absorbancia a 234 y $270 \mathrm{~nm}$ ), para detectar formación de dienos y trienos conjugados, y por ensayo de TBARS. Empleando $\mathrm{Fe}^{2+}$ como iniciador de reacción, tanto LS como LNS en buffer produjeron TBARS tras 60 min de iniciada la reacción, este tiempo fue de 30 min en agua y 0 min en solución fisiológica. La mayor y más rápida formación de dienos y trienos conjugados se observó en solución fisiológica mientras que la mínima producción se obtuvo en buffer. Empleando $\mathrm{Fe}^{3+}$ como iniciador, para ambos tipos de liposomas, la producción de TBARS fue más lenta en buffer que en los demás medios y la producción de dienos y trienos conjugados también fue la menor en buffer. Los resultados demuestran que: LS fueron más susceptibles a la peroxidación que LNS; solución fisiológica fue el medio en el que la peroxidación lipídica fue más eficiente, siguiendo en este orden agua y, en último lugar, buffer Tris- $\mathrm{HCl} ; \mathrm{Fe}^{2+}$ es un iniciador de peroxidación lipídica mucho más eficiente que $\mathrm{Fe}^{3+}$ cualquiera sea el medio acuoso de reacción o el tipo de liposoma empleado. En resumen, la peroxidación depende del tipo de liposoma, iniciador y medio de reacción.

\section{4) El efecto de melatonina e indolaminas relacionadas sobre la peroxidación iniciada por $\mathrm{Fe}^{2+}$ de liposomas sonicados de lípidos de retina.}

Melatonina es una hormona que ha demostrado amplia actividad antioxidante in vivo aunque su actividad como secuestrador directo de radicales no está muy bien definida. En esta tesis investigamos la capacidad antioxidante de melatonina y de algunos de sus análogos estructurales en un sistema de liposomas sonicados preparados con lípidos de retina bovina. La reacción fue iniciada por $\mathrm{Fe}^{2+}$ empleando agua como medio de reacción. La actividad antioxidante de melatonina (MLT), N-acetilserotonina (NAS), 5HO-triptófano (5HO-TRP) y 5 metoxitriptamina (5M TP) fue comparada con la de hidroxitolueno butilado (BHT), seleccionado como referencia por su conocido y elevado poder antioxidante. La reacción de peroxidación 
fue monitoreada por determinación de dienos conjugados y ensayo de TBARS. Tras la adición de $\mathrm{Fe}^{2+}$ al sistema de liposomas la formación de dienos conjugados fue inmediata. En presencia de diferentes concentraciones de BHT, el inicio de la formación de dienos conjugados fue retardado y la velocidad de formación fue disminuida. Sin embargo, estos parámetros no fueron modificados en presencia de MLT y demás indolaminas. La formación de TBARS fue inhibida por todas las concentraciones de BHT empleadas. M LT y las indolaminas analizadas no lograron disminuir la formación de TBARS. Mediante cromatografía gaseosa acoplada a espectrometría de masas (CG-MS) se analizaron los perfiles de ácidos grasos de retina y de los liposomas preparados con sus lípidos, antes y después de ser peroxidados, en presencia y ausencia de BHT, MLT o las indolaminas estudiadas. Los ácidos grasos poli-no-saturados (PUFAs) disminuyeron significativamente después de una hora de incubación con $\mathrm{Fe}^{2+}$ hasta casi desaparecer. La presencia de BHT protegió a los PUFAs de la peroxidación mientras que MLT y las indolaminas no presentaron efecto protector alguno. Los resultados obtenidos por las diferentes técnicas utilizadas son consistentes y sustentan la hipótesis de que MLT y algunos de sus análogos estructurales no poseen actividad antioxidante directa en este sistema modelo.

\section{Summary}

Lipids are a heterogeneous group of compounds with important body functions such as: an energy source, cell membranes and nerve tissues constituents, thermal and electrical insulators, local hormone function, etc. The direct reaction between a polyunsaturated lipid molecule and molecular oxygen is known as lipid peroxidation. This degradation reaction is catalyzed by free radicals (non-enzymatic peroxidation) or enzymatic systems (enzymatic peroxidation). It occurs by oxidation of unsaturated fatty acid $\alpha$-methylene bonds producing lipid and hydro peroxides and, finally, lipid molecule fragmentation. Apart from playing a major role in the aging process, free radicals are involved in the development of many diseases, namely atherosclerosis, diabetes, cancer, chronic inflammatory and neurodegenerative diseases. An antioxidant is a substance whose low concentrations levels, as compared to those of oxidizable substrate, prevent or slow its oxidation. Many substances have an antioxidant effect. Nevertheless, their effectiveness depends on various factors such as: polarity, the lipid substrate, $\mathrm{pH}$, temperature, concentration of antioxidants and physical properties of the substrate. Due to this variety of factors, it was noted that while some antioxidants delay lipid peroxidation others act as pro-oxidants. In this thesis we studied in vitro non enzymatic lipid 
peroxidation of different lipid species, in a more or less similar way to biological membranes, analyzing different pro oxidants and assessing antioxidant activity of various compounds.

In this thesis we investigated:

1) The effect of melatonin and related indoleamines on the lipid peroxidation of triglycerides with high content of $n-3$ polyunsaturated fatty acids.

The lipid peroxidation of triglycerides rich in polyunsaturated fatty acids was investigated by photoemission and TBARS assay. The reaction was initiated by cumen hydroperoxide (CHP). In this system, butylated hydroxitoluene (BHT), 5HO tryptophan (5HOTRP) and $\mathrm{N}$-acetylserotonin (NAS) inhibited light emission and TBARS production in a concentration dependent way. However, melatonin (MLT) and 5-methoxitryptamine (5MTP) enhanced light emission and TBARS production in a concentration dependent manner. Chemiluminescence was quantified by total Relative Luminic Units (RLUS) and IC $\mathrm{C}_{50}$ parameter. $\mathrm{IC}_{50}$ value to $5 \mathrm{HO}-\mathrm{TRP}, \mathrm{NAS}$ and BHT was $0.7,6.2$ and $9.7 \mathrm{mM}$. The possible formation of $\mathrm{N}(1)-$ acetyl-N (2) formyl-5-methoxykynuramine (AFM K) during lipid peroxidation of triglycerides rich in PUFAs in the presence of melatonin was also analyzed by thin layer chromatography (TLC). The free-radical scavenging activity of the indoleamine derivatives was also analyzed by the DPPH method, and the results indicate that 5OH-TRP, NAS and BHT exhibited a dosedependent free-radical scavenging ability at all tested concentrations. The $\mathrm{EC}_{50}$ value for these compounds was 4.1, 4.7 and $8.4 \mu \mathrm{M}$ respectively, while MLT and 5MTP did not show any radical scavenger activity.

\section{2) The effect of conjugated linoleic acid (CLAs) isomers on lipid peroxidation of triglycerides rich in fatty acids $n-3$.}

Different concentrations of linoleic acid (LA), two of its conjugated isomers (c9, t11 and t10, c12) and methyl linoleate (M LA) dissolved in chloroform were peroxidized with tert-butyl hydroperoxide (tBHP). The reaction was monitored by chemiluminescence detection. The results showed that both conjugated linoleic acid isomers enhanced photoemission with respect to control, while LA and M LA did not enhance light emission significantly. These results indicate that CLAs are more susceptible to lipid peroxidation than LA and M LA. Also, by means of photoemission, we investigated the effect of CLA, LA and MLA on lipid peroxidation of triglycerides rich in polyunsaturated fatty acids n-3 dissolved in chloroform initiated by tBHP. Both CLAs inhibited photoemission significantly and the isomer t10, c12 (100 mM) was more 
efficient than c9, t11 (200 mM ). LA and M LA did not show any protection in this system. DPPH assay was used to determine free radical scavenger activity of LA, MLA and conjugated isomers. CLA t10, c12 and c9, t11 reacted with DPPH giving $\mathrm{EC}_{50}$ values of $16,4 \pm 0,8$ y $16,9 \pm 0,9$ $m M$, respectively. LA and MLA did not present activity against DPPH. These results show that CLAs can protect lipids against free radical action but LA and M LA cannot. However, we must take into account the high effective concentrations used.

\section{3) The susceptibility of sonicated liposomes made of retinal lipids to lipid peroxidation: effect of sonication, medium and initiator.}

The retina is a tissue especially susceptible to lipid peroxidation due to its high content of polyunsaturated fatty acids (PUFAs), mainly docosahexaenoic acid (22:6n-3). It is known that lipid peroxidation is involved in many pathological and physiological retinal events. Model membranes can be used to address issues that otherwise cannot be directly studied in biological membranes, i.e.: liposomes. Obtaining an easily peroxidable system is necessary to analyze antioxidant activity in those model membranes. To achieve this goal we prepared sonicated (SL) and no-sonicated (NSL) liposomes made of retinal lipids. These liposomes were peroxidized by $\mathrm{Fe}^{2+}$ and $\mathrm{Fe}^{3+}$ in water, $\mathrm{NaCl} 0.15 \mathrm{M}$ or buffer Tris- $\mathrm{HCl} \mathrm{pH} \mathrm{7.4.} \mathrm{Conjugated} \mathrm{dienes}$ and trienes, determined by absorption at 234 and $270 \mathrm{~nm}$ respectively and TBARS were measured as a function of time. Using $\mathrm{Fe}^{2+}$ as reaction initiator, SL and LNS in buffer produced TBARS after $60 \mathrm{~min}$, in water this time was $30 \mathrm{~min}$ and in $\mathrm{NaCl} 0.15 \mathrm{M}$ was $0 \mathrm{~min}$. The highest and fastest dienes and trienes production was observed in $\mathrm{NaCl} 0.15 \mathrm{M}$, and the lowest in buffer. With $\mathrm{Fe}^{3+}$ as initiator, both liposomes presented the slowest TBARS production in buffer as it was the case for dienes and trienes production. These results show that: SL were more susceptible to lipid peroxidation than NSL, $\mathrm{NaCl} 0.15 \mathrm{M}$ was the medium where the lipid peroxidation was the most efficient and $\mathrm{Fe}^{2+}$ was a better initiator than $\mathrm{Fe}^{3+}$. Summarizing, lipid peroxidation depends on: liposome type, reaction initiator and reaction medium.

\section{4) The effect of melatonin and related indoleamines on lipid peroxidation initiated by $\mathrm{Fe}^{2+}$ of sonicated liposomes made of retinal lipids.}

Melatonin is a hormone with a high in vivo antioxidant power although its activity as a direct free radical scavenger is not very well defined. In this thesis we investigated the antioxidant activity of melatonin and some of its structural analogues in a system of sonicated liposomes made of retinal lipids. The reaction was initiated by $\mathrm{Fe}^{2+}$ in water as a reaction medium. The antioxidant activity of melatonin (MLT), N-acetylserotonin (NAS), 5HO- 
tryptophan (5HO-TRP) and 5-methoxytryptamine (5MTP) was compared to that of butylated hydroxytoluene (BHT) chosen because of its high well-known antioxidant power. The reaction was assessed by detection of conjugated dienes and TBARS. After addition of $\mathrm{Fe}^{2+}$, diene production started immediately. Different concentrations of BHT delayed the start of conjugated diene production. However, this parameter was not modified by MLT or the other indoleamines. TBARS production was inhibited by all concentrations of BHT. MLT and indoleamines were unable to prevent TBARS formation. By gaseous chromatography coupled to mass spectrometry (GC-MS) we analyzed fatty acids profiles of retinal lipids and liposomes made of retinal lipids, before and after $\mathrm{Fe}^{2+}$-peroxidation and with and without BHT, MLT and indoleamines. Polyunsaturated fatty acids (PUFAs) diminished significantly after one hour of incubation with $\mathrm{Fe}^{2+}$ until they almost disappeared. BHT protected PUFAs against peroxidation while MLT and indoleamines presented no protective effect. All these results support the hypothesis that MLT and some of its structural analogues do not show direct antioxidant activity in this model system. 


\section{Publicaciones originadas durante el periodo de formación doctoral}

> Natalia Fagali, Angel Catalá. 2007. The effect of melatonin and structural analogues on the lipid peroxidation of triglycerides enriched in $\omega-3$ polyunsaturated fatty acids. Life Sciences. 81: 299-305.

$\mathrm{IF}=2.661$

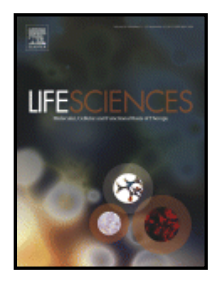

> Natalia Fagali, Angel Catalá. 2008. Antioxidant activity of conjugated linoleic acid isomers, linoleic acid and its methyl ester determined by photoemission and DPPH• techniques. Biophysical Chemistry. 137: 56-62. $\mathrm{IF}=2.254$

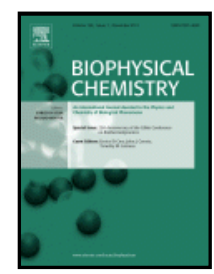

Natalia Fagali, Angel Catalá. 2009. $\mathrm{Fe}^{2+}$ and $\mathrm{Fe}^{3+}$ initiated peroxidation of sonicated and non-sonicated liposomes made of retinal lipids in different aqueous media. Chemistry and Physics of Lipids. 159: 88-94.

$\mathrm{IF}=2.861$

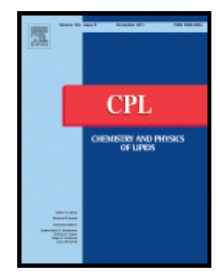

> Natalia Fagali, Angel Catalá. 2011. Melatonin and structural analogues do not possess antioxidant properties on $\mathrm{Fe}^{2+}$-initiated peroxidation of sonicated liposomes made of retinal lipids. Chemistry and Physics of Lipids. 164: 688-695.

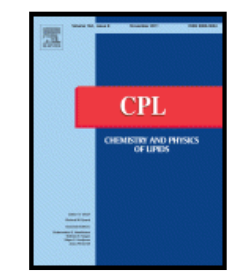

$\mathrm{IF}=2.861$ 


\section{C apitulo 1}

Introducción general y objetivos 


\subsection{Consideraciones generales}

Los lípidos constituyen un grupo heterogéneo de compuestos con funciones importantes diversas en el organismo tales como provisión de energía, constituyentes de membranas celulares y tejidos nerviosos, aislantes térmicos y eléctricos, función hormonal local, etc. Los lípidos son uno de los grupos dietarios principales no sólo por el alto contenido energético sino también por contener vitaminas liposolubles y ácidos grasos esenciales. Diversas investigaciones sugieren que el consumo de lípidos no saturados, especialmente ácidos grasos poli-no-saturados n-3 (PUFAs n-3), es beneficioso para la salud (Watkins y German, 1998). El organismo genera energía a partir de los lípidos cuando ellos sufren el proceso de $\beta$-oxidación y el oxígeno es reducido a agua en la cadena respiratoria de la mitocondria (M urray y col, 2000). Entre el 85 y 90\% del oxígeno consumido por el humano es utilizado por la mitocondria para producción de energía, mientras que el 10-15 \% restante es utilizado en reacciones químicas no enzimáticas y por varias enzimas oxidasas y oxigenasas (Gutteridge y Halliwell, 1994; Halliwell y Gutteridge, 1999). Los lípidos que contienen ácidos grasos PUFAs son susceptibles a las reacciones con oxígeno sin generación de energía. Esto ocasiona pérdida de la fluidez y funciones de las membranas de las que forman parte, inactivación de los receptores y enzimas unidos a membranas, aumento de la permeabilidad iónica $y$, eventualmente, ruptura de membrana y muerte celular (Gutteridge y Halliwell, 1990; Gutteridge, 1995). La incorporación de oxígeno a la estructura del lípido se conoce como peroxidación lipídica y puede ser catalizada por radicales libres (peroxidación lipídica no enzimática) o por enzimas (peroxidación lipídica enzimática). Esta reacción es reconocida desde la antigüedad como un problema en el almacenamiento de grasas y aceites y ha sido estudiada por químicos de los alimentos, de polímeros y hasta por curadores de museos interesados en la degradación de valiosas pinturas. El mecanismo de la peroxidación lipídica inducida por radicales libres fue establecido en 1940 por Farmer y sus colaboradores. A partir de los años '50 cobró gran importancia la investigación de la peroxidación lipídica en sistemas biológicos y en medicina.

\subsection{Lípidos}

Aunque no existe una definición universalmente aceptada de "lípidos", la definición propuesta por Christie (Christie, 1987) remonta a los orígenes del término y grafica adecuadamente este amplio grupo de compuestos:

“Lípidos son ácidos grasos y sus derivados, y sustancias relacionadas biosintética 0 funcionalmente a estos compuestos". 
Los ácidos grasos son compuestos sintetizados en la naturaleza por condensación de unidades de malonil- coenzima A por el complejo sintetasa de ácidos grasos. Según esta definición el colesterol (pero no las hormonas esteroideas) puede ser considerado un lípido, así como los fosfolípidos y glicolípidos.

Los ácidos grasos de origen vegetal, animal y microbiano generalmente están formados por cadenas de números pares de átomos de carbono, con un grupo carboxilo en un extremo y con dobles enlaces, si estuvieran presentes, en configuración cis. En tejidos animales, los ácidos grasos más comunes varían entre 14 y 22 átomos de carbono, pero en ocasiones pueden ampliar el rango de 2 a 36 y aún más. Los ácidos grasos no saturados de origen animal usualmente presentan entre uno y seis dobles enlaces mientras que en plantas raramente superan los tres. Ácidos grasos hidroxilados son sintetizados en algunos tejidos animales, pero ácidos grasos con otros grupos funcionales, cuando se encuentran presentes, provienen usualmente de la dieta. Los ácidos grasos vegetales y microbianos pueden contener una amplia variedad de grupos funcionales incluyendo dobles enlaces en configuración trans, enlaces acetilénicos, grupos epoxilo, hidroxilo, ceto y éter y anillos ciclopropeno, ciclopropano y ciclopenteno.

Los ácidos grasos saturados más abundantes en tejidos animales y vegetales son compuestos de cadena lineal de 14, 16 y 18 átomos de carbono, pero todos los ácidos grasos con número par e impar, entre 2 y 36 átomos de carbono se han encontrado en la naturaleza en su forma esterificada. Ácidos grasos de cadena impar son sintetizados en muchos microorganismos y son producidos, aunque en forma muy limitada, en tejidos animales cuando la sintetasa de ácidos grasos acepta propionil- coenzima A como sustrato.

El ácido graso monoenoico más abundante es probablemente el cis-9-octadecenoico (ácido oleico, 18:1n-9) aunque isómeros con configuración trans también se encuentran en la naturaleza. Por ejemplo, el trans-11-octadecenoico (ácido vaccénico, 18:1 t11) es un producto secundario de la biohidrogenación en el rumen, por lo que se encuentra presente en tejidos de rumiantes y, a través del consumo de productos lácteos, en tejidos humanos. Además, isómeros trans son producidos durante la hidrogenación industrial de grasas y aceites y en la manufactura de margarinas.

Los PUFAs de origen animal pueden clasificarse en familias de acuerdo a sus precursores biosintéticos y la proximidad del primer doble enlace al grupo metil terminal (n u omega). Así, las familias contienen de 2 a 6 dobles enlaces, separados por grupos metilenos simples y la misma estructura terminal. El ácido linoleico $(18: 2 n-6)$ es el más abundante en tejidos vegetales y animales. Es un ácido graso esencial en la dieta animal ya que no puede ser 
sintetizado en tejidos animales y es requerido para el crecimiento, reproducción y salud normales. Dado que las enzimas en animales sólo pueden insertar nuevos dobles enlaces entre un doble enlace existente y el grupo carboxilo, el ácido linoleico sirve como precursor de la familia n-6 de ácidos grasos formados por desaturación y elongación de la cadena, en la que la estructura terminal es conservada. De esta familia, el ácido araquidónico (20:4 n-6) es particularmente importante como componente de membrana y como precursor de prostaglandinas. Las enzimas vegetales son capaces de insertar un doble enlace en la región terminal de un doble enlace ya existente. El ácido linolénico (18:3n-3) es el punto final de biosíntesis en la mayoría de plantas superiores (Figura 1.1). Es un ácido graso esencial y, por lo tanto, debe incorporarse a los tejidos animales por medio de la dieta. Es el precursor de la familia n-3 que incluye al ácido docosapentenoico (DPA, 20:5 n-3), precursor de prostanoides específicos y al ácido docosahexenoico (DHA, 22:6n-3), que posee funciones específicas en los fosfolípidos de tejido nervioso y en el ojo. En cada paso, las cascadas de n-3 y n-6 compiten por las enzimas aunque su afinidad por las enzimas y su habilidad por inhibir las desaturasas es diferente (la afinidad de los ácidos grasos es n-3: n-6:n-9- 10:3:1) (Tvrzicka y col, 2011).

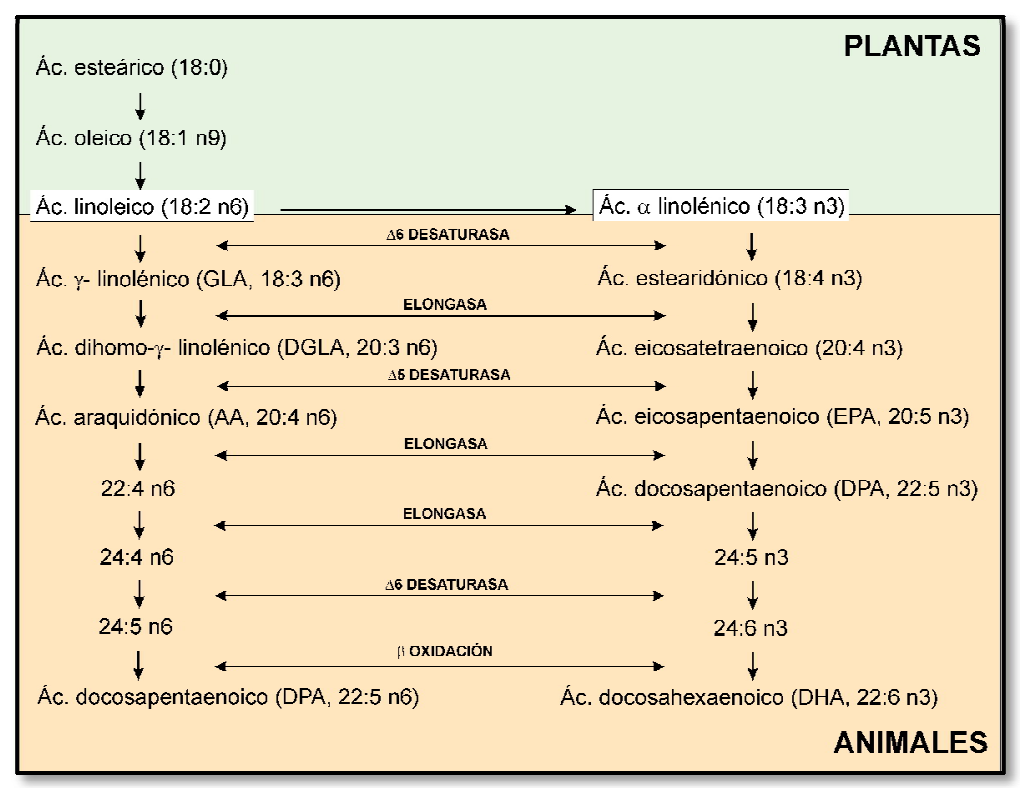

Figura 1.1. Vías de síntesis de ácidos grasos en vegetales y animales.

Recuadrados se encuentran los ácidos grasos esenciales 18:2 n-6 (linoleico) y 18:3n-3 (linolénico) que los animales deben incorporar con la dieta (modificado de Sangiovanni, 2005).

El grado de no saturación de ácidos grasos es el principal determinante de la temperatura de fusión de triglicéridos, como de la fluidez de membranas biológicas que están 
compuestas por fosfolípidos. Los PUFAs de cadena larga, tales como ácido araquidónico y docosahexenoico poseen funciones biológicas cruciales tales como conferir flexibilidad y permeabilidad selectiva a membranas celulares en eucariotas, entre otros procesos celulares y fisiológicos tanto en plantas como en animales (Catalá, 2011).

\subsection{Radicales libres}

Un radical libre se puede definir como un átomo o molécula que contiene uno o más electrones desapareados. Es capaz de una existencia independiente. Un electrón desapareado es un electrón que ocupa un orbital solo (indicado desde ahora como •), aunque los electrones usualmente se asocian en pares en orbitales de átomos o moléculas. Los radicales libres son generalmente más reactivos que los no-radicales debido a su electrón desapareado, pero diferentes radicales varían ampliamente su reactividad (Tabla 1.1). La molécula de oxígeno $\left(\mathrm{O}_{2}\right)$ califica como un radical libre porque contiene dos electrones desapareados, pero no es particularmente reactiva debido a una distribución electrónica especial (Halliwell y Gutteridge, 1990). Sin embargo, en los pasos intermedios de la reducción del oxígeno a agua se pueden formar radical anión superóxido $\left(\mathrm{O}_{2}{ }^{*}\right)$, peróxido de hidrógeno $\left(\mathrm{H}_{2} \mathrm{O}_{2}\right)$ y radical hidroxilo $(\mathrm{HO} \bullet)$. Además, el oxígeno molecular en su estado fundamental, puede ser excitado electrónicamente hacia el oxígeno molecular singlete $\left({ }^{1} \mathrm{O}_{2}\right)$. Se pueden formar otras especies reactivas cuando el oxígeno se combina con otros átomos o moléculas, como radical alcohoxilo (RO•), radical peroxilo $(\mathrm{ROO} \bullet)$, óxido nítrico $(\mathrm{NO} \bullet)$, peroxinitrito $(\mathrm{ONOO}-)$, triclorometilo $\left(\mathrm{CCl}_{3} \bullet\right)$ entre otros (Halliwell y Chirico, 1993; Slater, 1984; Rice-Evans y Burdon, 1993; Halliwell, 1994; Halliwell y col, 1995).

Tabla 1.1. Potenciales de reducción estándar de especies de interés en reacciones de radicales libres (Adaptado de Buettner, 1993)

\begin{tabular}{|l|l|l|}
\hline Especies & $\mathbf{E}^{\circ}(\mathbf{m V})$ & \\
\hline $\mathrm{HO} \cdot, \mathrm{H}^{+} / \mathrm{H}_{2} \mathrm{O}$ & 2310 & \\
$\mathrm{RO} \cdot, \mathrm{H}^{+} / \mathrm{ROH}$ & 1600 & Radical alcoxilo alifático, $\mathrm{H}$ alifático \\
$\mathrm{ROO} \cdot, \mathrm{H}^{+} / \mathrm{ROOH}$ & $1000^{*}$ & Radical alquil-peroxilo \\
$\mathrm{O}_{2}{ }^{\circ}, 2 \mathrm{H}^{+} / \mathrm{H}_{2} \mathrm{O}_{2}$ & 940 & \\
${ }^{1} \mathrm{O}_{2} / \mathrm{O}_{2}{ }^{\circ-}$ & 650 & \\
$\mathrm{PUFA} \cdot, \mathrm{H}^{+} /$PUFA-H & 600 & Ácido graso poli-no-saturado, $\mathrm{H}$ bis alílico \\
$\alpha$-tocoferoxilo, $\mathrm{H}^{+} / \alpha$-tocoferol & 500 & Vit. E \\
Trolox $\cdot, \mathrm{H}^{+} /$Trolox & 480 & Vit. E hidrosoluble
\end{tabular}




\begin{tabular}{|l|l|l|}
$\mathrm{H}_{2} \mathrm{O}_{2}, \mathrm{H}^{+} / \mathrm{H}_{2} \mathrm{O}, \mathrm{HO} \bullet$ & 320 & \\
$\mathrm{~A} \bullet^{-}, \mathrm{H}^{+} / \mathrm{AH}^{-}$ & 282 & Vit. C (Ascorbilo/Ascorbato) \\
$\mathrm{Fe}^{3+} / \mathrm{Fe}^{2+}$ (acuoso) & 110 & Determinado a pH 7 \\
& 770 & Determinado a pH 0 \\
$\mathrm{A}^{-} / \mathrm{A} \bullet$ & -174 & Vit. C (Dehidroascorbato/Ascorbilo) \\
\hline
\end{tabular}

* Los radicales peroxilo poseen un amplio rango de potenciales de reducción, $770 \ll \mathbb{E}^{\circ}<1440$

La vida media de las principales especies reactivas de oxígeno (ROS) es sumamente variada (Tabla 1.2). Las constantes de velocidad más altas para las reacciones con moléculas blanco fueron encontradas para el radical HO • Las reacciones de este radical son de difusión limitada ocurriendo prácticamente en el sitio de generación. En contraste, muchos de los radicales $\mathrm{ROO}$ - son relativamente estables, con una vida media en el rango de segundos. Tales moléculas pueden difundir desde su sitio de formación y transportar el radical o función oxidante hacia otros sitios blancos.

Tabla 1.2. Tiempos de vida estimados para especies reactivas (M odificado de Sies, 1993)

\begin{tabular}{|l|l|}
\hline Especies reactivas & Tiempo de vida media \\
\hline $\mathrm{HO} \cdot$ & $10^{-9}$ segundos \\
$\mathrm{RO} \cdot$ & $10^{-6}$ segundos \\
$\mathrm{ROO} \cdot$ & 7 segundos \\
$\mathrm{ONOO}^{-}$ & $0.05-1$ segundos \\
$\mathrm{NO} \cdot$ & $1-10$ segundos \\
\hline
\end{tabular}

Para poder predecir la dirección de procesos mediados por radicales libres es necesario conocer la termodinámica de estas reacciones. Una propiedad termodinámica clave a tener en cuenta es el potencial de reducción. La tabla 1.1 resume los potenciales estándar de reducción de un electrón de algunas especies de interés en la reacciones radicalarias. Esta tabla está basada en reacciones de transferencia de un electrón aunque se debe tener en cuenta que otras reacciones pueden ser posibles o preferidas. Por ejemplo, ${ }^{1} \mathrm{O}_{2}$ podría reaccionar con PUFA para formar anión superóxido y PUFA •. Sin embargo, la reacción cinéticamente preferencial no es la transferencia de electrones sino la reacción del ${ }^{1} \mathrm{O}_{2}$ con el doble enlace del PUFA para formar LOO •. Por lo tanto, se debe tener en cuenta que una reacción termodinámicamente posible 
puede no ser cinéticamente factible, por ejemplo, la constante de velocidad para una reacción puede ser demasiado pequeña para que la reacción tenga relevancia biológica (Buettner, 1993).

Reacciones de radicales libres

Los radicales pueden reaccionar con otras moléculas de diversas maneras. Dos radicales libres pueden compartir sus electrones formando un enlace covalente y generando una especie no radicalaria. Un radical puede ceder o tomar un electrón de una especie no radical convirtiéndola en un nuevo radical. Dado que la mayoría de las moléculas presentes en los organismos vivos son no radicales, un radical libre las podrá atacar generando nuevos radicales. Así, los radicales libres generan reacciones en cadena. Finalmente, los radicales formados pueden reaccionar con un antioxidante cortador de cadena que debido a sus propiedades estructurales, puede estabilizar el electrón desapareado haciéndolo menos reactivo.

Las dos caras de los radicales libres

Los radicales libres y varias ROS son continuamente producidos en el organismo (Halliwell y Chirico, 1993; Rice-Evans y Burdon, 1993; Halliwell, 1994; Halliwell y col, 1995). Pueden ser generados en la cadena respiratoria mitocondrial debido al escape de electrones desde la cadena de transporte de electrones o por reacciones catalizadas por metales de transición tales como hierro y cobre. También derivan de fuentes exógenas como el humo del cigarrillo, radiación, luz UV, contaminación y del metabolismo de ciertas drogas. Estos radicales libres pueden atacar al ADN, proteínas y lípidos y causar daño oxidativo extenso (Halliwell y Chirico, 1993; Rice-Evans y Burdon, 1993; Halliwell, 1994; Halliwell y col, 1995). Sin embargo, los radicales libres no sólo aparecen como productos indeseables sino que son producidos deliberadamente por el organismo para propósitos útiles y tienen importantes roles fisiológicos. Uno de estos roles beneficiosos surge cuando células fagocíticas activadas (neutrófilos, monocitos, macrófagos y eosinófilos) producen $\mathrm{O}_{2}{ }^{\cdot-}$ y $\mathrm{H}_{2} \mathrm{O}_{2}$ como mecanismo destructor de bacterias y hongos y para inactivar virus (Curnutte y Babior, 1987). Además, los radicales libres pueden ser producidos por varias enzimas como enzimas del metabolismo del piruvato, oxidasas, carboxilasas, hidroxilasas, peroxidasas y enzimas que participan de la maduración de las frutas (Halliwell y Gutteridge, 1999).

\section{Estrés oxidativo}

Se ha definido al estrés oxidativo como un desbalance entre antioxidantes y prooxidantes (radicales libres y otras especies reactivas) (Halliwell, 1997; Betteridge, 2000). Este 
desbalance puede deberse a un efecto de depleción de antioxidantes endógenos, una insuficiente incorporación dietaria de antioxidantes y/o una aumentada producción de radicales libres u otras especies reactivas (Figura 1.2).

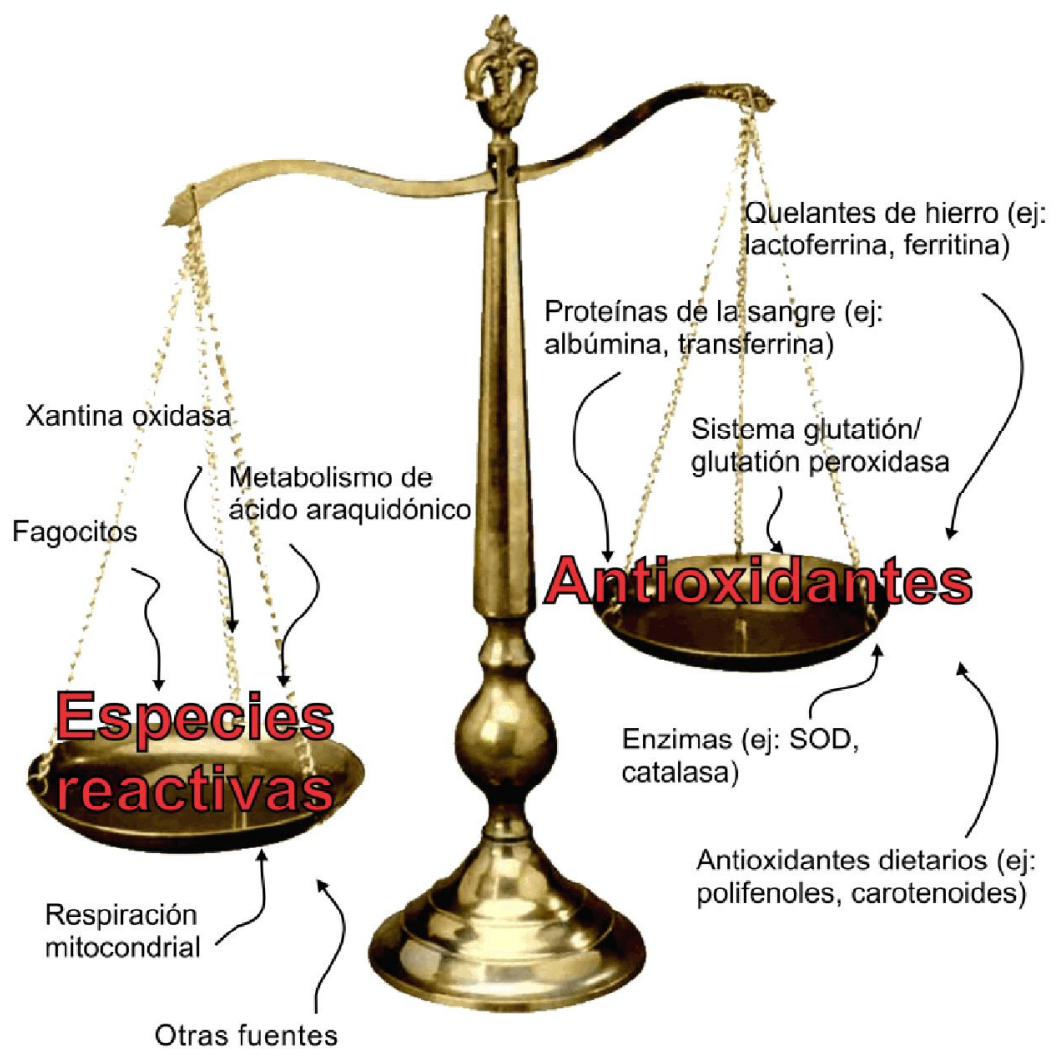

Figura 1.2. Balance de antioxidantes y especies reactivas in vivo (Adaptado de Halliwell, 2009)

Daño por radicales libres

El daño oxidativo a ADN, proteínas y lípidos puede dar lugar a desorganización, disfunción y destrucción de membranas, enzimas y proteínas (Slater, 1984; Halliwell, 1994; Halliwell, 1997). Específicamente, la peroxidación de los lípidos de membrana (Figura 1.3) puede causar deterioro de la función de membrana, disminución de la fluidez, inactivación de receptores y enzimas unidos a membranas, permeabilidad a iones aumentada y eventualmente, ruptura de membrana (Gutteridge y Halliwell, 1990; Gutteridge, 1995). Si el estrés oxidativo es particularmente severo puede producirse la muerte celular (Halliwell, 1997; Dypbukt y col, 1994). La muerte celular puede ocurrir por necrosis pero en ciertos tipos celulares, tales como células neuronales, un estrés oxidativo leve puede inducir el proceso de apoptosis (Stoian y col, 1996; Hampton, Orrenius, 1997). 


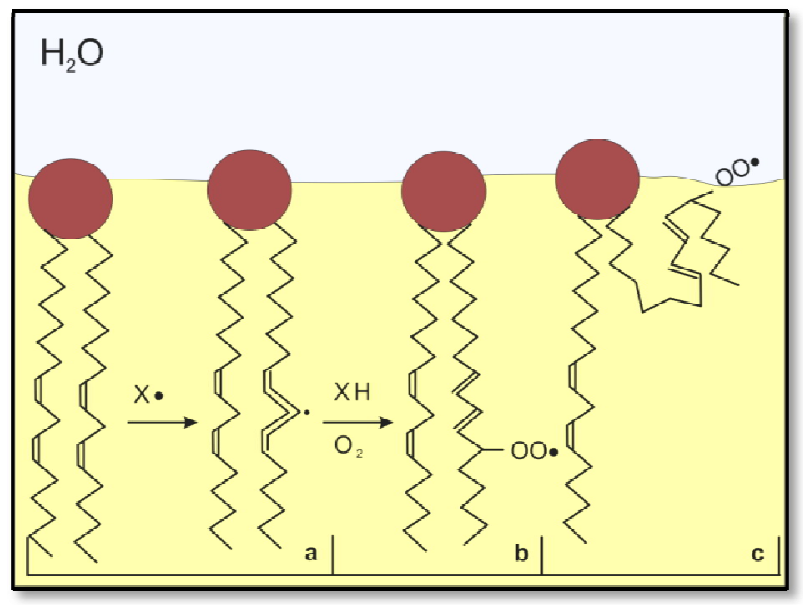

Figura 1.3. Peroxidación lipídica en membranas: a) iniciación de peroxidación, b) formación de dienos conjugado y oxigenación para formar luego un radical peroxilo y c) el radical peroxilo se sitúa en la interfase membrana-agua. (Adaptado de Buettner, 1993).

Radicales libres y antioxidantes en enfermedades

Los daños producidos por radicales libres pueden acumularse en el tiempo y pueden contribuir a las lesiones celulares y al desarrollo de enfermedades humanas. Los radicales libres han sido implicados en el desarrollo de muchas patologías incluyendo ateroesclerosis, diabetes, cáncer, enfermedades inflamatorias crónicas, enfermedades neurodegenerativas y el proceso de envejecimiento (Halliwell y Gutteridge, 1999; Halliwell y Gutteridge, 1990; Southorn y Powis, 1998; Halliwell y col, 1992; Gutteridge, 1993; Delanty y Dichter, 1998; Sastre y col, 2000). El rol potencial de los antioxidantes dietarios en la prevención y tratamiento de estas enfermedades, especialmente ateroesclerosis y cáncer han sido muy estudiadas en las últimas dos décadas (M achlin, 1995; Diplock y col, 1998; Hercberg y col, 1998; Kelly, 1998; Halliwell, 1999; Lee, 1999; Marchioli, 1999; McCall y Frei, 1999). Datos epidemiológicos indican que un elevado consumo de alimentos ricos en antioxidantes y vitaminas (principalmente $\beta$-caroteno, vitamina $C$ y E) 0 elevadas concentraciones en sangre de vitaminas antioxidantes están asociadas con un menor riesgo de enfermedades cardiovasculares y cáncer. Estudios realizados con el fin de investigar el potencial de suplementos antioxidantes son inconsistentes y no arrojan conclusiones firmes. Para confeccionar la recomendación de la ingesta de antioxidantes para prevenir enfermedades se debe contar con los resultados de muchos ensayos de intervención controlados. Sin embargo, basándonos en los datos disponibles, la protección frente al daño oxidativo puede obtenerse de 
una dieta rica en diversos antioxidantes que pueden encontrarse en frutas y verduras. Resulta difícil encontrar evidencias definitivas de la asociación entre generación de radicales libres y el desarrollo de enfermedades, y de la eficiencia de los antioxidantes en la prevención de estas enfermedades, debido principalmente a las limitaciones y deficiencias de los métodos empleados para analizar el estrés oxidativo in vivo (Gutteridge y Halliwell, 1990; Halliwell, 1999).

\subsection{Peroxidación lipídica}

\subsubsection{Peroxidación lipídica no enzimática}

La peroxidación lipídica es probablemente la reacción mediada por radicales libres más estudiada (Halliwell y Gutteridge, 1999; Gutteridge y Halliwell, 1990; Gutteridge, 1995; Halliwell y Gutteridge, 1990; Halliwell y Chirico, 1993; Slater, 1984). Una de las primeras descripciones de las diferentes etapas de la peroxidación lipídica data de finales de los años '20 y fue realizada por De Saussure, que empleó un simple manómetro de mercurio para estudiar el consumo de oxígeno por una capa de aceite de nuez en agua (Halliwell y Gutteridge, 1999).

Los lípidos que contienen PUFAs son particularmente susceptibles a la peroxidación debido a que sus hidrógenos bis-alílicos son fácilmente "extraíbles" $\left(E^{\circ}=+600 \mathrm{mV}\right)$ comparados con los hidrógenos alifáticos $\left(\mathrm{E}^{\circ} \approx+1900 \mathrm{mV}\right)$. De esta manera, cualquier especie oxidante cuyo potencial de reducción se encuentra por encima del de los PUFA-H (Tabla 1.1) puede dar inicio a la peroxidación. Una vez iniciado el proceso, éste prosigue como una reacción en cadena, involucrando las etapas de propagación, ramificación y terminación (Gutteridge, 1995) (Figura 1.4)

La reacción en cadena de la peroxidación lipídica

La iniciación de la peroxidación lipídica se origina por el ataque de cualquier especie con suficiente reactividad para sustraer un átomo de hidrógeno a un grupo metileno de un PUFA.

$$
\text { PUFA-H }+\mathrm{X} \bullet \rightarrow \text { PUFA } \bullet+X-H
$$

Dado que un átomo de hidrógeno es un radical libre ya que posee un electrón simple desapareado, su salida deja un electrón desapareado en el átomo de carbono al cual estaba originalmente unido. El radical centrado en carbono ( $L \cdot$ ó PUFA •) es estabilizado por una reorganización de los enlaces que da lugar a la formación de dienos conjugados, seguida por una rápida reacción con oxígeno para dar un radical peroxilo (LOO• ó PUFA-00•). Esta reacción es termodinámica y cinéticamente favorable.

$$
\text { PUFA }+\mathrm{O}_{2} \rightarrow \text { PUFA-OO } \quad \mathrm{k}=3.10^{8} \mathrm{M}^{-1} \mathrm{~s}^{-1}
$$




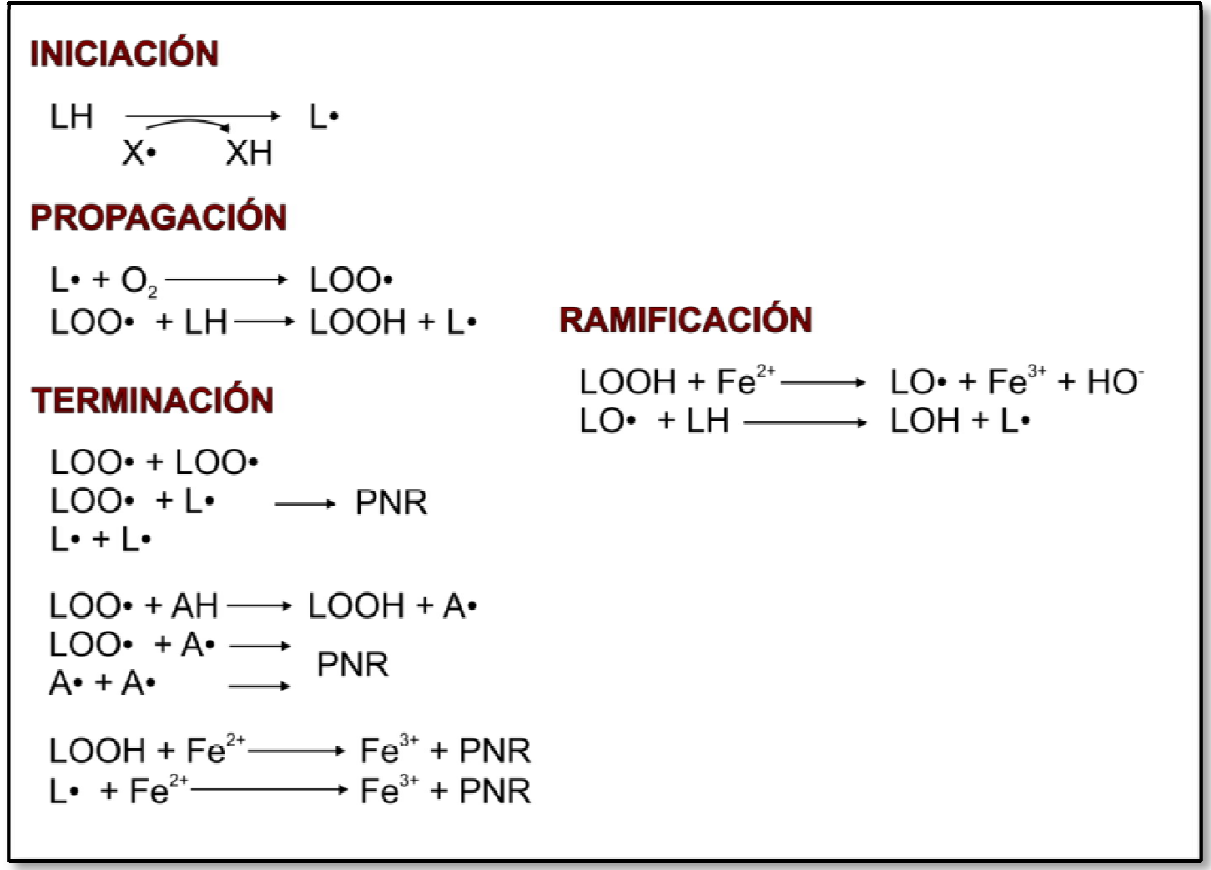

Figura 1.4.Esquema simplificado de las principales reacciones involucradas en el proceso de peroxidación lipídica. LH: lípido; $X \bullet:$ radical libre iniciador; L••, LO•, LOO : radicales libres producidos a partir de $\mathrm{LH}$; $\mathrm{LOOH}$ : hidroperóxido lipídico; AH: antioxidante; $A \bullet$ : radical libre del antioxidante; PNR: productos no radicales

Los LOO • poseen un potencial de reducción mayor al de los radicales $L \cdot$, por lo que son capaces de sustraer un átomo de hidrógeno de otro ácido graso para formar un hidroperóxido (LOOH) y un radical $(\llcorner\bullet)$ lipídico.

$$
\begin{array}{ll}
\text { PUFA-00 + PUFA-H } \rightarrow \text { PUFA-OOH +PUFA } \quad & \Delta \mathrm{E}^{\circ} \approx+400 \mathrm{mV} \\
& \mathrm{k} \approx 10 \mathrm{M}^{-1} \mathrm{~s}^{-1}
\end{array}
$$

Cuando el radical LOO quita un átomo de hidrógeno de un ácido graso, el nuevo radical L• puede reaccionar con oxígeno para formar otro radical $\mathrm{LOO} \bullet$, constituyendo una propagación de la reacción en cadena.

La reacción de peroxidación puede sufrir una ramificación cuando el LOOH sufre ruptura mediada por metales reducidos, como $\mathrm{Fe}^{2+}$

$$
\mathrm{Fe}^{2+}+\mathrm{PUFA}-\mathrm{OOH} \rightarrow \mathrm{Fe}^{3+}+\mathrm{HO}^{-}+\mathrm{PUFA}-\mathrm{O} \cdot
$$

El radical alcoxilo formado $(\mathrm{LO} \bullet$ ) posee un potencial de reducción superior al del radical $\mathrm{L} \bullet$ por lo que puede iniciar reacciones en cadena adicionales.

$$
\text { PUFA-O } 0 \text { + PUFA-H } \rightarrow \text { PUFA-OH +PUFA } \quad \Delta \mathrm{E}^{\circ} \approx+1000 \mathrm{mV}
$$


La extensión de la cadena de propagación antes de la terminación depende de varios factores, por ej: la concentración de oxígeno y los antioxidantes presentes. Los hidroperóxidos (productos primarios de peroxidación) son moléculas bastante estables, pero su descomposición puede ser estimulada por temperaturas elevadas o por metales de transición (iones hierro y cobre). La descomposición de hidroperóxidos genera una mezcla compleja de productos secundarios de peroxidación lipídica como hidrocarburos gaseosos (etano, pentano) y aldehídos (malondialdehído, 4-hidroxinonenal). La terminación de la peroxidación lipídica puede darse entonces por combinación de especies reactivas entre sí para formar productos no radicales 0 por reacción de estas especies con antioxidantes (Figura 1.5) (Buettner, 1993).

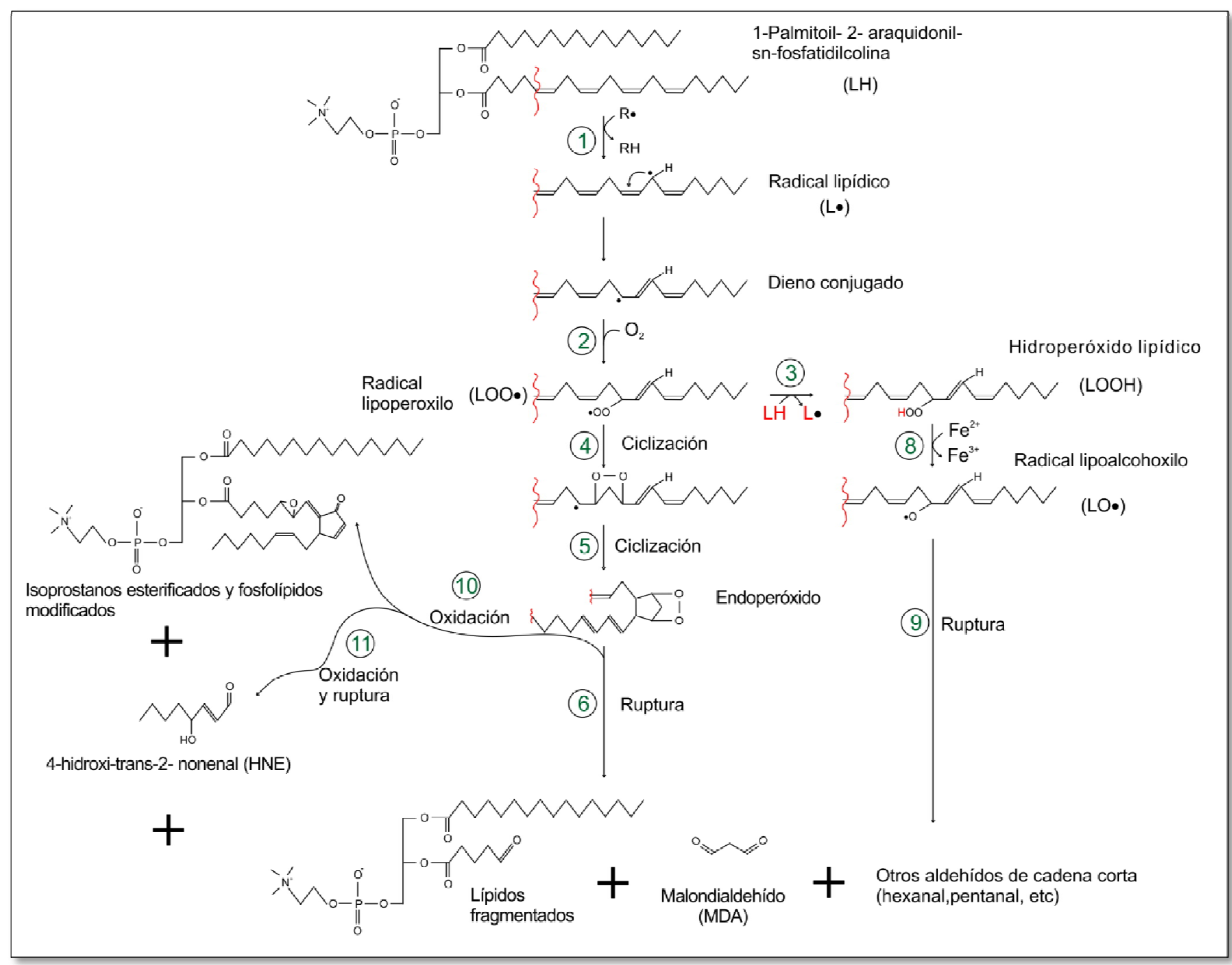

Figura 1.5. Esquema de las vías de peroxidación lipídica en un fosfolípido y formación de varios de sus productos (adaptado de Spickett y col, 2010 y Valko y col, 2005). Los átomos de hidrógeno de los ácidos grasos poli-no-saturados, luego de la interacción con un radical $(R \bullet)$, son removidos para formar un 
radical lipídico $(\mathbf{L})$ (1). El radical lipídico reacciona con oxígeno molecular para formar un radical peroxilo (LOO•) (2). El radical peroxilo puede sustraer un hidrógeno de una molécula de ácido graso cercana, generando un hidroperóxido lipídico ( $\mathrm{LOOH}$ ) estable en ausencia de metales (3) o bien, por ciclización,(4) producir un peróxido cíclico. Tras una segunda ciclización (5) puede formar un endoperóxido que al descomponerse (6) genera diversos lípidos fragmentados, malondialdehído y otros aldehídos e hidrocarburos de cadena corta. El hidroperóxido lipídico puede reaccionar con metales redox (por ej, hierro) para producir un radical alcohoxilo (LO•) (8) que por ruptura (9) puede generar aldehídos e hidrocarburos. Por oxidación (10), el endoperóxido genera isoprostanos esterificados y fosfolípidos modificados. Una nueva reacción de oxidación y posterior ruptura (11) genera aldehídos tales como el 4hidroxinonenal. Los productos de peroxidación lipídica son capaces de reaccionar con proteínas y ácidos nucleicos.

La estructura del ácido graso determina el producto

Otro aspecto en la complejidad del proceso de la peroxidación lipídica es que la abstracción inicial de un átomo de hidrógeno puede ocurrir en diferentes puntos de la cadena carbonada del ácido graso. De esta manera, la peroxidación del ácido araquidónico, por ejemplo, genera seis diferentes hidroperóxidos lipídicos como peróxidos cíclicos y otros productos como isoprostanos (Halliwell y Gutteridge, 1999). Además, el número de doble enlaces determina la susceptibilidad de los ácidos grasos a la peroxidación (Wagner y col, 1994; Porter y col, 1995). Un doble enlace debilita la unión del átomo de hidrógeno con el carbono adyacente. Por lo tanto, a mayor número de dobles enlaces en un ácido graso, más fácil resulta remover un átomo de hidrógeno. Es por esta razón que los PUFAs son más susceptibles a la peroxidación.

Como productos de la peroxidación lipídica se genera una gran diversidad de aldehídos. Se forman en los sistemas biológicos cuando los hidroperóxidos lípidicos se descomponen. Algunos de estos aldehídos son altamente reactivos y pueden considerarse como segundos mensajeros tóxicos que difunden y aumentan los eventos iniciales de los radicales libres. Los aldehídos más intensamente estudiados hasta ahora son 4-hidroxi-2-nonenal (HNE), 4-hidroxi-2hexenal (HHE) y malondialdehído (M DA) (Figura 1.6). El MDA, es un dialdehído de tres carbonos altamente reactivo, generado como uno de los principales bioproductos de la peroxidación de PUFAs (Janero, 1990) y también durante el metabolismo de ácido araquidónico para la síntesis 
de prostaglandinas (Marnette, 1999). MDA puede combinarse con diversos grupos funcionales de proteínas, lipoproteínas, ARN y ADN (Sevilla y col, 1997).HNE es conocido por ser el principal aldehído formado durante la peroxidación de lípidos conteniendo PUFAs n-6, tales como el ácido linoleico y ácido araquidónico. Por otro lado, la peroxidación lipídica de los PUFAs n-3 como ácido linolénico y docosahexenoico genera un compuesto estrechamente relacionado, $\mathrm{HHE}$, que es un mediador potencial de la transición de la permeabilidad mitocondrial (Kristal y col, 1996). 4-hidroxi-2-alquenales representan las sustancias más importantes de tipo aldehído generadas durante la peroxidación de lípidos. HNE fue identificado como un aldehído citotóxico hace tres décadas, formado durante la peroxidación inducida por NADPH-Fe ${ }^{2+}$ de lípidos microsomales hepáticos. Desde entonces, un gran número de informes han demostrado la intervención de este compuesto en una diversidad de procesos patológicos. HNE es considerado como un indicador de estrés oxidativo y un probable agente colaborador de varias enfermedades.

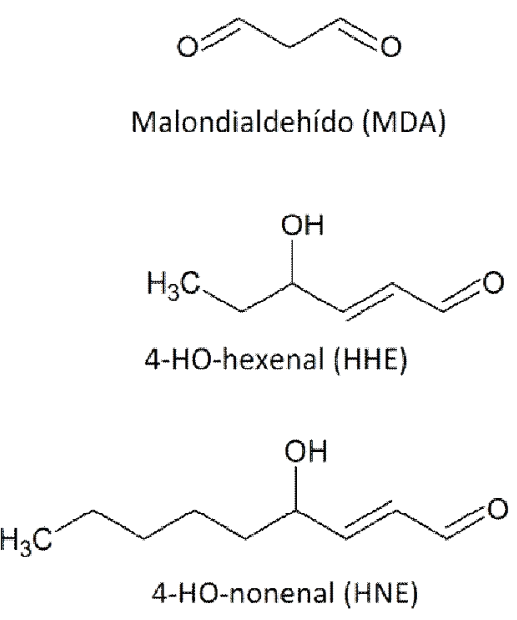

Figura 1.6. Principales aldehídos generados durante la peroxidación lipídica

Por otro lado, los lípidos que contienen PUFAS n-6 forman isoprostanos (64 isómeros) y los que contienen PUFAs n-3 forman neuroprostanos.

Los productos formados dependen de la naturaleza del ácido graso (número de átomos de carbono y de dobles enlaces) y del número de eventos de peroxidación, lo que hace que la complejidad de productos sea muy elevada. Cientos de productos diferentes se han identificado sólo para glicerofosfolípidos (Spickett y col, 2010).

\subsubsection{Peroxidación lipídica enzimática}


La peroxidación de PUFAs puede darse no sólo a través de vías mediadas por radicales libres, sino también por reacciones enzimáticamente catalizadas (Gutteridge, 1995; Halliwell y Gutteridge, 1990). La peroxidación lipídica enzimática se refiere a la generación de hidroperóxidos por la inserción de oxígeno molecular en el centro activo de la enzima. Los radicales libres son probablemente intermediarios importantes de las reacciones enzimáticas, pero están localizados en el sitio activo de la enzima. Ciclooxigenasa (COX) y lipooxigenasa (LO) satisfacen la definición de peroxidación lipídica enzimática dado que catalizan la peroxidación controlada de varios sustratos lipídicos. Los hidroperóxidos y endoperóxidos producidos enzimáticamente son esteroespecíficos y tienen importantes funciones biológicas. Ambas enzimas están involucradas en la formación de eicosanoides, que comprenden a una gran y compleja familia de lípidos biológicamente activos derivados de PUFAs con 20 átomos de carbono. Las prostaglandinas son producidas por peroxidación catalizada por COX de ácido araquidónico (Samuelsson y col, 1975). COX posee al menos dos isoformas (Mitchell y col, 1993; Vane, 1994; Vane y Botting, 1995). COX-1 está presente en células en condiciones fisiológicas mientras que COX-2 es inducida en macrófagos, células epiteliales y fibroblastos por diversos estímulos inflamatorios dando lugar a la liberación de prostaglandinas (Mitchell y col, 1993; Vane, 1994; Vane y Botting, 1995; Fu y col, 1990; Xie y col, 1991).

\subsection{Antioxidantes}

Halliwell y Gutteridge (1999) definieron a un antioxidante como una sustancia que, presente a bajas concentraciones comparadas con la del sustrato oxidable, significativamente retrasa o inhibe la oxidación del sustrato. Los organismos han desarrollado sofisticados sistemas de defensa antioxidante y de reparación para protegerse frente a radicales libres y los daños que éstos provocan (Gutteridge, 1995; Rice-Evans y Burdon, 1993; Halliwell, 1994; Halliwell y col, 1995; Halliwell, 1997; Halliwell, 1996; Chaudiere y Ferrari-lliou, 1999; Gaté y col, 1999). Hay antioxidantes presentes en el organismo y derivados de la dieta. De acuerdo a su localización en el organismo se pueden clasificar en antioxidantes intra y extracelulares (Gutteridge, 1995; RiceEvans y Burdon, 1993; Chaudiere y Ferrari-lliou, 1999). En general, los antioxidantes hidrosolubles reaccionan con oxidantes en el citosol celular y en el plasma de la sangre, mientras que antioxidantes liposolubles protegen las membranas celulares (Sies, 1997).

\subsubsection{Antioxidantes endógenos y dietarios}

Superóxido dismutasa (SOD), catalasa (CAT) y glutatión peroxidasa (GPx) son enzimas antioxidantes intracelulares que convierten sustancias reactivas $\left(\mathrm{O}_{2}{ }^{--}\right.$y $\left.\mathrm{H}_{2} \mathrm{O}_{2}\right)$ a formas menos 
reactivas en el organismo (Gutteridge, 1995; Rice-Evans y Burdon, 1993; Halliwell, 1994; Halliwell y col, 1995). Muchos antioxidantes extracelulares tales como proteínas (transferrina, lactoferrina, albúmina, ceruloplasmina) y urato previenen las reacciones de radicales libres secuestrando iones de metales de transición. Albúmina, bilirrubina y urato pueden también secuestrar radicales libres directamente (Gutteridge, 1995; Rice-Evans y Burdon, 1993).

Antioxidantes de origen dietario comprenden las vitaminas liposolubles como vitamina $E$ (Figura 1.7) y carotenoides, y el antioxidante hidrosoluble, vitamina C (Gutteridge, 1995; RiceEvans y Burdon, 1993; Halliwell, 1994; Halliwell y col, 1995; Halliwell, 1997; Gaté y col, 1999; Sies, 1997). El selenio de la dieta es importante para la función de la enzima antioxidante glutatión peroxidasa (Gutteridge, 1995). La identificación y estudio de antioxidantes de fuentes dietarias es un campo de investigación en expansión y diversos antioxidantes se han investigado tales como flavonoides y otros fenólicos como taurina y ácido lipoico (Gaté y col, 1999). La vitamina $\mathrm{E}$ parece ser uno de los más importantes antioxidantes secuestradores de radicales libres en membranas y lipoproteínas (Halliwell, 1994; Halliwell, 1997; Burton y col, 1982; Burton y Ingold, 1989). Es un efectivo antioxidante cortador de cadena que protege los PUFAs de la peroxidación secuestrando radicales peroxilo. Cuando la vitamina E actúa como un cortador de cadena dona un átomo de hidrógeno al radical libre, oxidándose a sí mismo y convirtiéndose en radical. El radical de vitamina $\mathrm{E}$ formado es regenerado a vitamina $\mathrm{E}$ por otros antioxidantes, principalmente vitamina C (Halliwell, 1994; Halliwell, 1997). La regeneración de vitamina E por otros antioxidantes es una parte de la intrincada cooperación que existe entre diferentes antioxidantes en el sistema de defensa antioxidante. $\alpha$ - tocoferol es la forma biológicamente más activa de la vitamina $E$ in vivo (Kamal-Eldin y Appelqvist, 1996). En estudios de suplementación se utilizan formas sintéticas de la vitamina E como tocoferil acetato y tocoferil succinato. Fuentes naturales ricas en vitamina $E$ son aceites vegetales, nueces y granos enteros y la principal ingesta dietaria proviene de margarinas y aceites vegetales.

\subsubsection{Modo de acción}

\subsubsection{Antioxidantes primarios o preventivos}

Es la primera línea de defensa frente a las especies reactivas de oxígeno, evitando su formación. La prevención de la iniciación de la cadena de peroxidación incluye la unión a iones metálicos, en particular a iones hierro y cobre. La quelación de metales es la principal forma de controlar la peroxidación lipídica y la fragmentación de ADN. De esta manera, las proteínas que unen metales como ferritina, transferrina, ceruloplasmina, metalotioneína son de importancia central para el control de reacciones generadoras de radicales. Algunos pigmentos protegen a la 
célula de radiación incidente, por ejemplo: melanina protege de radiación UV o carotenoides del estado electrónicamente excitado del oxígeno $\left({ }^{1} \mathrm{O}_{2}\right)$. Sin embargo, estas estrategias no son completamente preventivas debido a que actúan disminuyendo la eficacia de un determinado agente con una eficiencia menor al $100 \%$.

En las células y fluidos corporales hay diversos sistemas enzimáticos tales como las glutatión S - transferasas. Esta familia de enzimas cataliza la reacción del glutatión, principal tiol de bajo peso molecular, con reactivos electrofílicos para formar tioéteres, llamados Sconjugados. Intermediarios electrofílicos biológicamente reactivos pueden formarse en una variedad de vías metabólicas, como las que involucran a citocromo p450 y poseen interés en toxicología y farmacología.

\subsubsection{Antioxidantes secundarios o cortadores de cadena (chain-breaking)}

Antioxidantes no enzimáticos. Una vez formadas las especies reactivas existen antioxidantes que pueden prevenir su participación en posteriores reacciones deletéreas. Este proceso también se conoce como desactivación o intercepción. Para compuestos radicalarios, la desactivación final consiste en la formación de productos no radicales y no reactivos. Un segundo objetivo de importancia biológica es transferir la función radical de un sitio sensible de la célula a un compartimento en el que el daño oxidativo sea menos perjudicial. En general, esto significa transferir los equivalentes oxidados de la fase hidrofóbica a la fase acuosa del plasma. Biológicamente, el antioxidante interceptor más eficiente debe combinar ambas propiedades: reaccionar con el radical libre, como el radical peroxilo, a velocidades adecuadas y ser capaz de interactuar con compuestos hidrosolubles para su regeneración. Tales antioxidantes cortadores de cadena son generalmente compuestos fenólicos. $(R, R, R)$ - $\alpha$-tocoferol probablemente sea el compuesto más eficiente en la fase lipídica (Figura 1.7). Este antioxidante biológico contiene 3 grupos metilos en la vecindad del grupo hidroxilo fenólico y se encuentra óptimamente insertado en la membrana debido a su cadena lateral fitil.

Un requisito para una intercepción eficiente por antioxidantes fenólicos es que la vida media del radical no sea demasiado corta. Los radicales peroxilos son los mejores candidatos, dado que pueden existir en el rango de los segundos. Por el contrario, el radical $\mathrm{HO} \bullet$, con su elevada reactividad y su tiempo de vida extremadamente corto, no puede ser interceptado con eficiencia razonable. Para especies de corta vida y alta reactividad existen secuestradores altamente eficientes como polienos para ${ }^{1} \mathrm{O}_{2}$, carotenoides y oxi-carotenoides. 
Antioxidantes enzimáticos. Todos los organismos eucariotas contienen poderosas enzimas antioxidantes. Las tres clases principales de enzimas antioxidantes son la SOD, CAT y GPX. Además, existen numerosas enzimas antioxidantes especializadas que reaccionan y detoxifican compuestos oxidantes. Estas funciones antioxidantes indirectas son: 1) la función de regeneración, por ejemplo: la regeneración de GSH a partir de glutatión disulfuro (GSSG) por la flavoproteína glutatión reductasa y 2) el transporte y eliminación de compuestos reactivos, por ej: la glutatión S-transferasa y el sistema de transporte para los glutatión S-conjugados. Diferentes sitios subcelulares y diferentes tipos celulares pueden contener cantidades variables de enzimas antioxidantes.<smiles>Cc1c(C)c2c(c(C)c1O)CC(C)(CCCC(C)CCCC(C)CCCC(C)C)CO2</smiles>

Figura 1.7. Estructura de $\alpha$-tocoferol o vitamina E.

\subsubsection{Antioxidantes terciarios o reparadores}

La protección de los efectos de los oxidantes puede ocurrir también a nivel de la reparación del daño una vez que éste ha ocurrido. Dado que la prevención y la intercepción no son procesos completamente efectivos, se pueden generar productos como consecuencia del daño oxidativo. Estos daños pueden verse en daño al ADN, alteración de las bases, rotura de simple y doble hebra, daño en la membrana, formación de productos de oxidación de fosfolípidos, daño a proteínas y a otros compuestos. En respuesta a esto hay múltiples sistemas enzimáticos involucrados en reparación de ADN y enzimas lipolíticas y proteolíticas capaces de restituir o regenerar estos sustratos.

\subsubsection{Compuestos cuya actividad antioxidante se estudió en la presente tesis}

\subsubsection{Melatonina e indolaminas relacionadas}

\section{Melatonina}

Reseña histórica: La glándula pineal o epífisis cerebral se conoce desde hace más de 2000 años. Los escritos más antiguos coinciden con la descripción de Galeno (130-200 DC) que consideraba que la pineal sólo era una glándula que llenaba vacíos entre los vasos sanguíneos y los 
soportaba. Citas literarias clásicas de la India se refieren a la pineal como un órgano de clarividencia que también permite al hombre recordar su vida pasada. Hay una abundancia de representaciones del tercer ojo en las imágenes orientales (Figura 1.8). Probablemente el texto antiguo más famoso sobre la pineal es el de René Descartes (1662) quien en su libro De Homine afirmaba que la pineal es un centro donde el alma recibe la información desde el cuerpo. Allí describe la luz como imágenes trasmitidas a la retina y que estimulan el espíritu animal que viaja a través de nervios y activa la glándula pineal. Él pensaba que los estímulos de la función pineal venían desde la retina, una intuición más, que efectivamente es un hecho comprobado actualmente.

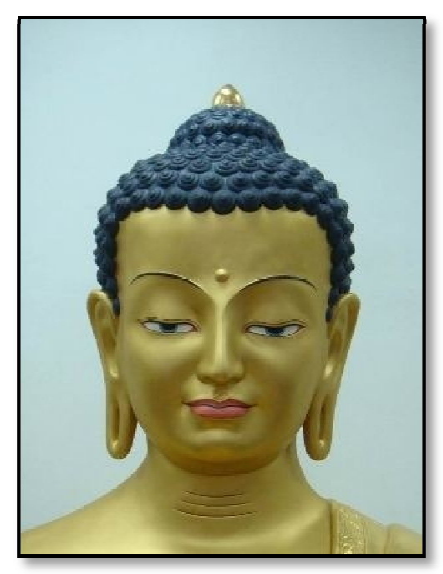

Figura 1.8. Representación del tercer ojo en Buda. Se observa el tercer ojo correspondiente al octavo chakra (ãjnã) que simboliza la visión total. (Tomada dewww.gabitogrupos.com/elojodelaluz/template.php?nm=1276976467)

Arendt (1995) afirmó que el órgano fotosensorial de poiquilotermos llegó a ser la pineal secretora de mamíferos. Esto es firmemente apoyado en la anatomía comparada moderna y se sabe de la influencia de la luz sobre este órgano secretor, la cual puede ser directa o indirecta. En la mitad del siglo XX, Holmgren observó las células pineales con una actividad secretora, los pinealocitos, de naturaleza similar a las células fotorreceptoras de la retina (Holmgren, 1959). En anfibios, lagartos y algunos peces, la glándula pineal es de naturaleza parietal extracraneal, con estructuras fotorreceptivas parecidas a las lentes o la retina que pueden actuar como un "tercer ojo". Estas características anatómicas y fisiológicas enuncian a la pineal, incluida la de humanos, para ser el candidato como vestigio de algún órgano visual primitivo (Collin, 1972).

En toda la historia de la investigación de la pineal no hay, sin embargo, ningún descubrimiento más extraordinario o importante que el de la estructura de su principal hormona, la melatonina (M LT) por Aaron Lerner y colaboradores en 1958. Ellos procesaron 
cromatográficamente miles de glándulas pineales bovinas e identificaron el compuesto bioactivo $\mathrm{N}$-acetil-5-metoxitriptamina (Lerner y col, 1958). Le dieron el nombre de melatonina por sus efectos sobre la pigmentación de la piel de ranas y por su relación química con la serotonina (5hidroxitriptamina) (Lerner y col, 1960). Observaron que MLT tenía efectos potentes sobre la pigmentación de la piel de muchos animales, aunque los más importantes descubrimientos fueron los relativos a sus efectos antigonadales sobre el sistema reproductivo de mamíferos (Lerner y Norklund, 1975). Sin embargo, a pesar de su nombre, hay que enfatizar que MLT no tiene efectos directos sobre los melanóforos en mamíferos sino sobre la liberación de MIH (factor inhibidor de los melanocitos) y consiguientemente presenta una acción inhibitoria sobre la producción de melanina (Guyton y Hall, 1997).

La presencia de MLT, con una estructura idéntica, ha sido descrita en: organismos unicelulares (Hardeland, 1999), plantas (Dubbels y col, 1995; Hattori, 1995), vertebrados (VivienRoels y Arent, 1983; Hardeland y Poeggeler, 2003) y algunos invertebrados. En plantas, su papel biológico no ha sido aún clarificado. En otros organismos, sin embargo, su papel ha sido relacionado a la transducción de la información fotoperiódica estacional y circadiana (Hardeland, 1993). Los niveles circulantes de MLT por la noche se elevan en casi todos los vertebrados, como resultado de un incremento de su síntesis y liberación por la glándula pineal. Este incremento desempeña la función de "señalización hormonal de la noche" y es la base de la coordinación de los ritmos diarios y estacionales con el ciclo día/noche. Por tanto, la señal de MLT es esencial para la supervivencia de muchos animales con reproducción estacional (Klein y col, 1992). A lo largo de los últimos años, a pesar de que todavía se está lejos de entender su exacto papel fisiológico y posibles cambios durante la evolución, MLT ha incrementado su interés público como droga contra el envejecimiento (Turek y col, 2000; Reiter 2000a; Reiter 2000b), insomnio y jet lag (Caspi, 2004), estrés (Reiter, 2003), disfunciones inmunes (Guerrero y Reiter, 2002) e incluso cáncer (Skwarlo-Sonta y col, 2003).

Síntesis y metabolismo de melatonina. M LT es el principal miembro de la familia de indolaminas sintetizadas a partir del triptófano circulante (Alonso, 1999). Además de ser sintetizada en los pinealocitos, también es sintetizada en otras muchas células, tales como células enterocromafines del intestino (Huether y col, 1992), plaquetas sanguíneas (Launay y col, 1982), células mononucleares de sangre periférica (Finocchiaro, 1988), células de medula ósea (Tan y col, 1999), así como en tejido ovárico de rata (Itoth y col, 1997) y humano (Itoth y col, 1999). En un estudio reciente realizado por Stefulj y colaboradores (2001) se ha demostrado que diversos tejidos como el fundus del estómago, intestino, testículos, medula espinal, corteza cerebral, 
núcleo del rafe y núcleo estriado, cuentan con cantidades suficientes de ARNm de las enzimas Nacetiltransferasa (NAT) e hidroxindol-0-metiltransferasa (HIOM T), estando así equipados con las herramientas necesarias para la síntesis de MLT.

La biosíntesis pineal de indolaminas comienza con la captación del triptófano (TRP) a través de un mecanismo de transporte activo que está bajo control adrenérgico (Alonso, 1999). Dentro de la célula el TRP se convierte en 5-hidroxitriptófano (5HO-TRP) por la enzima triptófano hidroxilasa. La enzima 5-hidroxitriptófano descarboxilasa actúa sobre el 5HO-TRP para formar 5-hidroxitriptamina (5-HT) o serotonina (Hadley, 1997). La concentración de serotonina en la pineal es muy elevada en todas las especies (niveles elevados durante las horas de luz y reducidos durante las horas de oscuridad). A partir de este momento, la vía más importante en el metabolismo pineal de la serotonina implica su transformación en $\mathrm{N}$ acetilserotonina (NAS) por acción de la N- acetil transferasa (NAT), enzima que constituye el paso limitante en la síntesis de MLT y presenta un marcado ritmo circadiano en todas las especies estudiadas, con niveles máximos durante las horas de oscuridad. Finalmente, la NAS es convertida mediante la O-metilación por medio de la HIOMT en M LT (Wurtman y Axelrod, 1968)

(Figura 1.9).

El paso de la acetilación de serotonina a NAS es necesario en la biosíntesis de la M LT, pero también puede producirse una desaminación de la serotonina por las monoaminooxidasas. El producto desaminado resultante puede continuar su oxidación a ácido 5-hidroxindolacético 0 puede reducirse a 5-hidroxitriptofol. Estos últimos productos son susceptibles de transformación por la HIOM T para dar ácido 5-metoxindolacético y 5-metoxitriptofol.

La M LT circulante es transportada en el plasma, en parte, unida a albúmina (70\%) y en parte en forma libre (30\%). La mayor parte de MLT circulante es inactivada mediante conservación hepática como 6-hidroximelatonina y es secretada en orina en forma de sulfatos (75\%) o glucurónicos (5\%). Otra fracción es transformada en el cerebro en compuestos derivados de la quinurenamina (15\%) y una pequeña fracción es excretada en forma libre (0,5\%).

Melatonina y especies reactivas de oxígeno. Además de sus funciones como reloj biológico se mostró que MLT tiene efectos oncostáticos (Blask y col, 2002), estimulante del sistema inmune (Guerrero y Reiter, 2002) y funciones anti-inflamatorias (Cuzzocrea y Reiter, 2002). Así, más recientemente fue identificada como un potente secuestrador de radicales libres (Tan y col, 2002) y antioxidante indirecto (Reiter y col, 2000a; Rodriguez y col, 2004). Además cabe citar la alta eficacia de la M LT como un protector contra ROS y especies reactivas de nitrógeno (RNS). 


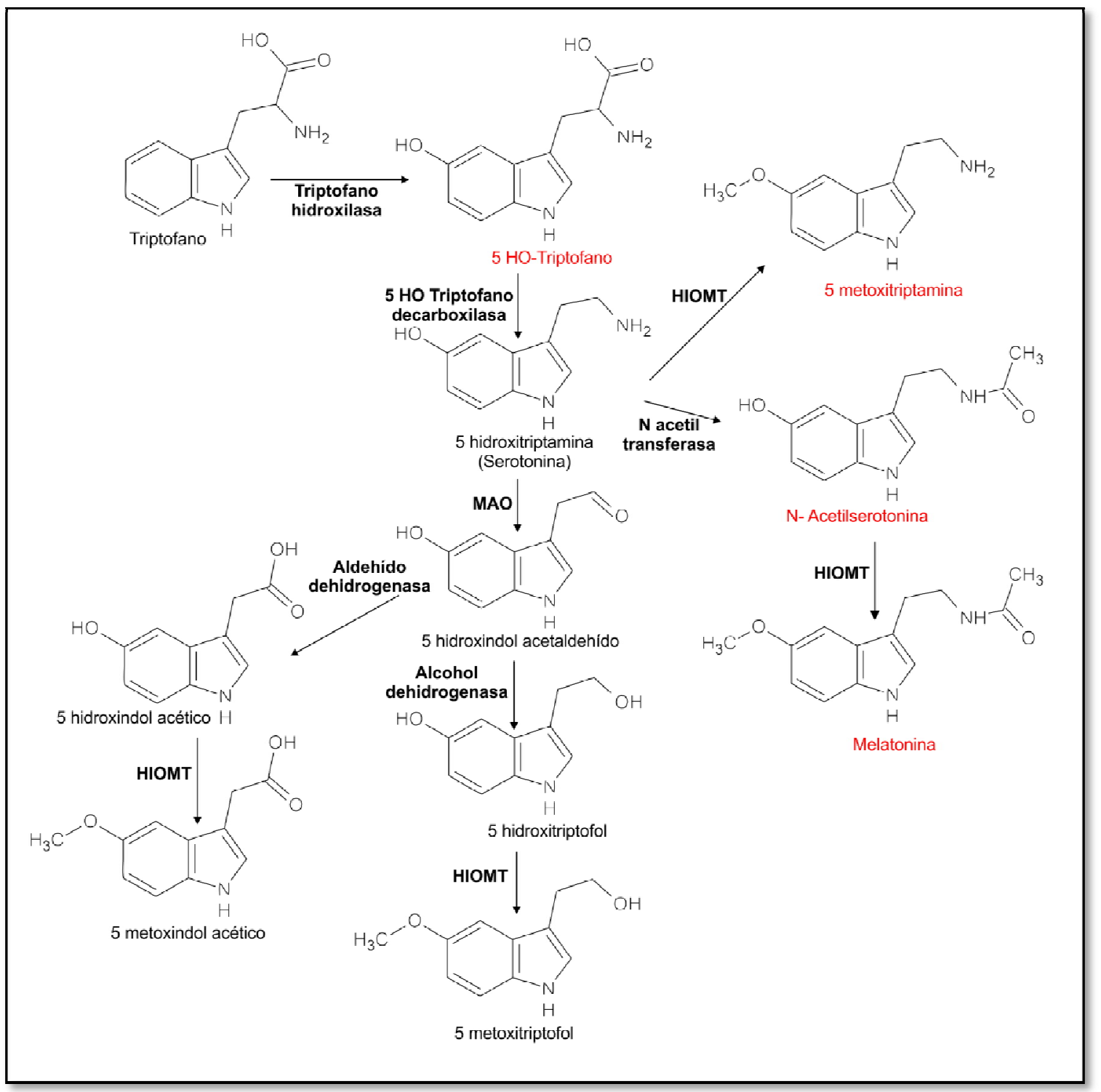

Figura 1.9. Representación esquemática del metabolismo de indoles pineales (modificada de Young y Silman, 1982). En rojo se destacan los indoles estudiados en la presente tesis. Enzimas: HIOMT, hidroxindol-0-metiltransferasa; MAO, monoaminooxidasa.

Este campo de investigación ha sido testigo de una expansión explosiva en las últimas décadas y mientras que todos los mecanismos de los efectos de la MLT como un secuestrador de radicales libres y productos afines no han sido identificados aún, no hay duda sobre su habilidad para moderar el daño molecular producido por el oxígeno tóxico y RNS (AcuñaCastroviejo y col, 2002; Reiter y col, 2002). Las funciones de M LT como un antioxidante incluyen: a) secuestrador directo de algunos radicales libres (Hardeland, 1993; Hardeland y col, 1995; 
Allegra y col, 2003), b) estimulación de enzimas antioxidantes (Reiter y col, 2000; Rodriguez y col, 2004), c) incremento de la eficiencia de la fosforilación oxidativa mitocondrial y reducción de los electrones (Acuña-Castroviejo y col, 2002; Okatani y col, 2003a) y d) aumento de la eficacia de otros antioxidantes (Gitto y col, 2001). Además habría otros mecanismos no descriptos que explicarían su habilidad para proteger contra el daño molecular por ROS y RNS. Numerosos estudios in vitro e in vivo han documentado la habilidad tanto de concentraciones fisiológicas como farmacológicas de M LT de proteger contra la destrucción causada por radicales libres (Reiter y col, 2003).

Acciones antioxidantes directas de la melatonina. Existe bastante evidencia documentada en la literatura sobre la interacción de la M LT tanto con ROS como RNS (Tan y col, 2002; Reiter y col, 2001; Poeggeler y col, 2002; Allegra y col, 2003). Las evidencias iniciales ilustran la habilidad de la MLT para neutralizar la alta toxicidad del radical OH• (Tan y col, 1993a). Desde entonces numerosos artículos parecen confirmar esta acción de la M LT (Hardeland y col, 1995; Poeggeler y col, 1994; Matusak y col, 1997; Li y col, 2002) e identificar además un producto potencial de la interacción entre la MLT y el $\mathrm{OH} \bullet$, la 3-hidroximelatonina cíclica (Tan y col, 1998). Este subproducto es excretado en la orina (humanos y ratas) y la cantidad de éste es proporcional a la cantidad de MLT administrada a un animal y el grado de estrés oxidativo que el animal ha experimentado. El $\mathrm{H}_{2} \mathrm{O}_{2}$ es generado in vivo por varios sistemas enzimáticos y adicionalmente, es producido intracelularmente por la dismutación del $\mathrm{O}_{2} \bullet$-. La capacidad de la MLT para secuestrar $\mathrm{H}_{2} \mathrm{O}_{2}$ fue demostrada inicialmente por Tan y colaboradores (1993a) aunque un trabajo cuestiona la interacción directa de la $\mathrm{MLT}$ con $\mathrm{H}_{2} \mathrm{O}_{2}$ (Fowler y col, 2003). El $\mathrm{O}_{2} \bullet$-es generado durante la respiración mitocondrial y durante el estallido respiratorio de las células fagocíticas. El radical $\mathrm{O}_{2} \bullet$-tiene baja toxicidad pero rápidamente se acopla con el NO • para producir el anión $\mathrm{ONOO}^{-}$; este producto se considera casi tan dañino como el HO • La eficacia de la M LT en neutralizar el $\mathrm{O}_{2} \bullet$-está pobremente definida. Poeggeler y colaboradores (1995) fueron los primeros en mostrar que MLT neutralizaba ${ }^{1} \mathrm{O}_{2}$. Esta habilidad fue confirmada por Zang y colaboradores(1998) y por Roberts y colaboradores (2000). También ha sido confirmado recientemente que N1-acetil, N2-formil-5-metoxikinuramina (AFMK) es el producto formado cuando la MLT es oxidada por ${ }^{1} \mathrm{O}_{2}$ (De Almeida y col, 2003).

Acciones antioxidantes indirectas de la melatonina.

1) Estimulación de enzimas antioxidantes 
Las enzimas antioxidantes proporcionan un mecanismo de defensa contra el daño de radicales libres por metabolización de las especies reactivas a bioproductos no tóxicos. Las enzimas antioxidantes que han sido estudiadas en relación a la M LT son: SOD, tanto Mn SOD como CuZnSOD, CAT, GPx, glutatión reductasa (GRd) y glucosa-6-fosfato deshidrogenasa (G6PD) (Reiter y col, 2000a; Rodriguez y col, 2004; M ayo y col, 2002). Así los estudios iniciales muestran que el efecto estimulador de la MLT sobre GPx cuando se administraron dosis farmacológicas a ratas (Barlow-Walden y col, 1995) y pollos (Pablos y col, 1997) in vivo, resultaban en un marcado aumento en la actividad de esta enzima.

2) Estimulación de la síntesis de glutatión.

El GSH es un secuestrador de radicales libres y antioxidante, muy abundante. Un único trabajo ha mostrado que MLT estimula la proporción limitante de la enzima -glutamilcisteína sintasa, incrementando la concentración de GSH (Urata y col, 1999). Esta acción de la MLT, a diferencia de la función directa de secuestrador de radicales libres, es mediada por receptores específicos. La estimulación de la síntesis de GSH por la MLT podría ser una de sus principales acciones antioxidantes.

3) Acción sinérgica de la M LT con otros antioxidantes.

De acuerdo con Gitto y colaboradores (2001) bajo condiciones in vitro y analizando los productos finales de la peroxidación lipídica como un índice del daño oxidativo inducido por los radicales libres, la M LT aumenta la acción protectora de la vit. E, vit. C y GSH contra la oxidación de los PUFAs mediada por radicales libres. Cuando se comparan bajo condiciones de alto estrés oxidativo in vivo, la M LT resulta superior a las vit. C y E en la reducción del daño oxidativo (Tan y col, 2002).

4) Acciones de la melatonina a nivel de las mitocondrias.

Las mitocondrias son la mayor fuente de radicales libres y como consecuencia estas organelas subcelulares están expuestas a un daño oxidativo intenso. La membrana mitocondrial es el sitio donde reside la cadena de transferencia de electrones (ETC), un sistema complejo proteínico oxido-reductor (complejos I, II, III y IV). En células aeróbicas la fosforilación oxidativa mitocondrial es responsable de la generación del 95\% del total del ATP. Deficiencias en ETC originan el escape de electrones que pueden formar radicales libres y otros reactivos tóxicos, produciendo daño molecular en las mitocondrias (Acuña-Castroviejo y col, 2002). El hecho de que la MLT tenga importantes acciones a nivel mitocondrial es sugerido por numerosas observaciones: a) la MLT, es un eficiente secuestrador de ROS/ RNS producidos abundantemente en las mitocondrias; b) aunque las mitocondrias son incapaces de sintetizar GSH (lo toman desde el citosol) poseen GPx y GRd, enzimas estimuladas ambas por la M LT; y c) la M LT puede 
estar en mayor concentración en la mitocondria que en otra parte de la célula y ser mayor que la concentración sérica (Acuña-Castroviejo y col, 2002). En largos períodos de administración de MLT se ha comprobado que se incrementa el número de mitocondrias en las células (Deker y Quay, 1982) mientras que experimentos con MLT radioactiva sugieren la existencia de sitios de unión para esta indolamina en las mitocondrias (Poon y Pang, 1992). Adicionalmente, se ha visto como la MLT protege el cerebro fetal de ratas contra el daño mitocondrial mediado por oxidantes (Wakatsuki y col, 2001) y estimula la respiración mitocondrial en el cerebro e hígado de ratones con senescencia acelerada (Okatani y col, 2003a; Okatani y col, 2002a; Okatani y col, 2002b; Okatani y col, 2003b).

La MLT y los antioxidantes clásicos muestran diferentes mecanismos en términos de reacción con los radicales libres. Los antioxidantes clásicos donan electrones para neutralizar los radicales libres y la MLT puede capturar radicales libres a través de una reacción aditiva (Tan y col, 1998; Stasica y col, 2000; Marshall y col, 1996) o en ciertas circunstancias puede donar o capturar electrones para detoxificar radicales libres. Finalmente, como ya se ha comentado, la MLT aumenta la acción protectora de las vit. E, C y glutatión contra la oxidación de PUFAs mediada por radicales libres. Así, la MLT incrementa claramente la eficacia de otros antioxidantes frente a la peroxidación lipídica tanto in vivo como in vitro, presentando ella por sí misma un poder superior que el resto de los antioxidantes clásicos frente al estrés oxidativo (Tan y col, 2002; Gitto y col, 2001).

\section{$\mathrm{N}$ - acetil serotonina}

NAS es sintetizada principalmente en la glándula pineal a partir de la serotonina vía Nacetilación.

Los mecanismos antioxidantes de NAS involucran la interacción con receptores del tipo 3 de la MLT y mecanismos no mediados por receptores tales como: la estimulación de la GPx; inhibición de la peroxidación lipídica; supresión de la activación de la fosfolipasa A2; atenuación de la producción del factor de necrosis; prevención de la apertura patológica de los poros de permeabilidad mitocondrial transitoria, e inhibición de la biopterina reductasa, la enzima encargada de la síntesis del NO•. Los efectos protectores de la NAS contra el daño oxidativo son independientes de los efectos de la MLT y dependiendo del modelo son de 5 a 20 veces más potentes. La NAS y sus derivados pueden ser útiles en la protección contra el daño oxidativo y sus desórdenes relacionados tales como muerte celular, mutagénesis, envejecimiento y 
enfermedades tales como sepsis, cáncer, trauma post-isquémico, enfermedades de Alzheimer y Parkinson.

\section{Otros indoles pineales}

El indol pineal más estudiado es, sin dudas, MLT (Reiter y col, 2003) mientras que los demás indoles secretados por la pineal no han sido examinados con la misma profundidad. Sin embargo, se ha demostrado efecto inmunomodulador y acciones antitumorales para metoxitriptamina y metoxitriptofol ( $\mathrm{Ng}$ y Lo, 1998; Sze y col, 1993; Nelson y col, 1995; Lissoni y col, 1996). 5- metoxitriptamina (5M TP) es un inhibidor más potente de la esteroidogénesis que M LT en células de Leydig de rata y de la proliferación de células tumorales ( $\mathrm{Ng}$ y Lo, 1998; Sze y col, 1993b). Ng y col (2000) demostraron que serotonina, 5- hidroxitriptofol, 5- metoxitriptofol y 5M TP inhibieron la peroxidación lipídica en homogenatos de cerebro, hígado y riñón de rata y la hemólisis de eritrocitos de rata. Entre varios indoles estudiados, incluyendo MLT, 5M TP exhibió la acción antioxidante más potente y careció de acción pro-oxidante.

Tal vez la consecuencia funcional más perjudicial de la peroxidación lipídica es la disminución de la fluidez de membrana. Una fluidez óptima es vital para varias funciones celulares esenciales incluyendo transporte de solutos, transducción de señales y actividad de enzimas asociadas a membranas (Curtis y col, 1984; García y col, 1997; Stubbs y Smith, 1984; Van Blitterswijk, 1985). Varias indolaminas pineales tales como MLT (García y col, 1997), NAS (Calvo y col, 2001); García y col, 2001; Karbownik y col, 2001b), 5- metoxitriptofol (García y col, 2000) y pinolina (Ortega-Gutiérrez et al. 2002) se han descripto como protectores de membranas celulares y de organelas al inhibir la peroxidación lipídica y prevenir la rigidez de membrana.

TRP es un aminoácido esencial constituyente de membranas biológicas y que contribuye a la solubilidad de proteínas de membrana (Schiffer y col, 1992). El 5- hidroxi derivado del TRP es empleado como un suplemento dietario muy popular para el tratamiento de depresión, fibromialgia, obesidad, hipertensión, insomnio y dolores de cabeza (Das y col, 2004). Algunos estudios in vivo han demostrado que TRP reduce el edema y la peroxidación lipídica en pancreatitis inducida por ceruleína o isquemia/reperfusión (Jaworek y col, 2003; Leja-Szpak y col, 2004) y acelera la recuperación de úlceras gástricas agudas inducidas por administración de irritantes locales (Brzozowska y col, 2002). Más aún, TRP mostró actividad antioxidante secuestrando NO - (Noda y col, 1999). Por otro lado, ratas alimentadas con dietas suplementadas con TRP presentaron peroxidación lipídica aumentada en plasma (Aviram y col, 1991) y daño en las lentes del ojo (Mathur y Sahai, 1990). Además, evidencias in vitro indican 
que TRP produce aumento de la peroxidación lipídica y disminuye las defensas antioxidantes en la corteza cerebral de ratas, lo que explicaría parcialmente los mecanismos neurotóxicos de daño cerebral inducidos por hipertriptofanemia (Feksa y col, 2006). Reyes-Gonzales y col (2009) demostraron que TRP no logró inhibir la peroxidación lipídica y proteica inducida por $\mathrm{FeCl}_{3} /$ ácido ascórbico, a diferencia de 5HO-TRP que presentó inhibición concentración-dependiente y, de esta manera, una estabilización de la membrana frente al estrés oxidativo.

\subsubsection{Familia de isómeros conjugados del ácido linoleico (CLAs)}

El término Ácido Linoleico Conjugado (CLA) engloba a un grupo de isómeros posicionales y geométricos del ácido linoleico $(18: 2 c 9, c 12 n-6)$. Se han identificado más de 20 isómeros de este ácido (Beaulieu y Drackley, 1999), siendo el isómero 18:2 c9, t11 (producto intermedio de la biohidrogenación del ácido linoleico por la bacteria ruminal Butyrivibrio fibrisolvens) (Pinto y col, 2002), el más abundante en este grupo. A éste último se le atribuyen diversos efectos benéficos tales como: regulador metabólico, efectos hipocolesterolémicos, antiaterogénicos, anticarcinogénicos, antioxidantes, e incluso presenta efectos favorables en la prevención y/o tratamiento de ciertas alergias alimentarias (Sanhueza y col, 2002). Este ácido graso se encuentra presente en aceites vegetales comunes como el aceite de soja o de maíz y en la carne y leche de los rumiantes (vacas, ovejas y cabras) (Gagliostro y col, 2002), donde puede alcanzar hasta $0,65 \%$ de los lípidos totales (Fritsche y Steinhart, 1998). Este isómero, encontrado en la grasa láctea, ha sido reconocido por la Academia Nacional de Ciencias, de EE UU, como el único ácido graso que ha presentado inequívocamente la propiedad de inhibir la carcinogénesis en animales experimentales (Kelly y col, 1998). Sehat y colaboradores (1998) señalaron que el isómero c9, t11 tendría un efecto anticancerígeno, mientras que el isómero t10, c12 actuaría en el aumento de la masa muscular y en la disminución del porcentaje de grasa. Otros efectos beneficiosos incluirían; la reducción en el aumento de las grasas corporales, retraso en el inicio de la diabetes tipo II, retardo en el desarrollo de la aterosclerosis, mejoramiento de la mineralización de los huesos y modulación del sistema inmune (Belury, 2002).

La concentración de CLAs en los productos lácteos es una función directa de su concentración en la leche cruda, la que puede variar ampliamente ante manipulaciones precisas de la dieta en el animal. La formulación de un concentrado tal vez sea la medida más efectiva, rápida y de fácil implementación a fin de modificar la composición de la grasa butirosa en forma natural. Los resultados demuestran un aumento potencial del orden del $300 \%$ en el contenido de CLAs en leche a través de manipulaciones precisas en la alimentación (Gagliostro y col, 2002). Actualmente, diversos estudios están modificando la dieta del animal para que la cantidad de 
CLAs en la leche producida se incremente de forma considerable, con el fin de obtener un producto que resulte aun más beneficioso para la salud humana.

\section{Estructura de CLAs}

La isomería geométrica de los ácidos grasos es importante en términos nutricionales. La gran mayoría de los ácidos grasos que se encuentran naturalmente poseen isomería cis, sin embargo en la dieta habitual de los humanos se consume una pequeña, pero no despreciable, proporción (1g a 7 g/día) de ácidos grasos con isomería trans (Valenzuela y Mogardo, 1999).En un ácido graso natural no saturado, los dobles enlaces están separados por un carbono intermedio que no participa de la estructura de insaturación. Esta estructura se denomina "no conjugada". Como consecuencia de la manipulación tecnológica de las grasas y aceites 0 , en casos particulares, por efecto de la metabolización a nivel celular de ciertos ácidos grasos, es posible que un doble enlace cambie de posición, desapareciendo el carbono metilénico intermedio y transformándose así en una estructura "conjugada". La conjugación de los dobles enlaces ocasiona un cambio en la isomería espacial del ácido graso (Pariza y col, 2001)(Figura 1.10).

\section{Síntesis de CLAs}

Eastridge y Qiu (2001) señalan que la grasa láctea bovina contiene ácidos grasos de 4 a 16 átomos de carbono que son sintetizados de novo en la glándula mamaria; y una fracción de ácido palmítico (16:0) y ácidos grasos con 18 átomos de carbono que provienen de los lípidos de la sangre y cuyo origen es dietario. Los ácidos grasos de 14 y 16 carbonos constituyen la grasa saturada de la leche, y contribuyen a la estructura física de la grasa. Sin embargo, un gran número de ácidos grasos en grasa de leche, está ganando una cantidad creciente de atención, ya que la mayoría se presenta en el metabolismo microbiano rumiante y son así únicos en estos animales. Entre ellos se encuentra el CLA c9,t11 (Eastridge y Qiu, 2001), el que debido a su origen ruminal, también se le identifica como "ácido ruménico" (Kramer y col, 1998). Se forma como intermediario durante la biohidrogenación ruminal del ácido linoleico a ácido estéarico (18:0) (Bauman y col, 2001) por la bacteria Butyrivibrio fibrisolvens (Kepler y col, 1966) y otras bacterias del rumen (Kritchevsky, 2000), o por la conversión endógena del ácido transvacénico, (TVA, 18:1t11) por la enzima $\Delta 9$ desaturasa en la glándula mamaria (Corl y col, 2001). El TVA es un intermediario en la biohidrogenación ruminal del ácido linoleico y linolénico (Griinari y col, 2000). El resto del CLA en la grasa de la leche surge directamente del CLA absorbido por el tracto digestivo (Figura 1.11). El contenido de CLA en la leche y en la carne está influenciado por 
numerosos factores tales como la dieta, el animal y el procesamiento de los productos. Las condiciones óptimas para la síntesis de CLA en la leche se producen a partir del aporte de PUFAs provenientes de forrajes frescos que aseguran un ambiente ruminal óptimo para la fermentación.

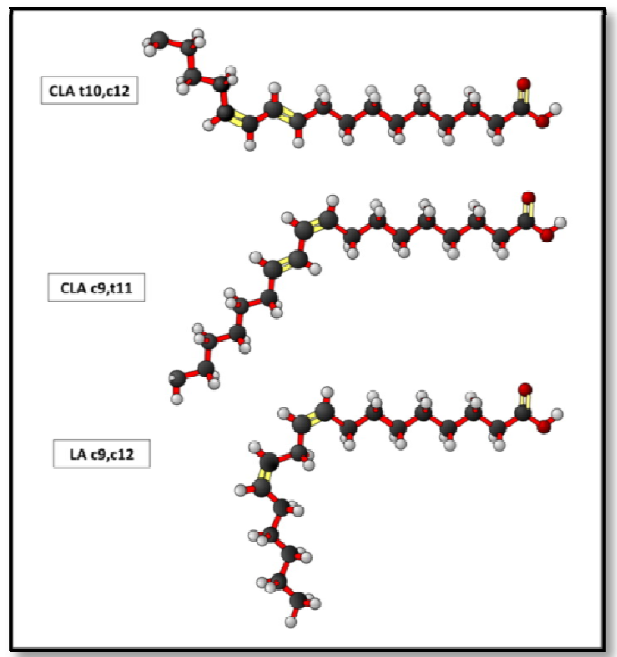

Figura 1.10. Estructura de los principales isómeros CLAs y ácido linoleico (LA)

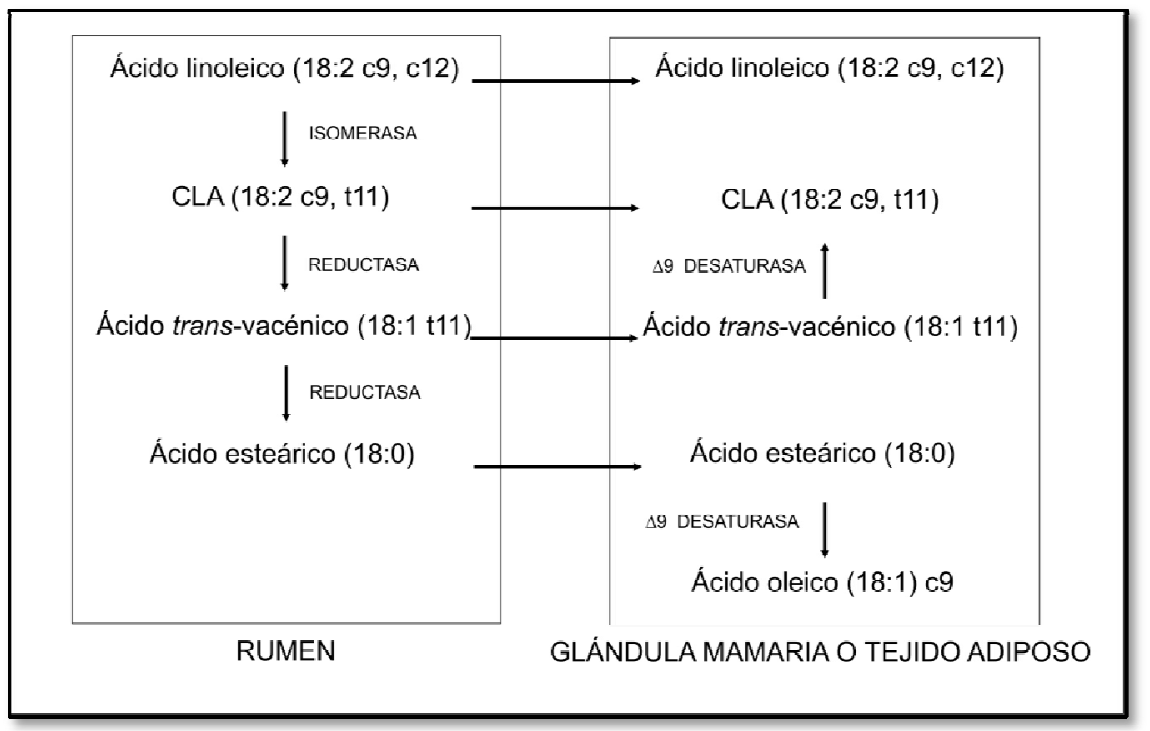

Figura 1.11. Vía metabólica propuesta para la biosíntesis de CLA 18:2 c9, t11 en rumiantes (tomado de Marchioli, 1991).

\section{Efectos benéficos de CLAs sobre la salud.}

El término, "alimento funcional" se utiliza a menudo como una descripción genérica para referirse a los efectos beneficiosos de los alimentos ingeridos, el que va más allá de su valor nutritivo tradicional (Bauman y col, 2001). Muchos componentes de la grasa de leche que 
poseen características anti-cancerígenas se han identificado, pero los componentes que han recibido el foco de atención son los llamados CLAs. El descubrimiento de CLAs como un "alimento funcional" ocurrió cuando Pariza y colaboradores (2001) encontraron en la carne un factor anti-mutagénico que consistía en una serie de isómeros conjugados del ácido linoleico. Luego, varios estudios demostraron que el CLA sintetizado químicamente podía reducir la incidencia de varios tipos de tumores en modelos animales. Pero, la mayoría de los agentes naturalmente anti-cancerígenos se encontraban presentes sólo en niveles traza y eran de origen vegetal. Sin embargo, los CLAs eran los únicos entre los agentes anti-cancerígenos naturales que presentaban potentes efectos en niveles extremadamente bajos y que se encontraban presentes en los productos lácteos y la carne de animales rumiantes (Tabla 1.3) (Bauman, 2002). Mientras los CLAs se estudiaban biomédicamente se evidenció que presentaban una gama de efectos positivos en la salud de animales experimentales, algunos de los cuales se señalan en la Tabla 1.4. Estos efectos beneficiosos incluían: la reducción en el aumento de las grasas corporales, retraso en el inicio de la diabetes tipo II, retardo en el desarrollo de la arterosclerosis, mejoramiento de la mineralización de los huesos y modulación del sistema inmune (Belury, 2002). Lo cual, ha dado lugar a un aumento exponencial en la investigación de CLAs en los últimos años (Bauman, 2002).

Tabla 1.3. Composición promedio de isómeros geométricos y posicionales ( $\%$ del total de isómeros CLA) en leche (adaptado de Khanal y Olson, 2004)

\begin{tabular}{|l|c|}
\hline Isómeros conjugados del ácido linoleico (CLA) & $\%$ \\
\hline Isómeros cis-trans & \\
\hline 7,9 & 5.5 \\
8,10 & 1.5 \\
9,11 & 72.6 \\
10,12 & 0.4 \\
11,13 & 7.0 \\
$12,14 \quad$ Total cis-trans (trans-cis) & 0.7 \\
& 87.7 \\
Isómeros trans-trans & \\
6,8 & - \\
7,9 & 2.4 \\
8,10 & 0.4 \\
9,11 & 2.0 \\
\hline
\end{tabular}


10,12

11,13

12,14

13,15

Tabla 1.4. Algunos de los efectos benéficos de CLAs en la salud informados en estudios biomédicos con modelos animales (tomado de Sanhueza García, 2004)

\begin{tabular}{|l|}
\hline \multicolumn{1}{|c|}{ Efectos biológicos de CLAs } \\
\hline Anticancerígenos (estudios in vivo e in vitro) \\
Antiaterogénicos \\
Alteración de metabolismo nutricional y lipídico \\
Antidiabetogénicos (diabetes tipo II) \\
Realza la inmunidad \\
Mineralización mejorada del hueso
\end{tabular}

\subsection{Objetivos}

\section{$\underline{\text { Objetivo general }}$}

El presente trabajo de tesis constituye la continuación de estudios previos realizados en nuestro grupo de trabajo en relación a la peroxidación de lípidos de membranas de origen animal y al efecto protector de antioxidantes endógenos y exógenos sobre ese sistema. Nuestro objetivo general fue realizar estudios in vitro de peroxidación no enzimática sobre diferentes sustratos lipídicos, con mayor o menor semejanza estructural a membranas biológicas, analizando diferentes prooxidantes y evaluando actividad antioxidante de diversos compuestos.

\section{$\underline{\text { Objetivos específicos }}$}

$\checkmark$ Analizar el efecto antioxidante de melatonina, $\mathrm{N}$-acetilserotonina, 5-metoxitriptamina y 5HO-triptófano sobre la peroxidación de triglicéridos ricos en PUFAs n-3 disueltos en cloroformo, cuando la reacción es iniciada por hidroperóxido de cumeno (Capítulo 2). 
$\checkmark$ Estudiar el efecto antioxidante de isómeros conjugados del ácido linoleico (CLAs), ácido linoleico y metil linoleato sobre triglicéridos ricos en PUFAs n-3 disueltos en cloroformo, cuando la reacción es iniciada por tert-butil hidroperóxido (Capítulo 3)

$\checkmark$ Determinar el efecto del medio de reacción y del iniciador sobre la peroxidación lipídica de diferentes tipos de liposomas preparados con lípidos de retina bovina (Capítulo 4)

$\checkmark$ Analizar el efecto de melatonina, N-acetilserotonina, 5-metoxitriptamina y 5-HO triptófano sobre la peroxidación iniciada por $\mathrm{Fe}^{2+}$ de liposomas de lípidos de retina bovina (Capítulo 5) 


\section{C apitulo2}

Efecto de melatonina e indolaminas relacionadas sobre la peroxidación lipídica de triglicéridos ricos en ácidos grasos n-3. 


\subsection{Introducción}

Es un hecho ampliamente reconocido que la ingesta de ácidos grasos poli-no-saturados de la familia n-3 (PUFAs n-3) representa un beneficio para la salud en general (Watkins y German, 1998). Diversos estudios básicos, clínicos y epidemiológicos han reportado ventajas importantes en campos tan diversos como cardiología, neurología, oncología, patologías inflamatorias crónicas, oftalmología, entre otros. Además, los ácidos grasos de la familia n-3 constituyen un componente crítico para el desarrollo y funcionalidad del tejido nervioso.

Síntesis de PUFAs n-3. Los ácidos grasos no pueden ser desaturados endógenamente a partir de la posición 9 debido a que el humano carece de las enzimas $\Delta 12$ - y $\Delta 15$-desaturasa. Por esta razón, los ácidos linoleico (LA, 18:2 n-6) y a-linolénico (ALA, 18:3 n-3) deben ser incorporados en la dieta y son llamados "esenciales". Elongaciones y desaturaciones de estos ácidos grasos producen los PUFAs de cadena larga entre los que se encuentran el ácido eicosapentenoico (EPA, 20:5 n-3), y el ácido docosahexenoico (DHA, 22:6n-3). Esta vía de biosíntesis es posible pero muy poco eficiente en humanos por lo que, sin ser considerados esenciales, también deben ser incorporados con la dieta (Tvrzicka y col, 2011; SanGiovanni y Chew, 2005). De hecho, los niveles tisulares de PUFAs son modificables con la ingesta y dependientes de ella.

Importancia fisiológica de los PUFAs n-3. El contenido elevado de DHA en tejido nervioso y retina es de extrema importancia, dado que sus propiedades únicas le dan un rol principal en el mecanismo de transducción de señales, probablemente involucrando la regulación de proteína G (Simopoulos, 1991; Simopoulos, 2009). Los PUFAs n-3 demostraron la capacidad de modular la producción, activación y potencia de moléculas bioactivas. En algunos casos operan como complejos lipoproteicos que desencadenan cascadas de señalización en compartimientos citosólicos y nucleares. En otros casos afectan pools de sustratos y disponibilidad de enzimas biosintéticas. También influencian la expresión génica como ligandos de factores de transcripción y actúan como autocoides endocanabinoides (SanGiovanni y Chew, 2005).

Los PUFAs n-3 poseen una gran variedad de efectos sobre el metabolismo lipídico y energético como ligandos del receptor activado por proliferadores peroxisomales (PPAR- $\alpha$ ). Se cree que activan el PPAR- $\alpha$ disminuyendo así la lipogénesis y la secreción de VLDL (Burdge y col, 2009). Otros efectos potenciales de PUFAs n-3 son aumentar la actividad de lipoproteínlipasa, disminuir la concentración de apo C III y potenciar el transporte reverso de colesterol (Calder y Yaqoob, 2009; Calder y Yaqoob, 2010). Como suplementos dietarios de 
elevada concentración, se cree que los PUFAs n-3 inducen expresión de proteínas desacoplantes y aumentan la densidad de mitocondrias en el músculo (Tvrzicka y col, 2011). El efecto inmunomodulador de PUFAs n-3 se asocia a su capacidad de suprimir la activación de linfocitos T (Calder, 2008).

Fuentes de PUFAs n-3. Las principales fuentes de ácido linolénico son aceites vegetales de soja, canola, entre otros, mientras que EPA y DHA se encuentran en elevadas concentraciones en aceites de pescados, mamíferos marinos 0 algas unicelulares. Aproximadamente el $10 \%$ de DHA proviene de la ingesta de huevos (SanGiovanni y Chew, 2005).

Como ya fue descripto en el Capítulo 1, en los sistemas químicos puros las moléculas más susceptibles al ataque de los radicales libres son, precisamente, los PUFAs y, en general, esta susceptibilidad aumenta con el número de dobles enlaces (Wagner y col, 1994). In vivo, se supone el mismo comportamiento. Entonces, se plantea la paradoja de que el organismo precisa de nutrientes que son altamente susceptibles a la peroxidación, haciendo que los tejidos a los que se incorporan también lo sean. In vivo, tal predisposición al daño resultaría catastrófica si no existiera un sistema antioxidante equiparable para responder a tal estrés. La susceptibilidad a la peroxidación de estos ácidos grasos también representa un problema en el almacenamiento de grasas, aceites y alimentos ricos en ellos. Por ello es que se hace imprescindible encontrar nuevos y más efectivos antioxidantes de origen natural, dado que existe una fuerte tendencia a reemplazar los antioxidantes sintéticos, que en varios casos presentan efectos secundarios indeseables e incluso, pueden llegar a ser cancerígenos (como en el caso de BHT). Basándonos en estos lineamientos planteamos como objetivo del presente capítulo:

Analizar el efecto antioxidante de melatonina, $\mathrm{N}$-acetilserotonina, 5-metoxitriptamina y 5HO-triptófano sobre la peroxidación de triglicéridos ricos en PUFAs n-3 disueltos en cloroformo, cuando la reacción es iniciada por hidroperóxido de cumeno.

Las técnicas empleadas en el presente capítulo fueron (ver Anexo):

* Quimioluminiscencia. Desde el punto de vista analítico la etapa de terminación de la reacción de peroxidación lipídica es muy interesante dado que se acompaña de emisión de luz al combinarse entre sí dos radicales lipoperoxilos ( $\mathrm{LOO} •$ ). La intensidad de luz emitida es útil para cuantificar la concentración de radicales LOO - (Vladimirov y col, 1980). Un compuesto capaz de reaccionar con radicales $\mathrm{LOO} \cdot$ es, por definición, un antioxidante cortador de cadena 
y por esta razón será capaz de evitar la emisión de luz. Basándonos en estos principios empleamos la técnica de fotoemisión para monitorear el proceso de peroxidación de triglicéridos enriquecidos en ácidos grasos n-3 (Tg PUFAs n-3) y la actividad antioxidante cortadora de cadena de melatonina (MLT) e indolaminas relacionadas.

* Determinación de sustancias reactivas al ácido tiobarbitúrico (TBARS). Esta reacción es ampliamente utilizada como un índice de peroxidación lipídica, dado que el ácido tiobarbitúrico (TBA) reacciona con productos de peroxidación de PUFAs generando un compuesto coloreado. Este compuesto posee un máximo de absorción a $532 \mathrm{~nm}$ y puede ser determinado espectrofotométricamente. El principal producto de peroxidación capaz de reaccionar con el TBA es el malondialdehído (MDA) aunque no es el único. Otros dialdehídos formados durante esta reacción pueden también formar un producto coloreado con el TBA. En el presente capítulo la determinación espectrofotométrica de TBARS fue utilizada para estimar la formación de productos de peroxidación de Tg PUFAsn-3, en ausencia y presencia de MLT e indoles relacionados.

* Ensayo de DPPH. Es una de las diversas técnicas empleadas para estimar la actividad anti-radicalaria de compuestos específicos o extractos naturales. Se determinó la capacidad de MLT, e indolaminas relacionadas, de decolorar el radical estable 2, 2, difenil-1-picrilhidracil $(\mathrm{DPPH} \bullet$ ) en solución metanólica (Blois, 1958). Esta técnica espectrofotométrica emplea DPPH, que posee un espectro de absorbancia característico, con un máximo de absorbancia a 515 $\mathrm{nm}$. La reducción de DPPH provocada por un antioxidante (AH) 0 un radical, implica disminución en la absorbancia a 515 nm (Brand-Williams y col, 1995). 


\subsection{Materiales y métodos}

\subsubsection{Materiales}

El proceso de peroxidación lipídica se estudió en aceite comercial de atún (triglicéridos enriquecidos en ácidos grasos n-3, Tg PUFAsn-3) donado por Winterization Europe Fécamp Cedex, Francia. Los triglicéridos utilizados contenían, según datos del productor: 18,43\% de ácido eicosapentenoico (EPA, 20:5 n-3) y 13,11\% de ácido docosahexenoico (DHA, 22:6 n-3).

1,1,difenil-2-picrilhidracil (DPPH•) como radical libre (90\% pureza), hidroxitolueno butilado (BHT), N-acetil-5-metoxitriptamina (melatonina, M LT), 5-metoxitriptamina (5MTP), 5hidroxitriptófano (5HO-TRP), N-acetilserotonina (NAS), placas de sílica gel sobre láminas de aluminio para cromatografía en capa delgada (TLC) con indicador fluorescente a $254 \mathrm{~nm}$, hidroperóxido de cumeno, (CHP, hidroperóxido de isopropilbenceno), trizma base y otros reactivos fueron suministrados por Sigma (St. Louis, MO, EEUU). Cloroformo estabilizado con etanol al $1 \%$ y $\mathrm{H}_{2} \mathrm{O}_{2}$ fueron provistos por la empresa Mallinkrodt Baker, México. Ácido tiobarbitúrico (TBA) fue suministrado por Fluka. Se utilizaron metanol, diclorometano y acetato de etilo de calidad cromatográfica.

Para los ensayos de determinación de quimioluminiscencia se empleó un contador fotónico (luminómetro) modelo 20/20n de Turner Biosystems, Sunnyvale, EEUU, con rango de respuesta espectral entre 350 y $650 \mathrm{~nm}$. El ensayo de $\mathrm{DPPH}$ • fue llevado a cabo en un espectrofotómetro Agilent Chem Station UV-VIS con arreglo de diodos.

\subsubsection{Métodos y técnicas}

\subsubsection{Determinación de quimioluminiscencia}

Un volumen de $100 \mu \mathrm{l}$ de aceite de pescado (Tg PUFAsn-3) disuelto en cloroformo fue incubado durante 90 minutos a $37^{\circ} \mathrm{C}$ en tubos Eppendorf en una cámara termostatizada (la $\mathrm{C}_{\mathrm{f}}$ de lípidos equivale $\approx 100 \mathrm{mM}$ tomando un PM promedio de triglicéridos $\approx 900 \mathrm{~g} / \mathrm{mol}$ y una densidad de 0,94 g/ml). La peroxidación fue iniciada por adición de $\operatorname{CHP}\left(C_{\mathrm{f}}=50 \mathrm{mM}\right)$ disuelto en cloroformo. Para analizar el efecto de MLT y demás indolaminas se preincubaron las muestras de Tg PUFAs $n-3$ disueltas en cloroformo durante 15 minutos con diferentes concentraciones de estos compuestos como se detalla en la tabla 2.1. BHT, M LT, 5MTP y NAS se disolvieron en etanol mientras que 5HO-TRP fue disuelto en metanol. 
Tabla 2.1. Concentraciones analizadas en los ensayos de quimioluminiscencia y producción de TBARS.

\begin{tabular}{|c|c|c|c|c|c|}
\hline \multirow[b]{2}{*}{ BHT } & \multicolumn{5}{|c|}{ Concentraciones finales analizadas (mM) } \\
\hline & & & 2,0 & 4,0 & 8,0 \\
\hline NAS & & & 2,3 & 4,6 & 9,2 \\
\hline MLT & 0,5 & 1,0 & 2,0 & $4,0 *$ & $8,0^{*}$ \\
\hline 5HO-TRP & 0,5 & 1,0 & 2,0 & & \\
\hline 5MTP & 0,5 & 1,0 & 2,0 & & \\
\hline
\end{tabular}

BHT: hidroxitolueno butilado, NAS: N-acetilserotonina, MLT: melatonina, 5HOTRP: 5-hidroxitriptófano y 5MTP: 5-metoxitriptamina. $(*)$ Concentraciones no analizadas con la técnica de TBARS

En todos los casos el volumen final fue de $1 \mathrm{ml}$. Todas las soluciones fueron preparadas al momento de la reacción.

El progreso de la reacción fue determinada mediante quimioluminiscencia. La intensidad lumínica se determinó en función del tiempo con un luminómetro, registrándose las unidades lumínicas relativas (RLUS) cada 5 minutos. Para comparar el efecto inhibitorio producido por los diferentes compuestos analizados se determinó la sumatoria de RLUs (RLUs totales).

\subsubsection{Determinación de sustancias reactivas al ácido tiobarbitúrico (TBARS)}

Al finalizar el tiempo de incubación, las muestras empleadas para el ensayo de quimioluminiscencia fueron analizadas con el ensayo de TBARS según el método de Buege y Aust (1978). Para ello alícuotas de $10 \mu \mathrm{l}$ de las mezclas de reacción fueron incubados con 500 $\mu \mathrm{l}$ de TBA durante $10 \mathrm{~min}$ a $100{ }^{\circ} \mathrm{C}$. Finalizado este lapso, se agregaron $2 \mathrm{ml}$ de agua y se midió la absorbancia en espectrofótometro a $532 \mathrm{~nm}$ (Maisuthisakul y col, 2006; Vasantha Rupasinghe y col, 2010).

\subsubsection{Determinación de actividad secuestradora de radicales mediante ensayo de 1,1 , difenil-2-picrilhidracil (DPPH)}

Para llevar a cabo el ensayo, se emplearon diferentes concentraciones de las indolaminas y BHT, disueltos en metanol. Un volumen de $100 \mu \mathrm{l}$ de soluciones de diferentes concentraciones de cada compuesto se agregó a 3,9 ml de solución de DPPH• en metanol (60 $\mu \mathrm{M})$.El blanco se realizó con $100 \mu \mathrm{l}$ de metanol agregados a 3,9 $\mathrm{ml}$ de solución de DPPH. La 
absorbancia de las mezclas de reacción fue determinada a 515 nm durante 350 minutos. La absorbancia inicial fue cercana a 0,700 en todos los casos. Las determinaciones fueron realizadas por triplicado. El porcentaje de $\mathrm{DPPH} \cdot$ remanente $\left(\% \mathrm{DPPH}_{\text {rem }}\right)$ en el estado estacionario fue calculado según la siguiente expresión:

$$
\% \text { DPP } H_{\text {rem }}=\frac{A_{f}}{A_{0}} \times 100
$$

$A_{0}$ y $A_{f}$ corresponden a la absorbancia a $515 \mathrm{~nm}$ de la solución de DPPH• al inicio y en el estado estacionario de la reacción, respectivamente. El \%DPPH rem en el estado estacionario es inversamente proporcional a la actividad anti-radicalaria del compuesto evaluado. El \%DPPH rem fue graficado en función de las concentraciones de los compuestos con el fin de calcular el índice "Concentración Efectiva 50" (EC 50 ). Este índice se define como la concentración de antioxidante necesaria para disminuir la absorbancia de DPPH • al 50\% de su absorbancia inicial, en el estado estacionario.

\subsubsection{Análisis de formación de AFMK durante la peroxidación lipídica de Tg PUFAs n-3 en presencia de melatonina}

$\mathrm{H}_{2} \mathrm{O}_{2}$ concentrado fue diluido a una concentración de $50 \mathrm{mM}$ con buffer Tris- $\mathrm{HCl}$ ( $\mathrm{pH}$ 7,4) y se agregó MLT para obtener una concentración final $2 \mathrm{mM}$ en $1 \mathrm{ml}$ de volumen final (Tan y col, 2000a). La mezcla fue incubada a $37^{\circ} \mathrm{C}$ durante $100 \mathrm{~min}$ en los que la reacción fue monitoreada por fotoemisión. Una vez cumplido este lapso se agregaron a la mezcla $200 \mu \mathrm{l}$ de diclorometano y se agitó manualmente durante $10 \mathrm{~min}$. Una alícuota de $10 \mu \mathrm{l}$ de esta fase orgánica fue sembrada en una placa $(5 \times 10 \mathrm{~cm})$ de sílica gel $(0,2 \mathrm{~mm}$ de espesor) soportada sobre aluminio. Las placas poseen indicador fluorescente que permite observar las manchas utilizando una lámpara de luz UV. El solvente de corrida utilizado fue acetato de etilo.

\subsubsection{Expresión de resultados}

Para identificar diferencias estadísticamente significativas entre las medias se utilizó ANOVA y Test Múltiple de Rango basado en el procedimiento de diferencia mínima significativa (LSD) de Fischer con un $95 \%$ de confianza para discriminar entre las medias. 


\subsection{Resultados}

Dependencia de quimioluminiscencia y formación de TBARS con la concentración de Tg PUFAs n-3.

El CHP es un peróxido orgánico utilizado como iniciador de reacciones radicalarias (por ej: polimerizaciones). Dado que el enlace 0-0 es lábil puede formar radicales libres del tipo RO - que, en este caso, inician la reacción de peroxidación lipídica. La peroxidación iniciada por CHP de Tg PUFAs n-3 fue analizada por determinación de fotoemisión. La figura 2.1 muestra la quimioluminiscencia (en unidades lumínicas relativas, RLUs) en función del tiempo producida por diferentes cantidades de triglicérido en solución clorofórmica. Previo al agregado de CHP se observó que la línea de base aumentó con la concentración del lípido y, por lo tanto, no está relacionado con la reacción. El salto de la señal al agregar el iniciador de reacción también aumentó con la concentración de lípido pero esta dependencia perdió linealidad por encima de $50 \mu \mathrm{l}$ de Tg PUFAs n-3. El área bajo la curva, estimada como la sumatoria de las RLUs (RLUs totales) en el rango de tiempo de la reacción (10 a $90 \mathrm{~min}$ ), fue una función que depende linealmente de la concentración de Tg PUFAs n-3 (Figura 2.2) y, por lo tanto, de la concentración de radicales LOO generados. Éste fue el parámetro que seleccionamos para cuantificar el efecto inhibidor de la peroxidación de M LT y demás indolaminas.

La cantidad de Tg PUFAs n-3 seleccionada para ser utilizada en todos los experimentos de fotoemisión y formación de TBARS fue de $100 \mu$ ya que mayores cantidades significaron una desviación de la linealidad de la respuesta lumínica (como RLUs totales) con respecto a la cantidad de Tg PUFAs n-3.

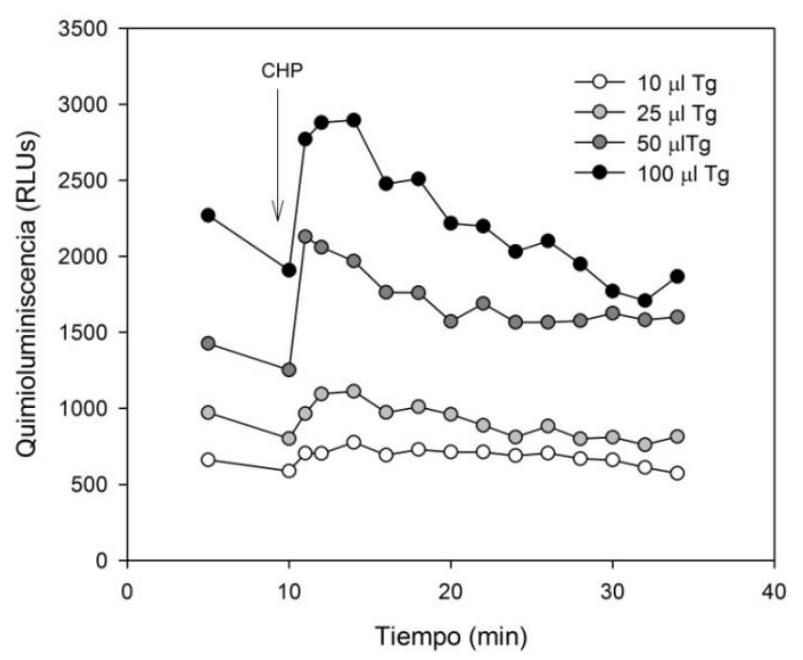

Figura 2.1. Quimioluminiscencia producida en función del tiempo por la peroxidación lipídica de diferentes cantidades de Tg PUFAs n-3 inducida por 
hidroperóxido de cumeno (50 $\mu \mathrm{M})$ en solución clorofórmica. Volumen final: 1 $\mathrm{ml}$.

La figura 2.2 muestra que también la dependencia de la producción de TBARS con la cantidad de lípido analizado fue lineal.

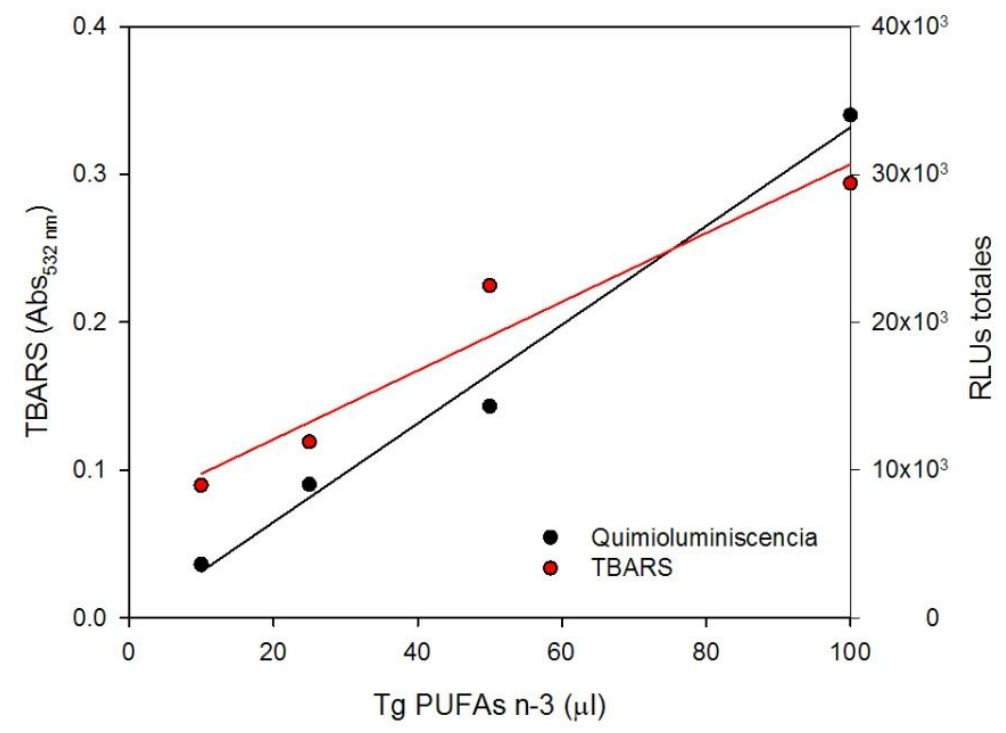

Figura 2.2. Peroxidación lipídica en función de diferentes cantidades de $\mathbf{T g}$

PUFAs n-3 determinada por quimioluminiscencia y ensayo de TBARS.

Efecto de melatonina y análogos estructurales sobre la peroxidación de Tg PUFAs n-3 determinado por quimioluminiscencia y formación de TBARS.

Los Tg PUFAs n-3 disueltos en cloroformo fueron rápidamente afectados por la peroxidación cuando se incubaron con CHP. La adición del iniciador de reacción a los triglicéridos produjo aumento de la fotoemisión con un pico máximo de 2851 RLUs 10 minutos después de agregado el CHP (Figura 2.3) (Tabla 2.2)

La figura 2.3 compara el efecto de las distintas indolaminas a una de las concentraciones estudiadas (2 mM) sobre la peroxidación de Tg PUFAs n-3. La presencia de BHT, NAS y 5HO-TRP disminuyó significativamente la fotoemisión (Figura 2.3 izq.) mientras que M LT y 5M TP la aumentaron notablemente (Figura $\mathbf{2 . 3}$ der.).Nótense las distintas escalas empleadas en ambos gráficos. La curva control (círculos negros), presente en ambos, hace evidente la marcada diferencia en el efecto que las diferentes indolaminas ejercieron sobre el sistema. 

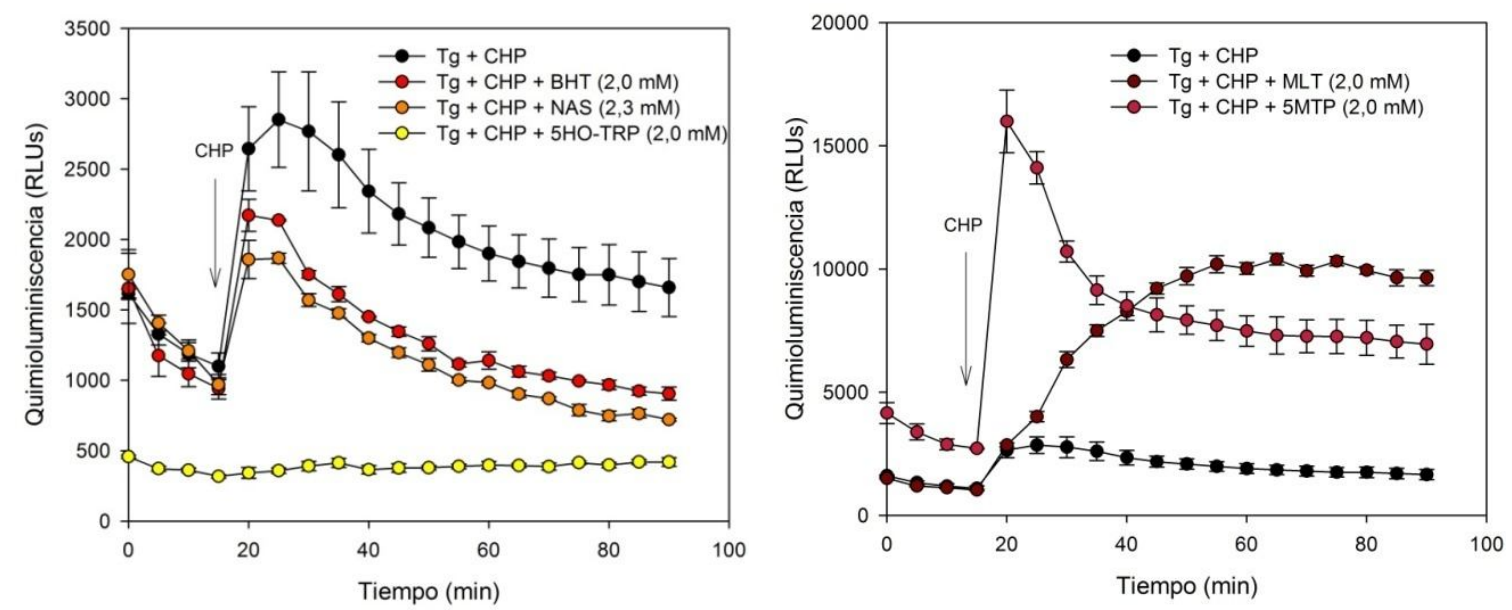

Figura 2.3. Gráfico comparativo del efecto de BHT e indolaminas sobre quimioluminiscencia producida por la peroxidación de Tg PUFAs n-3. BHT, NAS, 5HO-TRP (Izquierda), M LT y 5M TP (Derecha). Las curvas control (círculos negros) corresponden a Tg PUFAs $\mathrm{n}-3$ incubados con CHP $(50 \mu \mathrm{M})$. Cada punto representa: $\bar{x} \pm \frac{S D}{\sqrt{n}}$ de tres experimentos independientes

Según los datos de RLUs totales y RLUs máximas (Tabla 2.2) el efecto inhibidor de la quimioluminiscencia ejercido por BHT, NAS y 5HO-TRP fue dependiente de la concentración. Esto permitió calcular el índice $I_{50}$ (Tabla 2.3) definido como la concentración mínima necesaria para inhibir el 50\% de la fotoemisión (o de la producción de TBARS, según corresponda). Según este índice se deduce que 5HO-TRP $\left(I C_{50}=0,7 \pm 0,1 \mathrm{mM}\right)$ y NAS $\left(\mathrm{IC}_{50}=\right.$ $6,2+1,4 \mathrm{mM})$ fueron inhibidores de la quimioluminiscencia más efectivos que $\mathrm{BHT}\left(\mathrm{IC}_{50}=9,7 \pm\right.$ $1,5 \mathrm{mM})$.

MLT y 5MTP produjeron aumento en la emisión de luz (aumento de RLUs totales y RLUs máx.). 5MTP mostró un efecto amplificador de la luminiscencia dependiente de la concentración mientras que el efecto de MLT no fue dependiente de la concentración (Tabla 2.2). Dado que no presentaron inhibición no fue posible definir un valor de $I C_{50}$ para estos compuestos (Tabla 2.3).

Resultados similares a los obtenidos con la técnica de quimioluminiscencia se observaron en la determinación de productos de reacción por ensayo de TBARS. BHT, NAS y 5HO-TRP inhibieron la aparición de TBARS de manera dependiente de la concentración, mientras que MLT y 5MTP la aumentaron significativamente (Tabla 2.2). Para comparar la efectividad inhibitoria de formación de TBARS, se calculó el índice $\mathrm{IC}_{50}$. Según este índice, el 
inhibidor más efectivo fue 5HO-TRP $\left(I C_{50}=1,3 \mathrm{mM}\right)$, luego $\mathrm{BHT}\left(I \mathrm{C}_{50}=1,4 \mathrm{mM}\right)$ y NAS $\left(\mathrm{IC}_{50}=9,3\right.$ mM ) (Tabla 2.3). Dado que M LT y 5M TP no presentaron inhibición el índice $I_{50}$ no pudo ser calculado. Para descartar que el metanol o etanol en el que se disolvieron las indolaminas y el BHT hubieran producido algún efecto en la quimioluminiscencia o la producción de TBARS, se analizaron blancos de reactivos con agregado de estos solventes. Estos solventes no produjeron interferencias a las concentraciones analizadas.

Tabla 2.2. Efecto de diferentes concentraciones de BHT e indolaminas sobre la peroxidación lipídica de Tg PUFAs n-3 incubados con hidroperóxido de cumeno.

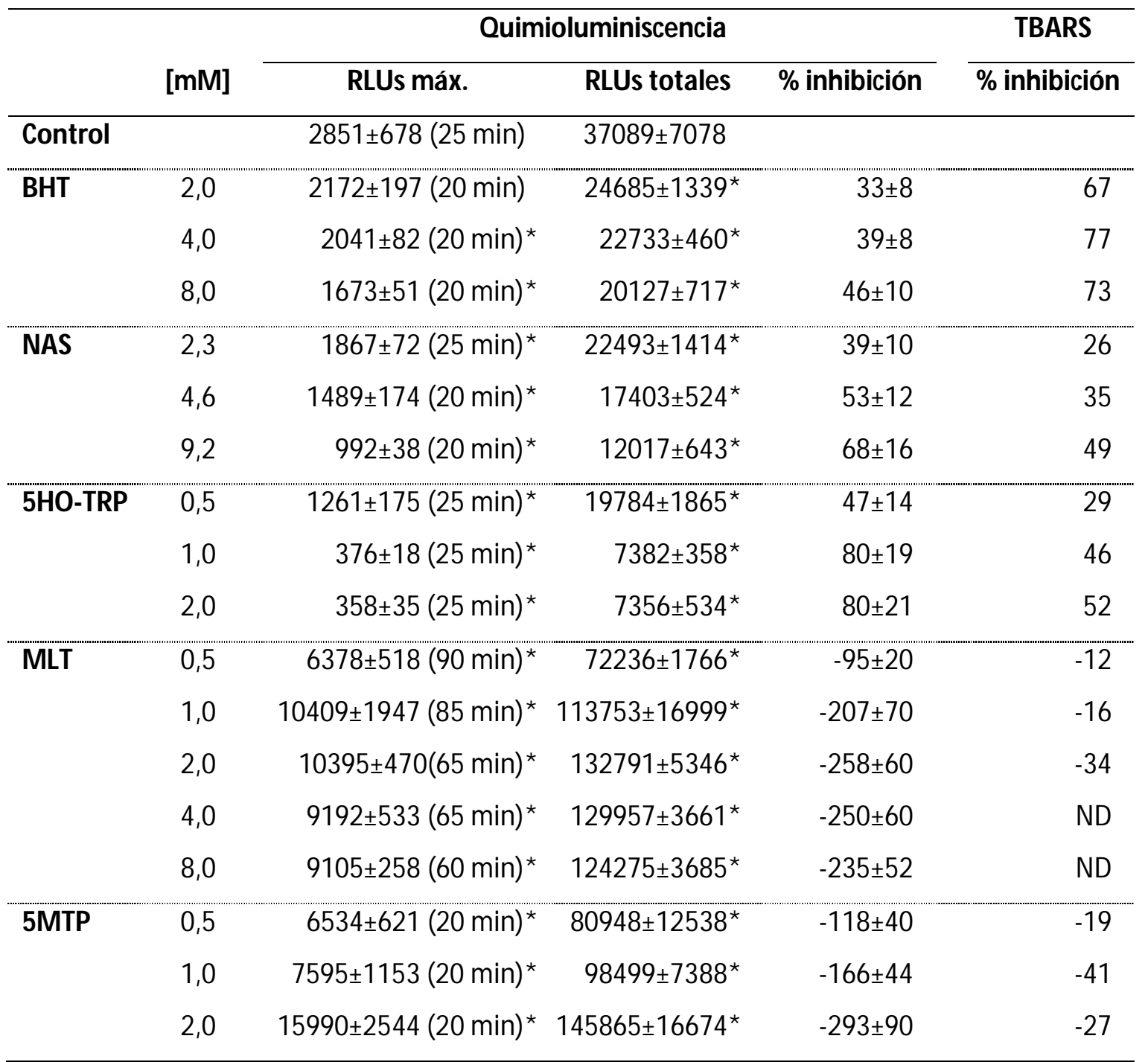

ND: no determinado. Cada valor representa: $\bar{x} \pm$ SD de tres experimentos independientes. El tiempo al que se produce el máximo valor de RLUs se indica entre paréntesis. Diferencias estadísticamente significativas con respecto al control se señalan con un asterisco (*). La inhibición porcentual se calculó a partir de los valores de RLUs totales (quimioluminiscencia) o de absorbancia a $532 \mathrm{~nm}$ (TBARS) con respecto al control (Tg PUFAs n-3 +CHP). 
Tabla 2.3. Inhibición de quimioluminiscencia y TBARS $\left(I C_{50}\right)$, y actividad secuestradora de radicales $\left(\mathrm{EC}_{50}\right)$ producidas por $\mathrm{BHT}$ e indolaminas.

\begin{tabular}{|c|c|c|c|}
\hline & \multicolumn{2}{|l|}{$\mathrm{IC}_{50}(\mathrm{mM})$} & \multirow{2}{*}{$\begin{array}{c}\mathrm{EC}_{50}(\mu \mathrm{M}) \\
\mathrm{DPPH}\end{array}$} \\
\hline & Quimioluminiscencia & TBARS & \\
\hline BHT & $9,7 \pm 1,5$ & 1,4 & $8,4 \pm 0,1$ \\
\hline NAS & $6,2 \pm 1,4$ & 9,3 & $4,7 \pm 0,3$ \\
\hline 5HO-TRP & $0,7 \pm 0,1$ & 1,3 & $4,1 \pm 0,2$ \\
\hline $5 M T P$ & ND & ND & ND \\
\hline MLT & ND & ND & ND \\
\hline
\end{tabular}

Actividad secuestradora de radicales de melatonina e indolaminas relacionadas.

La actividad secuestradora de radicales de MLT, NAS, 5HO-TRP y 5MTP fue determinada por el ensayo de DPPH y comparada con la actividad de BHT. Los resultados demostraron que 5HO-TRP y NAS presentaron una actividad secuestradora que es dependiente de la concentración analizada (Figura 2.4). Así, a una concentración de $10 \mu \mathrm{M}$, 5HO-TRP y NAS lograron reducir la concentración de DPPH• en un 85 y 74 \% respectivamente, en el estado estacionario (Figura 2.5). BHT presentó 51 \% de reducción mientras que MLT y 5 MTP sólo mostraron una reducción de 2 y $5 \%$ respectivamente.
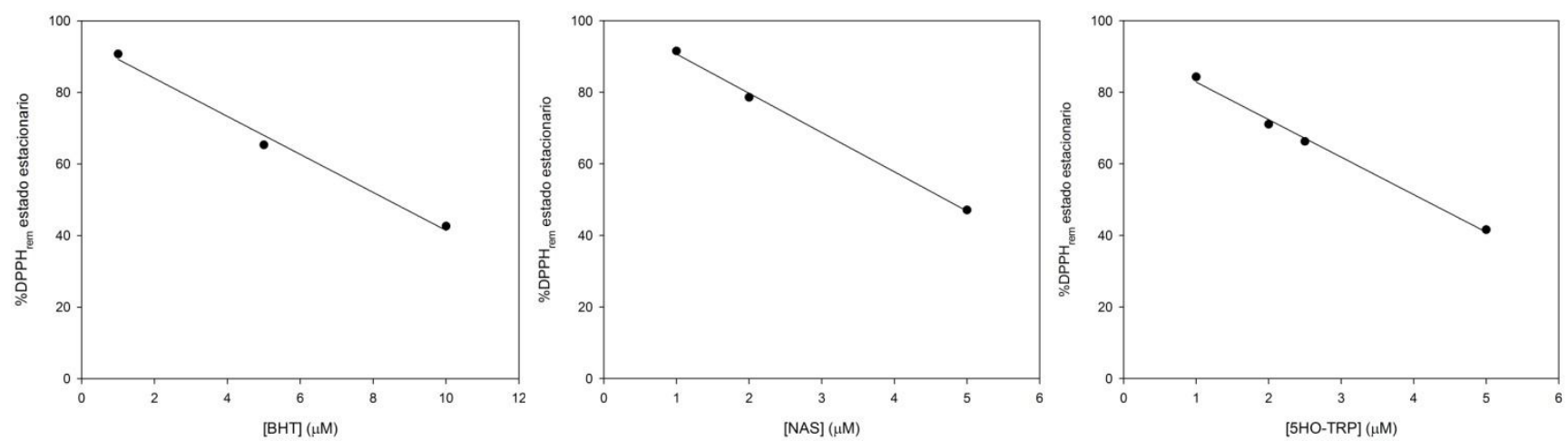

Figura 2.4. Dependencia de \%DPPH ${ }_{\text {rem }}$ en el estado estacionario con la concentración de BHT, NAS y 5HO-TRP

Para comparar la efectividad secuestradora de radical DPPH de BHT e indolaminas se calculó el índice $\mathrm{EC}_{50}$ (Tabla 2.3). Según este índice los secuestradores de radicales más 
potentes resultaron ser $5 \mathrm{HO}$-TRP $\left(\mathrm{EC}_{50}=4,1 \pm 0,2 \mu \mathrm{M}\right)$ y NAS $\left(\mathrm{EC}_{50}=4,7 \pm 0,3 \mu \mathrm{M}\right)$, seguidos de $\mathrm{BHT}\left(\mathrm{EC}_{50}=8,4 \pm 0,1 \mu \mathrm{M}\right)$. El índice $\mathrm{EC}_{50}$ no fue calculado para MLT ni 5M TP dado que no presentaron acción secuestradora de radicales relevante a las concentraciones analizadas.

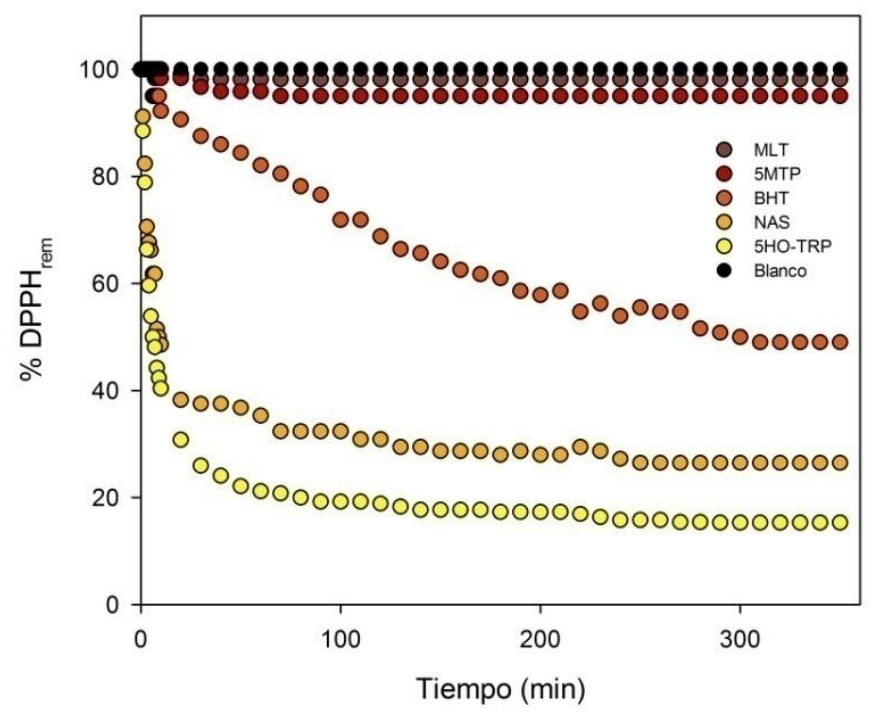

Figura 2.5. Gráfico comparativo de la capacidad secuestradora de radicales de melatonina y sus análogos estructurales (10 $\mu \mathrm{M})$.

Posible formación de AFMK durante la peroxidación de Tg PUFAs n-3 en presencia de melatonina.

Para determinar si el efecto amplificador de luminiscencia provocado por MLT en la peroxidación de Tg PUFAs $n-3$ se debe a la formación de N1-acetil, N2-formil, 5metoxikinuramina (AFM K) se empleó la técnica de cromatografía en capa delgada (TLC). LoS productos de reacción de $\mathrm{MLT}$ con $\mathrm{H}_{2} \mathrm{O}_{2}$ y Fe ${ }^{2+}$ se emplearon como control positivo para identificar la formación de AFMK como producto de peroxidación de Tg PUFAs n-3, en presencia de MLT.

La figura 2.6 muestra un análisis de TLC donde pueden observarse los productos de reacción de $\mathrm{MLT}$ con $\mathrm{H}_{2} \mathrm{O}_{2}$ y Fe${ }^{2+}$ (línea 4). En esta muestra se observaron claramente las manchas correspondientes a AFMK $(R f=0,15)$ y $M L T(R f=0,29)$ mientras que en la muestra de Tg + CHP + M LT (línea 3) la mancha correspondiente a AFM K no fue detectable. La figura 2.7 muestra el perfil de fotoemisión originado por la reacción de $\mathrm{MLT}(2 \mathrm{mM})$ con $\mathrm{H}_{2} \mathrm{O}_{2}(50 \mathrm{mM})$ y $\mathrm{FeCl}_{2}(0,5 \mathrm{mM})$ 


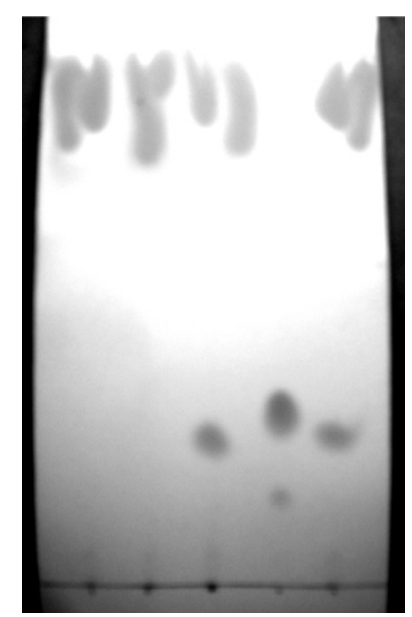

$1 \quad 23345$

Figura 2.6. Análisis por TLC de: 1) Tg PUFAs $n-3,2)$ Tg PUFAs $n-3+$ CHP, 3) Tg PUFAs n-3 + CHP + M LT, 4) M LT + $\mathrm{H}_{2} \mathrm{O}_{2}+\mathrm{Fe}^{2+}$ y 5) Tg PUFAs n-3 + CHP + MLT agregada después de la incubación). Se empleó acetato de etilo como solvente de corrida y las manchas fueron visualizadas con luz UV.

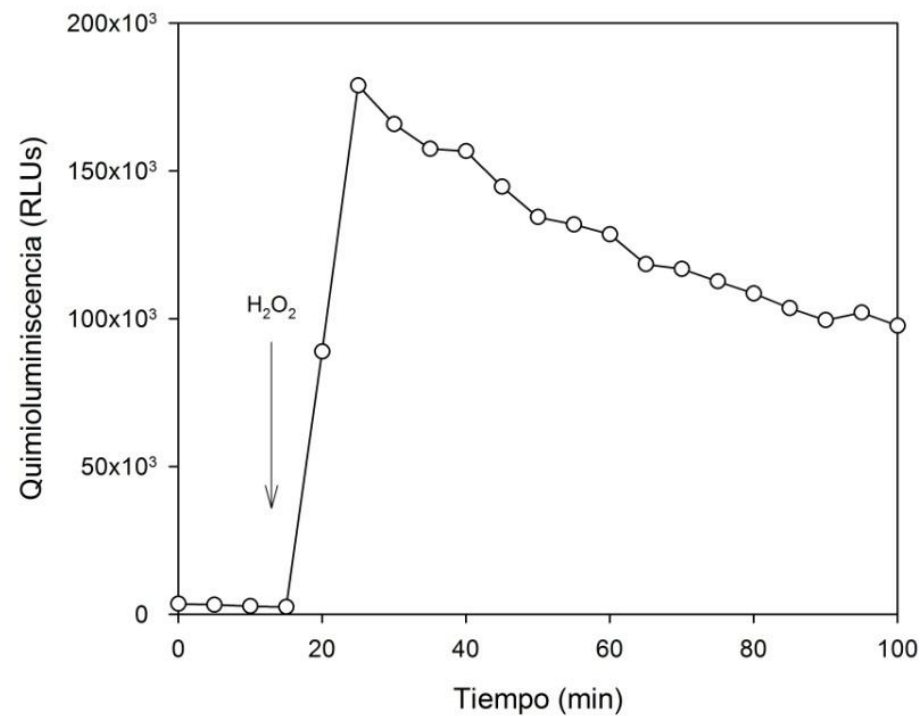

Figura 2.7. Quimioluminiscencia producida por reacción de melatonina $\left(C_{f}=2\right.$ $m M) \operatorname{con~} \mathrm{H}_{2} \mathrm{O}_{2}\left(\mathrm{C}_{\mathrm{f}}=50 \mathrm{mM}\right)+\mathrm{FeCl}_{2}\left(\mathrm{C}_{\mathrm{f}}=0,5 \mathrm{mM}\right)$ 


\subsection{Discusión}

Los antioxidantes cortadores de cadena (en inglés: chain-breaking) se definen como aquellos capaces de reaccionar con radicales $\mathrm{LOO} \bullet$, cediéndoles un radical $\mathrm{H} \cdot$ y cortando así la cadena de peroxidación (Laguerre y col, 2007). Sin embargo, esta propiedad por sí misma no es suficiente para catalogar a un antioxidante como un buen cortador de cadena. Además, debe poseer una estructura que le permita estabilizar el electrón desapareado por resonancia haciéndolo menos reactivo e impidiendo así que se inicien nuevas cadenas de reacción. El ejemplo típico de moléculas que cumplen estas condiciones son los fenoles (tocoferoles, flavonoides, etc). Un buen antioxidante cortador de cadena debe tener, además, la capacidad de llegar al lugar donde los radicales están siendo producidos. La capacidad antioxidante también está determinada por la energía de disociación de enlace (BDE) de la unión 0-H en estos compuestos, donde la capacidad dadora de un átomo $\mathrm{H}$ aumenta conforme BDE disminuye (Laguerre y col, 2007).

Comparando la estructura de MLT (1) con la de antioxidantes cortadores de cadena clásicos se observa que ésta no muestra similitudes con $\alpha$-tocoferol (vit. E) (2) ni sus análogos (3 y 4) ni cualquier otro antioxidante cortador de cadena conocido (Figura 2.8).

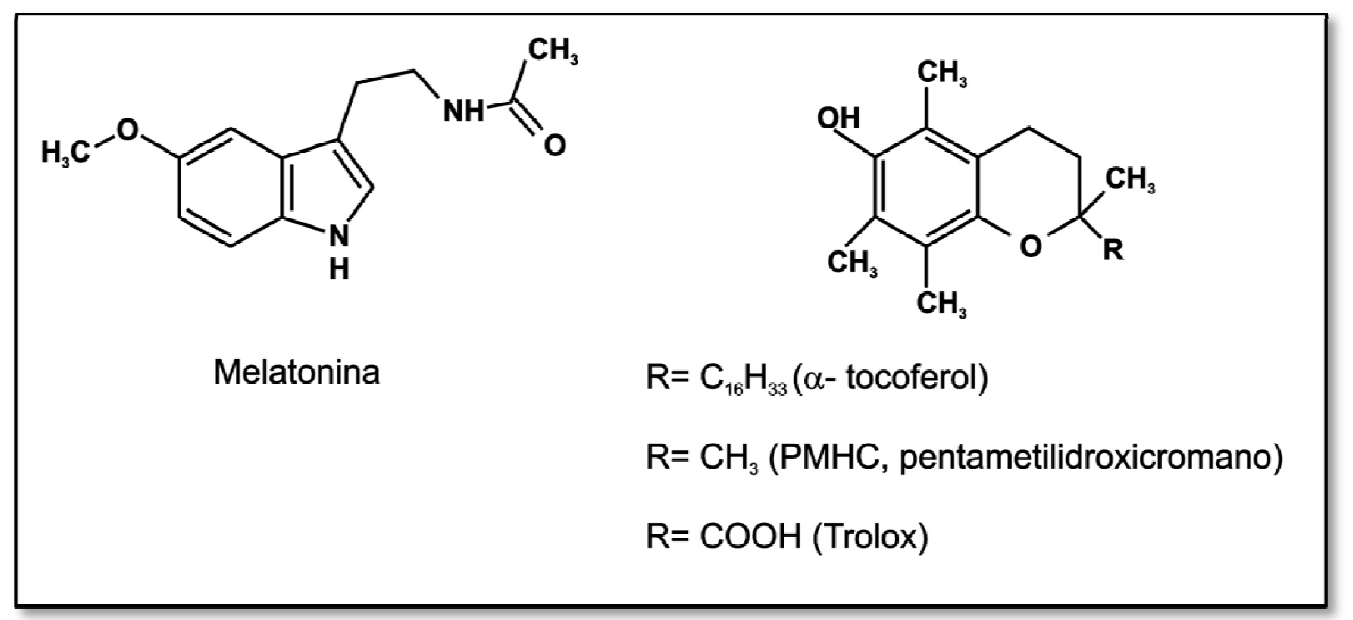

Figura 2.8. Comparación estructural entre melatonina y tocoferoles.

A pesar de tener cierto carácter bencílico, radicales derivados de MLT no son demasiado estabilizados, por lo que su formación no puede detener la reacción en cadena. MLT es un indol sustituido y sólo analizando su estructura, no podría ser considerada como un antioxidante atrapador de peroxilos. Antunes y colaboradores (1999) llevaron a cabo un estudio exhaustivo de la eficacia de MLT como atrapador de radicales LOO - y llegaron a la conclusión de que MLT no es un cortador de cadena eficaz. Más aún, señalaron que los 
compuestos que contienen un grupo $\mathrm{NH}$ en un anillo pirrólico sustituido en posición 5 , generalmente no son antioxidantes atrapadores de LOO •. Sin embargo, existen evidencias en la literatura de que MLT podría actuar como antioxidante cortador de cadena "no clásico" (Livrea y col, 1997; Marshall y col, 1996).

Desde el descubrimiento de la MLT como antioxidante (lanas y col, 1991) ha habido un enorme número de trabajos documentando esta acción bajo un casi ilimitado número de condiciones. In vivo, MLT ha demostrado reducir los efectos del estrés oxidativo en diversos estudios: disminuyendo la acción de agentes cancerígenos (Tan y col, 1993b), contrarrestando el efecto de lipopolisacárido (Sewerynek y col, 1995), inhibiendo el daño oxidativo generado por herbicidas (Melchiorri y col, 1995), entre otros. Para explicar estos resultados se han sugerido efectos indirectos tales como activación de enzimas antioxidantes e inducción por modulación de la expresión génica (Pandi-Perumal y col, 2006; Barlow-Walden y col, 1995). Sin embargo, el estudio de MLT y sus análogos estructurales en sistemas modelo in vitro arrojaron y arrojan resultados variables (Livrea y col, 1997; Abuja y col, 1997; Fowler y col, 2003) y, muchas veces, contradictorios indicando que su actividad antioxidante directa depende del sistema y las condiciones de estudio.

En el presente capítulo se estudió el efecto antioxidante (cortador de cadena) in vitro de MLT y de compuestos (Figura 2.9) que están estrechamente relacionados con ella dado que todos pertenecen a la familia de indolaminas. Para ello se utilizó un sistema puramente lipídico que, a diferencia de la complejidad de los sistemas utilizados en varios trabajos previos, elimina la contribución de enzimas y otros compuestos antioxidantes no enzimáticos, midiéndose únicamente las propiedades antioxidantes de las moléculas estudiadas.

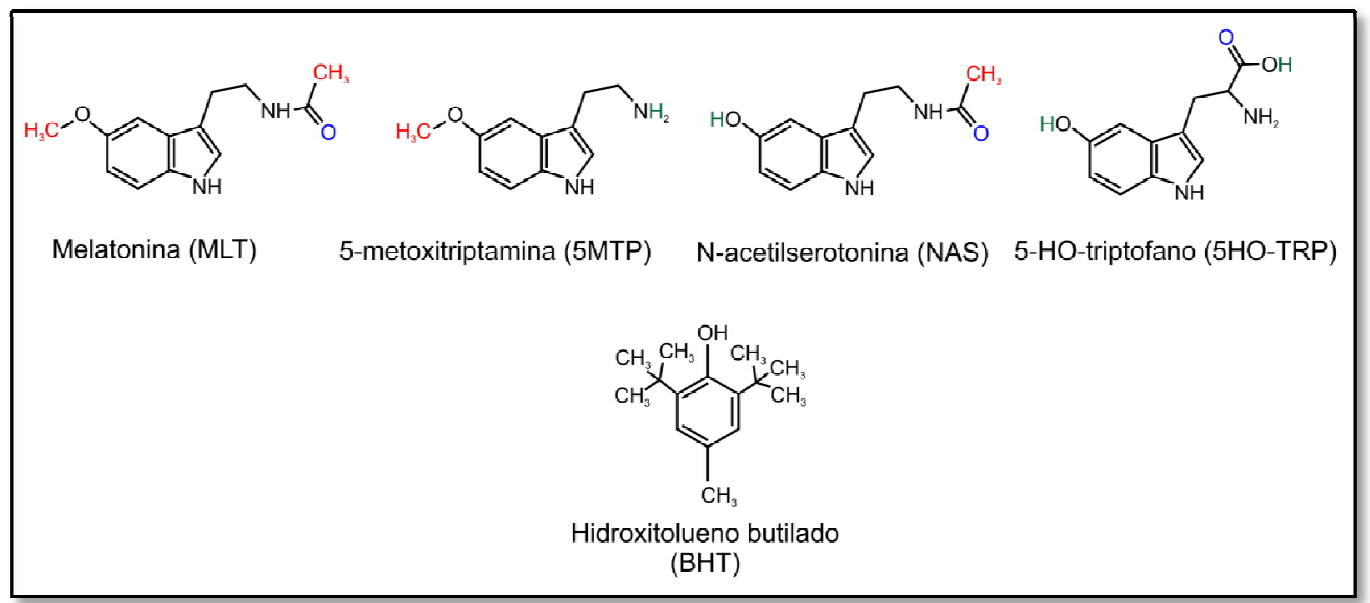

Figura 2.9. Estructura de los compuestos estudiados en el presente capítulo 
Según nuestros resultados, 5HO-TRP demostró ser un secuestrador de radicales peroxilos más efectivo que el BHT cuando se estudió por las técnicas de quimioluminiscencia y producción de TBARS. Este efecto es coherente con la elevada actividad demostrada frente al radical $\mathrm{DPPH}$ • lo que lleva a la conclusión de que este compuesto posee elevada tendencia a ceder un radical $\mathrm{H} \cdot$ a los radicales $\mathrm{LOO}$ • generados durante la peroxidación de Tg PUFAs n-3, cortando la cadena de peroxidación y protegiendo a los lípidos de sus efectos en forma dependiente de la concentración. NAS (también es un 5-HO derivado) mostró actividad secuestradora de radicales $\mathrm{LOO} \cdot$, disminuyendo la quimioluminiscencia e inhibiendo la formación de TBARS en forma concentración-dependiente. También demostró tener capacidad dadora de $\mathrm{H}$ • en el ensayo de DPPH. Su efectividad como antioxidante cortador de cadena fue menor que 5HO-TRP lo que indica que su única diferencia estructural (cadena lateral en posición 3) es un factor que influencia la actividad como antioxidante.

MLT no demostró ser un eficiente dador de $\mathrm{H}$ • cuando se analizó por ensayo de DPPH y el mismo comportamiento se observó para otro 5-metoxi derivado, 5-M TP. Estos resultados son consistentes con la falta de inhibición de producción de TBARS y la incapacidad de disminuir la producción de quimioluminiscencia demostrada por estos compuestos. Estos resultados nos permiten concluir que M LT y 5M TP no actuarían como antioxidantes cortadores de cadena clásicos en este sistema.

La formación de AFMK, el principal producto de reacción entre MLT y ciertas ROS (figura 2.10), es una reacción luminiscente. Esta reacción da lugar a la ruptura oxidativa del anillo indólico vía un intermediario dioxetano, o a través de la reacción de epoxidación de alquenos seguida de hidrólisis para formar el diol que puede ser oxidado a AFMK (Tan y col, 2000a). El intermediario formado excitado decae a una molécula estabilizada por resonancia lo que origina una típica reacción luminiscente (Fuhrberg y col, 1994; Hardeland y col, 1997). AFM K fue detectado como producto de reacción entre melatonina y ${ }^{1} \mathrm{O}_{2}$ (Poeggeler y col, 1994; Zang y col, 1998). La formación de AMK (metabolito de AFM K) también es quimioluminiscente. Por lo tanto, el efecto amplificador de quimioluminiscencia observado en presencia de MLT y 5MTP podría deberse a un efecto prooxidante (consistente con los resultados observados en TBARS) o podría deberse a un efecto antioxidante en el que MLT reacciona con radicales formando AFMK y generando quimioluminiscencia (Carampin y col, 2003). Para resolver esta situación analizamos la formación de AFMK por cromatografía en capa fina (TLC) empleando una reacción de MLT con $\mathrm{H}_{2} \mathrm{O}_{2}$ y Fe $\mathrm{Fe}^{2+}$ como control positivo. No se evidenció formación de AFM K en el sistema de Tg PUFAs n-3 peroxidados con CHP en presencia de MLT. La conclusión a la que nos llevan estos resultados es que M LT estaría reaccionando con especies generadas 
durante la reacción de peroxidación pero esto no significaría un efecto protector de los lípidos. Por lo tanto, M LT no se comporta en este sistema como un antioxidante cortador de cadena clásico. 5M TP presentó un comportamiento análogo al de MLT por lo que las conclusiones se hacen extensivas a este compuesto.

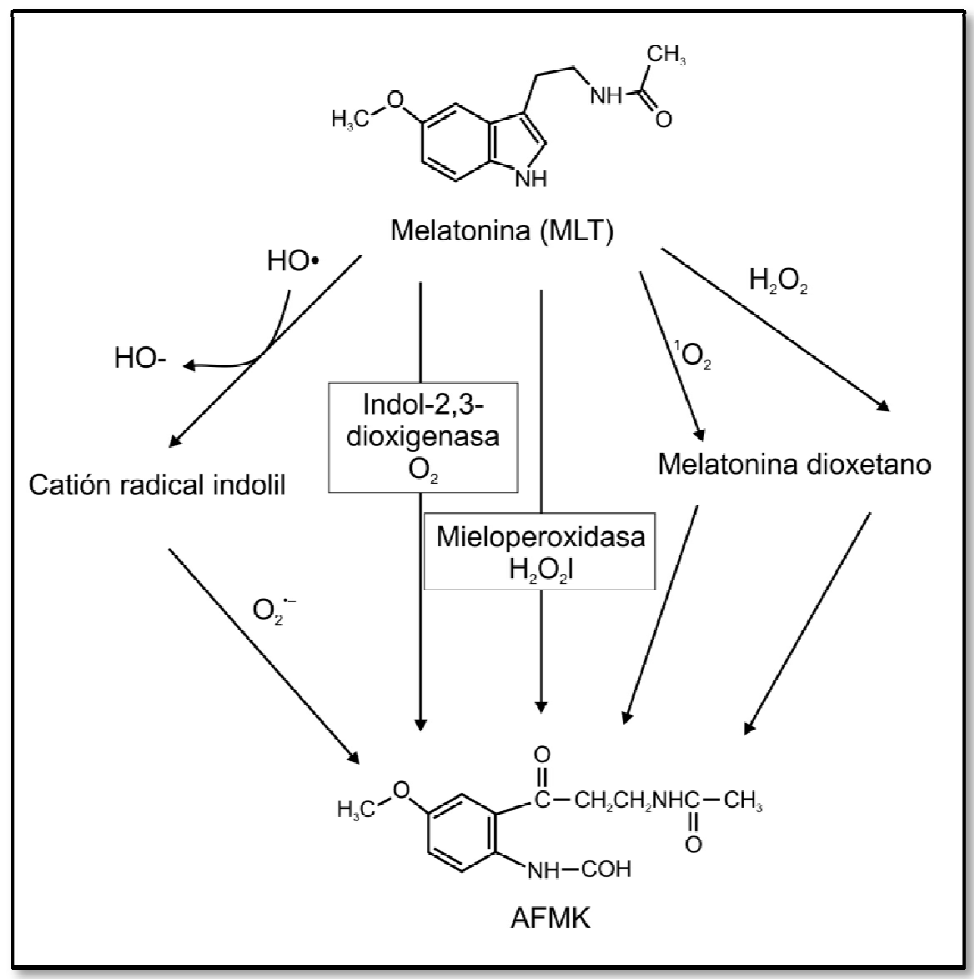

Figura 2.10.Vía química y enzimática de reacción de formación de AFMK a partir de melatonina (Tan y col, 2001)

Barsacchi y colaboradores (1998) obtuvieron resultados similares cuando evaluaron el efecto de MLT y NAS en el consumo de vitamina $E$ en glóbulos rojos peroxidados con CHP y cuando estudiaron su actividad frente al radical galvinoxilo (ensayo similar al de DPPH). En el primer ensayo MLT no sólo no presentó efecto protector sino que aumentó el consumo de vitamina E. Por el contrario, NAS logró suprimir el consumo de vitamina E, inhibiéndolo completamente a la máxima concentración analizada (400 mM). Por otro lado, M LT no mostró actividad dadora de $\mathrm{H}$ dado que no fue capaz de inhibir la señal de ESR del radical galvinoxilo. A la misma concentración, NAS logró reducir la intensidad de la señal mientras que vitamina $E$, empleada como control, la suprimió casi totalmente. Mediante estudios electroquímicos determinaron los potenciales de oxidación de MLT y NAS. Por los potenciales de oxidación obtenidos (positivos, menor para NAS) concluyeron que ambas indolaminas pueden actuar 
como antioxidantes por un mecanismo de transferencia de electrones. Por sus potenciales de oxidación moderadamente bajos, MLT y NAS podrían sufrir oxidación por radicales fuertemente oxidantes tales como hidroxilo (Keithanh y Lerchl, 2005), fenoxilo y alcoxilo. M LT presentó un potencial de oxidación similar a otros derivados 5-metoxi indol y el potencial de NAS fue cercano a los de otros 5-HO derivados. Sin embargo, debido a su estructura química que posee un grupo $\mathrm{OH}$ conjugado con un $\mathrm{NH}$, NAS puede sufrir el proceso de abstracción de hidrógeno antes que oxidación.

La comparación de análogos estructurales reveló una importancia crucial de los sustituyentes en las indolaminas. La presencia del grupo metoxi en posición 5 disminuye drásticamente la capacidad secuestradora de radicales (LOO - y DPPH). La presencia de un grupo $\mathrm{OH}$ en posición 5 determina una elevada actividad cortadora de cadena en NAS y $5 \mathrm{HO}$ TRP.

Varios trabajos presentan resultados que sustentan nuestras conclusiones: Marshall y colaboradores (1996) demostraron que MLT posee una limitada actividad antioxidante, Livrea y colaboradores (1997) demostraron que MLT ejerce una actividad antioxidante en liposomas de fosfatidilcolina de soja mucho menor que $\alpha$-tocoferol, Reiter y colaboradores (2001) encuentran debatible la capacidad de M LT para secuestrar radicales LOO•. 


\section{C aṕtulo3}

Efecto de isómeros conjugados de ácido linoleico (CLAs) sobre la peroxidación lipídica de triglicéridos ricos en ácidos grasos n-3. 


\subsection{Introducción}

La mayor parte de los ácidos grasos poli-no-saturados (PUFAs) se caracterizan por presentar sus dobles enlaces separados entre sí por grupos metileno. Una excepción a esta regla la constituyen los ácidos grasos conjugados. Los ácidos grasos conjugados más abundantes son los isómeros del ácido linoleico (CLAs).

Estructura, isómeros y fuentes. Existen 28 isómeros posibles de CLA que difieren en la posición (por ej.: 7 y 9, 8 y 10, 9 y 11, 10 y 12, 11 y 13 - contando a partir del grupo carboxilo) y configuración (cis o trans) de los dobles enlaces. El isómero más común encontrado en aceites vegetales comunes como el aceite de soja o de maíz y en carne y leche de rumiantes (vacas, ovejas y cabras) (Gagliostro y col, 2002), donde puede alcanzar hasta 0,65\% de los lípidos totales (Fritsche y Steinhart, 1998), es el Ilamado ácido ruménico (18:2 c9,t11), producto intermedio de la biohidrogenación del ácido linoleico (LA, 18:2 n-6) por la bacteria ruminal Butyrivibrio fibrisolvens (Pinto y col, 2002).

Incorporación y metabolismo. Se ha demostrado que CLAs, al igual que otros PUFAs, se incorporan en lípidos de membrana en un rango que abarca de 1 a 50\% del total de ácidos grasos de fosfolípidos, dependiendo del tipo celular (Subbaiah y col, 2010). Goedecke y col. (2009) han demostrado que una suplementación diaria de CLAs (50:50; t10, c12: c9, t11) durante 12 semanas aumenta el contenido de t10, c12 en triglicéridos de tejido adiposo mientras que el isómero c9, t11 tiende a aumentar en fosfolípidos de músculo esquelético. La incorporación de CLAs en lípidos neutros resulta en la acumulación en tejidos que son particularmente ricos en estos lípidos, tales como tejido mamario y adiposo (Banni, 2002).

Efectos sobre la salud. Se le atribuyen diversos efectos benéficos tales como: regulador metabólico, efectos hipocolesterolémicos, antiaterogénicos, anticarcinogénicos, antioxidantes, e incluso presenta efectos favorables en la prevención y/o tratamiento de ciertas alergias alimentarias (Sanhueza y col, 2002). Ha sido reconocido por la Academia Nacional de Ciencias de Estados Unidos, como el único ácido graso que ha presentado inequívocamente la propiedad de inhibir la carcinogénesis en animales experimentales (Kelly y col, 1998). Sehat y colaboradores (1998) señalaron que el isómero c9, t11 tendría un efecto anticancerígeno, mientras que el isómero t10, c12 actuaría en el aumento de la masa muscular y en la disminución del porcentaje de grasa. 
El papel que los CLAs juegan en el balance oxidativo ha sido investigado en algunos modelos y sistemas biológicos ya que éste podría ser la razón de algunos de sus efectos beneficiosos (Belury, 2002). Algunos autores demostraron que CLAs poseen actividad antioxidante y propusieron este mecanismo como explicación de sus efectos anticancerígeno y antiaterogénico. Sin embargo, otros investigadores señalaron que los CLAs poseen efectos prooxidantes (Basu y col, 2000). Paradójicamente, se descubrió su efecto anticancerígeno en un estudio que incluía carne frita (Pariza y Hargraves, 1985; Pariza y col, 1986). Hasta el presente no se sabe cómo estos ácidos grasos de estructura relativamente simple pueden tener tal variedad de funciones biológicas, por lo que es necesario profundizar el estudio de los diferentes efectos de los isómeros CLAs.

En el presente capítulo se planteó el objetivo de:

$\checkmark \quad$ Estudiar el efecto antioxidante de isómeros conjugados del ácido linoleico (CLAs), ácido linoleico y metil linoleato sobre triglicéridos ricos en PUFAs n-3 disueltos en cloroformo, cuando la reacción es iniciada por tert-butil hidroperóxido.

El progreso de la reacción de peroxidación fue determinado por quimioluminiscencia. Se analizó la capacidad secuestradora de radicales de estos compuestos mediante el ensayo de DPPH. A diferencia de la complejidad de los sistemas en los que se ha estudiado el comportamiento de los isómeros de ácido linoleico conjugado, el presente estudio in vitro elimina la contribución de enzimas y otros compuestos antioxidantes, midiendo la actividad antioxidante directa del compuesto analizado. 


\subsection{Materiales y métodos}

\subsubsection{Materiales}

El proceso de peroxidación lipídica se estudió en aceite comercial de pescado (triglicéridos enriquecidos en ácidos grasos n-3, Tg PUFAs n-3) donado por Winterization Europe Fécamp Cedex, Francia. Los triglicéridos utilizados contenían, según datos del productor, 20\% de ácido eicosapentenoico (EPA, 20:5 n-3) y 40\% de ácido docosahexenoico (DHA, 22:6 n-3). Los isómeros de ácido linoleico conjugado CLA c9, t11y CLA t10, c12 (ambos 90\%) fueron provistos por Natural ASA, Lysaker, Noruega. Ácido linoleico (LA) (>99\%), metil linoleato (MLA) (>99\%), 1,1-difenil-2-picrilhidracil (DPPH•) como radical libre (90\%), tert-butil hidroperóxido (tBHP), trizma base y otros reactivos fueron suministrados por Sigma, St. Louis, MO, EEUU. Los solventes utilizados fueron de calidad cromatográfica.

Para los ensayos de determinación de quimioluminiscencia se empleó un contador fotónico (luminómetro) modelo 20/20n de Turner Biosystems, Sunnyvale, EEUU, con rango de respuesta espectral entre 350 y $650 \mathrm{~nm}$.

El ensayo de DPPH • fue llevado a cabo en un espectrofotómetro Agilent Chem Station UV-VIS con arreglo de diodos.

\subsubsection{Métodos y técnicas}

\subsubsection{Determinación de peroxidación lipídica de ácido linoleico libre, metil linoleato, CLA} c9, t11 y CLA t10, c12 por detección de quimioluminiscencia.

LA, sus isómeros conjugados (CLA c9, t11 y CLA t10, c12) y su metil éster (MLA) disueltos en cloroformo ( $C_{f}: 1,4,10,20,100$ y 200 mM) fueron incubados durante 60 minutos en una cámara termostatizada a $37^{\circ} \mathrm{C}$ (volumen final: $1 \mathrm{ml}$ ). La reacción de peroxidación fue iniciada por el agregado de $10 \mu \mathrm{l}$ de solución metanólica de tBHP $\left(\mathrm{C}_{\mathrm{f}}: 36,4 \mathrm{mM}\right)$ cuya acción como iniciador de reacción es análoga a la de hidroperóxido de cumeno. Las unidades lumínicas relativas (RLUs) fueron determinadas mediante un luminómetro cada 5 minutos. La quimioluminiscencia total se determinó mediante la sumatoria de RLUs (RLUs totales), tomadas entre 15 y 45 minutos. Todas las soluciones fueron preparadas en el día. Se determinó la quimioluminiscencia de controles sin agregado de tBHP y estos valores se restaron a los valores obtenidos para las muestras peroxidadas. 


\subsubsection{Determinación de peroxidación lipídica de Tg PUFAs n-3 por detección de quimioluminiscencia. Efecto de CLAs, LA y MLA}

Un volumen de $100 \mu \mathrm{l}$ de aceite de pescado comercial (Tg PUFAs n-3) disuelto en cloroformo fue incubado durante $60 \mathrm{~min}$ a $37{ }^{\circ} \mathrm{C}$ en tubos Eppendorf en una cámara termostatizada (la $C_{f}$ de lípidos equivale $\approx 100 \mathrm{mM}$ tomando un PM promedio de triglicéridos $\approx 900 \mathrm{~g} / \mathrm{mol}$ y una densidad de 0,94 g/ml). La reacción de peroxidación fue iniciada por adición de $10 \mu \mathrm{l}$ de solución metanólica de tBHP $\left(C_{f}=36,4 \mathrm{mM}\right)$. Para analizar el efecto de CLAs, LA y MLA se utilizó el mismo procedimiento incubando los Tg PUFAs $n-3$ con estos compuestos $\left(C_{f}=\right.$ $0,1,4,10,20,100$ y $200 \mathrm{mM}$ ) durante 15 minutos previos al agregado de tBHP. En todos los casos el volumen final fue $1 \mathrm{ml}$. El progreso de la reacción fue determinado mediante quimioluminiscencia. Para monitorear la reacción de peroxidación se determinó la intensidad lumínica en función del tiempo con un luminómetro, registrándose las unidades lumínicas relativas (RLUs) cada 5 minutos. Para comparar el efecto producido por los diferentes compuestos analizados se determinó la sumatoria de RLUs entre 15 y 45 minutos (RLUs totales).

\subsubsection{Determinación de actividad secuestradora de radicales de CLAs, LA y M LA por ensayo} de DPPH.

La actividad secuestradora de radicales libres de los isómeros CLA, LA y MLA se determinó mediante su capacidad para decolorar el radical estable DPPH. $1 \mathrm{ml}$ de solución etanólica de diferentes concentraciones $\left(C_{f}=5,10,15,20\right.$ y $\left.25 \mathrm{mM}\right)$ de isómeros CLA, LA o M LA fueron agregados a $1 \mathrm{ml}$ de solución etanólica de $\mathrm{DPPH}\left(\mathrm{C}_{\mathrm{f}}=31,5 \mu \mathrm{M}\right)$. La absorbancia se midió a $518 \mathrm{~nm}$ durante $120 \mathrm{~min}$ contra un blanco de etanol. La absorbancia inicial fue cercana a 0,4 en todos los casos. El parámetro para estimar la actividad secuestradora de radicales de los compuestos fue el $\mathrm{EC}_{50}$ (ver Materiales y Métodos, Capítulo 2).

\subsubsection{Expresión de resultados}

Se calcularon la media $(\bar{x})$ y desviación estándar (SD) de al menos tres experimentos independientes. El análisis estadístico se realizó con ANOVA y Test Múltiple de Rango basado en el método de Tukey HSD $(p<0.05)$ para identificar diferencias significativas 


\subsection{Resultados}

Determinación de peroxidación lipídica de ácido linoleico libre, metil linoleato, CLA c9, t11 y CLA t10, c12 por detección de quimioluminiscencia.

Se analizó la respuesta quimioluminiscente de la reacción de LA, MLA e isómeros CLAs $(\mathrm{c} 9, \mathrm{t} 11$ y $\mathrm{t} 10, \mathrm{c} 12)$ con tBHP. El agregado de tBHP a diferentes concentraciones de LA (Figura 3.1) y MLA (Figura 3.2) no produjo un aumento significativo de la quimioluminiscencia con respecto al control $(0 \mathrm{mM})$ a ninguna de las concentraciones analizadas. En contraposición, CLA c9, t11 (Figura 3.3) y CLA t10, c12 (Figura 3.4) mostraron aumento significativo de la fotoemisión con respecto al control, a 100 y 200 mM. Estos resultados determinaron que los isómeros conjugados de ácido linoleico poseen mayor susceptibilidad a la acción de tBHP que el LA y su metil derivado. Cada punto en los perfiles de quimioluminiscencia representa la media de tres experimentos independientes. Las desviaciones estándar fueron omitidas intencionalmente para simplificar la visión de los resultados.
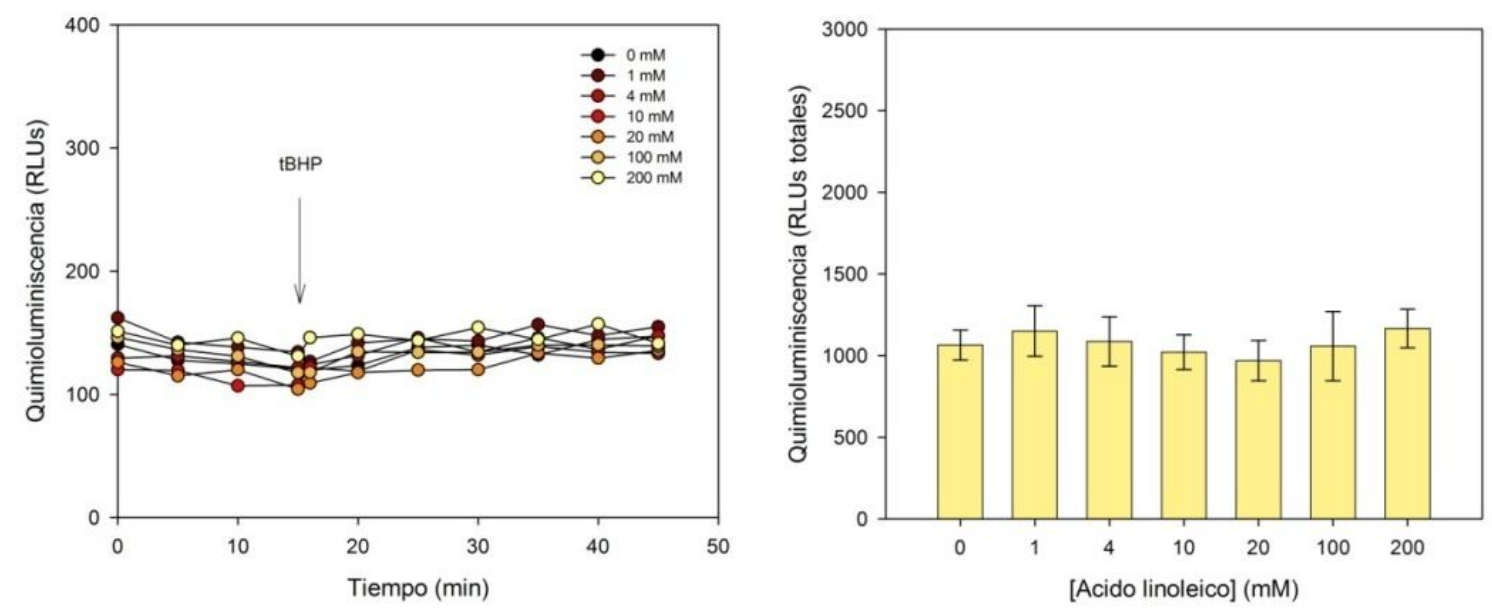

Figura 3.1. Izq. Quimioluminiscencia en función del tiempo durante la peroxidación lipídica iniciada por tBHP de diferentes concentraciones de ácido linoleico libre. Cada punto representa la media de tres determinaciones. Der. RLUs totales, sumadas entre 15 y 45 minutos, en función de las concentraciones de LA. Cada barra representa $\bar{x} \pm$ SD de tres experimentos independientes. 

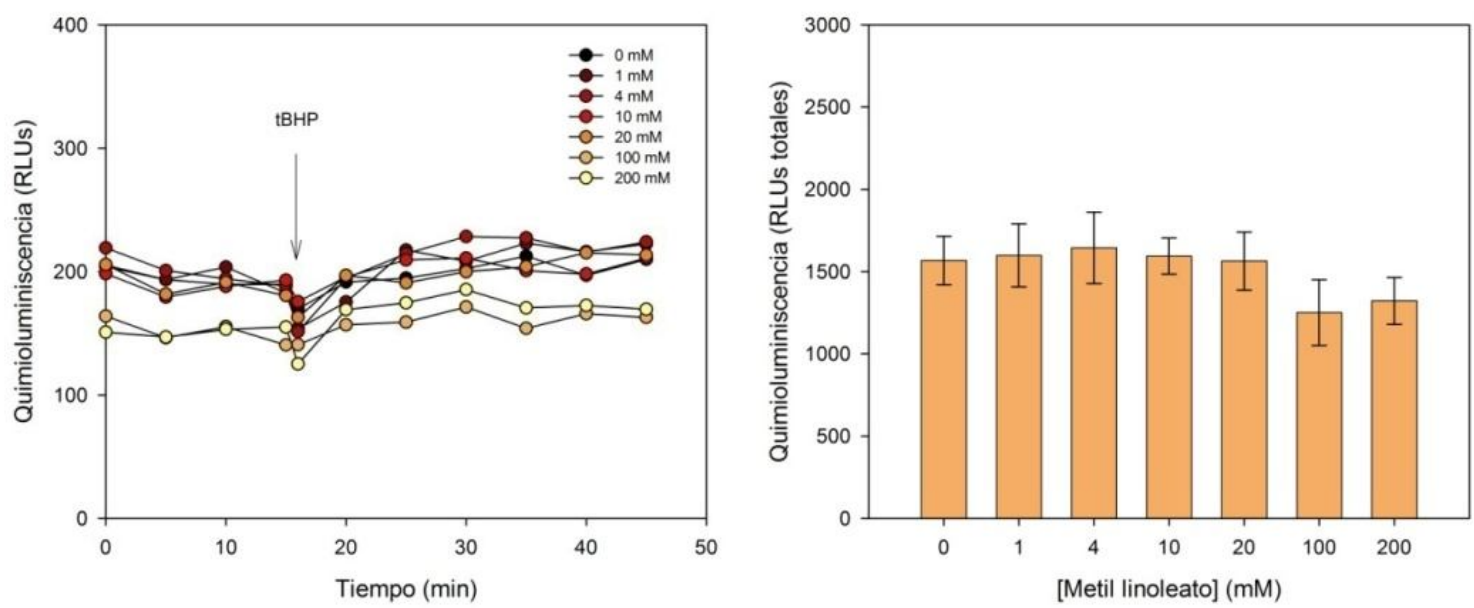

Figura 3.2. Izq. Quimioluminiscencia en función del tiempo durante la peroxidación lipídica iniciada por tBHP de diferentes concentraciones de metil linoleato. Cada punto representa la media de tres determinaciones. Der. RLUs totales, sumadas entre $\mathbf{1 5}$ y $\mathbf{4 5}$ minutos, en función de las concentraciones de MLA. Cada barra representa $\overline{\mathrm{x}} \pm$ SD de tres experimentos independientes.
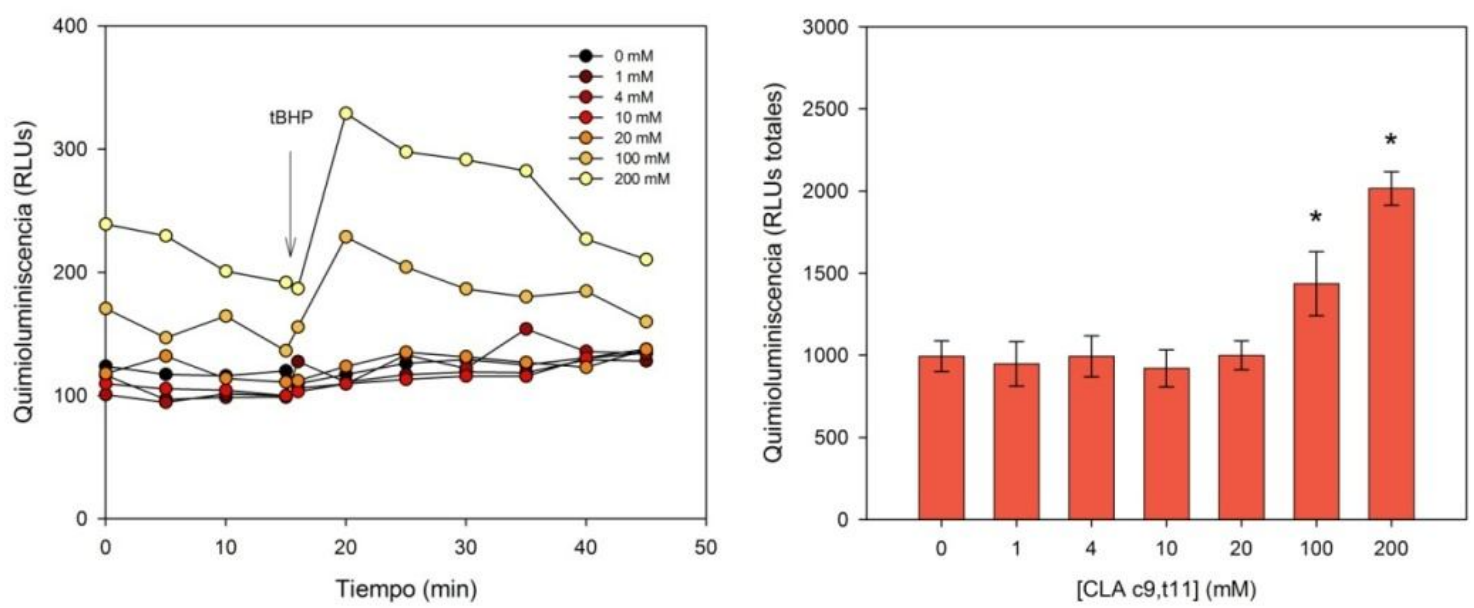

Figura 3.3. Izq. Quimioluminiscencia en función del tiempo durante la peroxidación lipídica iniciada por tBHP de diferentes concentraciones de CLA c9, t11. Cada punto representa la media de tres determinaciones. Der. RLUs totales, sumadas entre 15 y $\mathbf{4 5}$ minutos, en función de las concentraciones de CLA c9,t11. Cada barra representa $\overline{\mathrm{x}} \pm \mathrm{SD}$ de tres experimentos independientes. Un asterisco $(*)$ indica diferencia significativa con respecto al control $(0 \mathrm{mM}), \mathrm{p} \varangle 0,05$ 

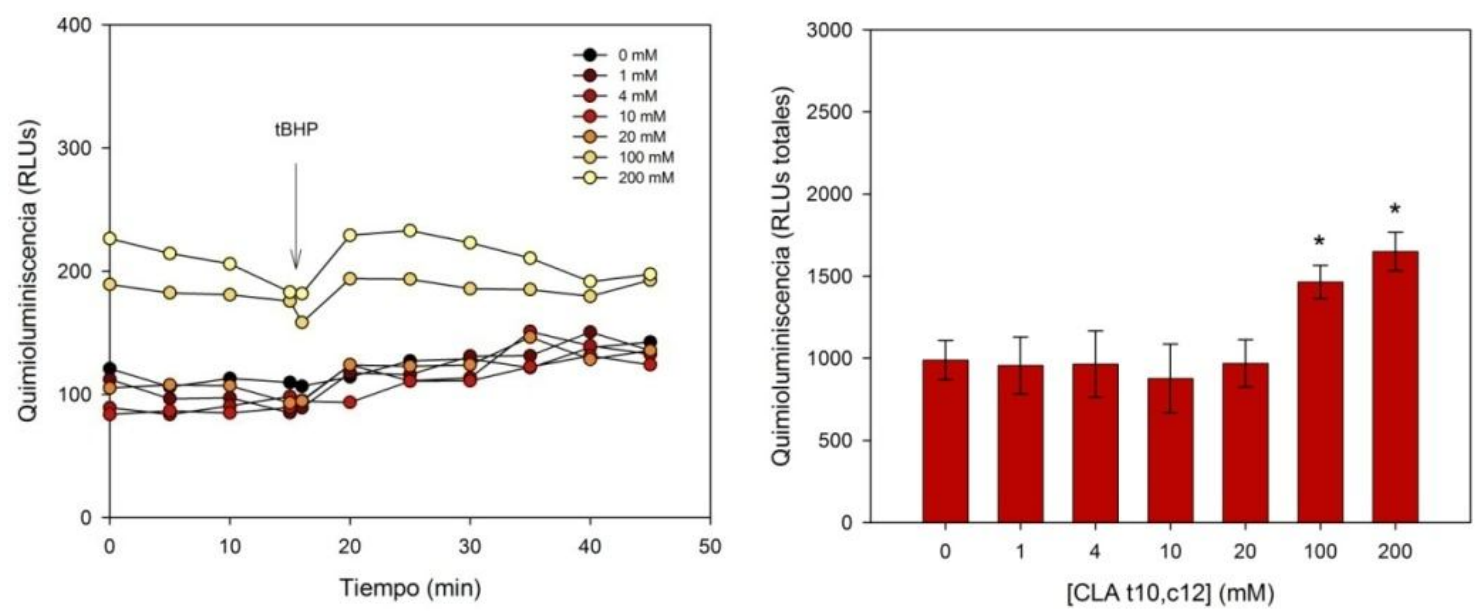

Figura 3.4. Izq. Quimioluminiscencia en función del tiempo durante la peroxidación lipídica iniciada por tBHP de diferentes concentraciones de CLA t10, c12. Cada punto representa la media de tres determinaciones. Der. Sumatorias de las RLUs totales, tomadas entre 15 y $\mathbf{4 5}$ minutos, en función de las concentraciones de CLA t10, c12. Cada barra representa $\bar{x} \pm$ SD de tres experimentos independientes. Un asterisco $(*)$ indica diferencia significativa con respecto al control $(0 \mathrm{mM}), \mathrm{p} \varangle 0,05$

Determinación de peroxidación lipídica de Tg PUFAs n-3 por detección de quimioluminiscencia. Efecto de CLAs, LA y MLA

Como se observa en la figura $\mathbf{3 . 5}$ triglicéridos ricos en ácidos grasos n-3 (Tg PUFAs n-3) producen un máximo de fotoemisión (3151 \pm 134 RLUs) 5 minutos después de agregado el $\mathrm{tBHP}$.

Los Tg PUFAs $n-3$ peroxidados en presencia de diferentes concentraciones (de 1 a 200 mM) de LA (Figura 3.6 A) y de MLA (Figura 3.6 B) no produjeron modificaciones en los niveles de fotoemisión con respecto al control $(0 \mathrm{mM})$. Cuando los triglicéridos se incubaron con CLA c9,t11 y CLA t10,c12, tras el agregado de tBHP se observó inhibición de la quimioluminiscencia: CLA t10, c12 disminuyó significativamente la fotoemisión a 100 y 200 mM (Figura 3.6 D), mientras que CLA C9, t11 sólo produjo disminución significativa a una concentración de 200 $\mathrm{mM}$ (Figura 3.6 C). 


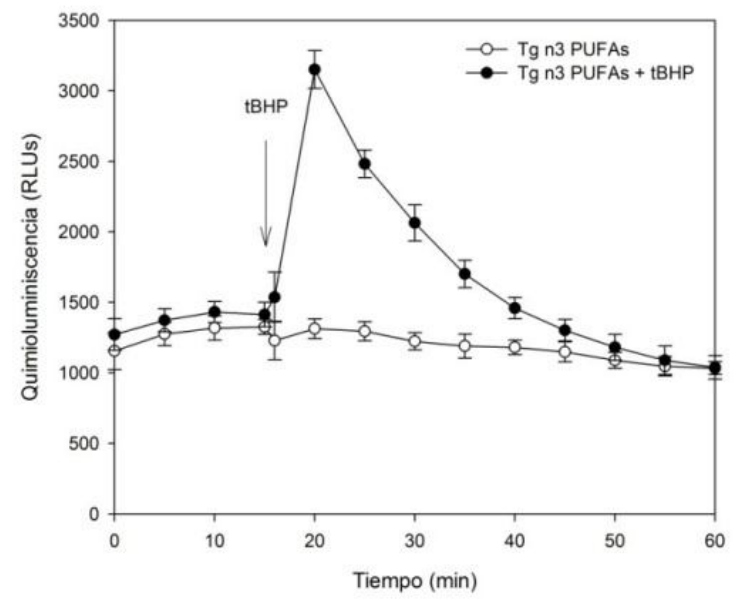

Figura 3.5. Perfil de quimioluminiscencia producida por la peroxidación lipídica de Tg PUFAs n-3 en función del tiempo. Cada punto representa $\bar{x} \pm$ SD de tres experimentos independientes.
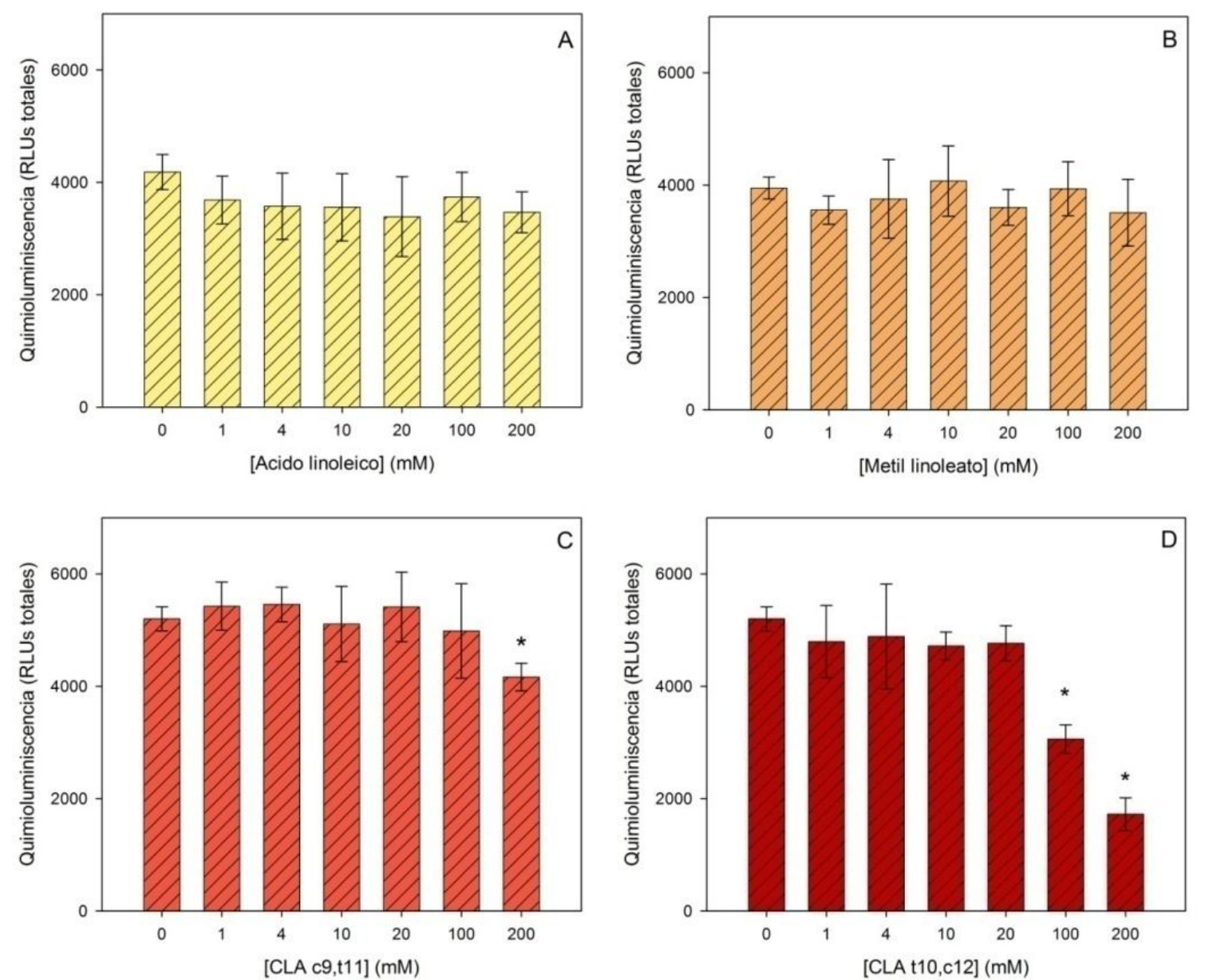

Figura 3.6. Efecto de la concentración de A) LA, B) MLA, C) CLA c9,t11 y D) CLA t10,c12 sobre la peroxidación lipídica de Tg PUFAs n-3 determinada por quimioluminiscencia. Cada barra representa la media de la sumatoria de RLUs 
(entre 15 y 45 minutos) $\pm S D$, para tres experimentos independientes. Un asterisco $(*)$ indica diferencias significativas con respecto al control $(0 \mathrm{mM})$, $p<0.05$.

Determinación de actividad secuestradora de radicales de CLAs, LA y MLA por ensayo de DPPH.

En las figuras 3.7A y B se observa que LA y MLA no presentaron actividad secuestradora de radical DPPH a las concentraciones ensayadas $(5-25 \mathrm{mM})$. En estas figuras sólo se representa la máxima concentración ( $25 \mathrm{mM}$ ) para una mejor visualización de los resultados. Tanto CLA C9, t11 como CLA t10, c12 presentaron actividad secuestradora de radicales dependiente de la concentración (Figuras 3.5 C y D).
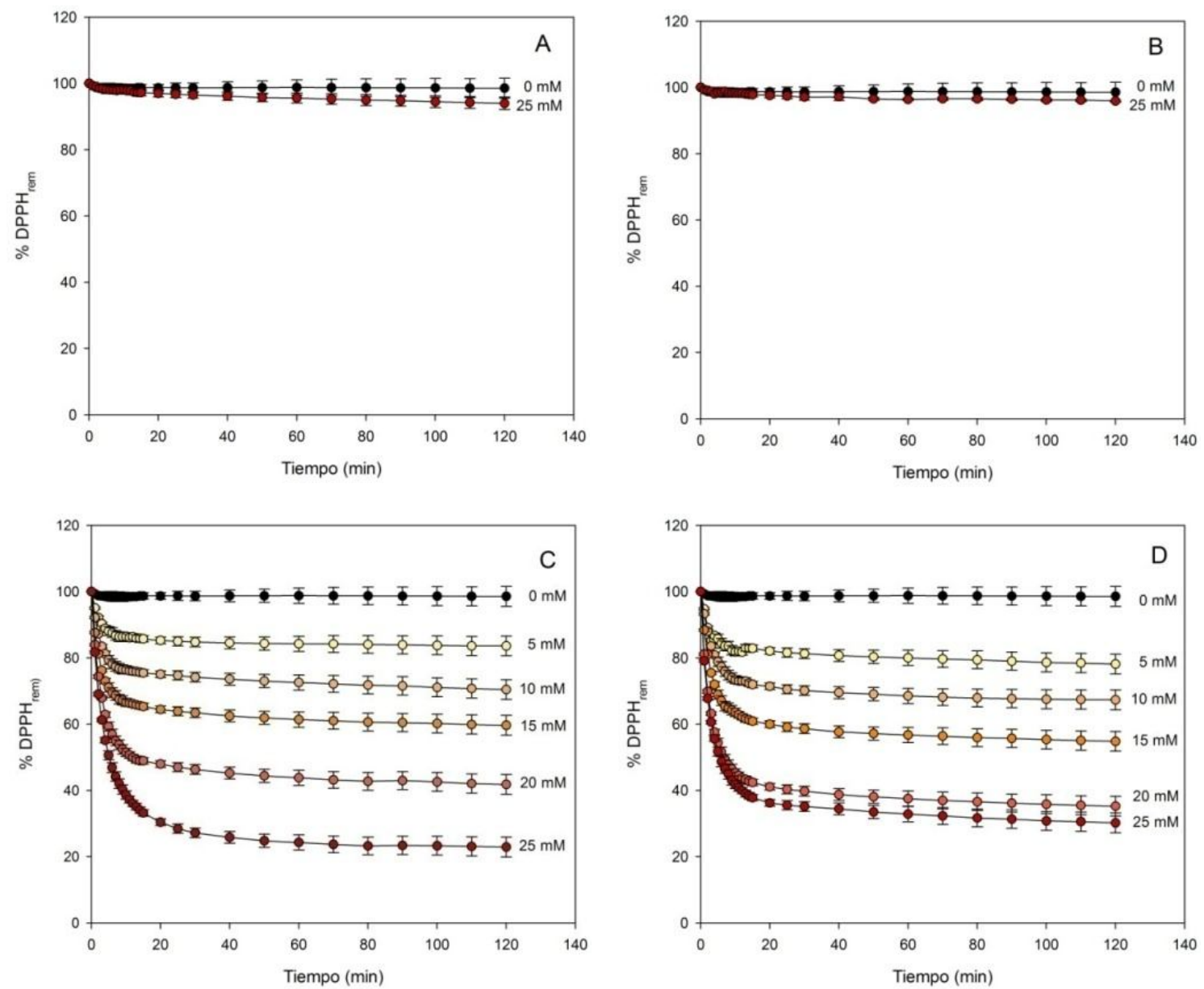

Figura 3.7. Reacción de DPPH con diferentes concentraciones de: A) LA, B) MLA, C) CLA c9, t11 y D) CLA t10, c12 en función del tiempo. Cada punto representa $\bar{x} \pm$ SD de tres experimentos independientes. 
El \%DPPH rem en el estado estacionario se graficó en función de la concentración de CLAs (Figura 3.8) para obtener $\mathrm{EC}_{50}$ cuyos valores promedio fueron $16,9 \pm 0,9 \mathrm{mM}$ para CLA c9, t11 y $16,4 \pm 0,8 \mathrm{mM}$ para CLA t10, c12. Estos valores de $\mathrm{EC}_{50}$ no poseen diferencias estadísticamente significativas, por lo que ambos isómeros CLA parecen poseer la misma actividad secuestradora de radicales, determinada por ensayo de DPPH.
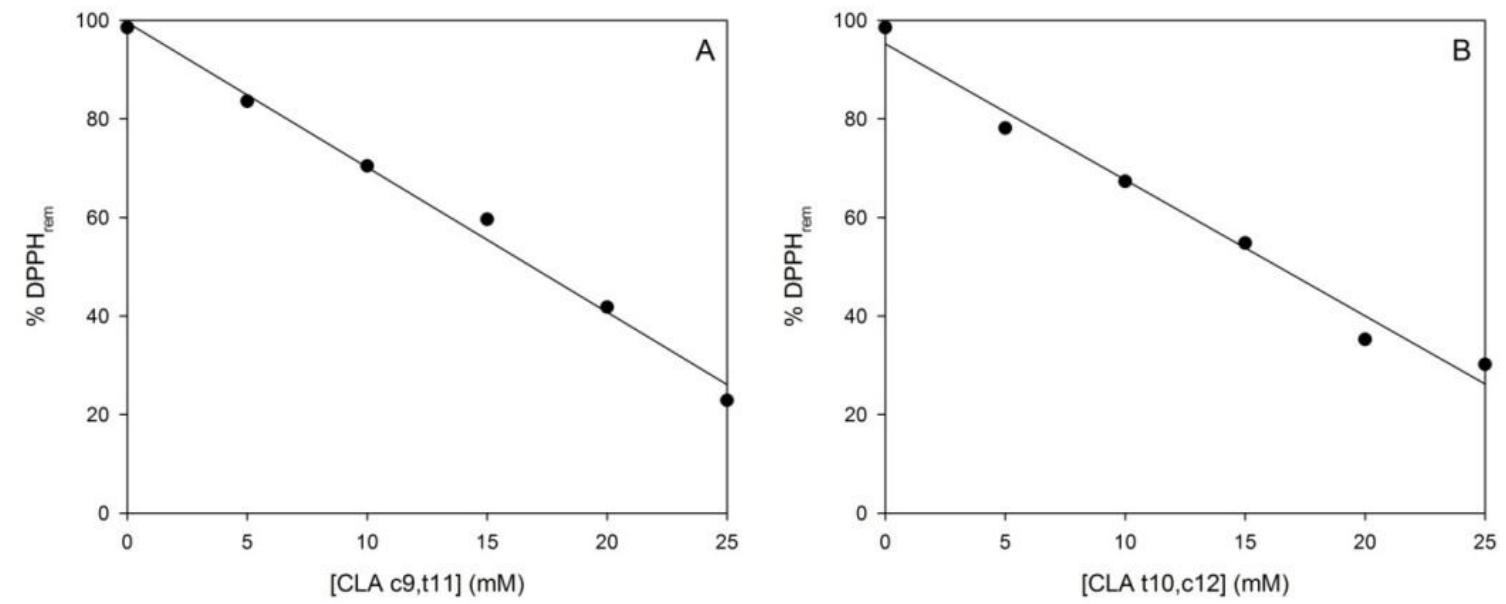

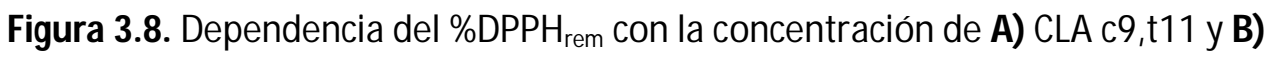
CLA t10, c12 


\subsection{Discusión}

Desde su descubrimiento como inhibidor de la carcinogénesis el ácido linoleico conjugado ha sido descripto como responsable de una gran variedad de efectos biológicos (Pariza, 2004). En realidad, el término "ácido linoleico conjugado" abarca a más de 20 isómeros estructurales. Entre ellos, los isómeros c9, t11 y t10, c12 han demostrado ser igualmente efectivos en la inhibición de la carcinogénesis (Ip y col, 1991). Sin embargo, isómeros diferentes parecen tener diferentes efectos aunque sus mecanismos bioquímicos aún necesitan ser estudiados. Por esta razón en este capítulo se detallan los resultados de nuestros estudios direccionados a investigar el efecto antioxidante de estos compuestos, lo que podría estar relacionado con sus efectos anticancerígenos. En este contexto se analizó la reactividad de dos de los isómeros CLA más importantes (c9, t11 y t10, c12) con radicales lipoperoxilos y con DPPH.

Nuestros resultados demuestran que CLAs fueron más susceptibles a la peroxidación que LA y M LA cuando se analizaron por quimioluminiscencia. Esta característica podría tener dos consecuencias diferentes: los CLAs podrían ser facilitadores de la fase de propagación de la peroxidación o bien, podrían retener la función radical estabilizándola en su estructura y actuando así como antioxidantes. Para definir cuál de estos mecanismos propician los CLAs estudiamos su efecto sobre un sistema de peroxidación de triglicéridos ricos en PUFAs. Los resultados indican que los CLAs lograron inhibir la reacción de peroxidación de los triglicéridos con una efectividad dependiente de la concentración mientras que LA y M LA no tuvieron esta capacidad. Por lo tanto, la diferencia estructural que distingue a los CLAs del LA determina una diferencia funcional que les da carácter antioxidante. No obstante, debemos considerar que las concentraciones de CLAs que resultaron efectivas fueron muy elevadas ( $\geq 100 \mathrm{mM}$ ). Existe evidencia que demuestra que CLAs, con sus dos dobles enlaces conjugados, serían más vulnerables a la autooxidación que el ácido linolénico, con tres dobles enlaces separados por puentes metileno. Esto se debe a que CLAs pueden donar un electrón o un hidrógeno eficientemente para formar un intermediario radical estabilizado por resonancia (Zhang y Chen, 1997). Tvrzicka y colaboradores (2011) atribuyeron el efecto antioxidante de CLAs a una mayor facilidad para formar estructuras furano.

La mayor reactividad de CLAs frente a radicales comparada con la de LA y M LA también se observó en el ensayo de DPPH donde también se hizo evidente el elevado valor de $\mathrm{EC}_{50}$ obtenido para CLAs. Fue necesaria una concentración $\approx 16 \mathrm{mM}$ de CLAs para poder decolorar una solución $\approx 30 \mu \mathrm{M}$ de DPPH. Es decir, fue necesaria una concentración de CLAs tres órdenes de magnitud mayor que la de DPPH. Debido a que las concentraciones efectivas de CLAs 
fueron muy elevadas creemos que estudios adicionales son necesarios para determinar la actividad secuestradora de radicales de estos compuestos en sistemas que simulen condiciones fisológicas y buscar una correlación entre su actividad antioxidante y sus ya asignados efectos biológicos. 


\section{C apitulo 4}

Estudio de la susceptibilidad a la peroxidación de liposomas de lípidos de retina. Efecto de sonicación, medio e iniciador de reacción. 


\subsection{Introducción}

Diversos aspectos de la morfología, fisiología y bioquímica de la retina han sido ampliamente estudiados, aunque en el área de bioquímica y metabolismo de los lípidos aún quedan interrogantes por responder. Los lípidos son constituyentes cuantitativamente muy importantes de la retina y su metabolismo es fundamental en la fisiología de la misma, especialmente en las células fotorreceptoras.

Organización celular de retina de vertebrados. La retina de vertebrados es un tejido delgado (0.1 a $0.3 \mathrm{~mm}$ de espesor) ubicado en la parte posterior interna del ojo (Figura 4.1). Es una extensión periférica del sistema nervioso central. Su organización celular consta de 6 tipos celulares neuronales: células fotorreceptoras (bastones y conos), células bipolares, células horizontales, células amacrinas, células interplexiformes y células ganglionares (Figura 4.2). Las células neuronales se encuentran rodeadas por células gliales conocidas como células de Muller. Funcionalmente, la retina está dividida en dos capas: la externa (sensorial), que contiene las células fotorreceptoras, y la interna (neural), que contiene el resto de células retinianas. Histológicamente, la retina se divide en 10 capas que incluyen los núcleos de las diferentes células y las conexiones sinápticas entre ellas (Fliesler y Anderson, 1983).

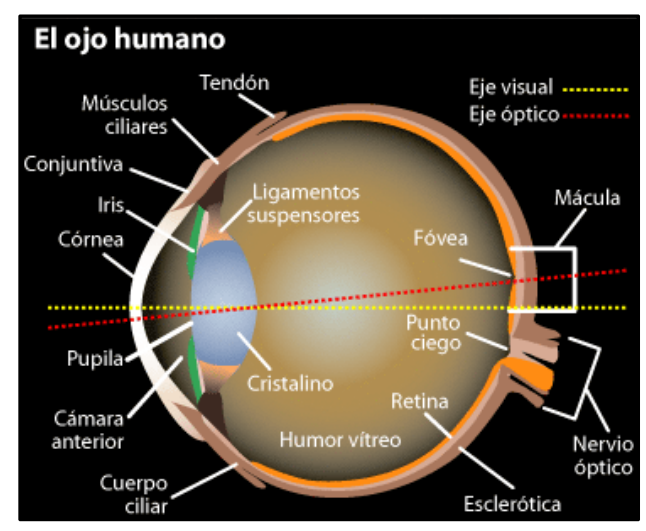

Figura 4.1. Esquema de corte del ojo (Tomada de www.gusgsm.com)

Irrigación sanguínea retiniana. La irrigación está determinada por dos sistemas circulatorios independientes: 1) el sistema coroidal (ubicado entre la esclerótica y células pigmentarias) conformado por una red de capilares fenestrados que nutren las capas retinianas más externas. El epitelio pigmentario de la retina (EPR) y la membrana de Bruch forman la barrera hemato-retiniana externa. La barrera hemato-retiniana interna está constituida 
principalmente por las células endoteliales. La presencia de uniones estrechas entre las células del EPR y del endotelio vascular es esencial para el control estricto del transporte de líquidos y solutos a través de la barrera hemato-retiniana, así como para prevenir la entrada de moléculas tóxicas y componentes del plasma en la retina (Strauss, 2005). El segundo sistema circulatorio proviene de la arteria retiniana y provee de nutrientes a todos los componentes de la retina neural. Los capilares que nutren la retina interna no son fenestrados y el intercambio pasivo de material se restringe a moléculas pequeñas, iones y gases (Fliesler y Anderson, 1983).

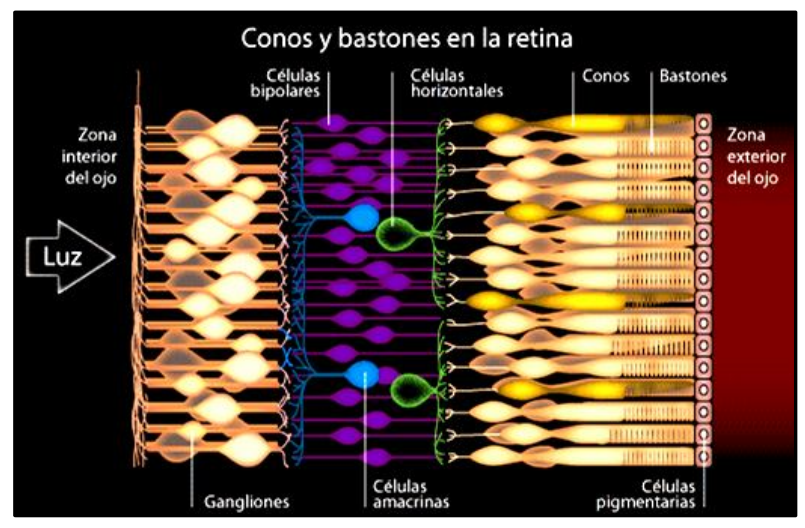

Figura 4.2. Esquema de corte de retina (Tomada de www.gusgsm.com)

Composición lipídica de retina. La retina posee la concentración de lípidos y fosfolípidos más alta que la de cualquier otro tejido ocular. Los lípidos constituyen el $20 \%$ de su peso seco, de los cuales, las 2/3 partes son fosfolípidos. En general, la relación entre lípidos no polares y fosfolípidos en este tejido se encuentra en el rango entre 0,3 y 0,5. Fosfatidilcolina (40-50 \%) y fosfatidiletanolamina (30-35\%) constituyen los principales fosfolípidos, encontrándose en menor proporción fosfatidilserina (5-10\%), fosfatidilinositol (3-6 \%) y esfingomielina (2-8 \%). Ácido fosfatídico y cardiolipina se encuentran en muy baja proporción (Fliesler y Anderson, 1983). El 50\% de los ácidos grasos de la retina son no saturados. Un $25 \%$ de sus ácidos grasos lo constituye el ácido docosahexenoico (DHA, 22:6 n-3), un ácido graso de 22 carbonos y 6 dobles enlaces.

Importancia de los lípidos en la función retiniana normal. Estudios comparativos de una amplia variedad de membranas biológicas con respecto a su composición molecular y actividad biológica sugirieron que elevado contenido de fosfolípidos y PUFAs y bajo contenido en colesterol son características de membranas "metabólicamente activas", tales como 
membrana mitocondrial y de cloroplastos, en contraste con las "metabólicamente inactivas", como mielina de los nervios (Fleischer y Rouser, 1965; O'Brien, 1967). Basándonos en este sistema de clasificación y la composición lipídica previamente descripta, es razonable pensar en la retina como un tejido rico en membranas "metabólicamente activas". Esta composición lipídica particular determina una gran fluidez de las membranas imprescindible para llevar a cabo las funciones normales de la retina. La función principal de la retina es absorber fotones de luz e iniciar la excitación visual. La absorción de fotones ocurre en los segmentos externos de las células fotorreceptoras iniciándose una reacción de isomerización cis-trans de 11-cisretinaldehído que se encuentra covalentemente unido a la porción proteica del pigmento visual (rodopsina). La composición lipídica de la membrana afecta también la movilidad lateral y rotacional de rodopsina (cambios conformacionales producidos por efecto de la luz), al igual que su orientación dentro de la membrana, regeneración, propiedades espectroscópicas y estabilidad térmica (Fliesler y Anderson, 1983).

Papel de la peroxidación lipídica en las patologías retinianas. Existe abundante evidencia que señala que la peroxidación lipídica daña las membranas fotorreceptoras retinianas. Claramente, las membranas presentes en la retina son sustratos ideales para las reacciones de peroxidación. Los fosfolípidos que forman parte de estas membranas contienen la concentración de PUFAs más elevada comparada con cualquier otro sistema de membranas estudiado. Su principal PUFA, el DHA, es especialmente susceptible a la peroxidación lipídica. Además, la retina posee el mayor consumo de oxígeno por peso que cualquier otro tejido y mantiene una tensión de oxígeno elevada, lo que puede resultar tóxico para este tejido (Stone y col, 1979; Winkler y col, 1999).

Existen datos que indican que la peroxidación lipídica produce alteraciones morfológicas de la retina. Los daños observados son típicamente: núcleos picnóticos, disrupción de la morfología de membranas con formación de vesículas, degeneración macular, aumento de gránulos de lipofucsina en epitelio pigmentado, entre otros (Fliesler y Anderson, 1983). Se ha comprobado que los niveles de peróxidos lipídicos en la retina están elevados en condiciones patológicas que involucran a radicales libres, mientras que el contenido de DHA decae significativamente. Además, biomoléculas tales como proteínas o aminolípidos, pueden ser modificados covalentemente por productos de descomposición lipídica (Catalá, 2009). Estas alteraciones morfológicas pueden encontrarse en patologías retinianas tales como: glaucoma, cataratas, retinopatía diabética, inflamación ocular, degeneración retiniana, etc (Nau-Staudt y col, 2001; Ueda y col, 1996). 
El elevado contenido de fosfolípidos de la retina hace posible la preparación de liposomas a partir de sus lípidos. Los fosfolípidos son moléculas anfipáticas, es decir, contienen una región polar (o cabeza del fosfolípido) constituida por el fosfato cargado y las sustituciones del mismo, y una cola no polar constituida por cadenas hidrocarbonadas hidrofóbicas. Los ácidos grasos esterifican al glicerol en las posiciones sn-1 y sn-2 y el grupo fosfato en la posición sn-3. Por lo general, el C-1 del glicerol se encuentra esterificado por un ácido graso saturado y el C-2 por un ácido graso no saturado (Berg y col, 2002). Los fosfolípidos en medios acuosos tienden a minimizar el contacto con el agua de las cadenas hidrocarbonadas, de naturaleza lipofílica formando estructuras que exponen las regiones polares al medio acuoso manteniendo aisladas las regiones no polares. De esta manera es posible obtener membranas liposomales. Esta habilidad espontánea del sistema para evolucionar desde un estado desordenado a estructuras definidas y ordenadas, responde a la necesidad de disminuir la función G (energía libre de Gibbs; Larsson, 1994).

Estudios de peroxidación sobre membranas modelo, tales como liposomas de lípidos de retina, son útiles para avanzar en el conocimiento sobre aspectos que no pueden ser estudiados directamente en membranas biológicas. Para estudiar el proceso de peroxidación lipídica en la retina, evitando la complejidad de este sistema biológico, se analizó el proceso sobre liposomas preparados con lípidos aislados de retina bovina.

En el presente capítulo el objetivo fue:

$\checkmark \quad$ Determinar el efecto del medio de reacción y del iniciador sobre la peroxidación lipídica de diferentes tipos de liposomas preparados con lípidos de retina bovina

La peroxidación de liposomas sonicados (LS) y sin sonicar (LNS) fue iniciada con $\mathrm{Fe}^{2+} \mathrm{y}$ $\mathrm{Fe}^{3+}$. Los medios de reacción empleados fueron agua, solución fisiológica $(\mathrm{NaCl} 0,15 \mathrm{M})$ y buffer Tris $(20 \mathrm{mM}$, pH 7,4). Para seguimiento de la reacción se determinó el aumento de absorbancia a $234 \mathrm{~nm}$ (dienos conjugados) y la producción de sustancias reactivas al TBA (ver Anexo). 


\subsection{Materiales y métodos}

\subsubsection{Materiales}

El proceso de peroxidación se estudió en diferentes tipos de liposomas preparados a partir de lípidos de retinas bovinas. Para ello, se obtuvieron ojos bovinos donados por Frigorífico Gorina (La Plata, Buenos Aires). Para la extracción de lípidos se utilizaron solventes de calidad cromatográfica: cloroformo (U.V.E.), metanol (Mallinckrodt). Los iniciadores de reacción fueron reactivos de alta pureza: $\mathrm{FeSO}_{4}$ (Fluka) y $\mathrm{FeCl}_{3}$ (Anhedra). Los demás reactivos utilizados fueron también de alta calidad: $\mathrm{NaCl}$ (Cicarelli), TBA (Fluka), Trizma base (Sigma), BHT (Sigma).

Para la obtención de retinas y, posteriormente, de lípidos se empleó un homogeneizador Ultraturrax X25. Para producir liposomas sonicados se empleó un sonicador Sonics vibra cell, M odelo VCX 750 (750 W, 20kHz). En la determinación de dienos conjugados y TBARS se utilizó un espectrofotómetro Shimadzu UV-1800.

\subsubsection{Métodos y técnicas}

\subsubsection{Obtención de homogeneizados de retina bovina}

Los ojos fueron enucleados en el frigorífico (Frigorífico Gorina) y transportados al laboratorio donde se obtuvieron las retinas. Con todos los tubos y soluciones en baño de hielo, se removieron las córneas, lentes y humor vítreo bajo luz roja. La copa del ojo fue invertida y con chorros de solución fisiológica se desprendió la retina dejándola caer cuidadosamente en un vaso de precipitados. Aproximadamente cuarenta retinas se homogeneizaron en solución de $\mathrm{NaCl}$ 0,15 M ( $1 \mathrm{ml} /$ retina) durante $120 \mathrm{seg}$ (en ciclos alternados de $20 \mathrm{seg}$ ) en baño de hielo con un homogeneizador Ultraturrax X25 a 7000 rpm (Guajardo y col, 2002).

\subsubsection{Extracción de lípidos}

Los lípidos totales de los homogeneizados de retina se extrajeron con cloroformo: metanol (2:1, v/v) (Folch y col, 1957), en una relación de una parte de muestra a 5 partes de mezcla extractiva. A la mezcla se agregó un 20 \% de su volumen de agua destilada, se agitó y se dejó decantar a baja temperatura para permitir la separación de dos fases: una superior metanólica acuosa y una inferior clorofórmica. La fase superior fue desechada y la inferior almacenada a $-22^{\circ} \mathrm{C}$ 


\subsubsection{Preparación de liposomas}

La fase clorofórmica conteniendo lípidos totales de retina se evaporó en baño de agua a $50{ }^{\circ} \mathrm{C}$ bajo corriente de nitrógeno hasta sequedad y se sometió a vacío para eliminar trazas de cloroformo. El film formado por los lípidos secos fue resuspendido en solución fisiológica ( $\mathrm{NaCl} 0,15 \mathrm{M}$ ) y agitado con ayuda de un vórtex para obtener $\mathrm{LNS}\left(\mathrm{C}_{\mathrm{f}}=2 \mathrm{mg}\right.$ lípido/ml). LS se prepararon en baño de hielo empleando un sonicador de punta. La sonicación se realizó al 75\% de la frecuencia máxima, hasta que la suspensión alcanzó la mínima densidad óptica (Gal y col, 2003).

\subsubsection{Determinación de tamaño de liposomas por dispersión dinámica de luz (Dinamic light Scattering, DLS)}

Para determinar el tamaño de los liposomas se midió la función de correlación $\mathrm{G}(\mathrm{q}, \mathrm{t})$ de la intensidad de luz dispersa a $90^{\circ}$ con un fotogoniómetro (ALV/CGS-5022F) acoplado a un correlador digital de tiempo múltiple (o múltiple $\tau$ ) (ALV-5000/EPP), que cubre un rango de tiempo de $10^{-6}-10^{-3}$ segundos. La fuente de luz empleada fue un láser de helio-neón con una longitud de onda de $633 \mathrm{~nm}$ operando a $22 \mathrm{~mW}$. Cada función de correlación fue analizada con el ajuste por cumulantes que brinda un coeficiente de difusión medio aparente (D) y la dispersión (סD) de este valor (Koppel, 1972).

$\mathrm{G}(q, \mathrm{t})$ corresponde al módulo de "vector de dispersión", esto es, el módulo de la diferencia entre el momento lineal de la luz dispersada (vector k') y el momento lineal de la luz incidente (vector k). El vector k' forma un ángulo $\Theta$ (ángulo de dispersión) con respecto al vector k. $\tau$ corresponde al tiempo de retardo. CONTIN es un software desarrollado por Provencher para resolver el llamado "problema inverso de dispersión". Normalmente, cada partícula (en este caso liposoma) dispersa la luz según su tamaño, su índice de refracción con respecto al solvente, etc. El problema inverso consiste en extraer información del coeficiente de difusión traslacional a partir de medidas experimentales de luz dispersada. El radio hidrodinámico se obtiene a partir del coeficiente de difusión por la fórmula de Stokes-Einstein. Los radios hidrodinámicos promedio se analizaron mediante la transformada inversa de Laplace (con software CONTIN).

Las mediciones se realizaron a $25^{\circ} \mathrm{C}$ empleando $80 \mu \mathrm{l}$ de LS y LNS ( $2 \mathrm{mg} / \mathrm{ml}$ lípidos) en agua, solución fisiológica y buffer Tris- $\mathrm{HCl} 20 \mathrm{mM}\left(\mathrm{V}_{\mathrm{f}}=2 \mathrm{ml}\right)$. La $\mathrm{C}_{\mathrm{f}}$ de lípidos es $\approx 0,1 \mathrm{mM}$, considerando un PM promedio de fosfolípidos $\approx 800 \mathrm{~g} / \mathrm{mol}$. 


\subsubsection{Determinación espectrofotométrica de dienos y trienos conjugados}

Liposomas de lípidos de retina sonicados y no sonicados $\left(C_{f} \approx 0,1 \mathrm{mM}\right.$ de lípidos) fueron incubados durante 180 min a temperatura ambiente en cubetas de cuarzo de $1 \mathrm{~cm} \times 1 \mathrm{~cm}$. La reacción de peroxidación fue iniciada por $\mathrm{Fe}^{2+}$ o $\mathrm{Fe}^{3+}\left(\mathrm{C}_{\mathrm{f}}=25 \mu \mathrm{M}\right)$ llevando a volumen final (2 ml) con agua, solución fisiológica ( $\mathrm{NaCl}$ 0,15 M) o buffer Tris-HCl 20 mM pH 7,4.

Para analizar la producción de dienos y trienos conjugados durante la peroxidación de liposomas, se registraron los espectros de absorción cada un minuto, entre 200 y 300 nm con un espectrofotómetro Shimadzu UV 1800. El aumento de absorción a 234 nm (debido a formación de dienos conjugados) y a $270 \mathrm{~nm}$ (trienos conjugados) se graficó en función del tiempo durante 180 min. La velocidad inicial de reacción se determinó como la pendiente de la recta con la que se ajustó el rango lineal de la curva $\Delta$ Abs en función del tiempo. El tiempo de retardo (fase lag) se define como el tiempo transcurrido hasta el inicio de la fase lineal de la curva $\triangle$ Abs en función del tiempo (Sargis y Subbaiah, 2003).

\subsubsection{Determinación de sustancias reactivas al ácido tiobarbitúrico (TBARS)}

Alícuotas de $150 \mu \mathrm{l}$ de mezcla de reacción (preparadas de la misma manera que en el ítem 4.2.2.5) fueron tomadas a distintos tiempos (0, 15, 30, 60, 120 y $180 \mathrm{~min}$ ) mezclándose con $10 \mu \mathrm{l}$ de BHT (0,1\% p/v en etanol) para evitar peroxidación adicional durante la incubación. Se agregaron $850 \mu$ l de TBA $(0,37 \% \mathrm{p} / \mathrm{v}$ en $\mathrm{HCl} 0,25 \mathrm{~N})$ y las muestras se incubaron durante 30 minutos a $75{ }^{\circ} \mathrm{C}$. Finalizado este lapso, las muestras se dejaron enfriar a temperatura ambiente, se agregó $1 \mathrm{ml}$ de agua y se determinó la absorbancia a $532 \mathrm{~nm}$. Velocidad inicial de reacción y tiempo de retardo en el inicio de la reacción fueron calculados de la misma manera que para dienos y trienos conjugados. 


\subsection{Resultados}

Determinación de tamaño de liposomas por dispersión dinámica de luz (Dinamic Light Scattering, DLS)

Los radios hidrodinámicos promedio de los liposomas determinados por análisis DLS se presentan en la tabla 4.1. Los datos obtenidos por dispersión dinámica de luz se traducen a valores de radios hidrodinámicos mediante el método de cumulantes. Para distribuciones de tamaño que no son muy anchas ( $\mathrm{PI}<0.30$ ) el método de cumulantes provee valores medios apropiados del radio hidrodinámico. Sólo las muestras sonicadas fueron analizadas con este método. Se seleccionaron hasta tres muestras representativas y se promediaron (resultados expresados en la tabla 4.1 como valores puntuales). LNS mostraron una distribución multimodal de tamaño cuando se analizaron mediante transformada inversa de Laplace (CONTIN), un resultado que es compatible con el alto valor del índice de polidispersidad del ajuste por cumulantes (PI >0.4). Por esta razón los valores se expresaron como un rango y no como un valor puntual.

Los radios hidrodinámicos para LNS en diferentes medios acuosos, cubrieron un rango amplio presentando una distribución de tamaños con máximos centrados entre 190 y $320 \mathrm{~nm}$. Por otra parte, los resultados para LS dan, a partir del método de cumulantes, radios hidrodinámicos del orden de 76,4 a 83,3 nm, mostrando, como era de esperar, una influencia significativa del sonicado sobre el tamaño de los mismos. Es claro que los LNS poseen radios hidrodinámicos mayores que los sonicados.

Tabla 4.1. Radios hidrodinámicos de liposomas sonicados y no sonicados en los

diferentes medios acuosos obtenidos por dispersión dinámica de luz.

\begin{tabular}{|c|c|c|c|}
\hline Liposomas & Medio acuoso & $\begin{array}{l}\text { Radio hidrodinámico } \\
\text { [nm] }\end{array}$ & $\begin{array}{l}\text { Índice de polidispersidad } \\
\text { (PI) }\end{array}$ \\
\hline \multirow{3}{*}{ Sonicados } & Agua & 76,4 & 0,31 \\
\hline & $\mathrm{NaCl}$ & 83,3 & 0,27 \\
\hline & Tris-HCl & 83,3 & 0,27 \\
\hline \multirow{3}{*}{$\begin{array}{l}\text { No } \\
\text { sonicados }\end{array}$} & Agua & $190-225$ & 0,44 \\
\hline & $\mathrm{NaCl}$ & $260-320$ & 0,45 \\
\hline & Tris-HCl & $200-240$ & 0,43 \\
\hline
\end{tabular}

Peroxidación de liposomas sonicados y no sonicados de lípidos de retina en diferentes medios acuosos empleando $\mathrm{Fe}^{2+}$ como iniciador de reacción. 

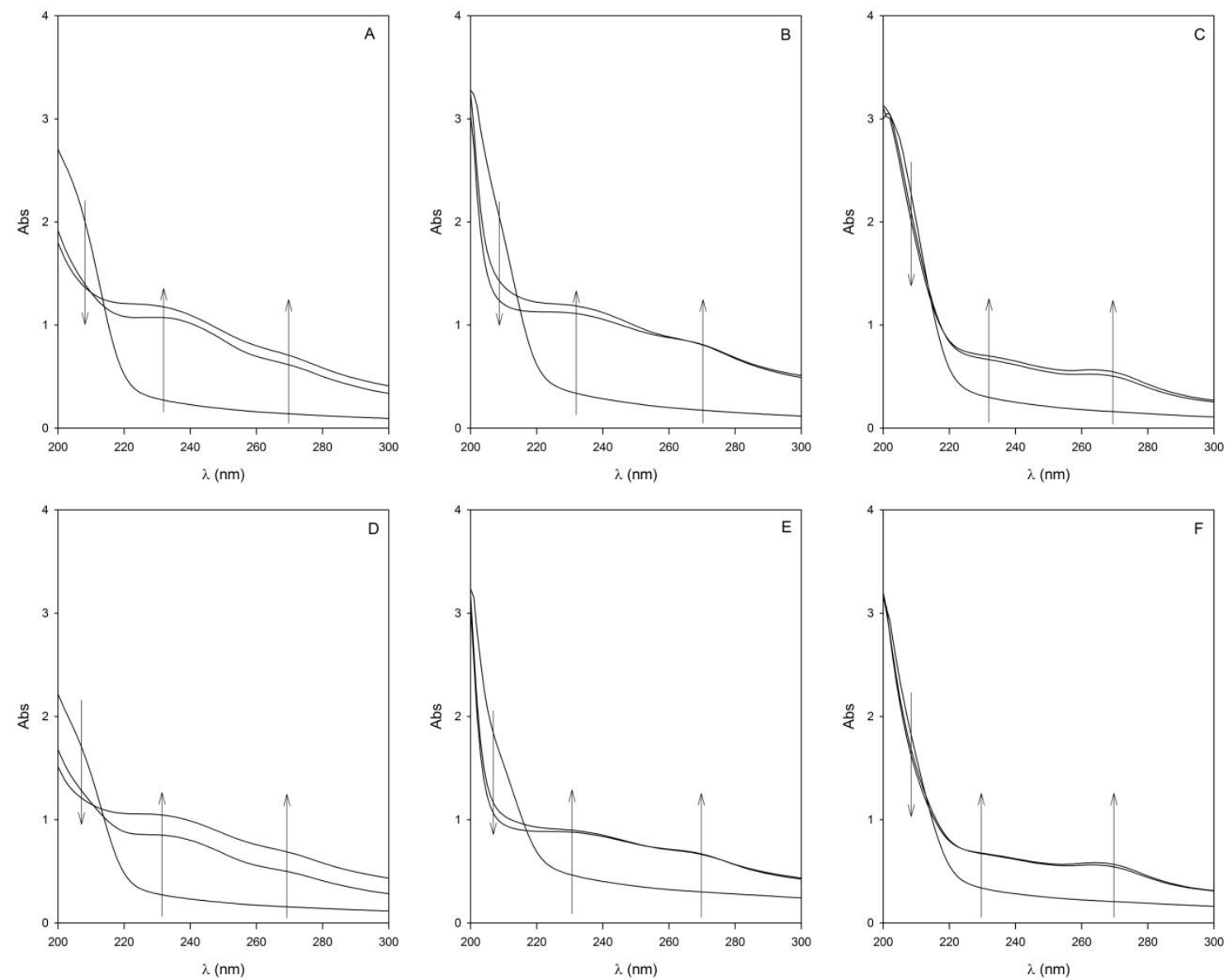

Figura 4.3. Evolución temporal (0,90 y $180 \mathrm{~min})$ de los espectros de absorción de liposomas peroxidados con $\mathrm{Fe}^{2+}$ como iniciador de la reacción. Liposomas sonicados en A) agua, B) solución fisiológica, C) buffer Tris. Liposomas no sonicados en D) agua, E) solución fisiológica, F) buffer Tris

La figura 4.3 muestra los cambios en los espectros de absorbancia de liposomas peroxidados con $\mathrm{Fe}^{2+}$ en los diferentes medios acuosos. LS y LNS presentaron tanto en agua como en solución fisiológica una disminución de la absorbancia entre 200 y 215 nm notoria. La disminución de absorbancia en este rango corresponde a la pérdida del enlace metilénico entre los dobles enlaces (lípidos no peroxidados) debido a la formación de dienos conjugados. Esta disminución fue mucho menor cuando la reacción se lleva a cabo en buffer Tris-HCl. Entre 230 - $240 \mathrm{~nm}$ y 260 - $280 \mathrm{~nm}$ se observaron aumentos de absorbancia en forma de "hombros" que son mayores en agua y solución fisiológica que en buffer. 

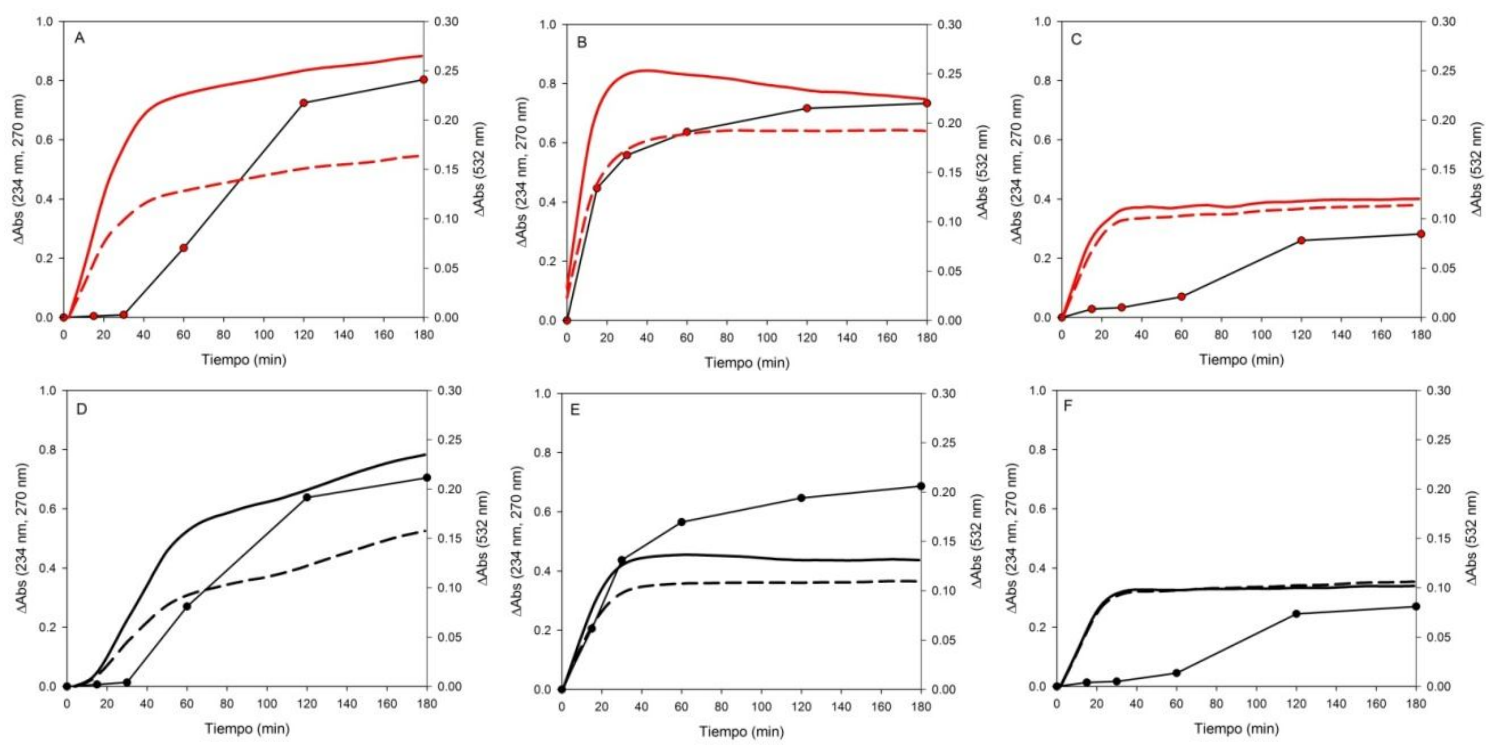

Figura 4.4. Producción de TBARS (puntos), dienos conjugados (línea continua) y trienos conjugados (línea discontinua) en función del tiempo de reacción con $\mathrm{Fe}^{2+}$ como iniciador. Liposomas sonicados en A) agua, B) solución fisiológica, C) buffer Tris. Liposomas no sonicados en D) agua, E) solución fisiológica, F) buffer Tris

La figura 4.4 representa la variación de absorbancia en función del tiempo de reacción a $234 \mathrm{~nm}$ (debida a formación de dienos conjugados) y a $270 \mathrm{~nm}$ (generada por trienos conjugados) durante la peroxidación iniciada por $\mathrm{Fe}^{2+}$. En los mismos gráficos se incluye la formación de TBARS.

En la peroxidación de LS en agua (figura 4.4 A) se observó un tiempo de retardo de 30 minutos en la formación de TBARS y un valor máximo de absorbancia a $532 \mathrm{~nm}$ de 0,24 DO. La formación de dienos conjugados mostró un tiempo de retardo de 7 minutos, una fase inicial rápida $\left(\mathrm{V}_{0}=2,07 \mathrm{DO} / \mathrm{h}\right)$ hasta los 40 min de reacción, a partir de los cuales la velocidad disminuyó, se mantuvo constante y positiva hasta el fin del tiempo de reacción (ver datos cinéticos en Tabla 4.2). La formación de trienos conjugados mostró la misma tendencia que dienos conjugados aunque su producción fue menor.

LS peroxidados en solución fisiológica (Figura 4.4.B) generaron una producción inmediata de TBARS (tiempo de retardo=0 $\mathrm{min}$ ) y alcanzaron un valor máximo de absorbancia de 0,23 DO, valor similar al obtenido cuando la reacción se llevó a cabo en agua. La velocidad inicial de reacción $\left(\mathrm{V}_{0}=4,8 \mathrm{DO} / \mathrm{h}\right)$ según la formación de dienos conjugados, duplicó a la obtenida en agua. A partir de los 30 min de reacción la absorbancia a $234 \mathrm{~nm}$ disminuyó en forma constante. La absorbancia a $270 \mathrm{~nm}$ también aumentó con una velocidad inicial superior 
a la observada en agua y se hace máxima alrededor de los 30 min. A partir de allí se mantuvo constante.

La presencia de buffer Tris-HCl (Figura 4.4.C) como medio de reacción determinó el mayor tiempo de retardo en la aparición de TBARS (60 min) y el menor valor máximo de $A_{b S_{532}}$ alcanzado (0,09 DO). La velocidad de formación de dienos conjugados fue la mínima $\left(\mathrm{V}_{0}=1,20\right.$ DO/h) comparada con las obtenidas en agua y solución fisiológica. La absorbancia a $234 \mathrm{~nm}$ alcanzó su valor máximo a los 30 minutos y a partir de allí se mantuvo constante. Los valores de absorbancia a $234 \mathrm{~nm}$ fueron similares a los obtenidos a $270 \mathrm{~nm}$.

La peroxidación de LNS en agua (Figura 4.4.D) mostró un tiempo de retardo para la producción de TBARS de 30 minutos y un valor de Abs máx a $532 \mathrm{~nm}$ de 0,21 DO. La formación de dienos conjugados mostró un tiempo de retardo de 16 min y una velocidad inicial de 0,7 DO/h que se mantuvo hasta los 60 min. A partir de entonces la velocidad disminuyó y se mantuvo constante y positiva. Trienos conjugados mostraron la misma tendencia que dienos pero su producción fue inferior.

Los LNS en solución fisiológica (Figura 4.4.E) produjeron TBARS sin tiempo de retardo y alcanzaron un valor final de $\mathrm{AbS}_{532}$ similar al obtenido en agua (0,21 DO). La formación de dienos conjugados presentó menor tiempo de retardo ( $2 \mathrm{~min}$ ) que en agua. La velocidad inicial de formación de dienos conjugados (1,35 DO/h) fue superior a la observada en agua. Esta velocidad se mantuvo hasta los 30 min y a partir de allí la absorbancia no varió en el tiempo. El valor final de $\mathrm{Abs}_{234}(0,44 \mathrm{DO})$ fue inferior al observado en agua.

LNS en buffer Tris-HCl (Figura 4.4.F) mostraron el mayor retardo en la producción de TBARS y el menor valor final de $\operatorname{AbS}_{532}$ (0,08 DO) comparando estos resultados con los obtenidos en agua y solución fisiológica. Si bien el inicio de la producción de dienos conjugados fue inmediato y la velocidad de formación fue superior a la del agua, el valor de $\mathrm{Abs}_{234}$ fue el menor de los tres medios de reacción.

Teniendo en cuenta el efecto de la sonicación deducimos que los liposomas sonicados fueron más susceptibles a la peroxidación iniciada por $\mathrm{Fe}^{2+}$ que los liposomas no sonicados. Esto se observó sobre todo en solución fisiológica y en agua, mientras que en buffer Tris- $\mathrm{HCl}$ no se observaron diferencias significativas en cuanto a la susceptibilidad de los diferentes liposomas. Solución fisiológica resultó ser el medio en que la peroxidación lipídica fue más eficiente. En este orden le siguió el agua y en último lugar buffer Tris- $\mathrm{HCl}$. 
Peroxidación de liposomas sonicados y no sonicados de lípidos de retina en diferentes medios acuosos empleando $\mathrm{Fe}^{3+}$ como iniciador de reacción.
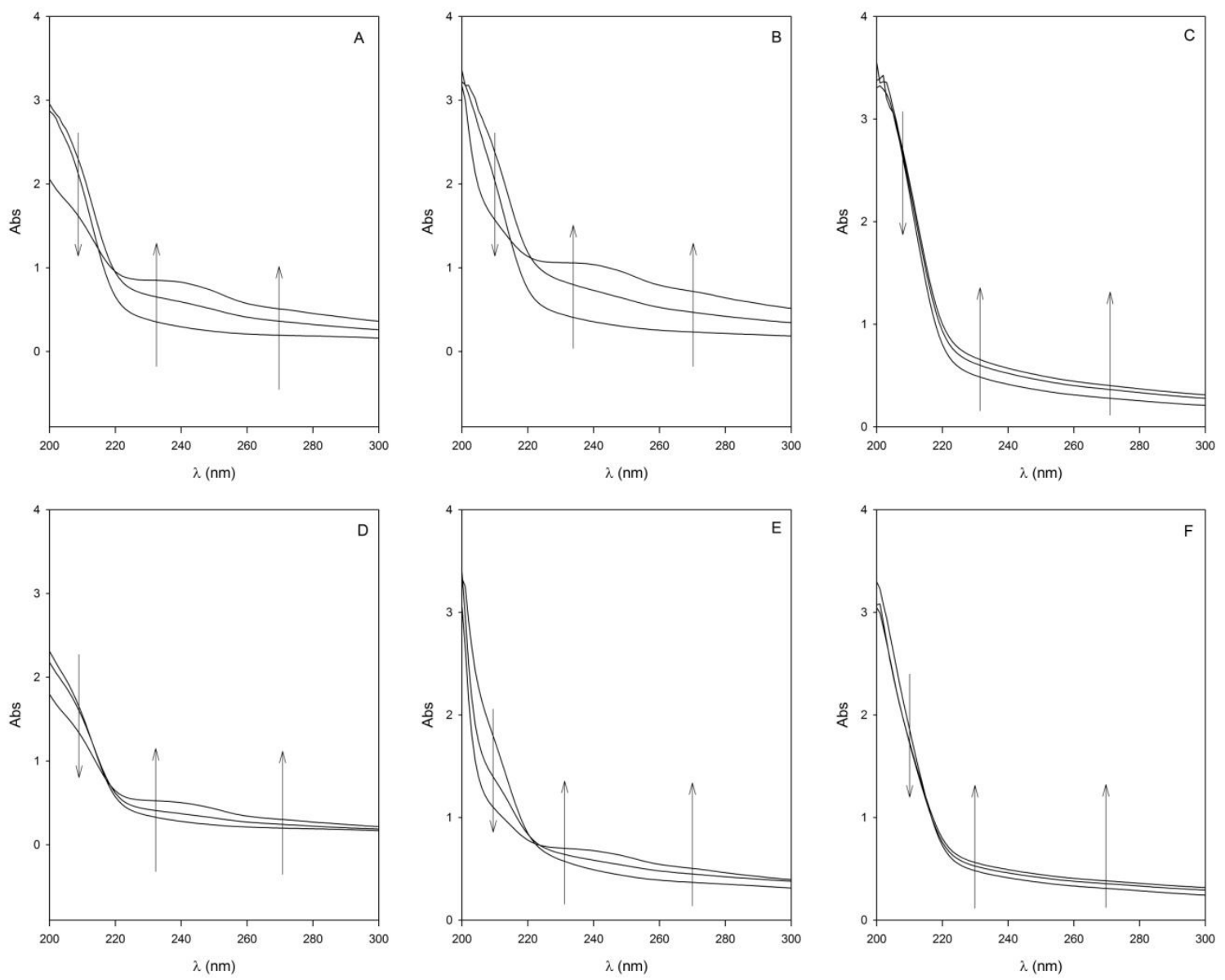

Figura 4.5. Evolución temporal (0,90 y $180 \mathrm{~min})$ de los espectros de absorción de liposomas peroxidados con $\mathrm{Fe}^{3+}$ como iniciador de la reacción. Liposomas sonicados en A) agua, B) solución fisiológica, C) buffer Tris. Liposomas no sonicados en D) agua, E) solución fisiológica, F) buffer Tris

La figura 4.5 muestra los cambios producidos en los espectros de absorbancia de liposomas peroxidados con $\mathrm{Fe}^{3+}$ en los diferentes medios acuosos. Al igual que con $\mathrm{Fe}^{2+}, \mathrm{LS}$ y LNS presentaron tanto en agua como en solución fisiológica una disminución notoria de la absorbancia entre 200 y 215 nm. Esta disminución no resultó tan evidente en buffer Tris-HCl. Entre $230-240 \mathrm{~nm}$ y $260-280 \mathrm{~nm}$ se observaron aumentos de absorbancia en forma de "hombros" que fueron mayores en agua y solución fisiológica que en buffer. 

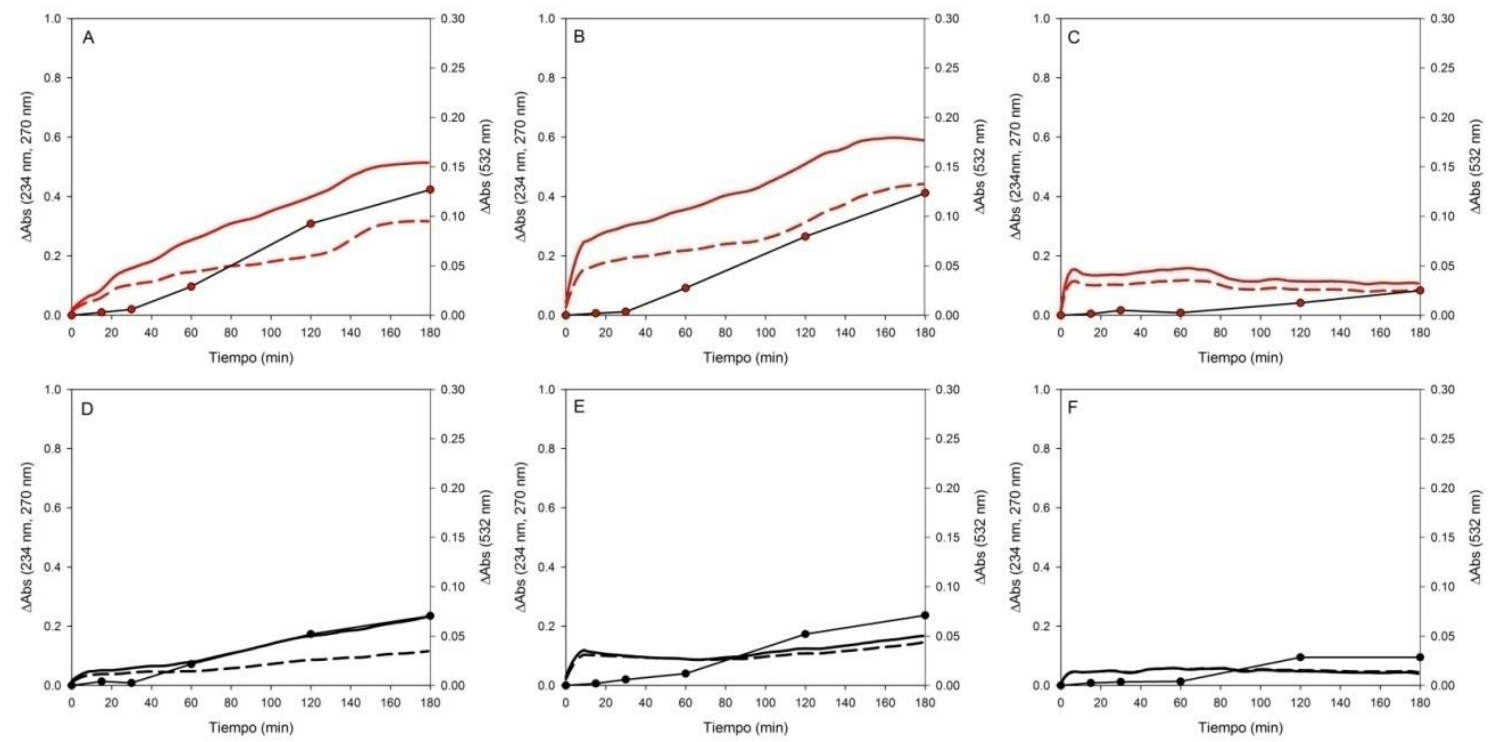

Figura 4.6. Producción de TBARS (puntos), dienos conjugados (línea continua) y trienos conjugados (línea discontinua) en función del tiempo de reacción con $\mathrm{Fe}^{3+}$ como iniciador. Liposomas sonicados en A) agua, B) solución fisiológica, C) buffer Tris. Liposomas no sonicados en D) agua, E) solución fisiológica, F) buffer Tris

En la figura 4.6 se observan la producción de TBARS junto a la de dienos y trienos conjugados en función del tiempo, empleando $\mathrm{Fe}^{3+}$ como iniciador de reacción. Comparando las figuras 4.6 A-C (liposomas sonicados) se observa que el mayor tiempo de retardo para la producción de TBARS se dio en buffer, siendo de $60 \mathrm{~min}$, mientras que en agua y solución fisiológica fue de $30 \mathrm{~min}$. El valor máximo alcanzado de Abs $_{532}$ fue 0,13 y 0,12 en agua y solución fisiológica, respectivamente, mientras que en buffer fue 0,03. Aunque la mayor velocidad de formación de dienos conjugados se observó en buffer, la reacción en forma global estuvo fuertemente inhibida como se observa según el valor máximo alcanzado de $\mathrm{Abs}_{234}=$ 0,11. En agua y solución fisiológica estos valores fueron 0,51 y 0,59 respectivamente.

Las figuras 4.6 D-F muestran las mismas tendencias observadas en LS aunque los LNS presentan mucho menor producción de dienos conjugados y TBARS.

Si comparamos los iniciadores de reacción, $\mathrm{Fe}^{2+}$ fue un iniciador de peroxidación mucho más eficiente que $\mathrm{Fe}^{3+}$ cualquiera sea el medio acuoso de reacción o el tipo de liposoma empleado. 
Tabla 4.2. Datos cinéticos de la peroxidación lipídica de liposomas de lípidos de retina sonicados y no sonicados, empleando $\mathrm{Fe}^{2+}$ y $\mathrm{Fe}^{3+}$ como iniciadores de reacción.

\begin{tabular}{|c|c|c|c|c|c|c|c|c|c|c|c|c|c|}
\hline & & \multicolumn{6}{|c|}{ LPOSOMAS SONICADOS } & \multicolumn{6}{|c|}{ LPOSOMAS NO SONICADOS } \\
\hline & & \multicolumn{3}{|c|}{ TBARS } & \multicolumn{3}{|c|}{ DIENOS CONJUGADOS } & \multicolumn{3}{|c|}{ TBARS } & \multicolumn{3}{|c|}{ DIENOS CONJUGADOS } \\
\hline & & Agua & $\mathrm{NaCl}$ & Tris & Agua & $\mathrm{NaCl}$ & Tris & Agua & $\mathrm{NaCl}$ & Tris & Agua & $\mathrm{NaCl}$ & Tris \\
\hline \multirow{3}{*}{$\mathrm{Fe}^{2+}$} & Tiempo retardo (min) & 30 & 0 & 60 & 7 & 0 & 0 & 30 & 0 & 60 & 16 & 2 & 0 \\
\hline & Velocidad. inicial (D.O./h) & 0.22 & 0.54 & 0.06 & 2.07 & 4.8 & 1.20 & 0.13 & 0.26 & 0.06 & 0.73 & 1.35 & 0.87 \\
\hline & Valor máximo (D.O.) & 0.24 & 0.22 & 0.08 & 0.88 & 0.75 & 0.40 & 0.21 & 0.21 & 0.08 & 0.78 & 0.44 & 0.34 \\
\hline \multirow{3}{*}{$\mathrm{Fe}^{3+}$} & Tiempo retardo (min) & 30 & 30 & 60 & 0 & 0 & 0 & 30 & 60 & 60 & 0 & 0 & 0 \\
\hline & Velocidad. inicial (D.O./h) & 0.06 & 0.05 & 0.01 & 0.23 & 3 & 3.75 & 0.03 & 0.04 & 0.03 & 0.27 & 0.84 & 0.55 \\
\hline & Valor máximo (D.O.) & 0.13 & 0.12 & 0.03 & 0.51 & 0.59 & 0.11 & 0.07 & 0.07 & 0.03 & 0.23 & 0.17 & 0.04 \\
\hline
\end{tabular}

Los valores informados son promedios de tres determinaciones. NaCl: solución fisiológica $\mathrm{NaCl}$ 0,15 M; Tris: buffer Tris-HCl 20 mM pH 7,4. 


\subsection{Discusión}

En el presente capítulo buscamos implementar un sistema modelo de peroxidación cuyo comportamiento se asemeje más al de una membrana biológica que simples soluciones de lípidos en cloroformo. Para ello estudiamos liposomas formados con lípidos de un tejido altamente susceptible a la peroxidación como lo es la retina. Las membranas biológicas presentes en retina son indudablemente sistemas complejos. Para evitar esta complejidad y las reacciones colaterales que se darían en retinas enteras, utilizamos un sistema modelo de membranas simplificado formado por sus lípidos dispersos en forma de liposomas. En este tipo de sistemas es posible monitorear la reacción de peroxidación modificando las condiciones en los que ésta se desarrolla. Vesículas de fosfolípidos son frecuentemente empleadas como sistemas modelo para estudiar los principios físicos del comportamiento biológico de las membranas.

El tamaño de los liposomas en los distintos medios acuosos fue estudiado por dispersión dinámica de luz (DLS), una técnica que permite determinar los radios hidrodinámicos de las partículas suspendidas. Con esta técnica también se obtuvo el índice de polidispersidad que es un parámetro que indica la distribución de los diámetros de las partículas en sistemas coloidales. Cuanto menor es su valor, la distribución de diámetros de partículas es más estrecha, por lo que las partículas muestran una mayor uniformidad de tamaño (Ruozi y col, 2005). Según los resultados obtenidos por esta técnica concluimos que, como era de esperarse, los LS fueron más pequeños que los LNS y presentaron una distribución de tamaño más uniforme. Los LNS presentaron distribuciones bi- y hasta trimodales.

En sistemas compartimentalizados tales como liposomas, es de suponer que los inductores de formación de radicales libres, como $\mathrm{Fe}^{2+}$ y Fe $\mathrm{Fe}^{3+}$ empleados en nuestro estudio, se localizan en el medio externo y deben alcanzar las cadenas de PUFAs inmersas en la bicapa lipídica para poder iniciar la reacción de lipoperoxidación. Por lo tanto, para que la reacción pueda iniciarse, los iones de metales de transición junto con el oxígeno deberían ingresar a la bicapa lipídica. Una mayor permeabilidad al agua de la bicapa puede claramente, colaborar con este proceso. Muchos estudios físicos sobre la estructura de las bicapas fosfolipídicas propusieron que el empaque de las cadenas acídicas depende en parte del radio de curvatura de las vesículas (Talbot y col, 1997; Korstanje y col, 1989). Los LS poseen un radio hidrodinámico que oscila entre 76,4 y $83,3 \mathrm{~nm}$, lo que determina que debido a su gran curvatura poseen una exposición de las cadenas acídicas al agua mayor que la de LNS (Rh=190$320 \mathrm{~nm}$ ). Sumado a este efecto, los LNS sólo exponen al medio pro-oxidante su capa lipídica 
más externa (Schnitzer y col, 2007). Li y colaboradores (2000) demostraron que las diferencias en la peroxidación de cada tipo de liposoma no se deben a artefactos del proceso de sonicado sino a las propiedades estructurales de los liposomas, donde los liposomas pequeños presentan un área superficial disponible, una curvatura y un empaque de ácidos grasos muy diferente a la observada en vesículas más planares. Nuestros resultados sustentan esta hipótesis dado que ninguno de los tipos de liposomas analizados produjo niveles detectables de TBARS antes del agregado del iniciador. Sin embargo, la sensibilidad del ensayo de TBARS no es necesariamente suficiente para detectar niveles de productos de descomposición de LOOHs que sí pueden ser suficientes para promover la reacción de peroxidación.

Los dienos conjugados se forman durante la reorganización de los dobles enlaces que se produce durante la peroxidación de PUFAs. Los TBARS son productos derivados de la ruptura de estos ácidos grasos peroxidados. Entre las diferentes condiciones de trabajo empleadas la mayor y más rápida producción de TBARS se obtuvo en solución fisiológica y agua, mientras que en buffer Tris- $\mathrm{HCl} 20 \mathrm{mM}$ la cantidad de TBARS producida fue notablemente disminuida y retardada. La formación de dienos conjugados también se encontró disminuida en buffer con respecto a agua y solución fisiológica. Fischer y colaboradores (1979) demostraron que buffer Tris forma complejos con iones metálicos lo que explicaría la menor disponibilidad del pro-oxidante y por lo tanto, la menor peroxidación lipídica observada en este medio. Aikens y Dix (1992) analizaron el efecto de la fuerza iónica sobre la peroxidación lipídica iniciada por $\mathrm{HOO}$ - y ROO •. Las mayores velocidades de peroxidación lipídica en solución fisiológica se atribuyen a cambios en la fuerza iónica de la solución antes que a reacciones de interacción específica con los iones. La formación de dienos conjugados, en los primeros pasos de la reacción, introduce un grupo hidroperoxilo relativamente polar en el medio hidrofóbico de la bicapa (Buettner, 1993). Esto puede alterar la localización de los lípidos en la bicapa. Más aún, la degradación de los hidroperóxidos resulta en la escisión de las cadenas hidrocarbonadas. Los fragmentos resultantes se particionan entre el medio acuoso y la bicapa. Los efectos específicos de la peroxidación lipídica incluyen cambios en el empaquetamiento de los lípidos de membrana, lo que modifica todas sus propiedades físicas medibles.

El ión ferroso puede promover la peroxidación lipídica por la formación de radicales hidroxilos en reacciones Fenton, ruptura de hidroperóxidos lipídicos preformados o generación de $\mathrm{H}_{2} \mathrm{O}_{2}$ consumida por la reacción Fenton (Pazos y col, 2006). Casi todos los lípidos contienen al menos trazas de peróxidos. Estudios de oxidación lipídica en sistemas coloidales acuosos sugieren que, durante la propagación, la interacción entre hidroperóxidos lipídicos (LOOH) y 
metales de transición es la causa más común de inestabilidad oxidativa (Frankel, 1998; Fukuzawa y col, 1993; Mei y col, 1998). Si los peróxidos son removidos, el hierro no induce peroxidación. Se propusieron dos vías a través de las cuales ocurriría la iniciación dependiente de $\mathrm{LOOH}$ (Nacka y col, 2001): (a) escisión de $\mathrm{LOOH}$ por Fe ${ }^{3+}$ y subsecuente abstracción de hidrógeno por LOO• (reacciones 1 y 2 )

$$
\begin{aligned}
& \mathrm{Fe}^{3+}+\mathrm{LOOH} \rightarrow \mathrm{Fe}^{2+}+\mathrm{LOO} \bullet+\mathrm{H}^{+} \\
& \mathrm{LOO} \bullet+\mathrm{LH} \rightarrow \mathrm{LOOH}+\mathrm{L} \bullet
\end{aligned}
$$

y (b) ruptura de $\mathrm{LOOH}$ por $\mathrm{Fe}^{2+}$ generando radicales alcoxilo (reacciones 3 y 4)

$$
\begin{aligned}
& \mathrm{Fe}^{2+}+\mathrm{LOOH} \rightarrow \mathrm{Fe}^{3+}+\mathrm{LO} \bullet+\mathrm{OH}^{-} \\
& \mathrm{LO} \bullet+\mathrm{LH} \rightarrow \mathrm{L} \bullet+\mathrm{LOH}
\end{aligned}
$$

Muchos estudios han investigado la oxidación inducida por hierro en liposomas y se han descripto diferentes cinéticas de oxidación. El pro-oxidante más usual en experimentos in vitro a pH neutro es el hierro no hemínico, siendo el ión ferroso mucho más potente que el férrico (Ottolenghi, 1959; Thiele y Huff, 1960). Si el hierro no es agregado deliberadamente al sistema, el hierro presente como contaminante de los reactivos utilizados puede ser suficiente para actuar como catalizador. En algunos estudios se observó una fase de retardo (fase lag) sin acumulación de productos de peroxidación. Se hipotetizó que este retardo es el tiempo necesario para alcanzar una relación óptima 1:1 entre $\mathrm{Fe}^{2+}$ y $\mathrm{Fe}^{3+}$ requerida para iniciar la oxidación (Djuric y col, 2001). En algunos estudios se observó que la peroxidación iniciada por $\mathrm{Fe}^{2+}$ presentó dos fases: una fase rápida que se produce en corto tiempo seguida de una fase lenta de oxidación (M oyzuraityte y col, 2006a; M oyzuraityte y col, 2006b; Genot y col, 1994). Sin embargo, el mecanismo de oxidación en esas dos fases no fue clarificado. Nuestros resultados, observados en agua y buffer Tris, concuerdan con estas observaciones dado que las fases de retardo son evidentes y sustentarían la hipótesis de que es necesario llegar a un equilibrio entre $\mathrm{Fe}^{2+}$ y $\mathrm{Fe}^{3+}$ para dar inicio a la reacción.

Mozuraityte y colaboradores (2008) propusieron un ciclo de reciclado entre $\mathrm{Fe}^{2+} \mathrm{y} \mathrm{Fe}^{3+}$ en la peroxidación de liposomas. En ese estudio concluyeron que el $\mathrm{Fe}^{2+}$ produce una escisión de peróxidos preformados generando radicales alcoxilos que propagan la peroxidación lipídica consumiéndose oxígeno. Cuando se alcanza el equilibrio entre $\mathrm{Fe}^{2+}$ y Fe $\mathrm{Fe}^{3+} \mathrm{la}$ tasa de consumo de oxígeno es constante. Según este estudio la reacción de $\mathrm{Fe}^{3+}$ con peróxidos fue más lenta 
que con $\mathrm{Fe}^{2+}$, efecto que también observamos en nuestro sistema. La menor eficiencia de peroxidación observada con $\mathrm{Fe}^{3+}$ podría deberse a que esta especie posee mayor susceptibilidad al pH que $\mathrm{Fe}^{2+}$. Los altos pHs utilizados en nuestro trabajo (cercanos a 7) hacen que $\mathrm{Fe}^{3+}$ forme su correspondiente hidróxido. Los hidróxidos de hierro formados juegan un papel determinante sobre la concentración de hierro activo sobre la superficie del liposoma. 


\section{C aṕtulo 5}

Efecto de melatonina e indolaminas relacionadas sobre la peroxidación iniciada por $\mathrm{Fe}^{2+}$ de liposomas sonicados de lípidos de retina. 


\subsection{Introducción}

La retina es un tejido excepcional ya que posee un perfil de ácidos grasos que contiene el mayor nivel de PUFAs de cadena larga del organismo (Anderson, 1970; Fliesler y Anderson, 1983; Lecomte y col, 1996; O'Brien y Sampson, 1965; SanGiovanni y Chew, 2005), incluyendo ácido docosahexenoico (DHA, 22:6n-3) y ácido araquidónico (20:4n-6). De éstos, el DHA es el más abundante en la parte neural como vascular de la retina (Fliesler y Anderson, 1983), en las células epiteliales pigmentarias retinianas (Wang y Anderson, 1993a; Wang y Anderson, 1993b) y en membranas de los discos del segmento externo de los fotorreceptores retinianos (Soubias y col, 2006; Suh y col, 1994). Las propiedades biofísicas y bioquímicas de DHA pueden afectar la función de la membrana del fotorreceptor alterando la permeabilidad, fluidez, espesor y otras propiedades de esta fase lipídica. El ácido graso DHA ejerce una función vital en la fototransducción a través de mecanismos de señalización celular. La insuficiencia tisular de DHA está asociada con alteraciones en la función retiniana.

En la retina de mamíferos, los radicales libres y lipoperóxidos juegan un papel importante en la evolución de diferentes retinopatías incluyendo glaucoma, cataractogénesis, retinopatía diabética, inflamación ocular y degeneración retiniana (Ueda y col, 1996; De La Paz y Anderson, 1992). La producción de radicales libres induce la formación de radicales LOO•, conocidos como radicales libres secundarios, que participan de la reacción en cadena de la peroxidación lipídica y que pueden dañar las membranas de la retina alterando la función visual (Catalá, 2006).

Melatonina (N-acetil-5-metoxitriptamina, MLT), hormona de la familia de las indolaminas, es sintetizada a partir de triptófano en pinealocitos y actúa como hormona endócrina que influencia ciclos circadianos en diversos órganos. Dos funciones bioquímicas en la glándula pineal, síntesis de MLT y lipoxigenación, parecen estar sinérgicamente reguladas por los niveles de ácidos grasos esenciales n-3 tisulares (Catalá, 2010). MLT también es sintetizada por fotorreceptores retinianos pero, aparentemente, ésta no ingresa a la circulación sino que actúa como una señal paracrina dentro del ojo. Cientos de investigaciones han señalado a MLT como un secuestrador eficiente de ciertas especies reactivas de oxígeno como $\mathrm{HO} \cdot, \mathrm{RO} \cdot, \mathrm{HClO},{ }^{1} \mathrm{O}_{2}$ y $\mathrm{H}_{2} \mathrm{O}_{2}$ (Allegra y col, 2003). Un gran número de estudios in vivo e in vitro señalan que MLT administrada exógenamente brinda protección frente a estrés oxidativo (Karbownik y col, 2001; Khaldy y col, 2000; Sinha y col, 2001; Giusti y col, 1997). Se ha sugerido que MLT y $\mathrm{N}$-acetilserotonina (NAS) pueden ejercer un efecto protector frente a peroxidación lipídica optimizando la fluidez de la membrana (García y col, 1997; García y col, 2001). En 
sistemas biológicos también ha presentado efecto protector de PUFAs frente a la peroxidación (Leaden y col, 2002; Leaden y Catalá, 2005). Este efecto puede deberse a la capacidad de M LT de secuestrar directamente especies reactivas de oxígeno y también a la inducción de los mecanismos de defensa antioxidante, como la activación de glutatión peroxidasa (BarlowWalden y col, 1995) y superóxido dismutasa (Antolín y col, 1996). Por otro lado, hay estudios que sugieren que MLT es ineficaz como antioxidante (Wang y col, 2001; Wölfler y col, 1999; Duell y col, 1998) 0, más aún, que tiene efecto prooxidante (Wölfler y col, 2001). En contraste con los estudios mencionados, el presente estudio in vitro elimina la contribución e interferencia de enzimas, proteínas y otras moléculas. El objetivo planteado en este capítulo fue:

$\checkmark \quad$ Analizar el efecto de melatonina, $\mathrm{N}$-acetilserotonina, 5-metoxitriptamina (5M TP) y 5HO triptófano (5HO-TRP) sobre la peroxidación iniciada por $\mathrm{Fe}^{2+}$ de liposomas de lípidos de retina bovina.

El sistema liposomal guarda similitudes con la fase lipídica de las membranas biológicas y conserva la composición de ácidos de grasos de la retina. Como iniciador de reacción empleamos $\mathrm{Fe}^{2+}$ que en presencia de hidroperóxidos lipídicos ( $\mathrm{LOOH}$ ) genera radicales libres. El efecto protector de MLT, NAS, 5HO-TRP y 5MTP sobre los liposomas se determinó analizando formación de dienos conjugados y TBARS, y los cambios en la composición de ácidos grasos por cromatografía gaseosa acoplada a espectrometría de masas (CG-MS). El antioxidante de referencia utilizado fue $\mathrm{BHT}$. 


\subsection{Materiales y métodos}

\subsubsection{Materiales}

El proceso de peroxidación se estudió en liposomas sonicados (LS) de lípidos de retina bovina. Para ello, se obtuvieron ojos bovinos donados por Frigorífico Gorina (La Plata, Buenos Aires). Para la extracción de lípidos se utilizaron solventes de calidad cromatográfica: cloroformo (U.V.E.) y metanol (Mallinckrodt). Los demás reactivos utilizados fueron de alta pureza: $\mathrm{NaCl}$ (Cicarelli), $\mathrm{FeSO}_{4}$ (Fluka), TBA (Fluka), 1,1,3,3 tetrametoxipropano (Fluka), Trizma base (Sigma), BHT (Sigma), BF 3 en metanol (Fluka), ácido heptadecanoico (Sigma). M elatonina, $\mathrm{N}$-acetilserotonina, 5-hidroxitriptófano y 5-metoxitriptamina (Sigma). Agua calidad mili-Q.

Para la obtención de retinas y, posteriormente, de lípidos se empleó un homogeneizador Ultraturrax X25. Para producir LS se empleó un sonicador Sonics XL-2000 Microson TM. En la determinación de dienos conjugados y TBARS se utilizó un espectrofotómetro Shimadzu UV-1800.

\subsubsection{Métodos y técnicas}

\subsubsection{Obtención de homogeneizados de retina bovina}

(Ídem punto 4.2.2.1.)

\subsubsection{Extracción de lípidos}

(Ídem punto 4.2.2.2.)

\subsubsection{Preparación de liposomas}

(Ídem punto 4.2.2.3.).

La sonicación se realizó a un voltaje de salida fijado en 12 watts, hasta que la suspensión alcanzó la mínima densidad óptica (Gal y col, 2003).

\subsubsection{Determinación espectrofotométrica de dienos conjugados}

LS de lípidos de retina $\left(C_{f} \approx 0,1 \mathrm{mM}\right)$ fueron incubados durante 9 horas a temperatura ambiente en cubetas de cuarzo de $1 \mathrm{~cm} \times 1 \mathrm{~cm}$. Los liposomas fueron incubados con diferentes concentraciones de los compuestos estudiados (BHT, MLT, 5MTP, NAS y 5HO-TRP) y en ausencia de éstos (muestras control), agitando manualmente durante un minuto y luego 
dejando la mezcla en reposo durante 4 minutos. Se agregó entonces cantidad necesaria de agua para llevar a un volumen final de $2 \mathrm{ml}$ y se inició la reacción de peroxidación por agregado de $\mathrm{Fe}^{2+}\left(\mathrm{C}_{\mathrm{f}}=25 \mu \mathrm{M}\right)$.

Para analizar la producción de dienos conjugados durante la peroxidación de liposomas, se registraron los espectros de absorción cada 9 minutos durante 9 horas, entre 200 y 300 nm con un espectrofotómetro Shimadzu UV 1800. El aumento de absorción a 234 nm (debido a formación de dienos conjugados) se graficó en función del tiempo. La velocidad inicial de reacción se determinó como la pendiente de recta con la que se ajustó el rango lineal de la curva $\Delta$ Abs en función del tiempo. El tiempo de retardo (fase lag) se define como el tiempo transcurrido hasta el inicio de la fase lineal de la curva $\Delta$ Abs en función del tiempo (Sargis y Subbaiah, 2003).

Diferencias entre los valores control y los obtenidos en presencia de BHT e indolaminas fueron analizadas por ANOVA

\subsubsection{Determinación de sustancias reactivas al ácido tiobarbitúrico (TBARS)}

La determinación de TBARS se realizó en placas de poliestireno de 96 pocillos de fondo plano (Camejo y col, 1998). Una alícuota de $10 \mu \mathrm{l}$ de BHT (0.01 \% p/v) se agregó a cada pocillo para prevenir peroxidación adicional durante la incubación. BHT 0.01 \% p/v se preparó por dilución con agua a partir de una solución 0.1 \% p/v en etanol para minimizar la concentración de etanol en el medio de reacción.

LS se incubaron durante 9 horas en las mismas proporciones y condiciones que para la determinación de dienos conjugados. Se tomaron alícuotas de $15 \mu \mathrm{l}$ (por triplicado) de las mezclas de reacción a diferentes tiempos y se dispusieron en las placas. Los pocillos ocupados se cubrieron con film adhesivo y las placas se mantuvieron a $-22{ }^{\circ} \mathrm{C}$ hasta completar la placa. A cada pocillo se agregaron $85 \mu \mathrm{l}$ de TBA $(0.375 \% \mathrm{p} / \mathrm{v}$ en $\mathrm{HCl} 0,25 \mathrm{~N})$, se taparon las placas y se incubaron a $65{ }^{\circ} \mathrm{C}$ durante 30 min en baño de agua. Cada placa contenía además, diferentes concentraciones de soluciones estándares de 1,1,3,3 tetrametoxipropano, para la confección de curvas de calibrado. Para la cuantificación se empleó un coeficiente de absorción molar de $156000 \mathrm{M}^{-1} \mathrm{~cm}^{-1}$ (Rice-Evans y col, 1991).

Diferencias entre las concentraciones de TBARS entre las muestras control y las obtenidas en presencia de BHT, M LT e indolaminas relacionadas fueron analizadas por ANOVA. 


\subsubsection{Preparación de metil derivados de ácidos grasos (FAMEs)}

Para poder analizar la composición de ácidos grasos de retina y liposomas preparados con sus lípidos por cromatografía gaseosa, las muestras deben ser previamente derivatizadas. Los lípidos de liposomas (sin peroxidar, peroxidados y peroxidados en presencia de BHT, M LT e indolaminas relacionadas) fueron extraídos de acuerdo al método de Folch (Folch y col, 1957). Las mezclas de las que se extrajeron los lípidos poseen la misma composición que las empleadas en la determinación de dienos conjugados pero a una escala 7,5 veces mayor $\left(\mathrm{V}_{\mathrm{f}}=\right.$ $15 \mathrm{ml})$.

Luego de una hora de incubación de los liposomas con y sin $\mathrm{Fe}^{2+}$, en presencia y ausencia de BHT e indolaminas, las muestras se mezclaron con igual volumen (15 ml) de cloroformo: metanol 2:1 v/v, conteniendo $0.01 \%$ p/v BHT para detener la reacción. Esta mezcla se agitó en vórtex, se gaseó con nitrógeno y se mantuvo en heladera toda la noche hasta lograr la separación de fases. La fase clorofórmica inferior se filtró con papel conteniendo $\mathrm{Na}_{2} \mathrm{SO}_{4}$ anhidro para absorber restos de agua. Como estándar externo testigo de metilación se agregaron $25 \mu$ de ácido heptadecanoico (17:0) 10000 ppm $\left(C_{\mathrm{f}}=16,67 \mathrm{ppm}\right)$. Este ácido graso no se encuentra naturalmente en retina.

La fase clorofórmica obtenida en la extracción de lípidos de retina y la fase clorofórmica obtenida en el paso anterior fueron evaporadas bajo corriente de nitrógeno. Los lípidos secos fueron trasmetilados con $300 \mu \mathrm{l}$ de $\mathrm{BF}_{3}$ en metanol $1,3 \mathrm{M}$, incubándolos a $65^{\circ} \mathrm{C}$ durante $180 \mathrm{~min}$. Luego de la incubación, se agregó $1 \mathrm{ml}$ de solución fisiológica y los metil derivados de ácidos grasos se extrajeron con $1 \mathrm{ml}$ de hexano.

\subsubsection{Cromatografía gaseosa acoplada a espectrometría de masas}

Para analizar la composición de ácidos grasos se empleó un cromatógrafo gaseoso Perkin Elmer Clarus 560D acoplado a un espectrómetro de masas. Columna: Recubierta. Elite 5MS (Perkin Elmer). Dimensiones: $30 \mathrm{~m} ; 0,25 \mathrm{~mm}$ de $\varnothing$ interno; $0.25 \mu \mathrm{m}$ de espesor de fase estacionaria. Muestra: $495 \mu \mathrm{l}$ fase hexano (obtenidos en el paso anterior) $+5 \mu l$ n-eicosano (C20) 25000 ppm ( $C_{f}=250$ ppm). Volumen de inyección: $1 \mu$ l. Inyector: $260^{\circ} \mathrm{C}$. Split: 10 . Modo: Flow. Gas de corrida: Helio. Flujo: $1 \mathrm{ml} / \mathrm{min}$. Rango de temperaturas: de 130 a $250{ }^{\circ} \mathrm{C}, 5$ ${ }^{\circ} \mathrm{C} / \mathrm{min} .250^{\circ} \mathrm{C}$ durante $6 \mathrm{~min}$. Temperatura línea de trasferencia: $250^{\circ} \mathrm{C}$. Temperatura fuente de iones: $180{ }^{\circ} \mathrm{C}$. Energía de ionización: 70 eV (El+). Identificación de compuestos: por comparación de espectros de masas con los de biblioteca NIST. 


\subsection{Resultados}

En el presente capítulo investigamos la actividad antioxidante de M LT y un grupo de indolaminas relacionadas, frente a la peroxidación iniciada por $\mathrm{Fe}^{2+}$ de liposomas sonicados de lípidos de retina. El proceso peroxidativo se analizó por formación de dienos conjugados, producción de TBARS y análisis de los cambios de composición de ácidos grasos. La actividad antioxidante de las indolaminas fue comparada con la de BHT seleccionado como antioxidante de referencia.

\section{Efecto de melatonina e indolaminas relacionadas sobre la producción de dienos conjugados durante la peroxidación de liposomas sonicados de lípidos de retina.}

La figura 5.1 muestra la evolución temporal de los espectros UV, tomados entre 200 y $300 \mathrm{~nm}$, durante la peroxidación iniciada por $\mathrm{Fe}^{2+}$ de: LS de lípidos de retina (Figura 5.1.A), LS en presencia de MLT $5 \mu \mathrm{M}$ (Figura 5.1.B) y LS en presencia de BHT $5 \mu \mathrm{M}$ (Figura 5.1.C). LoS espectros que se observan en la figura fueron tomados a 0, 4,5 y 9hs. Tras el agregado de $\mathrm{Fe}^{2+}$ como iniciador, se observó disminución en la absorbancia en el rango entre 200 y 215 nm debido a la pérdida de doble enlaces separados por un grupo metileno (lípidos no peroxidados) como consecuencia de la formación de doble enlaces conjugados como intermediarios de la peroxidación. Cuando los liposomas se incubaron con MLT $5 \mu \mathrm{M}$ (Figura 5.1.B) esta disminución también fue notoria, a diferencia de BHT $5 \mu$ M (Figura 5.1.C) que logró inhibir estos cambios. Entre 215 y $300 \mathrm{~nm}$, la absorbancia aumentó mostrando un máximo a $234 \mathrm{~nm}$ debido a los dienos conjugados. Esto se observó en ausencia y presencia de MLT, mientras que en presencia de BHT estos cambios fueron notablemente disminuidos. La evolución de espectros UV en presencia de NAS, 5MTP y 5HO-TRP fue similar a la observada para MLT, por esta razón y para no extender demasiado esta sección se obviaron estos gráficos.

Una vez iniciada la reacción, la producción de dienos conjugados fue inmediata (Figura 5.2, 0 MM: sin agregado de indolaminas o BHT). La presencia de concentraciones crecientes de BHT (Figura 5.2.A) determinó mayores tiempos de retardo en el inicio de la reacción y velocidades iniciales de reacción menores (Tabla 5.1). Dado que el tiempo de inicio de reacción obtenida en presencia de BHT $5 \mu \mathrm{M}$ fue superior a las 9 horas (tiempo de monitoreo de la reacción) no se determinó la velocidad de reacción a esta concentración. Si bien aumentó la fase de retardo en presencia de BHT, ésta no fue proporcional a la concentración. 

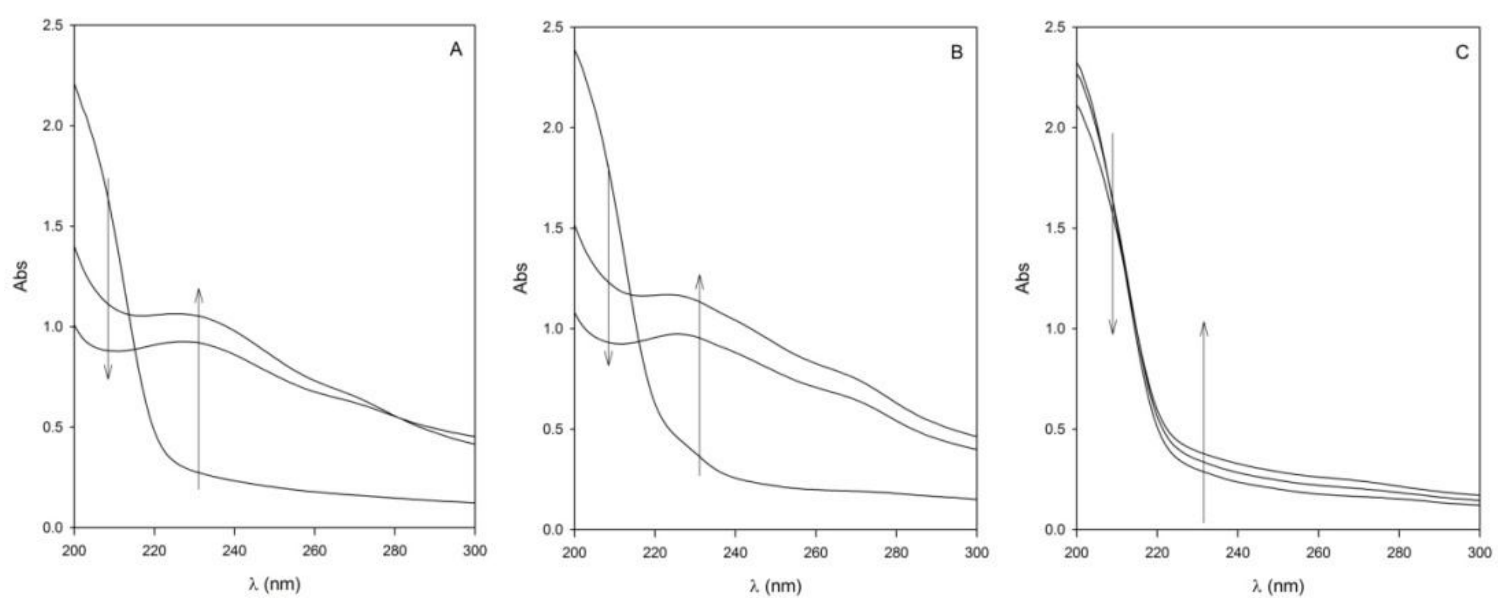

Figura 5.1. Evolución de espectros UV, entre 200 y 300 nm, determinados durante la peroxidación lipídica iniciada por $\mathrm{Fe}^{2+}$ de liposomas sonicados $(0$, 4,5 y 9 horas). A) Control, B) + M LT ( $5 \mu \mathrm{M})$ y C) +BHT (5 $\mu \mathrm{M})$

Los tiempos de inicio y las velocidades iniciales de reacción no fueron modificados con adición de concentraciones crecientes de M LT (1, 2, 5, 10, $20 \mu \mathrm{M})$ (Figura 5.2.B), aun cuando se analizaron concentraciones superiores $(10$ y $20 \mu \mathrm{M})$ a las ensayadas con BHT. En presencia de concentraciones crecientes de NAS, 5M TP y 5HO-TRP tampoco se detectó actividad inhibitoria de la peroxidación (Figuras 5.2. C, D y E). Si analizamos las velocidades iniciales de reacción en presencia de estas indolaminas se observa una tendencia a aumentar conforme lo hace la concentración, lo que se traduciría en un posible efecto prooxidante. 5HO-TRP $5 \mu \mathrm{M}$ mostró diferencias estadísticamente significativas de $\Delta \mathrm{Abs}$ con respecto a los de la curva control $(0 \mu \mathrm{M})$ manteniéndose por encima de esta curva en el rango de tiempo entre $150 \mathrm{y}$ 400 minutos.

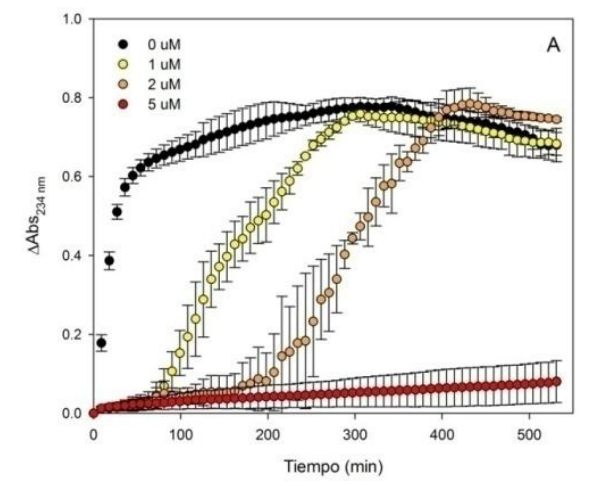



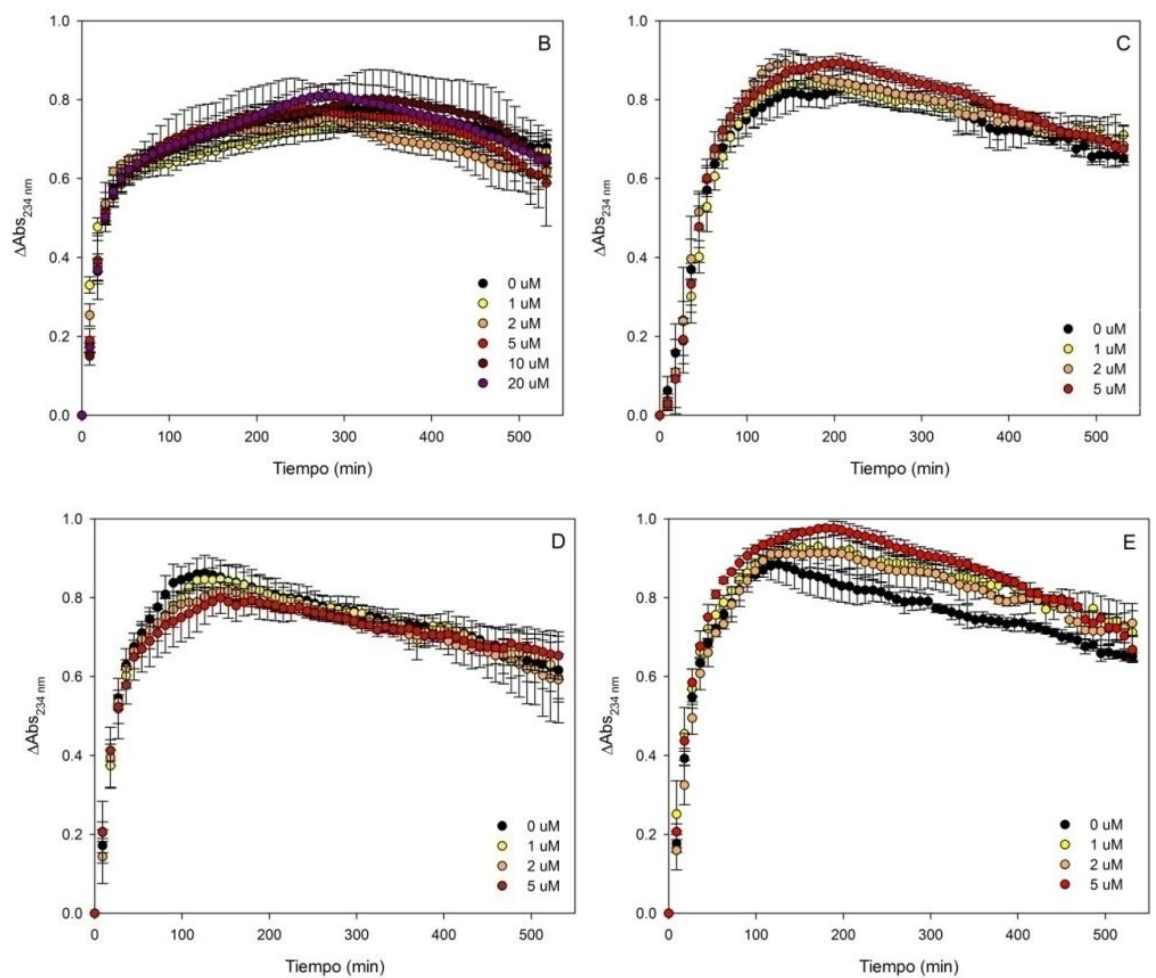

Figura 5.2. Variación de absorbancia a $234 \mathrm{~nm}$ en función del tiempo durante la peroxidación iniciada por $\mathrm{Fe}^{2+}$ de liposomas sonicados de lípidos de retina en presencia de A) BHT, B) MLT, C) NAS, D) 5MTP y E) 5HO-TRP. Cada punto representa $\tilde{\mathrm{x}} \pm \mathrm{SD}$ de 3 experimentos. Donde $\tilde{\mathrm{x}}$ : promedio y SD: desviación estándar.

Tabla 5.1.Datos cinéticos obtenidos del gráfico de la producción de dienos conjugados en función del tiempo, durante la peroxidación iniciada por $\mathrm{Fe}^{2+}$ de liposomas sonicados de lípidos de retina en ausencia y presencia de BHT, MLT e indolaminas relacionadas.

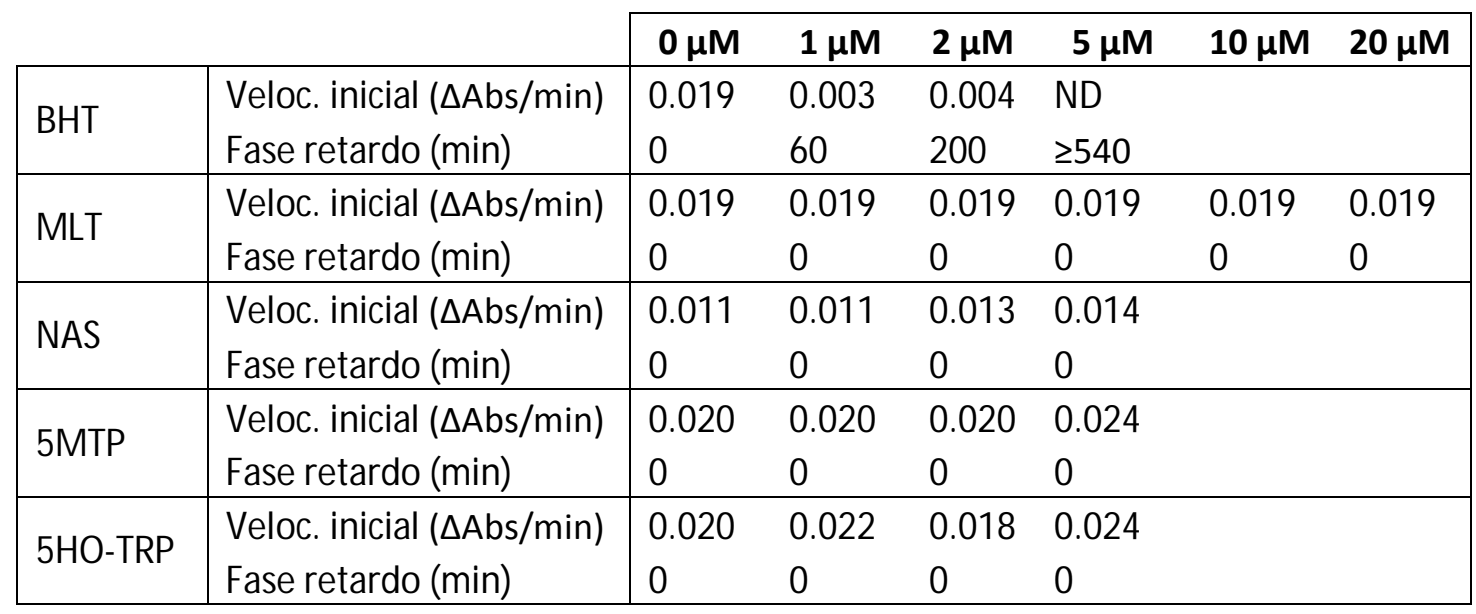


Efecto de melatonina e indolaminas relacionadas sobre la producción de TBARS durante la peroxidación de liposomas sonicados de lípidos de retina.

La figura 5.3.A representa la producción de TBARS en función del tiempo durante la incubación de liposomas sonicados de lípidos de retina con y sin $\mathrm{Fe}^{2+}$. La figura 5.3.B muestra la producción de TBARS durante la peroxidación de liposomas en presencia de diferentes concentraciones de BHT. Se observa que todas las concentraciones analizadas fueron igualmente efectivas en inhibir la generación de TBARS, haciendo que los niveles de TBARS sean comparables a los obtenidos en liposomas incubados sin $\mathrm{Fe}^{2+}$. En la figura 5.4.A es evidente que MLT no presentó efecto antioxidante a ninguna de las concentraciones analizadas $(1,2,5,10$ y $20 \mu \mathrm{M})$ dado que no hubo diferencias estadísticamente significativas con la curva control $(0 \mu \mathrm{M})$. Más aún, MLT $20 \mu \mathrm{M}$ presentó un valor superior al de la curva control a $540 \mathrm{~min}$, con diferencia estadísticamente significativa.

En presencia de diferentes concentraciones de NAS y 5MTP (Figura 5.4 B y C) no se observaron cambios significativos con respecto a la curva control. 5HO-TRP (Figura 5.4 D) no tuvo efecto sobre la peroxidación de liposomas cuando se analizaron las concentraciones 1 y 2 $\mu \mathrm{M}$. Sin embargo, una concentración de $5 \mu \mathrm{M}$ mostró aumento significativo de producción de TBARS con respecto al control luego de transcurridos 153 minutos de la reacción.

Estos resultados refuerzan la hipótesis de que M LT, NAS, 5MTP y 5HO-TRP no poseen un efecto antioxidante directo, es decir, no tienen la capacidad de secuestrar los radicales formados durante la reacción de peroxidación iniciada por $\mathrm{Fe}^{2+}$ de liposomas de lípidos de retina.
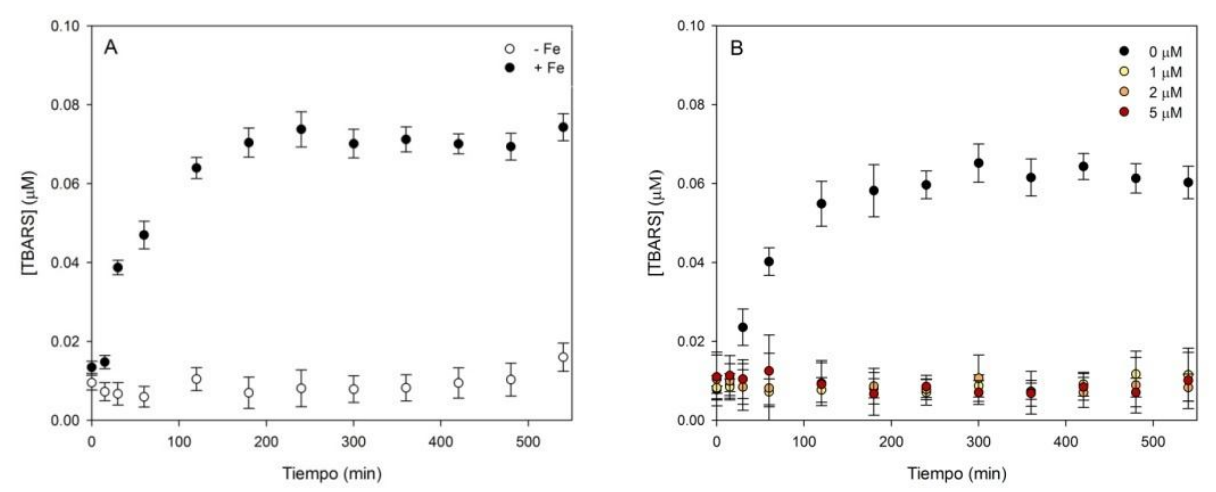

Figura 5.3. Formación de TBARS en función del tiempo, durante la incubación de liposomas sonicados de lípidos de retina en $\mathrm{A}$ ) ausencia y presencia de $\mathrm{Fe}^{2+}$ y B) presencia de $\mathrm{Fe}^{2+}\left(\mathrm{C}_{\mathrm{f}}=25 \mu \mathrm{M}\right)$ y diferentes concentraciones de BHT. Cada 
punto representa: $\overline{\mathrm{x}} \pm$ SD donde $\bar{x}$ : promedio de [TBARS] de 3 experimentos, SD: desviación estándar.
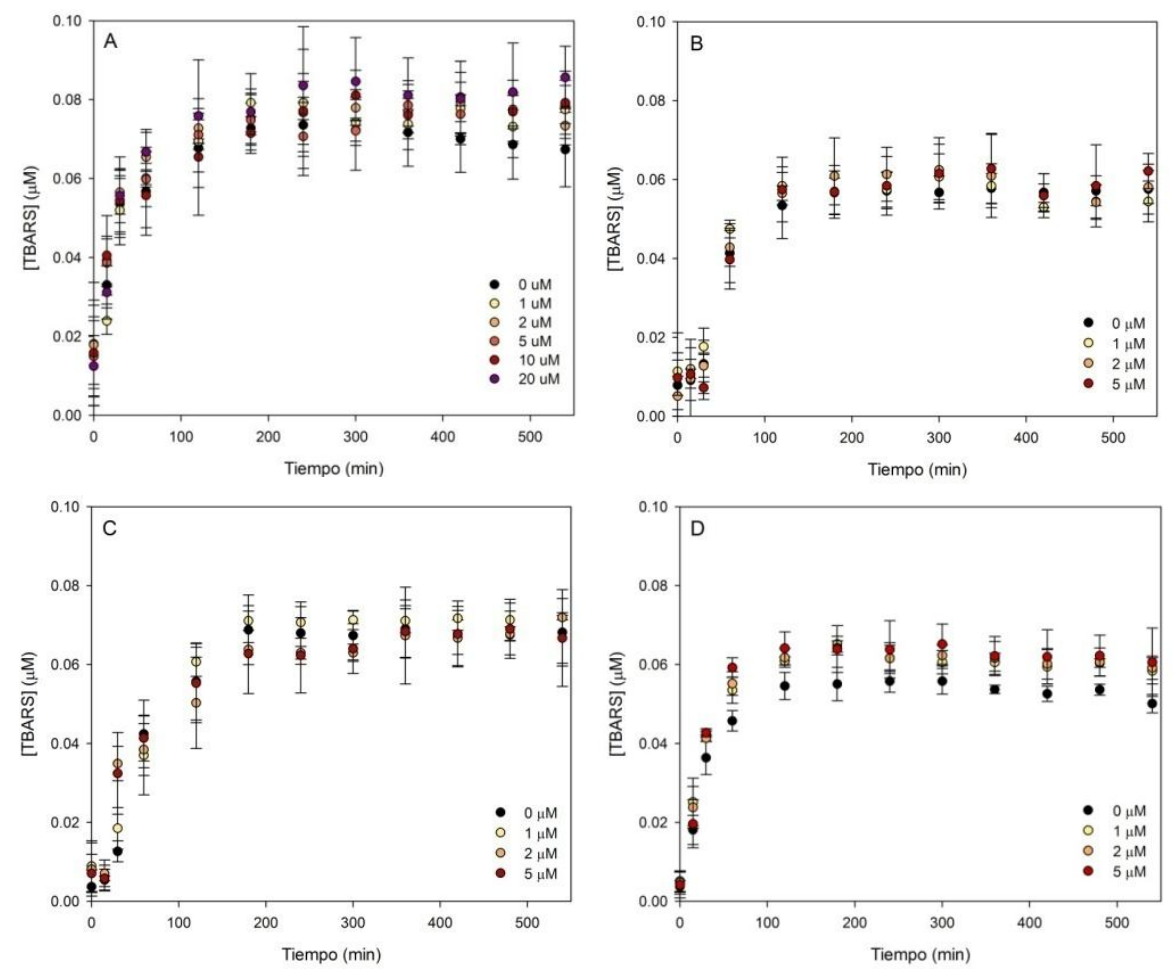

Figura 5.4. Formación de TBARS en función del tiempo, durante la peroxidación iniciada por $\mathrm{Fe}^{2+}$ de liposomas sonicados de lípidos de retina en presencia de diferentes concentraciones de A) MLT, B) NAS, C) 5MTP y D) 5HOTRP. Cada punto representa: $\overline{\mathrm{x}} \pm$ SD donde $\overline{\mathrm{x}}$ : promedio de [TBARS] de 3 experimentos y SD: desviación estándar.

Análisis de los cambios en la composición de ácidos grasos durante la peroxidación de liposomas. Efecto de melatonina e indolaminas relacionadas.

La figura 5.5 constituye un cromatograma representativo de los metil-derivados de ácidos grasos de retina bovina. Los metil derivados fueron obtenidos por transesterificación con metanol en presencia de $\mathrm{BF}_{3}$ como catalizador.

Los principales picos identificados correspondieron a los metil derivados de ácido palmítico (16:0), oleico (18:1 n-9), esteárico (18:0), araquidónico (AA, 20:4 n-6) y docosahexenoico (DHA, 22:6 n-3). En menor proporción se encontraron ácido linoleico (LA, 18:2 n-6) e isómeros de algunos de los ácidos grasos mayoritarios. 
La retina posee un elevado contenido de DHA $(25.8 \pm 0.6 \%)$, característico de este tejido. Retina posee aproximadamente un $40 \%$ de PUFAs y un $60 \%$ de saturados y monoetilénicos.

Los picos fueron correctamente separados e identificados por comparación de sus espectros de masas con los de la biblioteca NIST.

Los liposomas poseen los mismos ácidos grasos que la retina (Tabla 5.2) aunque el proceso de preparación de los mismos determinó diferencias en las proporciones en que éstos se encuentran. Específicamente, se observa una reducción en el contenido porcentual de DHA.

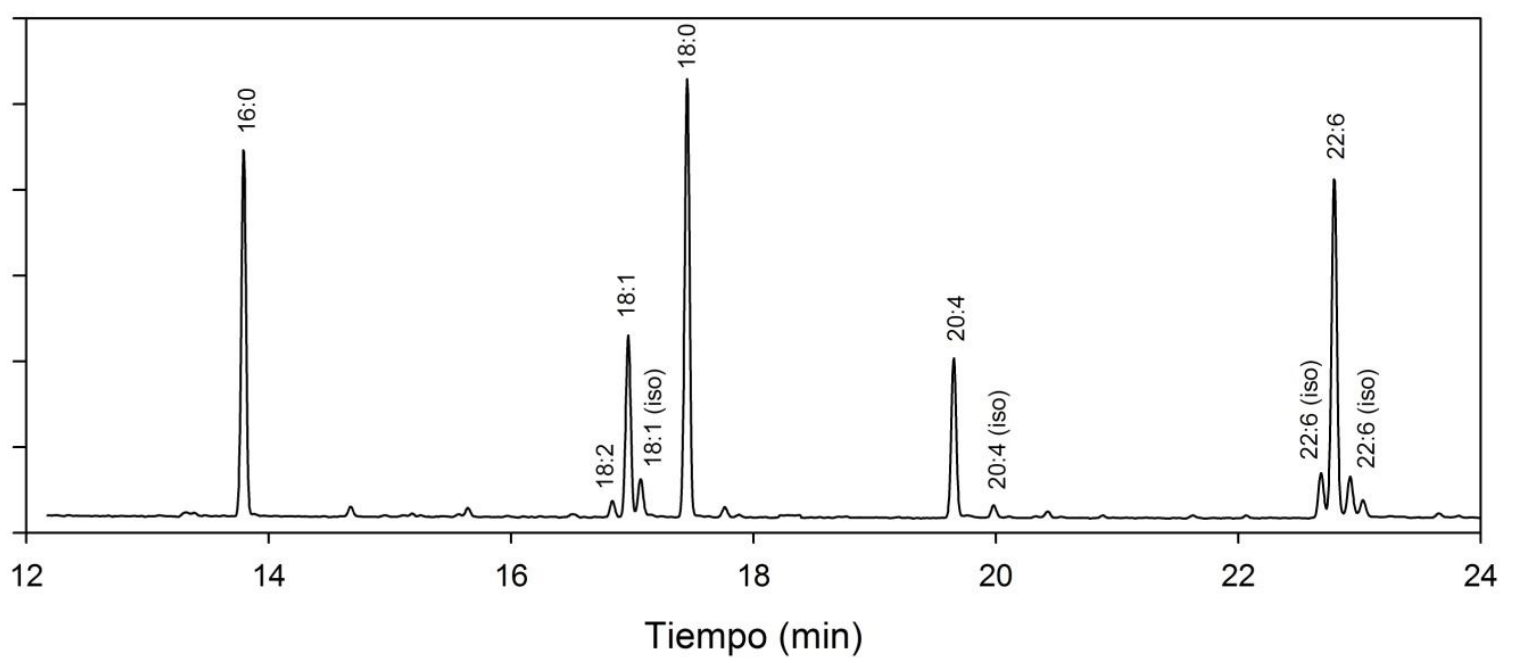

Figura 5.5. Cromatograma representativo de los metil derivados de ácidos

grasos de retina. Los compuestos fueron identificados en base a sus espectros de masa.

Todos los PUFAs (LA, AA y DHA) disminuyeron significativamente tras 1 hora de incubación con $\mathrm{Fe}^{2+}$, produciendo consecuentemente un incremento relativo de la composición porcentual de ácidos grasos saturados y monoetilénicos.

La presencia de $5 \mu \mathrm{M}$ de BHT logró proteger a los PUFAs de la degradación generada por el proceso de peroxidación. Esto se hace evidente ya que el perfil de ácidos grasos de liposomas peroxidados en presencia de BHT no difiere, dentro del error experimental, del control. M LT, NAS, 5M TP y 5HO-TRP ensayados a la misma concentración que BHT no lograron inhibir la degradación de los PUFAs. Los PUFAs disminuyeron drásticamente y el perfil de ácidos grasos obtenidos es similar al de los liposomas peroxidados (control). 
Tabla 5.2. Composición porcentual de ácidos grasos de retina y de liposomas sonicados de lípidos de retina. Los liposomas fueron incubados durante una hora en ausencia y presencia de $\mathrm{Fe}^{2+}$ ( LS - Fe y LS + Fe) y en presencia de $\mathrm{Fe}^{2+}$ junto a BHT y las indolaminas estudiadas.

\begin{tabular}{|c|c|c|c|c|c|c|c|c|c|}
\hline Ácido graso & Rt (min) & Retina & LS - Fe & LS + Fe & BHT $5 \mu$ & MLT $5 \mu \mathrm{M}$ & NAS $5 \mu \mathrm{M}$ & 5MTP $5 \mu \mathrm{M}$ & 5HO-TRP $5 \mu \mathrm{M}$ \\
\hline $16: 0$ & 13,34 & $25.2 \pm 0.6$ & $24.0 \pm 3.6$ & $39.8 \pm 9.2^{*}$ & $25.5 \pm 5.7$ & $40.7 \pm 2.3^{*}$ & $40.3 \pm 0.9 *$ & $37.6 \pm 0.6 *$ & $40.8 \pm 5.5^{*}$ \\
\hline $18: 2 n-6$ & 16,37 & $0.7 \pm 0.2$ & $1.2 \pm 0.4$ & ND* & $0.8 \pm 0.4$ & $0.7 \pm 0.3$ & ND* & $0.9 \pm 0.3$ & ND* \\
\hline 18:1 (iso) & 16,60 & $1.7 \pm 0.1^{*}$ & $2.3 \pm 0.1$ & $3.6 \pm 1.4$ & $2.0 \pm 1.0$ & $3.5 \pm 0.2 *$ & $3.9 \pm 0.1 *$ & $3.3 \pm 0.3 *$ & $4.3 \pm 0.4 *$ \\
\hline 18:0 & 16,99 & $22.2 \pm 0.2$ & $22.6 \pm 1.5$ & $35.8 \pm 5.2 *$ & $22.2 \pm 4.7$ & $33.7 \pm 0.4 *$ & $34.8 \pm 2.2 *$ & $33.5 \pm 0.2 *$ & $35.1 \pm 7.8^{*}$ \\
\hline $20: 4$ (iso) & 19,51 & $0.7 \pm 0.1$ & $1.0 \pm 0.3$ & ND* & $0.9 \pm 0.2$ & ND* & ND* & ND* & ND* \\
\hline 22:6 (iso) & 22,22 & $1.1 \pm 0.1$ & $1.8 \pm 0.9$ & ND* & $1.6 \pm 0.5$ & ND* & ND* & $0.6 \pm 0.1 *$ & ND* \\
\hline $22: 6 n-3$ & 22,23 & $25.8 \pm 0.6 *$ & $24.3 \pm 0.2$ & $1.0 \pm 1.0 *$ & $24.1 \pm 4.7$ & $1.5 \pm 0.4^{*}$ & ND* & $2.2 \pm 0.5^{*}$ & ND* \\
\hline $22: 6$ (iso) & 22,46 & $1.8 \pm 0.1$ & $2.4 \pm 1.0$ & $1.0 \pm 0.3 *$ & $2.5 \pm 0.1$ & ND* & ND* & $1.4 \pm 1.0$ & ND* \\
\hline $22: 6$ (iso) & 22,56 & $0.9 \pm 0.1$ & $1.0 \pm 0.8$ & ND* & $1.1 \pm 0.2$ & ND* & ND* & ND* & ND* \\
\hline
\end{tabular}

Los resultados se expresan como $\bar{x} \pm$ SD donde $\bar{x}$ : promedio del área porcentual de $n$ experimentos, SD: desviación estándar. Un asterisco $\left({ }^{*}\right)$ indica diferencias significativas con respecto al control (LS - Fe) según ANOVA, $p \varangle 0.05$. ND: no detectable. 


\subsection{Discusión}

La concentración inusualmente elevada de PUFAs, intensa actividad metabólica y elevada tensión de oxígeno a la que se encuentra expuesta debido a una importante irrigación, sumados a la presencia de pigmentos retinianos que pueden generar ROS cuando son iluminados (Beatty y col, 2000) hacen de la retina un tejido especialmente susceptible a sufrir estrés oxidativo. En el presente capítulo observamos que los PUFAs presentes en los liposomas de lípidos de retina fueron afectados por la peroxidación iniciada por $\mathrm{Fe}^{2+}$ disminuyendo hasta casi desaparecer. Una concentración de $5 \mu \mathrm{M}$ de BHT fue capaz de protegerlos, mientras que MLT y los análogos estructurales no presentaron efecto protector.

Los radicales que dieron inicio a la reacción de peroxidación de liposomas fueron mayoritariamente $\mathrm{LO}$ - y $\mathrm{LOO}$ • según las reacciones propuestas por Nacka y colaboradores (2001):

(a) Ruptura de $\mathrm{LOOH}$ por $\mathrm{Fe}^{2+}$ generando radicales alcoxilo (reacciones 1 y 2 )

$$
\begin{aligned}
& \mathrm{Fe}^{2+}+\mathrm{LOOH} \rightarrow \mathrm{Fe}^{3+}+\mathrm{LO} \bullet+\mathrm{OH}^{-} \\
& \mathrm{LO} \bullet+\mathrm{LH} \rightarrow \mathrm{L} \bullet+\mathrm{LOH}
\end{aligned}
$$

$y$, dado que en las reacciones anteriores se genera $\mathrm{Fe}^{3+}$ se considera también la reacción de

(b) escisión de $\mathrm{LOOH}$ por $\mathrm{Fe}^{3+}$ y subsecuente abstracción de hidrógeno por LOO• (reacciones 3 y 4 )

$$
\begin{aligned}
& \mathrm{Fe}^{3+}+\mathrm{LOOH} \rightarrow \mathrm{Fe}^{2+}+\mathrm{LOO} \bullet+\mathrm{H}^{+} \\
& \mathrm{LOO} \bullet+\mathrm{LH} \rightarrow \mathrm{L} \bullet+\mathrm{LOOH}
\end{aligned}
$$

El principal producto de la glándula pineal, MLT, ha sido descripto como un poderoso antioxidante en diversos tejidos (Catalá, 2007). Posee, además, la ventaja de ser una molécula anfifílica que puede atravesar fácilmente todas las membranas biológicas inclusive la barrera hemato-cerebral (Cabrera y col, 2000). Se ha reportado que MLT previene la formación de cataratas reduciendo el daño oxidativo sobre lípidos y también sobre proteínas (Abe y col, 1994). Aunque el mecanismo de acción no está completamente descripto, algunos investigadores creen que las propiedades antioxidantes de MLT están mediadas por su capacidad de secuestrar directamente especies reactivas de oxígeno, como $\mathrm{O}_{2}{ }^{-{ }^{-}}$y $\mathrm{HO} \cdot(T a n$ y col, 2000b), mientras que resulta ineficiente como secuestrador de radicales LOO • (Antunes y 
col, 1999; Galano, 2011). Por otro lado, algunos investigadores han sugerido que la acción antioxidante de M LT puede estar mediada por otros mecanismos tales como estabilización de membranas celulares (García y col, 1999) y estimulación de enzimas antioxidantes (Reiter y col, 2000b). Debido a que en el sistema de estudio utilizado en el presente capítulo no se encuentran enzimas ni genes que puedan ser modulados por MLT, no existe una fuente de formación de radicales $\mathrm{HO} \cdot \mathrm{O}_{2} \mathrm{O}_{2}^{\cdot-}$ y, que MLT y sus análogos estructurales no presentaron acción antioxidante, podemos deducir que el mecanismo de acción antioxidante de MLT in vivo no estaría relacionado a su capacidad secuestradora de radicales LOO • y LO • directa. Así, cobra mayor relevancia la hipótesis de que los efectos benéficos de MLT se deben a las acciones indirectas, tales como estimulación de enzimas antioxidantes y modificación de propiedades de membrana.

Además de la simplicidad del modelo, existe otro factor de interés del sistema en estudio como lo es la presencia de hidroperóxidos de ácidos grasos en el medio. Se sabe que los hidroperóxidos lipídicos derivados de fosfolípidos no saturados, glicolípidos y colesterol son intermediarios no radicales de la peroxidación lipídica que provocan perturbaciones en la estructura y función de la membrana con consecuencias citopatológicas. Debido a una mayor polaridad y un mayor tiempo de vida comparados con sus radicales libres precursores, los hidroperóxidos de PUFAs son capaces de migrar desde su sitio de formación a otros más sensibles. En la retina, los hidroperóxidos pueden formarse por oxidación enzimática de PUFAs endógenos como intermediarios de la formación de docosanoides (Bazan y col, 1984). De La Paz y Anderson (1992) postularon que es poco probable que el radical $\mathrm{HO}$ - sea el iniciador de la peroxidación en los segmentos externos de los bastones (ROSg). Ellos sugieren que los hidroperóxidos endógenos en presencia de $\mathrm{Fe}^{2+}$ forman radicales libres más estables que el radical $\mathrm{HO} \cdot$, lo que resulta en una entrada facilitada de estas especies a la bicapa para iniciar la peroxidación lipídica de las cadenas de ácidos grasos. En nuestro sistema es probable que hidroperóxidos de ácidos grasos se hayan formado durante la preparación de liposomas, aunque hayamos tomado precauciones para proteger a estas membranas de la peroxidación. Por lo tanto, hay un pequeño "pool" de hidroperóxidos en retina que, bajo ciertas condiciones, puede ser una fuente de radicales libres lipídicos y promover la peroxidación de PUFAs, abundantes en membranas retinianas y liposomas hechos a partir de sus lípidos. Dado que el contenido de DHA disminuye cuando los lípidos de retina son transformados en liposomas se sustenta la hipótesis de que durante los pasos de preparación de liposomas se generan hidroperóxidos lipídicos. Estos pueden generar radicales libres que atacan al DHA, altamente susceptible debido a sus 6 dobles enlaces. 
El sistema empleado permitió analizar la formación de dienos conjugados y TBARS $\sin$ la interferencia que producirían proteínas y otros compuestos presentes en la retina. A través de ambas técnicas se observó el claro efecto antioxidante de BHT. Mientras que MLT, NAS, 5MTP y 5HO-TRP no mostraron actividad antioxidante en este sistema, a pesar que M LT fue ensayada a concentraciones superiores a las de BHT. 5HO-TRP no sólo no mostró actividad antioxidante sino que es posible notar un efecto prooxidante por ambas técnicas. 


\section{C ondusiones}


Los resultados obtenidos a partir de este trabajo de tesis doctoral permiten formular las siguientes conclusiones:

\section{Sistema: triglicéridos en cloroformo}

$>$ 5HO-TRP y NAS demostraron ser secuestradores de radicales peroxilos más efectivos que BHT cuando se estudiaron por técnicas de quimioluminiscencia y producción de TBARS. Este efecto es coherente con la elevada actividad demostrada frente al radical $\mathrm{DPPH} \cdot$ lo que lleva a la conclusión de que estos compuestos poseen elevada tendencia a ceder un radical $\mathrm{H} \cdot$ a los radicales $\mathrm{LOO}$ - generados durante la peroxidación de triglicéridos ricos en PUFAs $n-3$, cortando la cadena de peroxidación y protegiendo a los lípidos de sus efectos en forma dependiente de la concentración.

> La efectividad de 5HO-TRP como antioxidante fue mayor que la de NAS lo que indica que su única diferencia estructural (cadena lateral en posición 3) es un factor importante en la determinación de la actividad.

MLT no demostró ser un eficiente dador de $H$ • cuando se analizó por ensayo de DPPH y el mismo comportamiento se observó para otro 5-metoxi derivado, 5MTP. Estos resultados son consistentes con la falta de inhibición de producción de TBARS y la incapacidad de disminuir la producción de quimioluminiscencia. Estos resultados nos permiten concluir que M LT y 5M TP no actuarían como antioxidantes cortadores de cadena clásicos en este sistema.

> No se evidenció formación de AFMK en el sistema de Tg PUFAs n-3 peroxidados con CHP en presencia de MLT. La MLT estaría reaccionando con especies generadas durante la reacción de peroxidación pero esto no implicaría un efecto protector de los lípidos.

Ambos isómeros de CLAs mostraron ser más susceptibles a la peroxidación que LA y que M LA cuando se sometieron a peroxidación cuantificada por quimioluminiscencia.

A diferencia de LA y M LA los isómeros CLAs mostraron inhibición de la peroxidación de Tg PUFAs n-3 cuando se analizaron por quimioluminiscencia. Sin embargo, las 
concentraciones de CLAs que resultaron efectivas son muy elevadas ( $\geq 100 \mathrm{mM}$ ), razón por la cual creemos que estudios adicionales son necesarios para determinar la actividad secuestradora de radicales de estos compuestos en sistemas que simulen condiciones fisiológicas y buscar una correlación entre su actividad antioxidante y sus ya asignados efectos biológicos.

> La mayor reactividad de CLAs frente a radicales comparada con la de LA y MLA también se observó en el ensayo de DPPH. Se debe tener en cuenta el elevado valor de $\mathrm{EC}_{50}$ obtenido para CLAs. Fue necesaria una concentración $\approx 16 \mathrm{mM}$ de CLAs para poder decolorar una solución $\approx 30 \mu \mathrm{M}$ de DPPH. Es decir, fue necesaria una concentración de CLAs tres órdenes de magnitud mayor que la de DPPH.

\section{Sistema: liposomas de lípidos de retina}

$>$ Los LS fueron más susceptibles a la peroxidación que los LNS, cualquiera sea el iniciador o medio de reacción utilizado.

$>$ Solución fisiológica y, en menor medida, agua fueron los medios donde la reacción de peroxidación fue más eficiente, determinada por TBARS y dienos conjugados. En buffer Tris-HCl pH 7,4 la reacción fue inhibida.

$>\mathrm{Fe}^{2+}$ es un iniciador de peroxidación mucho más eficiente que $\mathrm{Fe}^{3+}$ cualquiera sea el medio acuoso de reacción o el tipo de liposoma empleado.

La presencia de $5 \mu \mathrm{M}$ BHT logró proteger a los PUFAs de la degradación generada por el proceso de peroxidación mientras que MLT, NAS, 5HO-TRP y 5MTP no presentaron efecto protector de PUFAs.

> MLT, NAS, 5MTP y 5HO-TRP no poseen un efecto antioxidante directo, es decir, no tienen la capacidad de secuestrar los radicales formados durante la reacción de peroxidación iniciada por $\mathrm{Fe}^{2+}$ en liposomas de lípidos de retina. 


\section{Comentarios generales}

Las diferencias halladas en el comportamiento antioxidante de NAS y 5HO-TRP (amboS de carácter hidrofílico) en ambos sistemas de estudio pueden ser explicadas por la conocida teoría de la Paradoja Polar (Shahidi y Zhong, 2011). Esta teoría también explicaría el hecho de que estos compuestos hayan presentado mayor eficiencia antioxidante que BHT (lipofílico) en el sistema puramente lipídico. Esta teoría interpreta la aparente contradicción que supone el hecho de que los antioxidantes hidrofílicos resultan más efectivos en medios puramente lipídicos mientras que los lipofílicos lo son en medios acuosos. Se sabe que, sumada a su potencia innata, la efectividad de un antioxidante se ve también afectada por sus propiedades interfaciales y de partición en el medio. Los primeros estudios de oxidación en lípidos puros se basaron en la presunción de que la peroxidación ocurre en un medio homogéneo. La interfase aire-lípido fue considerada el sitio de inicio de la peroxidación propagándose luego al interior del aceite. Según esta suposición los antioxidantes parcialmente liposolubles se orientarían en la interfase aire-aceite donde ocurre la peroxidación y, por lo tanto, protegerían al sistema de los cambios oxidativos. Sin embargo, la distribución de antioxidantes polares en esta interfase fue cuestionada debido a que el aire es aún menos polar que el aceite. Así, se asumió que micro o nanoambientes afectan la química de la peroxidación y la acción antioxidante alterando la localización física de sustratos lipídicos y de antioxidantes. Por ejemplo, diferentes tipos de estructuras lamelares o miscelares (en presencia de trazas de agua) pueden formarse por autoensamble de componentes lipídicos (como fosfolípidos) o de productos de peroxidación (hidroperóxidos, aldehídos, cetonas). Actualmente existe evidencia suficiente que soporta la hipótesis que estas estructuras de asociación son los sitios donde ocurre la peroxidación en lípidos puros. Los antioxidantes polares, en lugar de ubicarse en la interfase aire-aceite como se creía previamente, están preferencialmente localizados en la interfase de estas estructuras coloidales (por ej: interfase agua-aceite) y resultan así más efectivos en la inhibición de la peroxidación que los no polares que se encuentran disueltos en la fase lipídica. Esta teoría fue sustentada por el hecho de que los antioxidantes polares, incapaces de disminuir la tensión superficial, sí lograron reducir la tensión interfacial (Chaiyasit y col, 2007)

Los resultados obtenidos en nuestro estudio refuerzan la hipótesis de que el elevado poder antioxidante demostrado por MLT en sistemas biológicos, debería ser adjudicado a la capacidad de MLT de modular enzimas y/o genes antes que a su capacidad secuestradora directa de radicales $\mathrm{LOO} \bullet$. 


\section{A nexo}

Técnicas y métodos 
Dado que la peroxidación lipídica iniciada por radicales libres es un proceso complejo y ocurre en múltiples etapas, diversas técnicas se encuentran disponibles para el estudio de esta reacción. La peroxidación puede ser estudiada mediante la determinación de pérdida de ácidos grasos no saturados, generación de productos primarios o secundarios de degradación o intermediarios de reacción.

En la tabla 6.1se resumen los métodos más utilizados para el seguimiento de la reacción de peroxidación lipídica.

Tabla 6.1. Métodos utilizados para detectar y medir peroxidación lipídica no enzimática (modificado de Södergren, 2000).

\begin{tabular}{|c|c|}
\hline ¿Qué se mide? & Método \\
\hline \multicolumn{2}{|l|}{ Pérdida de sustrato } \\
\hline PUFAs & GC/HPLC \\
\hline Incorporación de oxígeno & Electrodo de oxígeno \\
\hline \multicolumn{2}{|l|}{$\underline{\text { Intermediarios de reacción }}$} \\
\hline Radicales lipoperoxilos & Quimioluminiscencia \\
\hline \multicolumn{2}{|l|}{$\underline{\text { Productos primarios }}$} \\
\hline \multirow[t]{4}{*}{ Hidroperóxidos lipídicos totales } & Ensayo FOX-Absorbancia $550-600 \mathrm{~nm}$ \\
\hline & Oxidación de ioduro- Absorbancia 358 nm \\
\hline & Glutatión peroxidasa \\
\hline & Ciclooxigenasa \\
\hline \multirow[t]{2}{*}{ Hidroperóxidos lipídicos individuales } & HPLC-Quimioluminiscencia \\
\hline & GC-MS/HPLC \\
\hline \multirow[t]{3}{*}{ Dienos conjugados } & Absorbancia $230-235 \mathrm{~nm}$ \\
\hline & HPLC- Absorbancia 230-235 nm \\
\hline & Espectroscopía de derivados secundarios \\
\hline \multicolumn{2}{|l|}{ Productos secundarios de degradación } \\
\hline Hidrocarburos gaseosos & GC \\
\hline \multirow[t]{4}{*}{ TBARS/M DA } & Ensayo de TBARS- Absorbancia 532-535 nm \\
\hline & Ensayo de TBARS- Fluorescencia \\
\hline & Ensayo de TBARS - HPLC- Absorbancia 532-535 nm \\
\hline & Ensayo de TBARS - HPLC- Fluorescencia \\
\hline Aldehídos & GC-M S/HPLC/Anticuerpos/Fluorescencia \\
\hline $\mathrm{F}_{2}$-isoprostanos & GC-MS \\
\hline
\end{tabular}


Enzimoinmunoensayo

Radioinmunoensayo

GC: cromatografía gaseosa; HPLC: cromatografía líquida de alta performance; FOX: oxidación con $\mathrm{Fe}^{2+}$ en naranja de xilenol, M S: espectroscopía de masas; TBARS: sustancias reactivas al ácido tiobarbitúrico; M DA: malondialdehído y TBA: ácido tiobarbitúrico.

Por otro lado, existen diversos ensayos para determinar la actividad secuestradora de radicales de varios compuestos. La necesidad de identificar antioxidantes, que pueden secuestrar varios radicales libres y, por lo tanto, prevenir múltiples enfermedades, puede cubrirse por ensayos in vitro simples, sin embargo, los resultados obtenidos con estos ensayos deben ser confirmados con sistemas ex vivo e in vivo.

A continuación se describen las técnicas utilizadas en el presente trabajo de tesis:

\section{Espectrofotometría UV-visible}

Un espectro de absorción es un registro de la intensidad de la absorción de luz por una muestra en función de la longitud de onda de la radiación incidente. Éste muestra qué longitudes de onda son absorbidas por la molécula en estudio al pasar de niveles de menor a mayor energía. Las bandas observadas dan información sobre las diferencias energéticas entre los estados electrónicos de una molécula. Un espectro de absorción UV-visible no proporciona una clara identificación de un compuesto. Sin embargo, es muy útil para observar cambios en los grupos funcionales de una molécula, debido a que es muy sensible a ellos. Por ejemplo, las distintas formas ácido-base de una misma sustancia pueden claramente ser distinguidas por las diferencias en sus espectros de absorción. Para obtener un espectro de absorción se requiere de un equipo que posea una fuente de luz estable, y un dispositivo con capacidad de variar la longitud de onda en forma continua en la región UV-visible del espectro electromagnético. Debe poseer también un detector capaz de responder linealmente con la intensidad de la radiación transmitida a través de la muestra. La muestra puede encontrarse en fase gaseosa, líquida o sólida, pero usualmente se encuentra en soluciones diluidas, contenidas en celdas de vidrio o cuarzo. La celda debe ser transparente a la radiación, por ello el uso de celdas de cuarzo es esencial para longitudes de onda menores que $300 \mathrm{~nm}$. Si la muestra se encuentra en solución, debe realizarse una corrección por el solvente, debido a que el mismo puede presentar absorción (Dántola, 2008).

Con los datos obtenidos por esta técnica se realizaron gráficas de absorbancia versus tiempo para distintas longitudes de onda $(\lambda)$ (entre 200 y $300 \mathrm{~nm}$ ). El análisis de estas gráficas 
permite evaluar algunos aspectos cinéticos del proceso estudiado. Por ejemplo, observar si existen una o varias etapas de reacción, detectar en qué momento se producen cambios en las pendientes, etc.

Los cambios espectrales más notorios descriptos en la peroxidación de liposomas (capítulos 4 y 5) se observaron como una disminución entre 200 - 215 nm (desaparición de enlace metilénico entre dos dobles enlaces), aumento entre 230 - 240 nm (formación de dienos conjugados) y aumento entre 260 - $280 \mathrm{~nm}$ (aparición de trienos conjugados) (Buege y Aust, 1978). Dienos y trienos conjugados surgen tras el reordenamiento de los dobles enlaces del radical lipídico formado por acción de un radical libre iniciador. Los parámetros cinéticos obtenidos mediante esta técnica brindan información acerca de la actividad antioxidante de los diferentes compuestos estudiados.

\section{Quimioluminiscencia}

El estudio sistemático de la cinética de reacción de la peroxidación lipídica en membranas ha demostrado que este proceso, si bien es complejo, puede ser descripto por un conjunto de reacciones agrupadas en cuatro etapas generales (Vladimirov y col, 1980) (Figura 6.1):

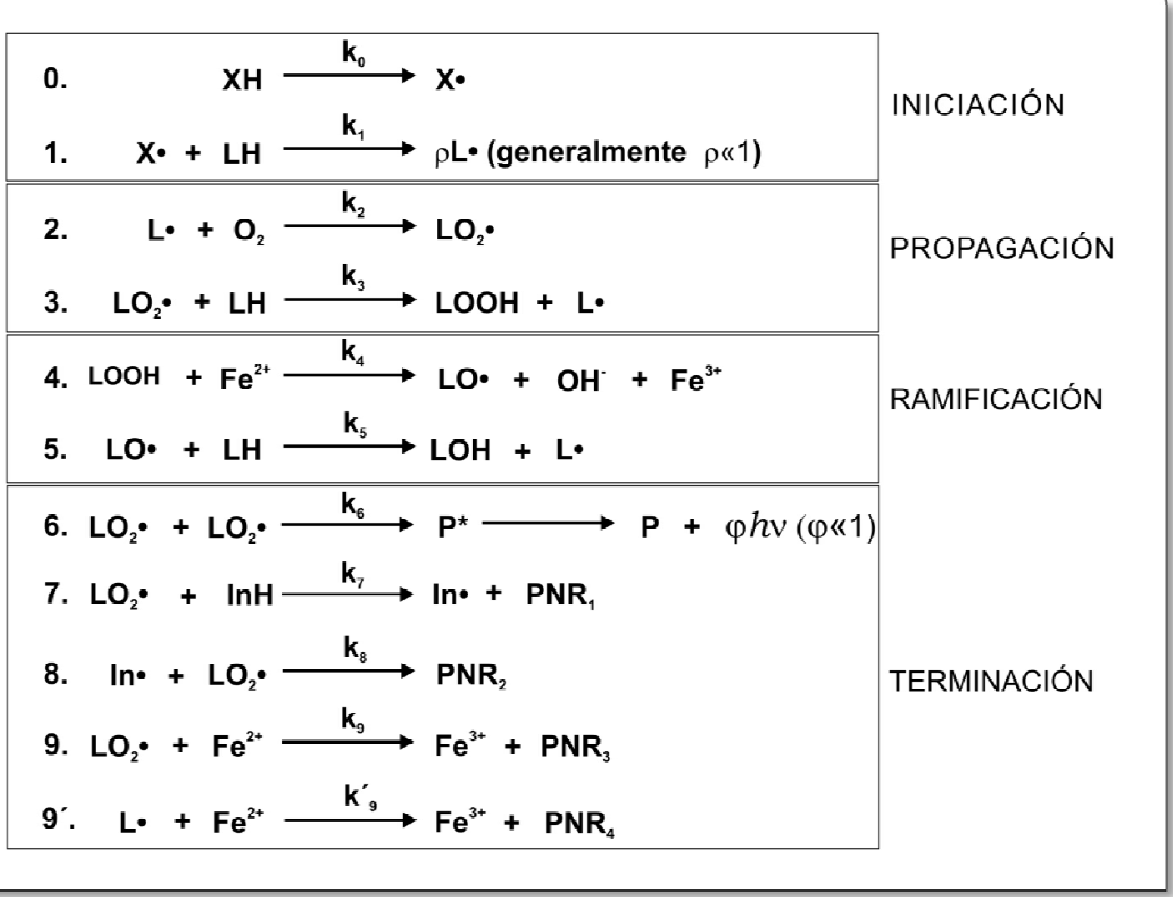

Figura 6.1. Esquema de las principales reacciones involucradas en el proceso de peroxidación lipídica. XH: iniciador de la cadena de peroxidación; X•: radical 
libre del iniciador; $\mathrm{LH}$ : lípido; $\mathrm{L} \bullet, \mathrm{LO} \bullet, \mathrm{LO}_{2} \bullet$ : radicales libres producidos a partir de LH; LOOH: hidroperóxido lipídico; InH: inhibidor (antioxidante); In •: radical libre del inhibidor; LOH, P, PNR : productos no radicales (tomado de Vladimirov y col, 1980).

1. Iniciación. Se generan radicales primarios de ácidos grasos polinosaturados (L・) como resultado de la acción de radicales iniciadores $(X \bullet)$ (Reacciones 0 y $\mathbf{1})$.

2. Propagación (Reacciones $\mathbf{2}$ y 3).En esta etapa el radical lipídico (L・) formado incorpora oxígeno molecular a su estructura para formar radical lipoperoxilo (LOO•). El radical LOO• puede atacar nuevas moléculas de lípido $(\mathrm{LH})$ generando una reacción en cadena.

La velocidad de la peroxidación lipídica es proporcional a la concentración de radicales L・ y LOO que dan lugar a la reacción en cadena, mientras que la relación [L• $] /[\mathrm{LOO} \cdot]$ en el estado estacionario depende de la relación entre las constantes $k_{2}$ y $k_{3}$ y de la concentración de oxígeno en el medio. La velocidad de reacción (w) aumenta con la concentración de PUFAs (LH) y depende del estado físico de la bicapa lipídica.

$$
\mathrm{w}=-\frac{\mathrm{d}[\mathrm{LH}]}{\mathrm{dt}}=\mathrm{k}_{3}[\mathrm{LH}]\left[\mathrm{LO}_{2}^{\cdot}\right]=\mathrm{k}_{2}\left[\mathrm{O}_{2}\right]\left[\mathrm{L}^{*}\right]
$$

3. Ramificación de la cadena. Hay evidencias de que en membranas biológicas esta etapa involucra al ión $\mathrm{Fe}^{2+}$ no hemínico (Reacción 4)

4. Terminación. Se conocen al menos tres formas de cortar la reacción en cadena: interacción de dos radicales (Reacción 6), interacción de un radical con un metal de transición (Reacción $\mathbf{9}$ o 9') y reacción entre un radical y una molécula de "antioxidante", es decir un compuesto cuyo radical sea incapaz de continuar la cadena de reacción (Reacción 7).

La investigación sobre la cinética de reacción de la lipoperoxidación fue significativamente estimulada por el descubrimiento de la quimioluminiscencia que acompaña a este proceso (Vladimirov y col, 1966). La generación espontánea de quimioluminiscencia en suspensiones mitocondriales y de microsomas hepáticos ligada a la reacción de lipoperoxidación, puede ser y ha sido interpretada como un indicador de la generación de oxígeno singlete (Howes y Steele, 1971). Sin embargo, la generación de otro producto de la dismutación del radical lipoperóxido, la cetona excitada, también fue propuesta como fuente de luminiscencia en la reacción de peroxidación (Zhuravlev, 1962; Zhuravlev, 1966) según el siguiente esquema de reacción: 


$$
\mathrm{LO}_{2}^{*}+\mathrm{LO}_{2}^{*} \rightarrow \mathrm{LO}^{*}+\mathrm{LOH}+\mathrm{O}_{2}
$$

donde $\mathrm{LO}_{2}^{*}$ : radical peroxilo, $\mathrm{LO}^{*}$ : cetona activada, $\mathrm{LOH}$ : alcohol lipídico, $\mathrm{O}_{2}$ : oxígeno

La reacción 6 es particularmente interesante dado que está acompañada de emisión de luz cuya intensidad (I) puede estimar la concentración de LOO • según la siguiente ecuación:

$$
\mathrm{I}=\mathrm{K} \phi \mathrm{k}[\mathrm{LOO} \bullet]^{2}
$$

donde $\phi$ representa la eficiencia cuántica de quimioluminiscencia y $k$ es un coeficiente que depende de la sensibilidad neta del instrumento (Vladimirov y col, 1980).

Antioxidantes, tales como $\alpha$-tocoferol reaccionan directamente con radicales libres que participan de la cadena de peroxidación (Reacción 7), evitando así la fase de propagación. De esta manera, la reacción entre un radical LOO • y una molécula de antioxidante (InH) previene la emisión de luz.

\section{Ensayo de sustancias reactivas al ácido tiobarbitúrico (TBARS)}

La utilización de la reacción con TBA para medir la peroxidación lipídica se remonta al año 1944 cuando Kohn y Liversedge (1944) observaron que tejidos animales incubados aeróbicamente con TBA producían un color rosado. Bernheim y colaboradores (1948) descubrieron que el color rosado se debía a un complejo formado por productos de oxidación de ácidos grasos no saturados y TBA. Yu y Sinnhuber (1957) reportaron que malondialdehído (MDA) era la principal sustancia reactiva al TBA aunque más tarde otros investigadores informaron que otros productos de oxidación podían estar involucrados, como aldehídos no saturados (por ej.: 4-hidroxialquenales) y varios precursores de estas sustancias no volátiles no identificados.

La principal sustancia reactiva al TBA, el malondialdehído, es un dialdehído de tres carbonos altamente reactivo, generado como uno de los principales bioproductos de la peroxidación de ácidos grasos polinosaturados (Janero, 1990) y también durante el metabolismo de ácido araquidónico para la síntesis de prostaglandinas (Marnette, 1999). MDA puede combinarse con diversos grupos funcionales de proteínas, lipoproteínas, ARN y ADN (Sevilla y col, 1997). La determinación de los niveles de MDA en materiales biológicos es un método conveniente, sensible y ampliamente utilizado para estimar cuantitativamente la extensión de la peroxidación lipídica. Se han descripto diversas técnicas para determinar MDA, como el ensayo de TBA espectrofotométrico, HPLC Kakuda y col, 1981) y cromatografía 
gaseosa. La determinación de MDA por este último precisa de su derivatización (Hamberg y col, 1968; Lakshminarayana y Cornwell, 1986; Tomita y col, 1990).

El método espectrofotométrico del TBA es el más comúnmente utilizado para la cuantificación de MDA. La reacción ocurre por ataque del MDA sobre el grupo metileno activo del TBA (Figura 6.2). Un mol de MDA reacciona con dos moles de TBA en medio ácido y a alta temperatura. La velocidad de esta reacción depende de la concentración de TBA, la temperatura y el pH. El pigmento generado posee un pico máximo de absorbancia a 532-535 $\mathrm{nm}$ y otro secundario a 245-305 nm (Sinnhuber y col, 1958). El ensayo de TBA puede determinarse también por un procedimiento espectrofluorométrico dado que el espectro de excitación del pigmento TBA-M DA posee un máximo a 532 nm (Yagi, 1984). La especificidad de este método es similar al del método espectrofotométrico, debido a que otros compuestos originados en la degradación de peróxidos lipídicos también pueden generar fluorescencia (Shimasaki y col, 1977).

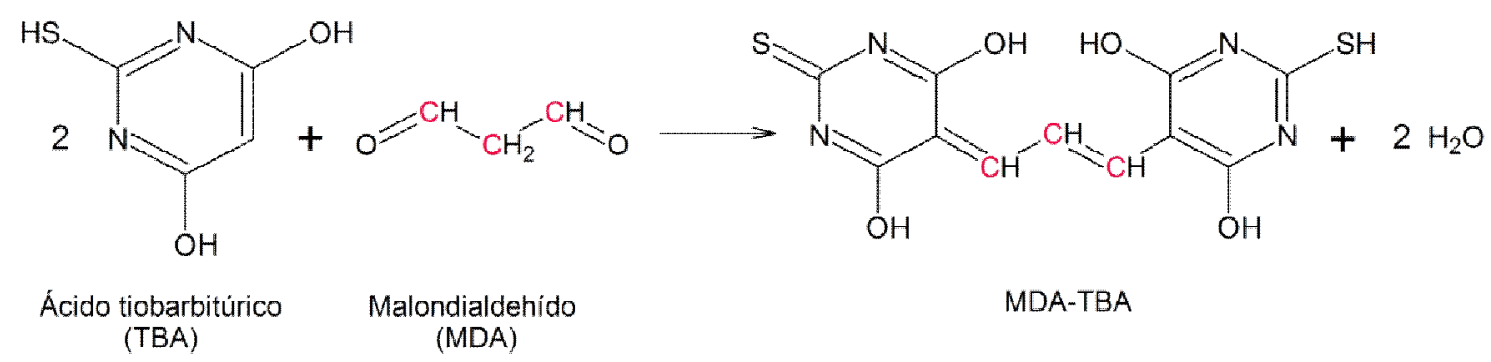

\section{Figura 6.2. Esquema de la reacción entre malondialdehído y ácido tiobarbitúrico.}

El principal problema con el ensayo de TBARS es su falta de especificidad. TBA reacciona con una variedad de aldehídos, no sólo con aquellos formados como resultado de la peroxidación lipídica sino también con glucosa, desoxirribosa, ácido ascórbico, homocisteína y algunos aminoácidos tales como, prolina, arginina y glutamato, por esta razón el análisis en fluidos biológicos por este método resulta complejo (Spickett y col, 2010). Otra limitación del ensayo de TBA es que el MDA y otros productos de cadena corta no son estables por largos períodos de tiempo. Esto se debe a que la oxidación de estos compuestos genera alcoholes y ácidos orgánicos que no son determinados por el ensayo de TBA (Tarladgis y Watts, 1960; Fernández y col, 1997).

En el presente trabajo de tesis esta técnica aportó información útil para el monitoreo de la reacción de peroxidación. Las interferencias comunes de esta técnica (azúcares, proteínas, aminoácidos, ácido ascórbico, etc) no constituyeron un problema ya que al utilizar 
sistemas puramente lipídicos las sustancias reactivas al TBA sólo provinieron de la reacción de peroxidación de los lípidos.

\section{Cromatografía gaseosa acoplada a espectrometría de masas}

El análisis de ácidos grasos requiere de las siguientes etapas:
a. Obtención de los lípidos por extracción con mezcla de solventes.
b. Derivatización de los ácidos grasos.
c. Análisis por cromatografía gaseosa.

a. El primer punto fue realizado mediante el llamado método de Folch (Folch y col, 1957) que emplea una mezcla de cloroformo: metanol (2:1). Con esta mezcla se realizó la extracción de lípidos de las retinas bovinas con los que se prepararon los liposomas y los lípidos de los liposomas ya preparados.

b. Los métodos de derivatización se pueden dividir en cuatro categorías (Christie, 1989):

1) transesterificación ácida: $\mathrm{HCl}$ en metanol $5 \% \mathrm{p} / \mathrm{v}, \mathrm{H}_{2} \mathrm{SO}_{4}$ en metanol 1 a $2 \% \mathrm{v} / \mathrm{v}$, cloruro de acetilo en metanol, $\mathrm{BF}_{3}$ en metanol

\section{Ventajas}

Todos estos métodos convierten los acilgliceroles o triglicéridos y ácidos grasos libres en ésteres metílicos. El más popular tal vez es el $\mathrm{BF}_{3} 12-14 \% \mathrm{p} / \mathrm{v}$ en metanol por usar el primer procedimiento aceptado por AOCS. Es un método rápido.

\section{Desventajas}

Forma compuestos ajenos o interferentes. No es útil para aceites de semilla que contienen ácidos grasos inusuales como epoxi, ciclopropeno, etc. Reacciona con colesterol formando colesterolmetiléster y colestadieno. El reactivo es caro e inestable. Debe refrigerarse. El empleo de $\mathrm{BF}_{3}$ antiguo o concentrado produce pérdidas de ácidos grasos poli no saturados.

2) transesterificación básica: M etóxido de sodio en metanol anhidro

\section{Ventajas}

Rápido, puede efectuarse a temperatura ambiente. Convierte los triglicéridos 0 acilgliceroles directamente a ésteres metílicos (transesterificación). No produce isomerización de dobles enlaces. No transesterifica ni esfingolípidos ni colesterol.

\section{Desventajas}


No convierte los ácidos grasos libres a ésteres metílicos. Por lo tanto no sirve para muestras de materias grasas con elevada acidez. Debe trabajarse en medio anhidro. La presencia de agua produce saponificación lo cual resulta en pérdida de ácidos grasos. El uso prolongado puede alterar la composición en ácidos grasos. Alta concentración de álcali y alta temperatura puede llevar a la formación de ácidos grasos conjugados.

\section{3) diazometano:}

\section{Ventajas}

Es un método rápido casi instantáneo a temperatura ambiente. Esterifica los ácidos grasos libres en presencia de metanol. El exceso de reactivo se elimina por evaporación bajo $\mathrm{N}_{2}$.

\section{Desventaja}

Reactivo muy tóxico. Se puede usar sólo si es estrictamente necesario. Es explosivo. Forma compuestos extraños reaccionando con dobles enlaces o grupos carbonilos.

4) otros métodos de esterificación: en la búsqueda de reactivos que metilen más rápidamente a los ácidos grasos se han desarrollado por ej: sales cuaternarias de amonio, cloruro de acetilo en metanol, guanidina y sus derivados alquilados en metanol, etc (Christie, 1989).

Para derivatizar los ácidos grasos provenientes de retina y de liposomas preparados con lípidos de la misma, seleccionamos el método que incluye $\mathrm{BF}_{3} /$ metanol como reactivo metilante, por poseer menos desventajas que los demás reactivos, ser un reactivo ampliamente utilizado en la bibliografía consultada, por su fácil manipulación y porque los resultados que obtuvimos con otros reactivos tales como $\mathrm{NaOH}$ /metanol y $\mathrm{HCl} /$ metanol no tuvieron diferencias significativas con los obtenidos empleando $\mathrm{BF}_{3}$.

c. La técnica de cromatografía gaseosa es una forma de cromatografía de partición en la cual la fase móvil es un gas y la fase estacionaria es un líquido. La muestra es inyectada en la fase gaseosa que es volatilizada y pasa a la fase líquida, que se encuentra retenida en la columna. Los componentes de la muestra pasan diferentes tiempos entre la fase móvil y la estacionaria dependiendo de sus afinidades relativas por esta última y emergen al final de la columna exhibiendo picos de concentración, con un distribución idealmente Gaussiana. Estos picos son detectados por algún sistema que convierte la concentración del componente en la fase gaseosa en una señal eléctrica, que es amplificado y registrada.

Un cromatógrafo básico posee tres componentes esenciales: el inyector (por el que se introduce la muestra a la columna), la columna en sí misma (que contiene la fase estacionaria y a través de la cual pasa la fase móvil) y el detector. 
Las columnas pueden ser empacadas o recubiertas y el principal factor a tener en cuenta es la selectividad de la misma para la separación requerida. El principal factor que influencia la separación es la polaridad de la fase líquida.

Existen numerosos detectores disponibles. El utilizado en este trabajo de tesis consiste en un detector de masa que permite, además de la cuantificación, la identificación de los compuestos. El principio en que se basa esta técnica es que los compuestos que eluyen en la fase gaseosa son bombardeados por electrones formando iones cargados positivamente que se fragmentan de distintas maneras generando especies iónicas de menor tamaño. Estos fragmentos llegan a un campo electromagnético que los separa según su relación masa/carga $(\mathrm{m} / \mathrm{z})$. Ellos son recolectados por el detector en orden creciente de esta relación $\mathrm{m} / \mathrm{z}$ y la corriente iónica es amplificada generando la señal. Al pico mayoritario se le asigna un valor de intensidad arbitrario igual a 100, y las intensidades de los demás iones se normalizan a éste. El ión formado de la molécula es denominado ión molecular $(M+)$. El gráfico de intensidad iónica en función de la relación $\mathrm{m} / \mathrm{z}$ se conoce como espectro de masas.

Las moléculas no se fragmentan de forma arbitraria sino que tienden a romperse en los enlaces más débiles, tales como aquellos adyacentes a grupos funcionales específicos, o de acuerdo a ciertas reglas complejas que han sido formuladas empíricamente a partir de estudios con compuestos modelos. Es posible deducir la estructura del compuesto original a partir de los fragmentos producidos. Para compuestos cuyos resultados son confusos, se pueden comparar sus espectros de masas con aquellos compuestos con propiedades similares. Estas comparaciones se facilitan enormemente con ayuda de programas informáticos especiales. En este trabajo de tesis, los espectros de masa obtenidos son comparados a través del software TurboMass, provisto por la empresa Perkin Elmer, con los de la biblioteca NIST lo que nos permitió identificar los diferentes derivados de ácidos grasos estudiados.

\section{Ensayo de DPPH}

El ensayo de DPPH es una de las diversas técnicas empleadas para estimar la actividad secuestradora de radicales de compuestos específicos o extractos naturales (Blois, 1958). Esta técnica espectrofotométrica emplea el radical 1,1-difenil-2-picrilhidracil (DPPH), que posee un espectro de absorbancia característico, con un máximo de absorbancia a $515 \mathrm{~nm}$ (Figura 6.3). La reducción de DPPH provocada por un antioxidante $(\mathrm{AH}) \mathrm{o}$ un radical, implica disminución en su absorbancia a 515 nm (Brand-Williams y col, 1995). 


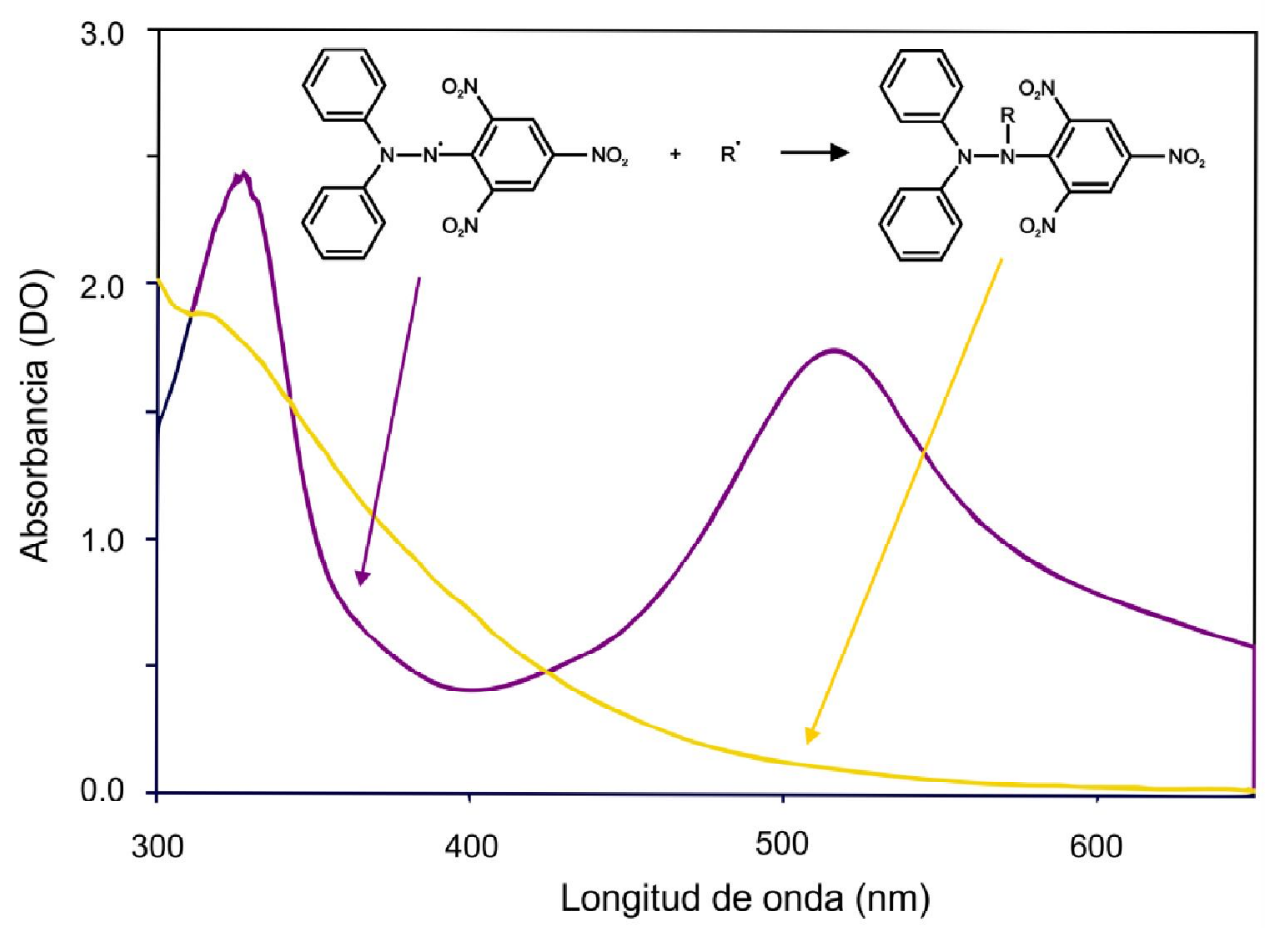

Figura 6.3. Estructuras y espectros del radical DDPH• (línea violeta) y de DPPH reducido (línea amarilla)

Se creía que el ensayo de DPPH involucraba una reacción de transferencia de un átomo de hidrógeno, pero Foti y colaboradores sugirieron que la reacción que tiene lugar corresponde a una transferencia de electrones (Foti y col, 2004). Los autores determinaron que el paso determinante de la velocidad para esta reacción consiste en un proceso rápido de transferencia de electrones de un anión fenóxido al DPPH. Que el DPPH sustraiga un átomo de hidrógeno a partir del antioxidante fenólico neutral resulta una vía secundaria de reacción, dado que ésta ocurre muy lentamente en solventes tales como metanol y etanol. Además, los autores indicaron que ácidos o bases presentes como contaminantes en el solvente pueden influenciar dramáticamente el equilibrio de ionización de fenoles, alterando los valores de las constantes de velocidad de reacción medidas.

Además de las diferencias mecanísticas entre la reacción de transferencia de átomos de hidrógeno que ocurre normalmente entre antioxidantes y radicales peroxilos, DPPH es un radical nitrogenado de larga vida, que no guarda relación con los radicales peroxilos altamente reactivos involucrados en la peroxidación lipídica. Muchos antioxidantes que reaccionan rápidamente con radicales peroxilos pueden reaccionar lentamente 0 , aún más, ser inertes 
frente al DDPH (Huang y col, 2005). A pesar de estas desventajas, el ensayo de DPPH sigue siendo una técnica ampliamente utilizada debido a su simplicidad y a la ventaja de emplear un radical libre estable disponible comercialmente. Es altamente reproducible y comparable con otros métodos como ABTS, reducción de anión superóxido e inhibición de peroxidación lipídica (Villaño y col, 2007). 


\section{Bibliografía}

Abe M, Reiter RJ, Orhii PB, Hara M, Poeggeler B. Inhibitory effect of melatonin on cataract formation in newborn rats: evidence for an antioxidative role for melatonin. J. Pineal Res. 17: 94-100. 1994.

Abuja PM, Liebmann P, Hayn M, Schauenstein K, Esterbauer H. Antioxidant role of melatonin in lipid peroxidation of human LDL. FEBS Letters. 413: 289-293. 1997

Acuña-Castroviejo D, Escames G, Carozo A, Leon J, Khaldy H, Reiter RJ. Melatonin, mitocondrial homeostasis and mitocondrial-related diseases. Cur., Topics. Med. Chem.2:133-52. 2002

Aikens J, Dix TA. Effect of solution ionic strength on lipid peroxidation initiation by the perhydroxyl (xanthine oxidase-derived) and peroxyl radicals. Chem. Res. Toxicol. 5: 263-267. 1992

Allegra M, Reiter RJ, Tan DX, Gentile C, Tesoriere L, Livrea MA. The chemistry of melatonin's interaction with reactive species. J. Pineal Res. 34: 1-10. 2003

Alonso R. La glándula pineal. Fisiología Humana. Eds.: Tresguerres JAF.; Aguilar E, Cachofeiro MV y cols. M cGraw-Hill. Interamericana. 891-901. 1999

Anderson RE. Lipids of ocular tissues. IV. A comparison of the phospholipids from the retina of six mammalian species. Exp. Eye Res. 10: 339-344. 1970.

Antolín I, Rodríguez C, Saínz RM, Mayo JC, Uría H, Kotler ML, Rodríguez-Colunga MJ, Tolivia D, Menéndez-Peláez A. Neurohormone melatonin prevents cell damage: effect on gene expression for antioxidant enzymes. FASEB J. 10: 882-90. 1996.

Antunes F, Barclay LRC, Ingold KO et al. On the antioxidant activity of melatonin. Free Radical Biol Med. 26: 117-128. 1999

Arendt J. M elatonin and the mammalian pineal gland. Arent J. Chapman and Hall. 1-5. 1995.

Aviram M, Cogan U, Mokady S. Excessive dietary tryptophan enhances plasma lipid peroxidation in rats. Atherosclerosis. 88: 29-34. 1991

Banni, S. Conjugated linoleic acid metabolism. Current Opinion in Lipidology. 13: 261-266. 2002.

Barlow-Walden LR, Reiter RJ, Abe M, Pablos M, M enendez-Pelaez A, Chen LD, Poeggeler B. Melatonin stimulates brain glutathione peroxidase activity. Neurochem. Int. 26: 497502. 1995

Barsacchi R, Kusmic C, Damiani E, Carloni P, Greci L, Donato L. Vitamin E consumption induced by oxidative stress in red blood cells is enhanced by melatonin and reduced by $\mathrm{N}$ - 
acetylserotonin. Free Radic Biol Med. 24: 1187-1192. 1998

Basu S, Smedman A, Vessby B. Conjugated linoleic acid induces lipid peroxidation in humans. FEBS Letters. 468: 33-36. 2000

Bauman DE, Corl BA, Baumgard LH, Griinari JM. Conjugated linoleic acid (CLA) and the dairy cow. Recent Advances in Animal Nutrition. NottinghamUniversity Press, Nottingham, UK. 221-250. 2001.

BaumanDE. Conjugated Linoleic Acid (CLA) and Milk Fat: A Good News Story. Department of Animal Science, Cornell University, Ithaca, EEUU. 2002

Bazan NG, Birkle DL, Reddy .S. Docosahexaenoic acid $(22: 6, n-3)$ is metabolized to lipoxygenase reaction products in the retina. Biochem. Biophys. Res. Commun. 125: 741-747. 1984

Beatty S, Koh H, Phil M, Henson D, Boulton M. The role of oxidative stress in the pathogenesis of age-related macular degeneration. Surv. Ophthalmol. 45: 115-134. 2000.

Beaulieu A, Drackley J. Conjugated linoleic acid content of milk fat is increased by feeding an animal fat low in linoleic acid. J. Dairy Sci. 82: 848. 1999

Belury MA. Dietary conjugated linoleic acid in health: physiological effects and mechanisms of action. Annu. Rev. Nutr. 22: 505-531. 2002

Bernheim FM, Bernheim LC, Wilbur KM. The reaction between thiobarbituric acid and the oxidation products of certain lipids. J. Biol. Chem. 174: 257-264. 1948

Berg JM, Tymoczko JL, Stryer L. Biochemistry. Ed. W.H. Freeman and Company, New York (EEUU) 2002

Betteridge DJ. What is oxidative stress? Metabolism. 49: 3-8. 2000.

Blask DE, Sauer LA, Dauchy RT. Melatonin as a chronobiotic/anticancer agent: cellular, biochemical, and molecular mechanisms of action and their implications for circadianbased cancer therapy. Curr. Top. M ed. Chem. 2: 113-132. 2002

Blois, MS. Antioxidant determination by the use of stable free radical. Nature. 181: 11991200. 1958.

Brand-Williams W, Cuvelier ME, Berset C. Use of a free radical method to evaluate antioxidant activity. Food Sci Technol. 28: 25-30. 1995

Brzozowska I, Konturek PC, Brzozowski T, Konturek SI, Kwiecien S, Pajdo R, Drozdowicz D, Pawlik M, Ptak A, Hahn EG. Role of prostaglandins, nitric oxide, sensory nerves and gastrin in acceleration of ulcer healing by melatonin and its precursor, L-tryptophan. J Pineal Res. 32: 149-162. 2002

Buege JA, Aust SD. Microsomal lipid peroxidation. M ethods Enzymol. 52: 302-310. 1978 
Buettner GR. The pecking order of free radicals and antioxidants: lipid peroxidation, alphatocopherol, and ascorbate. Arch Biochem Biophys. 300: 535-543. 1993

Burdge GC, Powell J, Dadd T, Talbot D, Civil J, Calder PC. Acute consumption of fish oil improves postprandial VLDL profiles in healthy men aged 50-65 years. $\mathrm{Br}$ J Nutr. 102: 160-165. 2009;

Burton GW, Ingold KU. Vitamin E as an in vitro and in vivo antioxidant. Ann N Y Acad Sci. 570:7-22. 1989

Burton GW, Joyce A, Ingold KU. First proof that vitamin E is major lipid-soluble, chain-breaking antioxidant in human blood plasma. Lancet. 2: 327. 1982

Cabrera J, Reiter RJ, Tan DX, Qi W, Sainz RM, Mayo JC, Garcia JJ, Kim SJ, El-Sokkary G. Melatonin reduces oxidative neurotoxicity due to quinolinic acid: in vitro and in vivo findings. Neuropharmacology. 39: 507-514. 2000

Calder PC. The relationship between the fatty acid composition of immune cells and their function. Prostaglandins Leukot Essent Fatty Acids. 79: 101-108. 2008;

Calder PC, Yaqoob P. Omega-3 polyunsaturated fatty acids and human health outcomes. Biofactors. 35: 266-272. 2009

Calder PC, Yaqoob P. Omega-3 (n-3) fatty acids, cardiovascular disease and stability of atherosclerotic plaques. Cell Mol Biol. 56: 28-37. 2010

Calvo JR, Reiter RJ, Garcia JJ, Ortiz GG, Tan DX, Karbownik M. Characterization of the protective effects of melatonin and related indoles against alphanaphthylisothiocyanate-induced liver injury in rats. J Cell Biochem. 80: 461-470. 2001

Camejo G, Wallin B, Enojärvi M. Analysis of oxidation and antioxidants using microtiter plates. Free Radical and Antioxidant Protocols. Methods in Molecular Biology. 108 (ed. D. Armstrong), 377-386. Totawa, NJ : Humana Press Inc. 1998.

Carampin P, Rosan S, Dalzoppo D, Zagotto G, Zatta P. Some biochemical properties of melatonin and the characterization of a relevant metabolite arising from its interaction with $\mathrm{H}_{2} \mathrm{O}_{2}$. J. Pineal Res. 34: 134-142. 2003.

Caspi O. Melatonin for the prevention and treatment of jet lag. Alther Ther Health Med. 10: 74-78. 2004.

Catalá A. An overview of lipid peroxidation with emphasis in outer segments of photoreceptors and the chemiluminescence assay. Int. J. Biochem. Cell. Biol. 38: 14821495. 2006.

Catalá A. Lipid peroxidation of membrane phospholipids generates hydroxyalkenals and oxidized phospholipids active in physiological and/or pathological conditions. Chem. 
Phys. Lipids. 157: 1-11, Review. 2009.

Catalá A. The ability of melatonin to counteract lipid peroxidation in biological membranes. Curr. Mol. Med. 7: 638-649.2007.

Catalá A. The function of very long chain polyunsaturated fatty acids in the pineal gland. Biochim. Biophys. Acta. 1801: 95-99. 2010.

Catalá A. Lipid peroxidation. Principles of Free Radical Biomedicine. Volume 1. Ed: K. Pantopoulos, H. M. Schipper. Nova Science Publishers, Inc. 2011

Chaudiere J, Ferrari-lliou R. Intracellular antioxidants: from chemical to biochemical mechanisms. Food Chem Toxicol. 37: 949-962. 1999

Collin JP. Differentiation and regression of the cells of the sensory line in the epiphysis cerebri. In The Pineal Gland (Ed). Wolstenhome GEW y Knight J. Churchill Livingstone. Edinburgh. 79-125. 1972.

Corl B, Baumgard L, Dwyer D, Griinari J, Phillips B , Bauman D. The role of delta (9)-desaturase in the production of cis-9, trans-11 CLA. J. Nutr. Biochem. 12: 622-630. 2001.

Christie WW. High-Performance Liquid Chromatography and Lipids. Pergamon Books, Oxford. 1987

Christie WW. Gas chromatography and lipids. The oily press. Scotland. 1989

Curnutte JT, Babior BM . Chronic granulomatous disease. Adv Hum Genet. 16: 229-297. 1987

Curtis MT, Gilfor D, Farber JL. Lipid peroxidation increases the molecular order of microsomal membranes. .Arch Biochem Biophys 235: 644-649. 1984

Cuzzocrea S, Reiter RJ. Pharmacological actions of melatonin in acute and chronic inflammation. Curr. Topics. Med. Chem. 2: 153-166. 2002.

Dántola ML. Reactividad térmica y fotoquímica de 7,8-dihidropterinas frente a especies oxidantes en condiciones fisiológicas (Tesis doctoral). Dpto. Química. Facultad de Cs. Exactas. Universidad Nacional de La Plata. La Plata, Buenos Aires, Argentina. 2008

Das YT, Bagchi M, Bagchi D, Preuss HG. Safety of 5-hydroxy-L-tryptophan. Toxicol Lett. 150: 111-122. 2004

De Almeida EA, Martinez GR, Klitzke CF, De Medeiros MHG, Di Mascio P. Oxidation of melatonin by singlet molecular oxygen produces N1-acetyl-N2-formyl-5methoxykynuramine. J. Pineal Res. 35: 131-137. 2003.

De La Paz MA, Anderson R. Lipid peroxidation in rod outer segments. Role of hydroxyl radical and lipid hydroperoxides, Invest.Ophthalmol. Vis. Sci. 33: 2091-2096. 1992.

Deker JF, Quay WB. Stimulatory effects of melatonin on ependymal epithelium of choroids plexuses in golden hamsters. J. Neural. Trasnm. 55: 53-67. 1982. 
Delanty N, Dichter MA. Oxidative injury in the nervous system. Acta Neurol Scand.98: 145-153. 1998

Descartes R. De Homine. Figuritis et Latinitate Donatus a Schuyl. F. Lugdni Batavorum. 1662.

Diplock AT, Charleux JL, Crozier-Willi G, Kok FJ, Rice-Evans C, Roberfroid M, Stahl W, VinaRibes J. Functional food science and defence against reactive oxidative species. $\mathrm{Br} J$ Nutr. 80: 77-112. 1998

Djuric Z, Potter DW, Taffe BG, Strasburg GM. Comparison of iron-catalyzed DNA and lipid oxidation. J. Biochem.M ol. Toxicol.15: 114-119. 2001

Dubbels R, Reiter RJ, Klenke E, Goebel A, Schnakenberg E, Ehlers C, Schiwara HW, Schloot W. Melatonin in edible plants identified by radioimmunoassay and by high performance liquid chromatography-mass spectrometry. J. Pineal Res. 18: 28-31. 1995.

Duell PB, Wheaton DL, Shultz A, Nguyen $\mathrm{H}$. Inhibition of LDL oxidation by melatonin requires supraphysiologic concentrations. Clin. Chem. 44: 1931-1936. 1998.

Dypbukt JM, Ankarcrona M, Burkitt M, Sjöholm A, Ström K, Orrenius S, Nicotera P. Different prooxidant levels stimulate growth, trigger apoptosis, or produce necrosis of insulinsecreting RINm5F cells. The role of intracellular polyamines. J Biol Chem. 269: 3055330560. 1994

Eastridge M, Qiu X. Conjugated linoleic acid in milk from cows on pasture. Department of Animal Sciences. The OhioStateUniversity, Special Circular Ohio Agricultural Research and DevelopmentCenter. № 182. Ohio, EEUU. 37-40. 2001

Feksa LR, Latini A, Rech VC, Wajner M, Dutra-Filho CS, de Souza Wyse AT, Wannmacher CM. Promotion of oxidative stress by L-tryptophan in cerebral cortex of rats. Neurochem Int. 49: 87-93. 2006

Fernández J, Pérez-Álvarez JZ,Fernández-López JA. Thiobarbituric acid test for monitoring lipid oxidation in meat. Food Chemistry. 59: 345-353. 1997.

Finocchiaro LM, Arzt ES, Fernandez-Castelo S, Criscuolog M, Finkielman S, Nahmod VE. Serotonin and melatonin synthesis in peripheral blood mononuclear cells: stimulation by interferon-gamma as part of and immunomodulatory pathway. J. Interferon Res. 8: 705-716. 1988.

Fischer BE, Haring UK, Tribolet R, Sigel H. Metal ion/buffer interactions. Stability of binary and ternary complexes containing 2 -amino-2 (hydroxymethyl)-1,3 -propanediol (Tris) and adenosine 5'-triphosphate (ATP). Eur. J. Biochem. 94:523-530. 1979

Fleischer S, Rouser GJ. Lipids of subcellular particles. Am. Oil Chem. Soc. 42 (7) 588-607. 1965.

Fliesler SJ, Anderson RE. Chemistry and metabolism of lipids in the vertebrate retina.Prog. 
Lipid Res. 22: 79-131. 1983

Folch J, Lees N, Sloane Stanley GA. A simple method for the isolation and purification of total lipids from animals tissues. J. Biol. Chem. 226: 497-509. 1957

Foti MC, Daquino C, Geraci C. Electron-transfer reaction of cinnamic acids and their methyl esters with the DPPH radical in alcoholic solutions. J. Org. Chem. 69, 2309 2314. 2004

Fowler G, Daroszewska M, Ingold KU. Melatonin does not "directly scavenge hydrogen peroxide": Demise of another myth. Free Radic Biol Med. 34: 77-83. 2003

Frankel EN. Free radical oxidation. Lipid oxidation; Frankel, E. N., Ed.; Oily Press: Dundee, Scotland, 1998; pp 1322

Fritsche J, Steinhart H. Analysis, occurrence and physiological properties of trans fatty acids (TFA) with particular emphasis on conjugated linoleic acid isomers (CLA) a review. Fett. / Lipid. 100: 190-210. 1998

Fu JY, Masferrer JL, Seibert K, Raz A, Needleman P. The induction and suppression of prostaglandin $\mathrm{H} 2$ synthase (cyclooxygenase) in human monocytes. J Biol Chem. 265: 16737-16740. 1990

Fuhrberg B, Hardeland R. In: Hardeland, R. (Ed.). Oxidation of melatonin by free radicals: catalysis by hemin. In: Cell Biological Problems in Chronobiology. University of Goettingen, Goettingen. 75-81. 1994

Fukuzawa K, Seko T, Minami K, Terao J. Dynamics of iron ascorbate- induced lipid peroxidation in charged and uncharged phospholipid vesicles. Lipids. 28: 497-503. 1993.

Gagliostro G, Vidaurreta L, Schroeder G, Rodríguez A, Gatti P. Incrementando los valores basales de ácido linoleico conjugado (CLA) en la grasa butirosa de vacas lecheras en condiciones de pastoreo. Rev. Arg. Prod. Anim. 25 Congreso Argentino de Producción Animal. Buenos Aires, Argentina. 22: 59-60. 2002

Gal S, Pinchuk I, Lichtenberg D. Peroxidation of liposomal palmitoyllinoleoylphosphatidylcholine (PLPC), effects of surface charge on the oxidizability and on the potency of antioxidants. Chem. Phys. Lipids. 126: 95-110. 2003

Galano A. On the direct scavenging activity of melatonin towards hydroxyl and a series of peroxyl radicals. Phys Chem Chem Phys. 13, 7178-7188. 2011

García JJ, Reiter RJ, Guerrero JM, Escames G, Yu BP, Oh CS, Muñoz-Hoyos A. Melatonin prevents changes in microsomal membrane fluidity during induced lipid peroxidation. FEBS Lett. 408: 297-300. 1997

García JJ, Reiter RJ, Cabrera JJ, Pié J, M ayo JC, Sáinz RM , Tan DX, Qi W, Acuña-Castroviejo D. 5Methoxytryptophol preserves hepatic microsomal membrane fluidity during oxidative 
stress. J Cell Biochem. 76: 651-657. 2000

García JJ, Reiter RJ, Karbownik M, Calvo JR, Ortiz GG, Tan DX, Martínez-Ballarín E, AcuñaCastroviejo D. $\mathrm{N}$-acetylserotonin suppresses hepatic microsomal membrane rigidity associated with lipid peroxidation. Eur J Pharmacol. 428: 169-175. 2001

García JJ, Reiter RJ, Pié J, Ortiz GG, Cabrera J, Sáinz RM , Acuña-Castroviejo D. Role of pinoline and melatonin in stabilizing hepatic microsomal membranes against oxidative stress. J. Bioenerg. Biomembr. 31: 609-616. 1999.

Gaté L, Paul J, Ba GN, Tew KD, Tapiero H. Oxidative stress induced in pathologies: the role of antioxidants. Biomed Pharmacother. 53: 169-180. 1999

Genot C, Kansci G, Laroche M. Measurement of phospholipid oxidation in model membranes by determination of oxygen consumption with a semi-automatic polarographic method. Sci.Aliments. 14: 673-682. 1994.

Gitto E, Tan DX, Reiter RJ, Karbownik M, Manchester LC, Cuzzocrea S, Fulia F, Barberi I. Individual and synergistic actions of melaton: Studies with vitamin E, vitamin C, glutatione and desferoxamine in liver homogenates. J. Pharm. Pharmacol. 53: 13931401. 2001

Giusti P, Lipartiti M, Gusella M, Florean M, Manev $\mathrm{H}$. In vitro and in vivo protective effects of melatonin against glutamate oxidative stress and neurotoxicity. Ann.N.Y. Acad. Sci. 825: 79-84. 1997.

Goedecke JH, Rae D, Smuts C, Lambert E, O'Shea M.Conjugated Linoleic Acid Isomers, t10c12 and c9t11, are Differentially Incorporated into Adipose Tissue and Skeletal Muscle in Humans. Lipids. 44: 983-988. 2009.

Griinari J, Corl B, Lacy S, Chouinard P, Nurmela K, Bauman D. Conjugated linoleic acid is synthesized endogenously in lactating cows by delta 9-desaturase. J. Nutr. 130: 22852291. 2000.

Guajardo MH, Terrasa AM and Catalá A. Retinal fatty acid binding protein reduce lipid peroxidation stimulated by long-chain fatty acid hydroperoxides on rod outer segments. Biochim Biophys Acta.581: 65-74. 2002

Guerrero JM, Reiter RJ. M elatonin-Immune system relationships. Curr. Top. Med. Chem. 2: 167-179. 2002.

Gutteridge JM, Halliwell B. Antioxidants in nutrition, health, and disease.Oxford: Oxford University Press; 1994.

Gutteridge JM, Halliwell B. The measurement and mechanism of lipid peroxidation in biological systems. Trends Biochem Sci. 15: 129-135. 1990 
Gutteridge JM. Free radicals in disease processes: a compilation of cause and consequence. Free Radic Res Commun. 19: 141-158. 1993

Gutteridge JM . Lipid peroxidation and antioxidants as biomarkers of tissue damage. Clin Chem. 41: 1819-1828. 1995

Guyton y Hall. Tratado de Fisiología M édica. 9 edición. M cGraw-Hill. Interamericana. 1997.

Hadley ME. Papel endócrino de la glándula pineal. En: Endocrinología. Prentice may.: 535557.1997.

Halliwell B, Chirico S. Lipid peroxidation: its mechanism, measurement, and significance. Am J Clin Nutr. 57: 715-724. 1993

Halliwell B, Gutteridge JM, Cross CE. Free radicals, antioxidants, and human disease: Where are we now? J Lab Clin M ed. 119: 598-620. 1992

Halliwell B, Gutteridge JM. Role of free radicals and catalytic metal ions in human disease: an overview. Methods Enzymol. 186: 1-85. 1990

Halliwell B, Gutteridge JMC. Free radicals in biology and medicine. 3rd ed.Oxford: Oxford University Press; 1999.

Halliwell B, M urciaM A, Chirico S, Aruoma Ol. Free radicals and antioxidants in food and in vivo: what they do and how they work. Crit Rev Food Sci Nutr. 35: 7-20. 1995

Halliwell B. Antioxidants and human disease: a general introduction. Nutr Rev.55: 44-49. 1997

Halliwell B. Establishing the significance and optimal intake of dietary antioxidants: the biomarker concept. Nutr Rev. 57: 104-113. 1999

Halliwell B. Free radicals and antioxidants: a personal view. Nutr Rev. 52: 253-265. 1994

Halliwell B. Oxidative stress, nutrition and health. Experimental strategies for optimization of nutritional antioxidant intake in humans. Free Radic Res. 25: 57-74. 1996

Halliwell B. The wanderings of a free radical. Free Radic Biol Med. 46:531-542. 2009

Hamberg M, Niehaus WG Jr, Samuelsson B. Preparation, isolation and characterization of a derivative of malonaldehyde. Anal. Biochem. 22: 145-153. 1968.

HamptonMB, Orrenius S. Dual regulation of caspase activity by hydrogen peroxide: implications for apoptosis. FEBS Lett 414: 552-556. 1997

Hardeland R, Balzer I, Poeggeler B, Fuhrber B, Uría H, Behrmann G, Wolf R, M eyer TJ, Reiter RJ. On the primary functions of melatonin in evolution: mediation of photoperiodic signals in a unicell, photooxidation, and scavenging of free radicals. J. Pineal Res. 18: 104-111. 1995.

Hardeland R, Fuhrberg B, Zsizsik BK. Chemiluminescence as a tool for monitoring the oxidation of indolic and quinaldic radical scavengers. Eur. J. Clin. Chem. Clin. Biochem. 35: A108. 
1997

Hardeland R, Poeggeler B. Non-vertebrate melatonin. J. Pineal Res. 34: 233-241. 2003.

Hardeland R. Melatonin and 5-methoxytryptamine in non-metazoans. Reprod. Nutr. Dev. 39: 399-408. 1999.

Hardeland R. The presence and function of melatonin and structurally related indoleamines in a dinoflagellate, and a hypothesis on the evaluationary significance of these tryptophan metabolites in unicellulars. Experientia. 49: 614-622. 1993.

Hattori A, M igataka H, ligo M, Itoh M, Yamamoto K, Ohtani-Kaneko R, Hara M, Suzuki T, Reiter RJ. Identification of melatonin in plants and its effects on plasma melatonin levels and biding to melatonin receptors in vertebrates. Biochem. Mol. Biol. Int. 35: 627-634. 1995

Hercberg S, Galan P, Preziosi P, Alfarez MJ, Vazquez C. The potential role of antioxidant vitamins in preventing cardiovascular diseases and cancers. Nutrition.14: 513-520. 1998

HolmgrenU. On the structure of the pineal area of teleost fishes with special reference to a few deep sea fishes. Göteborgs Kungl. Vetensk. Vitterhets-Samh. Handl. Ser. B. 8: 166. 1959.

Howes RM, Steele RH. Microsomal (S) chemiluminescence $(\mathrm{CL})$ induced by NADPH and its relation to lipid peroxidation. Res Commun Chem Pathol Pharmacol. 2: 619-26. 1971

Huang D, Ou B, Prior RL. The chemistry behind antioxidant capacity assays. J. Agric. Food. Chem. 53: 1841-1856. 2005.

Huether G, Poeggeler B, Reimer A, George A. Effect of tryptophan administration on circulating melatonin levels in chicks and rats: evidence for stimulation of melatonin synthesis and release in the gastrointestinal tract. Life Sci. 51: 945-53.1992.

lanas 0, Olinescu R, Badescu I. Melatonin involvement in oxidative processes. Endocrinologie. 29: 147-153. 1991

Ip C, Chin SF, Scimeca JA, Pariza MW. Mammary cancer prevention by conjugated dienoic derivative of linoleic acid. Cancer Res. 51: 6118-6124. 1991

ItothMT, Idhizuka B, Kudo Y, Fusama S, Amemiya A, Sumi Y. Detection of melatonin and serotonin $\mathrm{N}$-acetyltransferase and hydroxyndole-0-methyltransferase activities in rat ovary. Mol. Cell. Endocrinol. 136: 7-13. 1997.

Itoth MT, Ishizuka B, Kuribayashi A, Amemiya A, Sumi Y. Melatonin, its precursors, and synthesizing enzyme activities in the human ovary. Mol. Hum. Reprod. 5: 402408.1999. 
Janero DR. Malondialdehyde and thiobarbituric acid-reactivity as diagnostic indices of lipid peroxidation and peroxidative tissue injury. Free Radic Biol M ed. 9: 515-540. 1990

Jaworek J, Leja-Szpak A, Bonior J, Nawrot K, Tomaszewska R, Stachura J, Sendur R, Pawlik W, Brzozowski T, Konturek SJ. Protective effect of melatonin and its precursor Ltryptophan on acute pancreatitis induced by caerulein overstimulation or ischemia/reperfusion. J Pineal Res. 34: 40-52. 2003

Kakuda Y, Stanley DW, Van de Voort FR. Determination of TBA number by high performance liquid chromatography. J. Am. Oil Chem. Soc. 58: 773-775. 1981.

Kamal-Eldin A, Appelqvist LA. The chemistry and antioxidant properties of tocopherols and tocotrienols. Lipids. 31: 671-701. 1996

Karbownik M, Lewinski A, Reiter RJ. Anticarcinogenic actions of melatonin which involve antioxidative processes: comparison with other antioxidants. Int. J. Biochem. Cell. Biol. 33: $735-753.2001$

Karbownik M, Gitto E, Lewinski A, Reiter RJ. Relative efficacies of indole antioxidants in reducing autoxidation and iron-induced lipid peroxidation in hamster testes. J. Cell. Biochem 81: 693-699. 2001b

Keithahn C, Lerchl A. 5-hydroxytryptophan is a more potent in vitro hydroxyl radical scavenger than melatonin or vitamin C. J. Pineal Res. 38: 62-66. 2005

Kelly FJ. Use of antioxidants in the prevention and treatment of disease. J Int Fed Clin Chem. 10: 21-23. 1998

Kelly M L, Kolver ES, Barman DE, Van Amburgh ME, Muller LD. Effect of intake of pasture on concentrations of conjugated linoleic acid in milk of lactating cows. J. Dairy Sci. 81: 1630-1636. 1998

Kepler CR, Tucker WP and Tove SB. Intermediates and products of the biohydrogenation of linoleic acid by Butyrivibrio fibrisolvens. J. Biol. Chem. 241: 1350-1354. 1966

Khaldy H, Escames G, León J, Vives F, Luna JD, Acuña-Castroviejo D. Comparative effects of melatonin, L-deprenyl, Trolox and ascorbate in the suppression of hydroxyl radical formation during dopamine autoxidation in vitro. J Pineal Res. 29: 100-107. 2000.

Khanal RC, Olson KC. Factors affecting Conjugated Linoleic Acid (CLA) content in milk, meat, and egg: A Review . Department of Animal, Dairy and Veterinary Sciences, Asian Network for Scientific Information. Utah State University, Logan, UT 84322, EEUU.Pakistan Journal of Nutrition. 3: 82-98. 2004

KleinDC, Roseboom PH, Donohue SJ, Marrs BL. Evolution of melatonin as a night signal: contribution from a primitive photosynthetic organism. Mol. Cell. Neurosci. 3: 181- 
183. 1992.

Kohen R, Nyska A. Oxidation of biological systems: oxidative stress phenomena, antioxidants, redox reactions, and methods for their quantification. Toxicol. Pathol. 30: 620-650. 2002.

Kohn HI, Liversedge M. On a new aerobic metabolite whose production by brain is inhibited by apo-morphene, emetine, epinephrine and menadione. J. Pharmacol. 82: 292-297. 1944.

KoppelDE. Analysis of macromolecular polydispersity in intensity correlation spectroscopy: the methods of cumulants. J. Chem. Phys. 57: 4814-4820. 1972

Korstanje LJ, van Taassen EE, Levine YK. Reorientational dynamics in lipid vesicles and liposomes studied with ESR: effects of hydration, curvature and unsaturation. Biochim. Biophys. Acta. 982: 196-204. 1989

Kramer JK, Parodi PW, Jensen RG, M ossoba M M, Yurawecz MP and Adlof RO. Rumenic acid: A proposed common name for the major conjugated linoleic acid isomer found in natural products. Lipids. 33: 835-840. 1998.

Kristal BS, Park BK, Yu BP. 4-Hydroxyhexenal is a potent inducer of the mitochondrial permeability transition. J. Biol. Chem. 271: 6033-6038. 1996

Kritchevsky D. Antimutagenic and some other effects of conjugated linoleic acid. Br. J. Nutr. 83: $459-465.2000$

Laguerre M, Lecomte J, Villeneuve P. Evaluation of the ability of antioxidants to counteract lipid oxidation: Existing methods, new trends and challenges. Prog. Lipid Res. 46: 244282. 2007

Lakshminarayana G, Cornwell DG. Localization of fatty acids double bonds by gas chromatography of intermediate aldehydes as 1,3 dioxane. Lipids. 21: 175-177. 1986.

Larsson K. Liquid crystalline lipid-water phases. Lipids, molecular organization, physical functions and technical applications. Eds. Larsson K, The Oily Press, Glasgow (UK). 1994

Launay JM , Lamaitre BJ, Husson HP, Dreux C, Hartmann L, Da Prada M. Melatonin synthesis by rabbit platelets. Life Sci. 31: 1487-1494. 1982.

Lawson RE, M ossAR, Givens DI. The role of dairy products in supplying conjugated linoleic acid to man's diet: a review. Nutr Res Rev. 14: 153-172. 2001

Leaden P, Barrionuevo J, Catalá A. The protection of long chain polyunsaturated fatty acids by melatonin during nonenzymatic lipid peroxidation of rat liver microsomes. J. Pineal Res. 32: 129-134. 2002 
Leaden PJ, Catalá A. Protective effect of melatonin on ascorbate- $\mathrm{Fe}^{2+}$ lipid peroxidation of polyunsaturated fatty acids in rat liver, kidney and brain microsomes: a chemiluminescence study. J. Pineal Res. 39: 164-169. 2005

Lecomte M, Paget C, Ruggiero D, Wiernsperger N, Lagarde M. Docosahexaenoic acid is a major n-3 polyunsaturated fatty acid in bovine retinal microvessels. J. Neurochem. 66: 21602167. 1996.

Lee IM. Antioxidant vitamins in the prevention of cancer. Proc Assoc Am Physicians.111:10-15. 1999

Leja-Szpak A, Jaworek J, Tomaszewska R, Nawrot K, Bonior J, Kot M, Palonek M, Stachura J, Czupryna A, Konturek SJ, Pawlik WW. Melatonin precursor L-tryptophan protects the pancreas from development of acute pancreatitis through the central site of action. J Physiol Pharmacol. 55: 239-254. 2004

Lerner AB, Case JD, Takahashi Y. Isolation of melatonin and 5-methoxyndole-3-acetic acid from bovine pineal gland. J. Biol. Chem. 235: 1992-1997. 1960

Lerner AB, Case JD, Takahaski Y. Isolation of melatonin, the pineal gland factor that lightens melanocyte. J. Amer. Chem. Soc. 80: 2587-2594. 1958.

Lerner $A B$, Norklund JJ. Administration of melatonin to human subjects. Frontiers of Pineal Physiology. 42-43. (Eds). Altschule M.D. Cambridge Press. 1975.

Li Q, Yeo M, Tan B. Lipid Peroxidation in Small and Large Phospholipid Unilamellar Vesicles Induced by Water-Soluble Free Radical Sources. Biochem. Biophys. Res. Commun.273: 72-76. 2000

Li XJ, Gu J, Lu SD. Melatonin attenuates MPTP-induced dopaminergic neuronal injury associated with scavenging hydroxyl radical. J. Pineal Res. 32: 47-52. 2002.

Lissoni R, Brivio O, Brivio F, Barni S, Tancini G, Crippa D, M eregalli S. Adjuvant therapy with the pineal hormone melatonin in patients with lymph node relapse due to malignant melanoma. J Pineal Res. 21: 239-242. 1996

Livrea MA, Tesoriere L, D’Arpa D, M orreale M. Reaction of melatonin with lipoperoxyl radicals in phospholipid bilayers. Free Radic. Biol. M ed. 23: 706-711. 1997

Machlin LJ. Critical assessment of the epidemiological data concerning the impact of antioxidant nutrients on cancer and cardiovascular disease. Crit Rev Food Sci Nutr.35:41-50. 1995

Maisuthisakul P, Pongsawatmanit R, Gordon M H. Antioxidant Properties of Teaw (Cratoxylum formosum Dyer)Extract in Soybean Oil and Emulsions. J. Agric. Food Chem. 54, 2719-2725. 2006 
Marchioli R. Antioxidant vitamins and prevention of cardiovascular disease: laboratory, epidemiological and clinical trial data. Pharmacol Res. 40: 227- 238. 1999

Marnette $L$ J. Generation of mutagens during arachidonic acid metabolism. Cancer Metastas. Rev. 13: 303-308. 1999

Marshall KA, Reiter RJ, Poeggeler B, Aruoma OI, Halliwell B. Evaluation of the antioxidant activity of melatonin in vitro. Free Radic. Biol. M ed. 3: 307-315. 1996.

Mathur RL, Sahai P. Effects of a tryptophan supplemented diet and U.V. radiation on the rat lens. Lens Eye Toxic Res. 7: 143-160. 1990

Matusak Z, Reszka K, Chignell CF. Reaction of melatonin and related indoles with hydroxyl radical:EPR and spin trapping investigators. Free Radic. Biol. M ed. 23: 367-372. 1997.

Mayo JC, Sainz RM, Antolin I, Herrera F, Martin V, Rodriquez C. Melatonin regulation of antioxidant enzyme gene expresión. Cell. M ol. Life Sci. 59: 1706-1713. 2002.

McCall MR, Frei B. Can antioxidant vitamins maternally reduce oxidative damage in humans? Free Radic Biol Med.26: 1034-1053. 1999

Mei L, McClements J, Wu J, Decker EA. Iron-catalyzed lipid oxidation in emulsion as affected by surfactant, pH, NaCl. Food Chem. 61: 307-312. 1998

Melchiorri D, Reiter RJ, Attia AM, Hara M, Burgos A, Nistico G Potent protective effect of melatonin on in vivo paraquat-induced oxidative damage in rats. Life Sci. 56: 83-89. 1995

Mitchell JA, Akarasereenont P, Thiemermann C, Flower RJ, Vane JR. Selectivity of nonsteroidal antiinflammatory drugs as inhibitors of constitutive and inducible cyclooxygenase. Proc Natl Acad Sci. 90: 11693- 11697. 1993

M ozuraityte R, Rustad T, Storrø I. Oxidation of cod phospholipids in liposomes: Effects of salts, pH and zeta potential. Eur. J. Lipid Sci. Technol. 108: 944-950. 2006a

M ozuraityte R, Rustad T, Storrø I. Pro-oxidant activity of $\mathrm{Fe}^{2+}$ in oxidation of cod phospholipids in liposomes. Eur. J. Lipid Sci.Technol.108: 218-226.2006b

Mozuraityte R, Rustad T, Storro I. The Role of Iron in Peroxidation of Polyunsaturated Fatty Acids in Liposomes. J. Agric. Food Chem. 56:, 537-543. 2008

Murray RK, Granner DK, Mayes PA, Rodwell VW. Harper's biochemistry. 25th ed. Stamford, Connecticut: Appleton \& Lange. 2000

Nacka F, Cansell M, Meleard P, Combe N. Incorporation of alpha-tocopherol in marine lipidbased liposomes: in vitro and in vivo studies. Lipids. 36: 1313-1320. 2001

Nau-Staudt K, Nau WM, Haefliger IO, Flammer J. Lipid peroxidation in porcine irises: dependence on pigmentation. Curr. Eye Res. 22: 229-234. 2001. 
Nelson RJ, Demas GE, Klein SL, Kriegsfeld LJ. The influence of season, photoperiod, and pineal melatonin on immune function. J Pineal Res. 19: 149-165. 1995

Nelson GJ. Effects of dietary fatty acids on lipid metabolism. In: Chow, K.C. (Ed.), Fatty Acids in Foods and their Health Implications, 2nd ed. M arcel Dekker, Inc., New York. 481-516. 2000.

Ng TB, Lo LLH. Inhibitory Actions of Pineal Indoles on Steroidogenesis in Isolated Rat Leydig Cells. J Pineal Res. 5: 229-243. 1988

$\mathrm{Ng} \mathrm{TB}$, Liu F, Zhao L. Antioxidative and free radical scavenging activities of pineal indoles. J Neural Transm. 107: 1243-51. 2000

Noda Y, Mori A, Liburdy R, Packer L. Melatonin and its precursors scavenge nitric oxide. J Pineal Res. 27: 159-163. 1999

O'Brien JS. Cell membranes-Composition: Structure: Function. J. Theoret. Biol. 15: 307-324. 1967.

O'Brien JS, Sampson EL. Fatty acid and fatty aldehyde composition of the major brain lipids in normal human gray matter, white matter, and myelin. J. Lipid Res. 6: 545-551. 1965.

Okatani Y, Wakatsuki A, Reiter RJ, Enzan H, M iyahara Y. Protective effective of melatonin against mitochondrial injury induced by ischemia and reperfusion of rat liver. Eur. J. Pharmacol. 469: 145-152. 2003b.

Okatani Y, Wakatsuki A, Reiter RJ, Miyahara Y. Acutely administered melatonin restores hepatic mitochondrial physiology in old mice. Int. J. Biochem. Cell. Biol. 35: 367-375. $2003 a$

Okatani Y, Wakatsuki A, Reiter RJ. Hepatic mitochondrial dysfunction in senescenceaccelerated mice: Correction by long-term, orally administered physiological levels of melatonin. J. Pineal Res. 33: 127-133. 2002b.

Okatani Y, Wakatsuki A, Reiter RJ. Melatonin protects hepatic mitochondrial chain activity in senescence-accelerated mice. J. Pineal Res. 23: 143-148. 2002a.

Ortega-Gutiérrez S, García JJ, Martínez-Ballarín E, Reiter RJ, Millán-Plano S, Robinson M, Acuña-Castroviejo D. Melatonin improves deferoxamine antioxidant activity in protecting against lipid peroxidation caused by hydrogen peroxide in rat brain homogenates. Neurosci Lett. 323: 55-59. 2002

Ottolenghi A. Interaction of ascorbic acid and mitochondria lipids. Arch. Biochem. Biophys. 79: 355-359. 1959

Pablos MI, Guerrero JM, Ortiz GG, Agapito MT, Reiter RJ. Both melatonin and a putative nuclear receptor agonist CGP 52608 stimulate glutathione peroxidasa and glutathione 
reductasa activities in mouse brain in vivo. Neuro Endocrinol Lett. 18: 49-58. 1997.

Pandi-Perumal SR, Srinivasan V, Maestroni GJ, Cardinali DP, Poeggeler B, Hardeland R. Melatonin. FEBS Journal. 273: 2813-2838 (Review). 2006

Pariza M W, HargravesWA. A beef-derived mutagenesis modulator inhibits initiation of mouse epidermal tumors by 7, 12-dimethylbenz[a]anthracene. Carcinogenesis. 6:591-593. 1985

Pariza MW, HargravesWA, Boissonneault GA. Modulation of carcinogenesis by a beef-derived mutagenesis modulator, and by dietary fat. Prog Clin Biol Res. 206: 265-271. 1986

Pariza MW, Park Y, Cook ME. The biologically active isomers of conjugated linoleic acid. Prog Lipid Res. 40: 283-298. 2001

Pariza MW. Perspective on the safety and effectiveness of conjugated linoleic acid. Am J Clin Nutr. 79: 1132- 1136. 2004

Pazos M, Lois S, Torres JL, M edina I. Inhibition of hemoglobin- and iron-promoted oxidation in fish microsomes by natural phenolics. J. Agric. Food Chem. 5: 4417-4423. 2006

Pinto M, Rubilar A, Carrasco E, Ah - Hen KS, Brito C, Molina L. Efecto estacional y del área geográfica en la composición de ácidos grasos en la leche de bovinos. Agro sur. 2002

Poeggeler B, Saarela S, Reiter RJ, Tan DX, Chen LD, Manchester LC, Barlow-Walden LR. Melatonin, a high potent endogenous scavenger and electron donor: new aspects of the oxidation chemistry of this indole assessed in vitro. Ann.N.Y.Acad. Sci. 738: 419420. 1994

Poeggeler BH, Barlow-Walden LR, Reiter RJ, Saarela S, Menendez-Pelaez A, Yag, Manchester LC, Chen LD, Tan DX. Red-light-induced supresión of melatonin synthesis is mediated by methyl-D-aspartate receptor activation in retinally normal and retina degenerate rats. J. Neurobiol. 28: 1-8. 1995.

Poeggeler G, Thuermann S, Does A, Schoenke M, Burkhardt S, Hardeland R. Melatonin's unique scavenging properties roles of its functional substituents as revealed by a comparison with its structural analogues. J. Pineal Res. 33: 20-30. 2002.

Poon AMS, Pang SF. 2-[125I] iodomelatonin binding sites in spleens of guinea pig. Life Sci. 50: 1709-1726. 1992.

Porter NA, Caldwell SE, Mills KA. Mechanisms of free radical oxidation of unsaturated lipids. Lipids. 30: 277-290. 1995

Reiter RJ, Tan DX, Acuña-Castroviejo D. M elatonin: mechanisms and actions as an antioxidant. Curr. Top. Biophys. 24: 171-183. 2000a

Reiter RJ, Tan DX, Manchester LC, Qi W. Biochemical reactivity of melatonin with reactive 
oxygen and nitrogen species: a review of the evidence. Cell Biochem. Biophys. 34: 237-256. 2001

Reiter RJ, Tan DX, Mayo JC, Sainz RM, Leon J, Czarnocki Z. Melatonin as an antioxidant: biochemical mechanisms and pathophysiological implications in humans. ReviewActa Biochim. Pol. 50: 1129-1146. 2003.

Reiter RJ, Tan DX, M ayo JM, Sainz RM, Lopez-Burilla S. M elatonin, longevity and health in the aged: an assessment. Free Radic. Res. 36: 1323-1329. 2002a

Reiter RJ, Tan DX, Osuna C, Gitto E. Actions of melatonin in the reduction of oxidative stress. A review. J. Biomed. Sci. 7: 444-458. 2000b.

Reiter RJ. M elatonin and aging. The Science of Geriatrics. (Ed). M osley J.E; Armbrecht H.J.; Coe R.M. y Vellas B. Vol I: 232-333. Springer. New York. 2000b

Reiter RJ. Melatonin: Clinical relevance. Best. Pract. Res. Clin. Endocrinol. Metab. 17: 273-285. 2003.

Reiter RJ. Melatonin: lowering the high price of free radicals. News Physiol. Sci. 15: 246-250. 2000a.

Reyes-Gonzales MC, Fuentes-Broto L, M artínez-Ballarín E, M iana-Mena FJ, Berzosa C, GarcíaGil FA, Aranda M, García JJ. Effects of tryptophan and 5-hydroxytryptophan on the hepatic cell membrane rigidity due to oxidative stress.J Membr Biol. 231: 93-99. 2009

Rice-Evans C, Burdon R. Free radical-lipid interactions and their pathological consequences. Prog Lipid Res. 32: 71-110. 1993

Rice-Evans CA, Diplock AT, Symons MCR. Laboratory techniques in biochemistry and molecular biology. Techniques in free radical research, Elsevier, Amsterdam, 1991.

Roberts JE, Hu DN, Martinez L. Photophysical studies on melatonin and its receptor agonists. J. Pineal Res. 29: 94-99. 2000.

Rodriguez C, Mayo JC, Sainz RM, Antolin I, Herrera F, Martin V,y Reiter RJ. Regulation of antioxidant enzymes: a significant role for melatonin. J. Pineal Res. 36: 1-9. 2004.

Ruozi B, Tosi G, Forni F, Fresta M, Vandelli MA. Atomic force microscopy and photon correlation spectroscopy: two techniques for rapid characterization of liposomes. Eur. J. Pharm. Sci. 25: 81-89. 2005

Samuelsson B, Granström E, Green K, Hamberg M, Hammarström S. Prostaglandins. Annu Rev Biochem.44: 669-695. 1975

SanGiovanni JP, Chew EY. The role of omega-3 long-chain polyunsaturated fatty acids in health and disease of the retina. Prog. Retin. Eye Res. 24: 87-138. 2005

Sanhueza CJ, Nieto KS y Valenzuela BA. Acido linoleico conjugado: un ácido graso con isomería 
trans potencialmente beneficioso. Rev.Chi.Nutr. 29: 98-105. 2002

Sanhueza García MD. Tesis de Grado: Determinación de ácido linoleico conjugado (CLA) en leche de bovinos del sector Vilcún, Novena Región. Escuela de medicina veterinaria, Facultad de Acuicultura y Ciencias Veterinarias, Universidad Católica de Temuco, Chile. 2004

Sargis RM, Subbaiah PV. Trans unsaturated fatty acids are less oxidizable than cis unsaturated fatty acids and protect endogenous lipids from oxidation in lipoproteins and lipid bilayers. Biochemistry. 42: 11533-11543. 2003

Sastre J, Pallardo FV, Garcia de la Asuncion J, Vina J. M itochondria, oxidative stress and aging. Free Radic Res. 32: 189-198. 2000

Schiffer $\mathrm{M}$, Chang $\mathrm{CH}$, Stevens FJ. The functions of tryptophan residues in membrane proteins. Protein Eng. 5: 213-214. 1992

Schnitzer E, Pinchuk I, Lichtenberg D. Peroxidation of liposomal lipids. Eur Biophys J. 36: 499515. 2007

Sehat N, Kramer JKG, M ossoba M M, Yurawecz MP, Roach JAG, Eulitz K, M orehouse K, Ku Y. Identification of conjugated linoleic acid isomers in cheese by gas chromatography, silver ion high performance liquid chromatography and mass spectral reconstructed ion profiles. Comparison of chromatographic elution sequences. Lipids. 33, 963-971. 1998

Sevilla CL, Mahle NH, Eliezer N, Uzieblo A, O'Hara SM, Nokubo M, M iller R, Rouzer CA, Marnett LI. Development of monoclonal antibodies to the malondialdehyde-deoxyguanosine adduct, pyrimidopurinone. Chem Res Toxicol. 10: 172-180. 1997

Sewerynek E, Melchiorri D, Chen LD, Reiter RJ. Melatonin reduces both basal and bacterial lipopolysaccharide induced lipid peroxidation in vitro. Free Radic Biol Med. 19: 903909. 1995

Shimasaki H, Privett 0 S, Hara I. Studies of the fluorescent products emulsion with glycine and on the surface of silica gel. J. Am. Oil. Chem. Sot. 54: 119-123. 1977.

Sies H. Strategies of antioxidant defense. Eur J Biochem. 215: 213-219. 1993

Sies H. Oxidative stress: oxidants and antioxidants. Exp Physiol. 82: 291-295. 1997

Simopoulos AP. Omega-6/omega-3 essential fatty acids: biological effects. World Rev Nutr Diet 99: 1-16. 2009

Simopoulos AP. Omega-3 fatty acids in health and disease and in growth and development. Am J Clin Nutr. 54: 438-463. 1991

Sinha K, Degaonkar MN, Jagannathan NR, Gupta YK. Effect of melatonin on ischemia 
reperfusion injury induced by middle cerebral artery occlusion in rats. Eur J Pharmacol. 428, 185-192. 2001.

Sinnhuber RO, Yu IC, Yu TC. Characterization of the red pigment formed in the 2-thiobarbituric acid determination of oxidative rancidity. Food Res. 23: 624-634. 1958.

Skwarlo-Sonta K, Majewski P, Markowska M, Oblap R, Olszanska B. Bidirectional communication between the pineal gland and the immune System. Can. J. Physiol. Pharmacol. 81: 342-349. 2003.

Slater TF. Free-radical mechanisms in tissue injury. Biochem J. 222: 1-15. 1984

Södergren E. Lipid Peroxidation in vivo. Evaluation and Application of Methods for Measurement (Tesis). Acta Universitatis Upsaliensis. Uppsala. Suecia. 2000

Soubias O, Teague WE, Gawrisch K. Evidence for specificity in lipid-rhodopsin interactions. J. Biol. Chem. 281: 33233-33241. 2006.

Southorn PA, Powis G. Free radicals in medicine. II. Involvement in human disease. Mayo Clin Proc. 63: 390-408. 1988

Spickett CM, Wiswedel I, Siems W, Zarkovic K, Zarkovic N. Advances in methods for the determination of biologically relevant lipid peroxidation products. Free Radic Res. 44: 1172-1202. 2010

Stasica P, Paneth P, Rosiak JM. Hydroxyl radical reaction with melatonin molecule: a computational stydy. J. Pineal Res. 29: 125-127. 2000

Stefulj J, Hörtner M, Ghosh M, Schauenstein K, Rinner I, Wölfler A, Semmler J, Liebmann PM. Gene expression of the key enzymes of melatonin synthesis in extrapineal tissues of the rat. J. Pineal Res. 30: 243-247. 2001.

Stoian I, Oros A, Moldoveanu E. Apoptosis and free radicals. Biochem Mol Med. 59:93-97. 1996.

Stone WL, Farnsworth CC, Dratz EA. A reinvestigation of the fatty acid content of bovine, rat and frog retinal rod outer segments. Exp. Eye Res. 28: 387-397. 1979

Strauss 0. The retinal pigment epithelium in visual function. Physiol Rev. 85: 845-881. 2005.

Stubbs CD, Smith AD. The modification of mammalian membrane polyunsaturated fatty acid composition in relation to membrane fluidity and function. Biochim Biophys Acta. 779: 89-137. 1984

Subbaiah PV, Sircar D, Aizezi B, Mintzer E. Differential effects of conjugated linoleic acid isomers on the biophysical and biochemical properties of model membranes. Biochim. Biophys. Acta 1798: 506-514, 2010

Suh M, Wierzbicki AA, Clandinin MT. Dietary fat alters membrane composition in rod outer 
segments in normal and diabetic rats: impact on content of very-long-chain $(C>$ or $=$ 24) polyenoic fatty acids. Biochim. Biophys. Acta. 1214: 54-62. 1994

Sze SF, Liu WK, $\mathrm{Ng}$ TB. Stimulation of murine splenocytes by melatonin and methoxytryptamine. J Neural Transm Gen Sect. 94: 115-126. 1993

Sze SF, Ng TB, Liu WK. Antiproliferative effect of pineal indoles on cultured tumor cell lines.J Pineal Res. 14: 27-33. 1993b

TalbotWA, Zheng LX, Lentz BR. Acyl chain unsaturation and vesicle curvature alter outer leaflet packing and promote poly (ethylene glycol)-mediated membrane fusion. Biochemistry. 36: 5827- 5836. 1997

Tan DX, Chen LD, Poeggeler B, Manchester LC, Reiter RJ. Melatonin: a potent, endogenous hydroxyl radical scavenger. Endocr J.1:57-60. 1993a

Tan DX, Manchester LC, Burkhardt S, Sainz RM, Mayo JC, Kohen R, Shohami E, Huo Yu-Shu, Hardeland R, Reiter RJ. N1-acetyl-N2-formyl-5-methoxykynuramine, a biogenic amine and melatonin metabolite, functions as a potent antioxidant. FASEB J. 15: 2294-2296. 2001

Tan DX, Manchester LC, Reiter RJ, Cabrera J, Burkhardt S, Phillip T, Gitto E, Karbownik M, Li QD. Melatonin suppresses autoxidation and hydrogen peroxide-induced lipid peroxidation in monkey brain homogenate. Neuro Endocrinol. Lett. 21: 361-365. $2000 \mathrm{~b}$

Tan DX, Manchester LC, Reiter RJ, Plummer BF, Hardies LJ, Weintraub ST, Vijayalaxmi Shepherd AMM. A novel melatonin metabolite cyclic 3- hydroxymelatonin: A biomarker of in vivo hydroxyl radical generation. Biochem. Biophys. Res. Commun. 253: 614-620. 1998.

Tan DX, Manchester LC, Reiter RJ, Plummer BF, Limson J, Weintraub ST, Qi W. Melatonin directly scavenges hydrogen peroxide: a potentially new metabolic pathway of melatonin biotransformation. Free Radic. Biol. Med. 29: 1177-1185. 2000a

Tan DX, M anchester LC, Reiter RJ, Qi WB, Zhang M, Weintraub ST, Cabrera J, Sainz RM, M ayo JC. Identification of highly elevated levels of melatonin in bone marrow: its origin and significance. Biochim. Biophys. Acta. 1472: 206-214. 1999.

Tan DX, Poeggeler B, Reiter RJ, Chen LD, Manchester LC, Barlow-Walden LR. The pineal hormone melatonin inhibits DNA adduct formation induced by the chemical carcinogen safrole in vivo. Cancer Lett. 70: 65-71. 1993b

Tan DX, Reiter RJ, M anchester LC, Yan M T, El-Sawi M, Sainz RM, M ayo JC, Kohen R, Allegra M, Hardeland R. Chemical and physical properties and potencial mechanisms: Melatonin 
as a broad-spectrum antioxidant and free radical scavenger. Curr. Topics. M ed. Chem. 2: 181-198. 2002.

Tarladgis BG, Watts BM. Malonaldehyde production during the controlled oxidation of pure, unsaturated fatty acids. J. Am. Oil Chem. Soc., 37: 403-406. 1960.

Thiele EH, Huff JW. Lipide peroxide production and inhibition by tumor mitochondria. Arch. Biochem. Biophys. 88: 208-211. 1960

Tomita M, Okuyama T, Hatta Y, Kawai S. Determination of free malonaldehyde by gas chromatography with an electron-capture detector. J. Chromatogr. 526: 174-179. 1990

Turek FW, Zee P, Van Reeth O. M elatonin and aging. Kluwer Academic. Plenum Publishers.New York. 2000

Tvrzicka E, Kremmyda LS, Stankova B, Zak A. Fatty acids as biocompounds: their role in human metabolism, health and disease - a review. Part 1: classification, dietary sources and biological functions. Biomed Pap Med Fac Univ Palacky Olomouc Czech Repub.155: 117-30. 2011

Ueda T, Ueda T, Armstrong D. Preventive effect of natural and synthetic antioxidants on lipid peroxidation in the mammalian eye. Ophthalmic Res. 28: 184-192. 1996.

Urata Y, Homma S, Goto S, Todoroki S, Cho S, Homma K, Kondo T. Melatonin induces $\mathrm{Y}^{-}$ glutamyl-cysteine synthetase mediated by activator protein-1 in human vascular endotelial cells. Free Radic. Biol. Med. 27: 838-847. 1999

Valko M, Morris H, Cronin M TD. Metals, Toxicity and Oxidative Stress. Curr. Med. Chem. 12: 1161-1208. 2005

Valenzuela A, Mogardo M. Trans fatty acid isomers in human health and in the food industry. Biol Res. 32: 273- 287. 1999

Van Blitterswijk WJ. Disease processes. In: Aloia RC, Boggs JM (eds) Membrane fluidity in biology, vol 3. Academic Press, Orlando, FL. 85-159. 1985

Vane J. Towards a better aspirin. Nature. 367: 215-216. 1994

Vane JR, Botting RM . A better understanding of anti-inflammatory drugs based on isoforms of cyclooxygenase (COX-1 and COX-2). Adv Prostaglandin Thromboxane Leukot Res. 23: 41-48. 1995

Vasanta Rupasinghe HP, Erkan N, Yasmin A. Antioxidant Protection of Eicosapentaenoic Acid and Fish OilOxidation by Polyphenolic-Enriched Apple Skin Extract.J. Agric. Food Chem. 58, 1233-1239. 2010

Villaño D, Fernández-Pachón MS, Moyá ML, Troncoso MS, García-Parrilla MC. Radical 
scavenging ability of polyphenolic compounds towards DPPH free radical. Talanta. 71: 230-235. 2007

Vivien-Roels B, Arent J. How does the indoleamine production of the pineal gland respond to variations in the environment in a non mammalian vertébrate, Testudo Gemilin. Psychoneuroendocrinology. 8: 327-332. 1983.

Vladimirov YA, L'vova OF, Cheremisina ZP. Ultra-weak luminescence of mitochondria and its relation to enzymic oxidation of lipids. Biokhimiia. 31:507-515. 1966. (Article in Russian)

Vladimirov YA, Olenev VI, Suslova TB, Cheremisina ZP. Lipid peroxidation in mitochondrial membrane. Adv.Llipid Res. 17: 173-249. 1980

Wagner BA, Buettner GR, Burns CP. Free radical mediated lipid peroxidation in cells: oxidizability is a function of cell lipid bis-allylic hydrogen content. Biochemistry. 33: 4449-4453. 1994

Wakatsuki A, Okatani Y, Shinohara K. Melatonin protect fetal rat brain against oxidative mitochondria damage. J. Pineal Res. 30: 22-28. 2001.

Wang HX, Liu F, Ng TB. Examination of pineal indoles and 6-methoxy-2-benzoxazolinone for antioxidant and antimicrobial effects. Comp. Biochem. Physiol. C Toxicol. Pharmacol. 130: 379-388. 2001

Wang N, Anderson RE. Synthesis of docosahexaenoic acid by retina and retinal pigment epithelium. Biochemistry (M osc). 32, 13703-13709. 1993a

Wang N, Anderson RE. Transport of 22:6 n-3 in the plasma and uptake into retinal pigment epithelium and retina. Exp. Eye Res. 57: 225-233. 1993b.

Watkins SM, German JB. Omega Fatty Acids. Lipid Chemistry. Akoh CC, Min DB. Eds. Marcel Dekker: New York, 1998.

Winkler BS, Boulton ME, Gottsch JD, Sternberg P. Oxidative damage and age-related macular degeneration. Mol. Vis. 5: 1-32. 1999.

Wölfler A, Abuja PM, Schauenstein K, Liebmann PM. N-acetylserotonin is a better extra- and intracellular antioxidant than melatonin. FEBS Lett. 449: 206-210. 1999.

Wölfler A, Caluba HC, Abuja PM, Dohr G, Schauenstein K, Liebmann PM. Prooxidant activity of melatonin promotes fas-induced cell death in human leukemic Jurkat cells. FEBS Lett. 502: 127-131. 2001

Wurtman RJ, Axelrod J. The formation, metabolism and physiologic effects of melatonin. Adv. Pharmacol. 6: 141-151. 1968.

www.gabitogrupos.com/elojodelaluz/template.php?nm =1276976467 
www.gusgsm.com/funciona_ojo_humano

Xie WL, Chipman JG, Robertson DL, Erikson RL, Simmons DL. Expression of a mitogenresponsive gene encoding prostaglandin synthase is regulated by mRNA splicing. Proc Natl Acad Sci. 88: 2692-2696. 1991

Yagi K. Assay for blood plasma or serum. M ethods Enzymol. 105: 321-328. 1984.

Young IM, Silman RE. Reiter R.J. (Ed) In The Pineal Gland: Extra-Reproductive Effects, Vol. 3. Florida: CRC, 189-218. 1982

Yu TC, Sinnhuber R0. 2-Thiobarbituric acid method for the measurement of rancidity in fishery products. Food Tech. 11: 104-108. 1957.

Zang LY, Cosma G, Gardner H, Vallyathan V. Scavenging of reactive oxygen species by melatonin. Biochim. Biophys. Acta. 1425: 469-477. 1998

Zhang $A$, Chen ZY. Oxidative stability of conjugated linoleic acids relative to other polyunsaturated fatty acids. J Am Oil Chem Soc. 74: 1611-1613. 1997

Zhuravlev Al. An anomaly of lipid chemiluminescence. Biolyuminestsentsiya. (Bioluminescence). Trudy M OIP. 21, 133- 196. 1966

Zhuravlev Al. Determination of free radicals in fats. Zh. Prikl. Khim. 35: 1153. 1962. 